VANDERLI CORREIA PRIETO

IMPACTO DO ALINHAMENTO DA ESTRATÉGIA DE NEGÓCIOS SOBRE O DESEMPENHO

Tese apresentada à Escola Politécnica da Universidade de São Paulo para obtenção do título de Doutor em Engenharia de Produção. 
VANDERLI CORREIA PRIETO

\section{IMPACTO DO ALINHAMENTO DA ESTRATÉGIA DE NEGÓCIOS SOBRE O DESEMPENHO}

Tese apresentada à Escola Politécnica da Universidade de São Paulo para obtenção do título de Doutor em Engenharia de Produção.

Área de Concentração: Qualidade e Engenharia de Produto.

Orientadora: Prof ${ }^{\mathrm{a}}$. Livre Docente Marly Monteiro de Carvalho 
FICHA CATALOGRÁFICA

\section{Prieto, Vanderli Correia}

Impacto do alinhamento da estratégia de negócios sobre o desempenho / V.C. Prieto. -- São Paulo, 2011.
p. 191

Tese (Doutorado) - Escola Politécnica da Universidade de São Paulo. Departamento de Engenharia de Produção.

1. Administração estratégica 2. Estratégia organizacional 3. Planejamento estratégico 4. Desempenho organizacional 5. Eficácia organizacional I. Universidade de São Paulo. Escola Politécnica. Departamento de Engenharia de Produção. II. t. 


\section{AGRADECIMENTOS}

À minha orientadora, Marly, pelo incentivo em minha carreira profissional e conselhos para que eu direcionasse da melhor maneira possível o encaminhamento desta tese.

Aos professores que participaram da banca de qualificação, Alceu Gomes Alves Filho e Diógenes de Souza Bido, pelo direcionamento e apoio ao projeto.

Um agradecimento especial ao Prof. Bido que com tanto esmero compartilha seus conhecimentos sobre estatística que acabou me contagiando.

Aos professores especialistas Adalberto, Bandeira de Melo, Fleury, Marta, Guilherme, Reinaldo e Thomaz e aos executivos Ciro, Edson, Gisa e Luis que tanto contribuíram para o aperfeiçoamento do instrumento de pesquisa.

Aos meus colegas professores do Mackenzie pela oportunidade de trocar conhecimento e pelo incentivo em todo esse processo de construção da tese.

Aos meus colegas do stricto sensu pelo companheirismo.

Aos meus colegas e alunos que se envolveram no processo de indicação de executivos que pudessem participar da pesquisa.

Aos meus amigos Marcelo, Cris, Ana, Luzia e Gilberto pela intercessão e palavras de incentivo.

Ao meu pai, José Alberto, pelo seu exemplo de dedicação.

Ao meu marido, Evandro, por todo o suporte e compreensão nesse período.

Aos da minha família, Rose e Jardel, Ismael e Cidinha, Bruna, Carol e Jú pelo amor sempre demonstrado por mim.

A Deus que me dá força. 
Tanto riquezas como honra veem de ti, tu dominas sobre tudo, na tua mão há força e poder; na tua mão está o engrandecer e a tudo dar força.

1 Crônicas 29:12 


\section{RESUMO}

Esta tese propõe um modelo teórico de alinhamento estratégico interno e defende a hipótese de que o alinhamento interno, a partir do modelo proposto, tem impacto positivo sobre o desempenho organizacional. Define-se a estratégia, com base na tipologia de Miles e Snow, e a incerteza ambiental como variáveis moderadoras. Conceitua-se o alinhamento como o ajuste da organização tanto na dimensão vertical quanto horizontal. O alinhamento vertical refere-se ao conjunto de ações necessárias à implementação da estratégia, desde a estratégia formulada até o seu desdobramento por todos os níveis da organização. Define-se que os fatores envolvidos no alinhamento vertical são a abrangência da formulação da estratégia, capacidades gerenciais para a implementação da estratégia e envolvimento das pessoas com a estratégia. $O$ construto abrangência da formulação é definido como multidimensional, composto pelas variáveis processo formal de planejamento, envolvimento da média gerência na formulação e consenso sobre a estratégia. O alinhamento horizontal envolve a compreensão das necessidades do cliente e o alinhamento dos processos (inter-funcionais) capazes de entregar o que o cliente necessita. As duas dimensões, vertical e horizontal, representam as variáveis a serem alinhadas e a ideia presente é que isoladamente não são suficientes para produzir o alinhamento interno, o que implica que nesta tese adota-se a perspectiva holística do alinhamento, também comumente denominada pela literatura como perspectiva sistêmica ou da covariação. Para a definição dos construtos componentes do modelo realizou-se uma revisão sistematizada da literatura, utilizando a base de dados Web of Science, que resultou em um total de 141 artigos. A revisão também serviu de base para a definição do instrumento de pesquisa que foi submetido à validação de conteúdo por especialistas e executivos. Os dados foram coletados por meio de um link para acesso on line e também em papel. A pesquisa foi conduzida com a média gerência ou profissionais diretamente envolvidos com a implementação da estratégia de negócios, de 125 empresas, de porte médio e grande. Os dados foram processados e validados por meio da técnica de Modelagem de Equações Estruturais com estimação pelo método Partial Least Squares (PLS), utilizando o software SmartPLS 2.0. Os resultados dão validação empírica ao modelo especificado, confirmando-se que a covariação entre o alinhamento vertical e horizontal tem impacto positivo sobre o desempenho organizacional. Contribuições desse estudo e sugestões para outros trabalhos também estão registradas.

Palavras-chave: Administração estratégica. Estratégia organizacional. Planejamento estratégico. Desempenho organizacional. Eficácia organizacional. 


\section{ABSTRACT}

This thesis proposes a theoretical model of internal strategic alignment and defends the hypothesis that an internal alignment, from the proposed model, is positively related to organizational performance. It is defined that the strategy, considering Miles and Snow typology, and the environmental uncertainty moderate this relationship. The alignment is conceptualized as an adjustment in both vertical and horizontal dimensions. Vertical alignment refers to the set of actions necessary to the strategy implementation, from the formulated strategy to its deployment at all organizational levels. Its is defined that the factors involved in the vertical alignment are strategy formulation comprehensiveness, management capacity to the strategy implementation and employees involvement with the strategy. The construct strategy formulation comprehensiveness is defined as multidimensional composed with the variables formal process planning, middle management involvement in the formulation process and consensus about the strategy. Horizontal alignment involves understanding the customers needs and the alignment of the process (inter-functional) capable of delivering what the customers need. Both dimensions, vertical and horizontal, represent the variables to be aligned and the idea is that isolated they are not sufficient to produce the internal alignment. Therefore, this thesis adopts the alignment in the holistic perspective, also commonly named by the literature as systemic or covariation perspective. In order to define the model constructs it was performed an extensive literature review consulting Web of Science database which resulted in a total of 141 articles. This search also was the start point to the research instrument definition, which was submitted to validation of content by specialists and executives. The data were collected through a link to access the questionnaire on the internet and through paper. The research was conducted with middle managers and professionals directly involved in business strategy implementation, from 125 middle and large companies. The data were analyzed using structural equation modeling with estimation by partial least squares (PLS), using the software SmartPLS 2.0. The results give empirical and methodological validation to the model specified and confirm that the covariation between vertical and horizontal alignment has positive impact in the organizational performance. Contributions of this study and suggestions for other researches also are recorded.

Keywords: Strategic management. Organizational strategy. Strategic planning. Organizational performance. Organizational effectiveness. 


\section{LISTA DE FIGURAS}

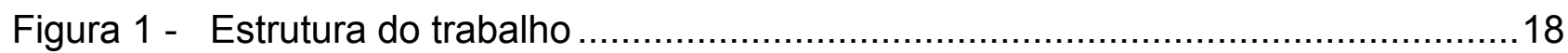

Figura 2 - Distribuição dos artigos coletados por área de pesquisa ..............................49

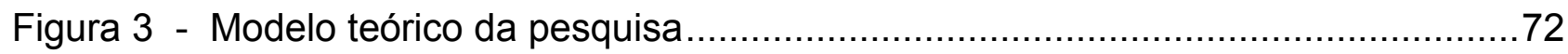

Figura 4 - Construto abrangência da formulação com parâmetros estimados pela MEEPLS

Figura 5 - Construtos do alinhamento vertical com parâmetros estimados pela MEEPLS

Figura 6 - Construtos do alinhamento horizontal com parâmetros estimados pela MEEPLS

Figura 7 - Construto Desempenho Organizacional com parâmetros estimados pela MEEPLS

Figura 8 - Construto Alinhamento Interno com parâmetros estimados pela MEEPLS

Figura 9 - Resultados do modelo estrutural com parâmetros estimados pela MEEPLS

Figura 10 - Construto incerteza ambiental com parâmetros estimados pela MEEPLS

Figura 11 - Efeito da incerteza ambiental sobre o desempenho com parâmetros estimados pela MEEPLS

Figura 12 - Efeito moderador da incerteza ambiental sobre o desempenho organizacional 


\section{LISTA DE QUADROS}

Quadro 1 - Definição dos termos-chave sobre alinhamento 30

Quadro 2 - Ações para promover o alinhamento estratégico.

Quadro 3 - Fatores envolvidos no alinhamento estratégico

Quadro 4 - Relacionamento teórico entre abrangência da formulação da estratégia e alinhamento vertical

Quadro 5 - Relacionamento teórico entre capacidades gerencias para a implementação da estratégia e o alinhamento vertical

Quadro 6 - Relacionamento teórico entre envolvimento das pessoas com a estratégia e o alinhamento vertical

Quadro 7 - Relacionamento teórico entre orientação para processos e orientação para clientes e o alinhamento horizontal

Quadro 8 - Síntese da base teórica: principais construtos.

Quadro 9 - Características dos modelos reflexivo e formativo. .77

Quadro 10 - Etapas de validação e critérios adotados .83

Quadro 11 - Assertivas inicialmente propostas para o construto processo formal de planejamento .88

Quadro 12 - Assertivas inicialmente propostas para o construto envolvimento da média gerência

Quadro 13 - Assertivas inicialmente propostas para o construto consenso estratégico

Quadro 14 - Assertivas inicialmente propostas para o construto capacidades gerenciais 90

Quadro 15 - Assertivas inicialmente propostas para o construto envolvimento das pessoas com a estratégia 91

Quadro 16 - Assertivas propostas para o construto orientação para processos. .92

Quadro 17 - Assertivas propostas para o construto orientação para clientes. .93

Quadro 18 - Assertivas para o construto desempenho organizacional. .95

Quadro 19 - Assertivas propostas para o construto estratégia .95

Quadro 20 - Assertivas para o construto de incerteza ambiental .97 


\section{LISTA DE TABELAS}

Tabela 1 - Caracterização da amostra por área de atuação e porte...............................100

Tabela 2 - Caracterização da amostra por tipo de estratégia e área de atuação ...........101

Tabela 3 - Perfil dos respondentes por cargo e área de atuação ...................................102

Tabela 4 - Estatísticas descritivas do construto processo formal de

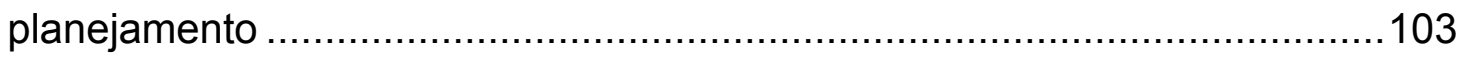

Tabela 5 - Estatísticas descritivas do construto envolvimento da média

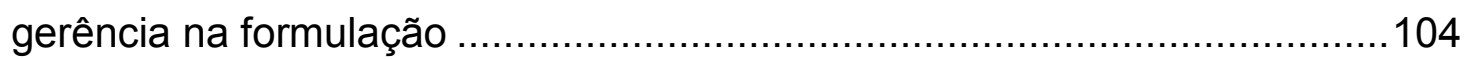

Tabela 6 - Estatísticas descritivas do construto consenso estratégico .........................105

Tabela 7 - Estatísticas descritivas do construto capacidades gerenciais para implementação

Tabela 8 - Estatísticas descritivas do construto envolvimento das pessoas com a estratégia

Tabela 9 - Estatísticas descritivas do construto orientação para processos..................107

Tabela 10 - Estatísticas descritivas do construto orientação para clientes .....................108

Tabela 11 - Estatísticas descritivas do construto desempenho organizacional ...............109

Tabela 12 - Estatísticas descritivas do construto incerteza ambiental ...........................110

Tabela 13 - Validade convergente e confiabilidade das VL do construto abrangência da formulação

Tabela 14 - Validade discriminante das VL do construto abrangência da formulação

Tabela 15 - Validade convergente e confiabilidade das VL do alinhamento vertical 113

Tabela 16 - Validade convergente e confiabilidade do alinhamento horizontal 114

Tabela 17 - Validade convergente e confiabilidade da VL desempenho organizacional

Tabela 18 - Validade convergente e confiabilidade da VL alinhamento interno... 116

Tabela 19 - Correlação entre as VL de primeira ordem. 116

Tabela 20 - Correlação entre as VL de segunda ordem 117

Tabela 21 - Validade convergente e confiabilidade da VL incerteza ambiental 119

Tabela 22 - Síntese dos resultados da avaliação estatística do modelo teórico. 120 


\section{LISTA DE SIGLAS}

AVE Average Variance Extracted - Média da variância extraída

AF Abrangência da formulação da Estratégia

Al Alinhamento interno

AV Alinhamento Vertical

$\mathrm{AH} \quad$ Alinhamento Horizontal

BSC Balanced Scorecard

CC Indicador de confiabilidade composta

CE Consenso Estratégico

CG Capacidades Gerenciais para implementação da estratégia

DO Desempenho Organizacional

EMG Envolvimento da Média Gerência na Formulação

EP Envolvimento das Pessoas com a estratégia

IA Incerteza Ambiental

MEE Modelagem de Equações Estruturais

MEEBC Modelagem de equações estruturais baseada em covariância

MEEPLS Modelagem de equações estruturais com estimação via PLS

OC Orientação para clientes

OP Orientação para Processos

PFP Processo Formal de Planejamento

PLS Partial Least Square

SI Sistemas de Informação

TI Tecnologia da Informação

VI Variável Independente 


\section{SUMÁRIO}

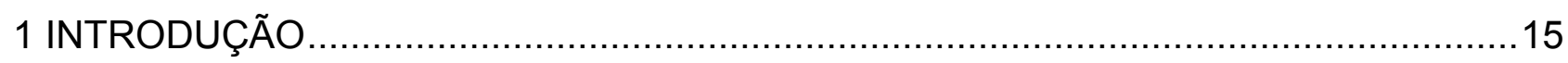

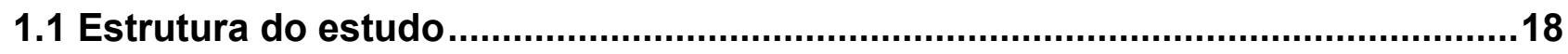

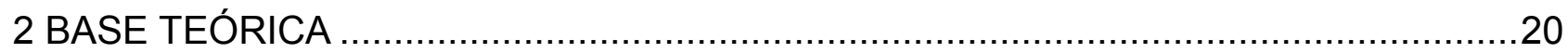

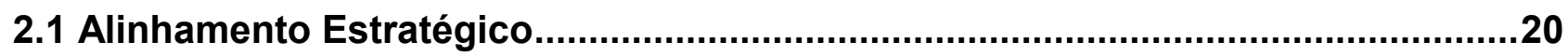

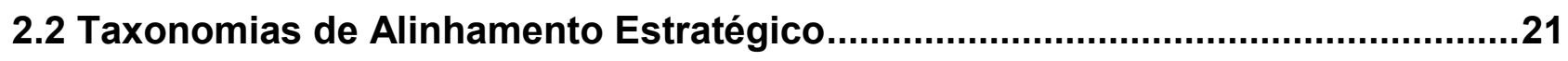

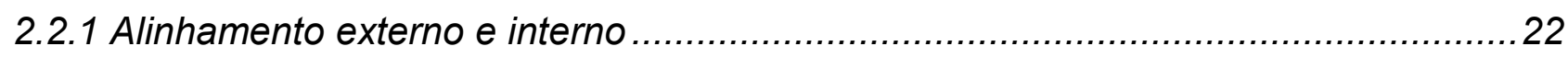

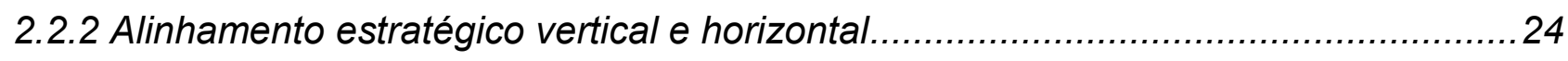

2.3 Formulação e implementação da estratégia ............................................................26

2.4 Síntese dos conceitos de alinhamento estratégico ................................................29

2.5 Desempenho organizacional e o conceito de alinhamento ....................................30

2.5.1 Alinhamento estratégico na perspectiva normativa ..................................34

2.6 A influência da estratégia na relação alinhamento-desempenho...........................38

2.7 A influência da incerteza ambiental na relação AI-DO ........................................41

2.8 Fatores envolvidos no alinhamento estratégico...................................................45

2.8. 1 Fatores envolvidos no alinhamento estratégico vertical......................................54

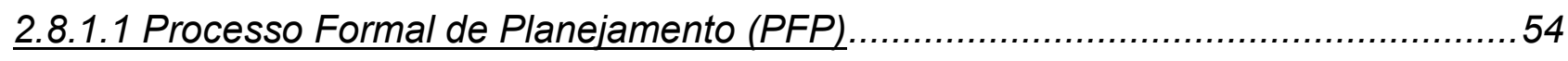

2.8.1.2 Envolvimento da média gerência na formulação (EMG)....................................56

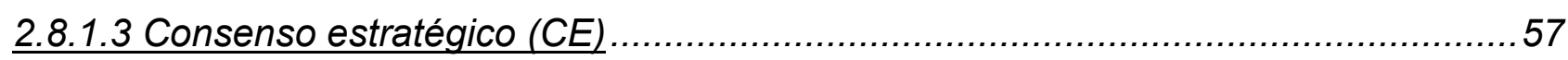

2.8.1.4 Capacidades gerencias para a implementação da estratégia (CG).......................58

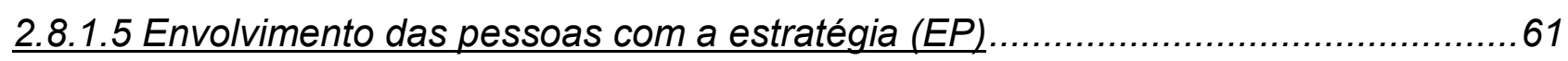

2.8. 2 Fatores envolvidos no alinhamento estratégico horizontal ..................................64

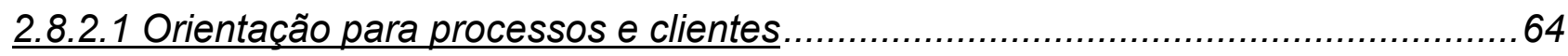

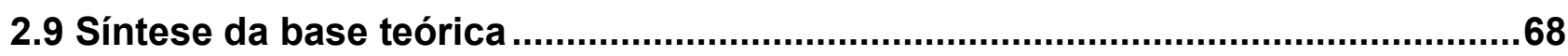

3 MODELO TEÓRICO, OBJETIVOS E HIPÓTESES DA PESQUISA ..............................71

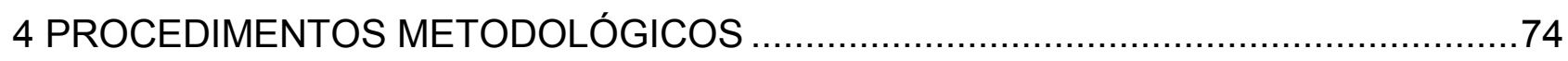

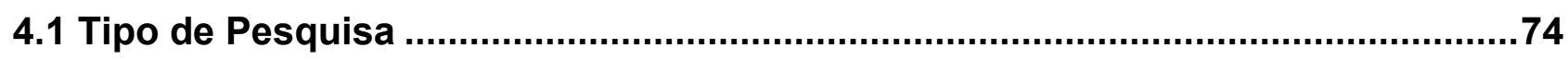

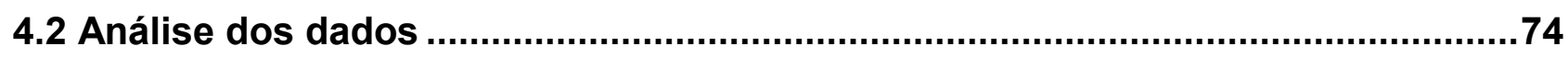

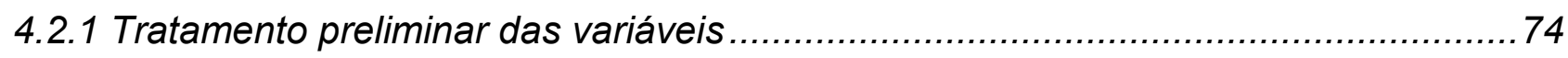

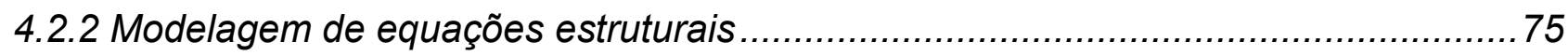

4.2.3 Aplicação e contribuições da MEE neste trabalho .............................................. 79

4.3 Validação dos construtos e critérios de análise dos dados .................................79

4.4 Construção do instrumento de coleta de dados.................................................82 
4.5 Definição dos construtos e dos instrumentos de pesquisa .86

4.5.1 Definição dos Construtos do Alinhamento Vertical .........................................87

4.5.1.1 Processo Formal de Planejamento ....................................................... 87

4.5.1.2 Envolvimento da média gerência na formulação (EMG) ..................................87

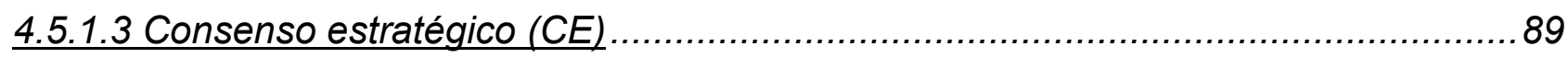

4.5.1.4 Capacidades Gerencias (CG) para a Implementação da Estratégia ...................90

4.5.1.5 Envolvimento das Pessoas (EP) com a estratégia ........................................91

4.5.2 Definição dos Construtos do Alinhamento Horizontal ............................................92

4.5.2.1 Orientação para processos $(O P)$..................................................... 92

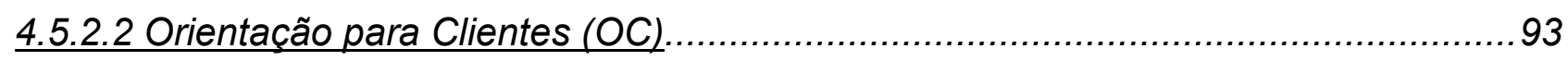

4.5.3 Definição do Construto de Desempenho Organizacional ...................................93

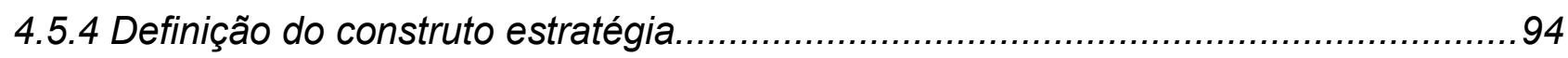

4.5.5 Definição do construto incerteza ambiental ............................................ 97

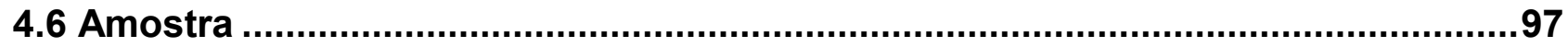

5 APRESENTAÇÃO E ANÁLISE DOS RESULTADOS .......................................... 99

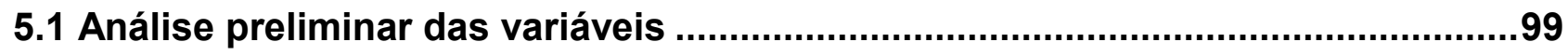

5.2 Caracterização da amostra ..........................................................................100

5.3 Análise descritiva dos dados .........................................................................103

5.3.1 Análise descritiva dos construtos do alinhamento vertical ................................103

5.3.1.1 Processo formal de planejamento (PFP) ...............................................103

5.3.1.2 Envolvimento da média gerência na formulação ............................................104

5.3.1.3 Consenso estratégico (CE) ............................................................. 105

5.3.1.4 Capacidades gerenciais para implementação da estratégia.............................105

5.3.1.5 Envolvimento das Pessoas com a Estratégia ............................................106

5.3.2 Análise descritiva dos construtos do alinhamento horizontal.............................107

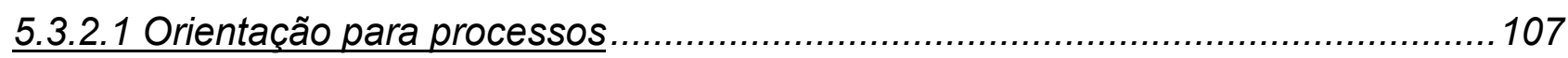

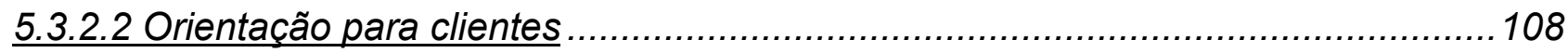

5.3.3 Análise descritiva do construto desempenho organizacional..............................109

5.3.4 Análise descritiva do construto incerteza ambiental .......................................110

5.4 Análise do modelo de mensuração..................................................................110

5.4.1 Análise do Construto Abrangência da Formulação............................................111

5.4.2 Análise das VL do construto alinhamento vertical .........................................112

5.4.3 Análise das VL do construto alinhamento horizontal ......................................114

5.4.4 Análise da VL Desempenho Organizacional..............................................115 
5.4.5 Análise da VL Alinhamento Interno. 115

5.4.6 Validade Discriminante entre as variáveis latentes. 116

5.5 Análise do modelo estrutural

5.5.1 - Efeito moderador da incerteza ambiental 118

5.5.2 - Efeito moderador da estratégia. 120

6 CONSIDERAÇÕES FINAIS 121

6.1 Contribuições, limitações e sugestões para outros estudos 123 REFERÊNCIAS 127

APÊNDICE A - ESTUDOS EMPÍRICOS SOBRE ALINHAMENTO ESTRATÉGICO VERTICAL E HORIZONTAL

APÊNDICE B - ESTUDOS EMPÍRICOS SOBRE ALINHAMENTO ESTRATÉGICO.......144 APÊNDICE C - SÍNTESE DA BASE TEÓRICA: ESTUDOS EMPÍRICOS SOBRE A RELAÇÃO ALINHAMENTO E DESEMPENHO 157

APÊNDICE D - MODELO TEÓRICO DA PESQUISA (COMPLETO) 162

APÊNDICE E - MATRIZ DE AMARRAÇÃO. 163

APÊNDICE F - RELATÓRIO DA VALIDAÇÃO DE CONTEÚDO 164

APÊNDICE G - VERSÃO FINAL DO QUESTIONÁRIO. 176

APÊNDICE H - RESULTADOS DO TESTE DA MEDIANA DE MOOD 181 APÊNDICE I - CARGAS CRUZADAS PARA AVALIAÇÃO DA VALIDADE DISCRIMINANTE 190

APÊNDICE J - MODELO FINAL COM PARÂMETROS ESTIMADOS VIA MEEPLS 191 


\section{INTRODUÇÃO}

O alinhamento é um conceito central na literatura de estratégia, estando presente nos trabalhos seminais de Andrews (1971) - alinhamento da estratégia ao ambiente externo e Chandler (1962) - alinhamento entre a estrutura e a estratégia, e nos modelos de formulação da estratégia que têm como expoentes Porter (1986) alinhamento da estratégia ao mercado e Barney (1991), Collis e Montgomery (1995) e Wernerfelt (1984), cuja ênfase do alinhamento estratégico recai primeiramente sobre os fatores internos.

Devido à abrangência das variáveis envolvidas nos estudos da área de estratégia, diferentes taxonomias são empregadas em pesquisas envolvendo o conceito de alinhamento (VENKATRAMAN; CAMILLUS, 1984). Nesse sentido, a literatura distingue entre alinhamento externo e interno.

Os estudos sobre o alinhamento externo relacionam-se à formulação da estratégia e tratam do ajuste da organização ao seu ambiente de atuação. Tais estudos têm dominado as pesquisas, uma vez que a prioridade de pesquisadores e executivos tem sido a formulação, em detrimento da implementação da estratégia (ATKINSON, 2006; HREBINIAK; JOYCE, 2001; ZAJAC; KRAATZ; BRESSER, 2000).

Em contraste, o foco do alinhamento interno é a implementação, que compreende o ajuste entre a estratégia e as variáveis internas (VENKATRAMAN; CAMILLUS, 1984).

Adota-se, nesta tese, a taxonomia do Alinhamento Interno, conceituado como o alinhamento da organização tanto na dimensão vertical quanto horizontal. O Alinhamento Vertical refere-se ao conjunto de ações necessárias à implementação da estratégia, desde a estratégia formulada até o seu desdobramento por todos os níveis da organização. O Alinhamento Horizontal envolve a compreensão das necessidades do cliente e o alinhamento dos processos (inter-funcionais) capazes de entregar o que o cliente necessita.

Entre o alinhamento vertical e o alinhamento horizontal, o primeiro tem recebido consideravelmente maior atenção por parte da literatura, como indica uma survey recentemente realizada por Kathuria, Joshi e Porth, 2007.

A maioria desses estudos explora o conceito do alinhamento entre a estratégia de negócios e uma determinada área funcional (Manufatura, Operações, Marketing, Sistemas de Informação), buscando identificar se o alinhamento vertical 
existe ou não, ou então, exploram o impacto do alinhamento em um conjunto específico destas unidades funcionais sobre o desempenho. Ainda segundo os autores, esse tipo de estudo é fácil de conceituar e permite que a pesquisa seja conduzida na área de especialização do pesquisador, o que talvez justifique o interesse por essa abordagem.

Os esparsos estudos que existem sobre o alinhamento horizontal também tendem a examinar a relação entre duas áreas funcionais; por isso, a definição operacional do conceito de alinhamento que atravessa as funções tem se tornado crítica (KATHURIA; JOSHI; PORTH, 2007).

Até onde se pesquisou, são raros os estudos envolvendo as duas dimensões, no entanto, elas estão imbricadas no processo de implementação da estratégia.

A implementação da estratégia envolve o ajuste entre vários elementos organizacionais, por isso, a literatura também aponta a necessidade de ampliar o escopo dos elementos que têm sido considerados nas pesquisas, indo além da tradicional perspectiva bivariada (MILLER, 1987; VENKATRAMAN; CAMILLUS, 1984).

Segundo Venkatraman e Prescott (1990) conceituar o alinhamento na "perspectiva holística" tem a vantagem de manter a natureza complexa ou sistêmica da inter-relação entre variáveis organizacionais.

Nesse sentido, estudos mais recentes adotam a perspectiva do alinhamento como a interação entre vários elementos, adotando a perspectiva da congruência (SIGGELKOW, 2001, 2002) ou da complementaridade (CARMELI; TISHLER, 2004; PETERAF; REED, 2007; ENNEN; RICHTER, 2010).

Dadas essas lacunas, esta tese se propõe a investigar o conceito de alinhamento interno, considerando tanto o alinhamento vertical como o horizontal. $\mathrm{O}$ conceito de alinhamento empregado é o da covariação, que prevê que o alinhamento é resultado da interação conjunta entre essas dimensões.

O principal objetivo desta pesquisa é avaliar o impacto do alinhamento interno sobre o desempenho organizacional.

Uma contribuição teórica só faz sentido se puder contribuir para alavancar a gestão das organizações (VOSS; TSIKRIKTSIS; FROHLICH, 2002). Nesse sentido, O desempenho organizacional é amplamente reconhecido como uma das variáveis mais importantes nas pesquisas desenvolvidas no campo de gestão estratégica (CHAKRAVARTHY, 1986; COMBS; CROOK; SHOOK, 2005) e na opinião de Meyer 
(1991) é um fator que diferencia esse campo de pesquisa dos demais, e deve contribuir para aumentar a compreensão sobre os determinantes do desempenho organizacional e para explicar como os gestores podem alcançar um desempenho superior.

A relação alinhamento-desempenho é amplamente aceita nos estudos envolvendo o conceito de alinhamento, tendo sido estabelecida desde os contingencialistas que afirmam que o bom desempenho das organizações é resultado do ajuste adequado entre variáveis endógenas, tais como, estratégia, estrutura e processos gerenciais e variáveis exógenas, como a incerteza ambiental e tecnologia.

No campo de estudos sobre estratégia, essa mesma relação é discutida por autores tais como, Galbraith e Kazanjian (1986), Ginsberg e Venkatraman (1985), Miles e Snow (1984), Prieto e Carvalho (2010) e Zajac, Kraatz e Bresser (2000). É esperado que uma organização que apresente um alto grau de ajuste ou congruência entre seus elementos também apresente desempenho superior.

Kathuria, Joshi e Porth (2007) afirmam que ainda é necessário investigar a relação alinhamento-desempenho porque nem todos os estudos têm sido capazes de evidenciar essa relação direta, mas, indiretamente, por meio de variáveis moderadoras ou mediadoras.

Articulados ao objetivo geral, também foram definidos outros resultados a serem alcançados com esta tese, considerados os objetivos específicos:

1) Definir as variáveis componentes do alinhamento vertical e horizontal.

2) Avaliar o impacto da estratégia sobre a relação alinhamento internodesempenho.

3) Avaliar o impacto da incerteza ambiental sobre a relação alinhamento interno-desempenho.

O primeiro objetivo está relacionado à definição do modelo teórico de alinhamento estratégico interno a ser analisado. Muitas variáveis têm sido empregadas nos estudos empíricos e entende-se que é necessário selecionar aquelas mais adequadas ao conceito de alinhamento proposto.

Os outros dois objetivos representam variáveis moderadoras do estudo.

Quanto ao segundo objetivo, pretende-se investigar a relação alinhamento interno-desempenho organizacional no contexto de empresas que adotam diferentes estratégias, utilizando-se a tipologia de Miles e Snow (2003), que identifica quatro 
orientações estratégicas dentro da indústria: Defensores (Defenders), Analisadores (Analyzers), Prospectores (Prospectors) e Reatores (Reactors).

A literatura também reconhece que fatores contextuais podem influenciar 0 ajuste das variáveis internas (LAWRENCE; LORSCH, 1967), sendo que uma das variáveis contingenciais mais contempladas nos estudos empíricos tem sido a incerteza ambiental (GINSBERG; VENKATRAMAN, 1985). Nesse sentido, a proposta com relação ao terceiro objetivo é investigar a relação alinhamento internodesempenho organizacional, moderada pela incerteza ambiental.

\subsection{Estrutura do estudo}

A Figura 1 apresenta a estrutura utilizada para o desenvolvimento do trabalho.

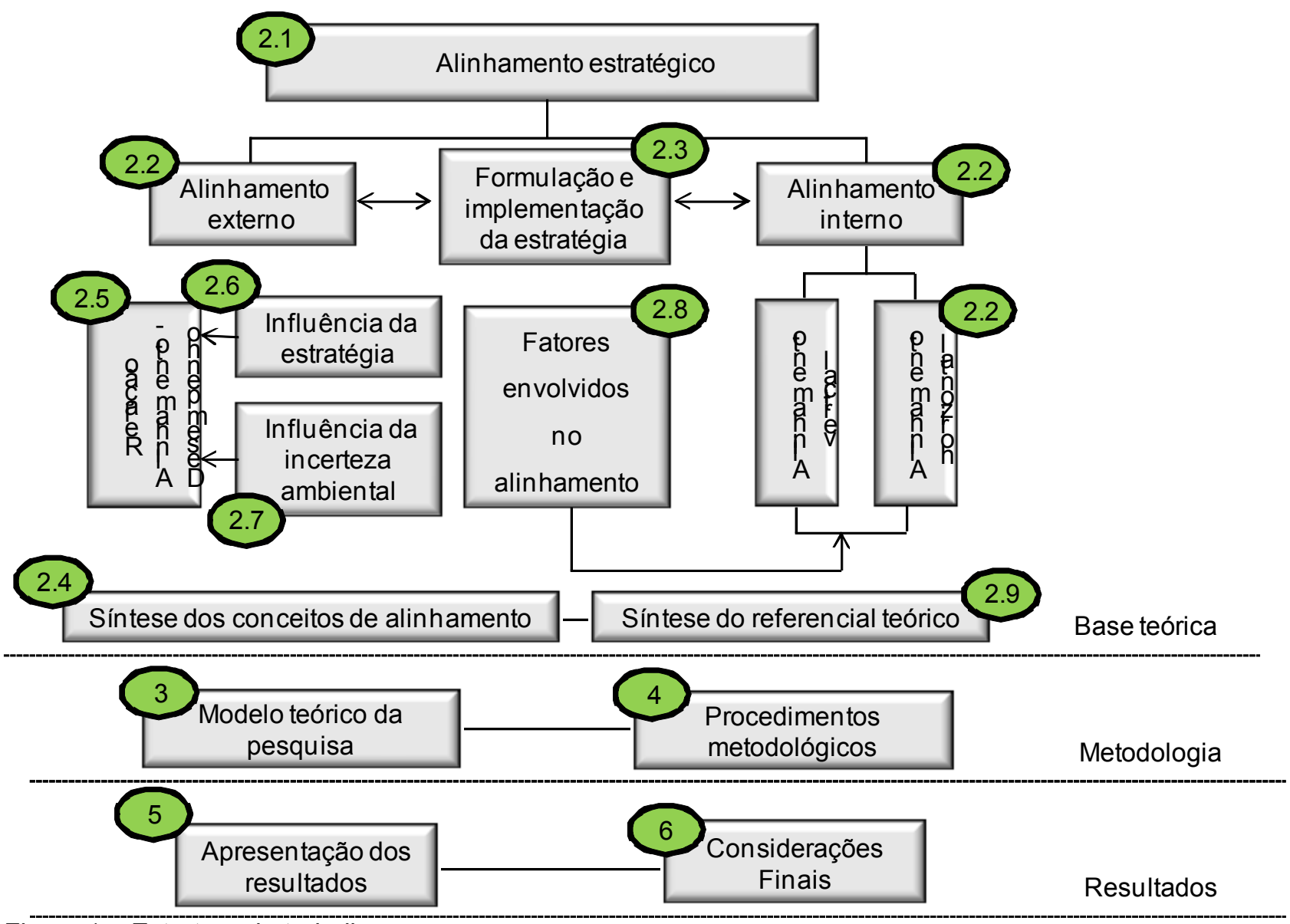

Figura 1 - Estrutura do trabalho

No capítulo 2 desenvolve-se a base teórica, iniciando-se pelo conceito de alinhamento estratégico e suas origens (seção 2.1), em seguida são apresentadas as taxonomias de alinhamento estratégico com ênfase naquelas que serão consideradas neste trabalho, as de alinhamento interno, alinhamento vertical e 
horizontal (seção 2.2). A seção 2.3 trata da relação entre as taxonomias de alinhamento estratégico e os conceitos de formulação e implementação da estratégia. A seção 2.4 apresenta uma síntese dos conceitos de alinhamento que serão empregados nesta tese. As seções 2.5 a 2.8 tratam do embasamento teórico para os construtos componentes do alinhamento estratégico. A seção 2.9 apresenta uma síntese da base teórica com ênfase nos construtos que farão parte do modelo da pesquisa e na principal relação a ser investigada, entre alinhamento e desempenho.

O capítulo 3 apresenta o modelo teórico da pesquisa e busca estabelecer as relações teóricas que levaram à sua proposição. Também são apresentados os objetivos e hipóteses da pesquisa.

O capítulo 4 apresenta os procedimentos metodológicos, incluindo os critérios que serão utilizados para a validação dos construtos e para a análise dos dados e os procedimentos utilizados para a operacionalização dos construtos e para a definição da amostra.

O capítulo 5 apresenta os resultados da pesquisa, incluindo a análise descritiva dos dados por construto e a análise do modelo teórico com base na modelagem de equações estruturais, iniciando-se pela análise do modelo de mensuração e, em seguida, a análise do modelo estrutural. As devidas validações dos construtos são relatadas.

No capítulo 6 discutem-se os resultados obtidos com maior profundidade, procurando estabelecer as conexões com a base teórica e com os objetivos propostos, em seguida apresentam-se as contribuições, limitações e sugestões para outros trabalhos. 


\section{BASE TEÓRICA}

A base teórica está estruturada visando conceituar os principais construtos de alinhamento contemplados por esta tese, fornecer um panorama de como eles se inserem na literatura de alinhamento estratégico, bem como fundamentar as relações teóricas entre as variáveis do estudo.

Inicia-se com a apresentação dos conceitos e taxonomias do alinhamento estratégico, em seguida faz-se uma distinção sobre os processos de formulação e implementação da estratégia, uma vez que eles estão intrinsecamente relacionados a esta pesquisa. Também é abordada a relação entre alinhamento e desempenho e a influência da estratégia e da incerteza ambiental sobre a mesma.

\subsection{Alinhamento Estratégico}

O conceito de alinhamento está presente nos trabalhos seminais da literatura de estratégia. Andrews (1971) propõe a clássica definição de estratégia como sendo o alinhamento entre forças e fraquezas organizacionais e ameaças e oportunidades do ambiente no qual a organização está inserida; Chandler (1962) propõe a clássica concepção do alinhamento entre a estrutura e a estratégia.

O alinhamento também é um conceito central retratado nas duas correntes da literatura que representam dois eixos sobre a questão da vantagem competitiva. Para a linha de pesquisa que aborda a questão da vantagem competitiva com ênfase no poder do mercado, o alinhamento é uma condição inerente ao ajuste da estratégia às forças competitivas da indústria (PORTER, 1986), enquanto para os proponentes da Visão da Empresa Baseada em Recursos (Resourced Based View RBV), a ênfase do alinhamento recai primeiramente sobre os fatores internos (BARNEY, 1991; COLLIS; MONTGOMERY, 1995; WERNERFELT, 1984).

No campo da estratégia, o conceito de alinhamento é também um requisito presente tanto no processo de formulação quanto de implementação da estratégia (HREBINIAK; JOYCE, 2001; VENKATRAMAN; CAMILLUS, 1984).

$\mathrm{Na}$ formulação o conceito refere-se ao ajuste da estratégia ao ambiente competitivo, e também está presente na ideia do consenso entre os estrategistas quanto ao resultado das decisões estratégicas, o que irá influenciar o grau de 
comprometimento e impulsionar a comunicação da estratégia aos demais níveis hierárquicos (EISENHARDT, 1999; FLOYD; WOOLDRIDGE, 1992a).

$\mathrm{Na}$ implementação é requerida a integração entre vários elementos, em especial o alinhamento entre estrutura, pessoas, sistema de informações, sistema de métricas e de recompensas para viabilizar a proposta estratégica.

O conceito de alinhamento tem a sua origem nos estudos da abordagem contingencial (VENKATRAMAN; CAMILLUS, 1984) que afirmam que não existe uma única melhor maneira de administrar e que tudo depende das características ambientais relevantes para a organização.

Adicionalmente os contingencialistas também estabeleceram a conexão entre o alinhamento e o DO que, em geral, apresenta uma correlação positiva, ou seja, o bom desempenho das organizações está associado a um alinhamento adequado entre as variáveis endógenas (estratégia, estrutura e processos gerenciais) e as variáveis exógenas (incerteza ambiental e tecnologia).

O pensamento sistêmico também é outra corrente influente na literatura sobre alinhamento, principalmente o conceito de sistemas abertos originário dos estudos de Bertalanffy nos anos 50. De acordo com essa abordagem a organização é considerada um organismo vivo, que influencia e é influenciada pelo ambiente, o que exige capacidade de adaptação e equilíbrio. Adaptação no sentido de que mudanças internas serão necessárias para atender às demandas do ambiente externo, enquanto o equilíbrio visa manter o grau de coesão entre as dimensões internas.

Não há um consenso quanto ao termo empregado para referir-se ao alinhamento que pode assumir o sentido de coalinhamento, agrupamento, coesão, ajuste ou congruência entre diferentes dimensões (GALBRAITH; KAZANJIAN, 1986; VENKATRAMAN; PRESCOTT, 1990). Neste trabalho será utilizado o termo alinhamento, no entanto, na revisão da teoria busca-se preservar o termo originalmente utilizado pelos autores.

\subsection{Taxonomias de Alinhamento Estratégico}

Destaca-se também na literatura a busca por classificações e taxonomias relacionadas ao alinhamento.

Venkatraman e Camillus (1984) propõem um esquema conceitual para a compreensão da evolução das pesquisas no campo da estratégia, no qual coexistem 
diferentes perspectivas para a aplicação do conceito de alinhamento dependendo das escolas de pensamento que o empregam.

Os autores verificam que dada a sua complexidade o conceito de alinhamento é tratado e investigado segundo construtos distintos, de alinhamento externo (formulação da estratégia), alinhamento interno (implementação da estratégia) e integrado. Existem, ainda, as classificações quanto ao conteúdo, elementos a serem alinhados com a estratégia, ou quanto ao processo, como realizar o alinhamento.

Segundo Venkatraman e Camillus (1984), quando o foco do trabalho é o conteúdo da estratégia (o que deve ser feito - what should be done) o alinhamento é uma questão da escolha da melhor ação estratégica para enfrentar diferentes condições ambientais, por exemplo, as estratégias genéricas de Michael Porter (1986). Quando a estratégia é tratada como processo (como ela é desenvolvida how it is to be developed), a adaptação significa percorrer um caminho para compor diferentes elementos, alguns internos, como competências e recursos e outros externos, como lidar com as oportunidades e ameaças, até chegar à estratégia desejada (VENKATRAMAN; CAMILLUS,1984, p. 514).

Ainda segundo os autores, a teoria subjacente é a de que a estratégia envolve o ajuste ou a arte de combinar vários componentes do mix estratégico; e remonta a uma visão da estratégia consistente com a perspectiva dos sistemas abertos na teoria das organizações.

Tal visão é que leva a estratégia a ser conceituada como padrão ou conjunto de decisões tomadas para alcançar o melhor alinhamento entre o ambiente externo e a estrutura e os processos internos, ideia presente nos trabalhos de Miles e Snow (2003), Mintzberg (1978) e Venkatraman e Camillus (1984).

\subsubsection{Alinhamento externo e interno}

Uma característica dos estudos de alinhamento é que as bases teóricas traçadas e os principais construtos e variáveis para o alinhamento interno e externo são distintos, conforme destacado nos trabalhos de Hrebiniak e Joyce (2001), Stepanovich e Mueller (2002) e Venkatraman e Camillus (1984). O alinhamento externo considera a perspectiva da formulação da estratégia e, prioritariamente, o 
ajuste da estratégia às variáveis ambientais. Em contraste, o foco do alinhamento interno é a implementação e o ajuste entre a estratégia e as variáveis internas.

O termo mais utilizado para abordar o alinhamento estratégico externo é ajuste (do inglês, fit). O conceito de alinhamento externo está presente na literatura referindo-se ao ajuste das capacidades, recursos e estratégia ao ambiente competitivo da organização. Mais precisamente, "fit" tem sido definido como o grau de ajuste da organização ao ambiente (NAMAN; SLEVIN, 1993).

As pesquisas sobre alinhamento externo têm sido conduzidas em termos de integração de capacidades (FUCHS et al., 2000); alinhamento dinâmico e inércia organizacional (SIGGELKOW, 2001; ZAJAC; KRAATZ; BRESSER, 2000) e formulação da estratégia e DO (DESS, 1987), dentre outras.

O alinhamento interno refere-se à mobilização dos recursos, tangíveis ou intangíveis, para implementação da estratégia formulada. As suas raízes teóricas estão na literatura de implementação da estratégia e de mudança organizacional (STEPANOVICH; MUELLER, 2002; VENKATRAMAN; CAMILLUS, 1984). A proposição de Chandler (1962) sobre o alinhamento da estrutura à estratégia é seminal nesse campo de estudos. Também são relevantes os trabalhos que surgiram nos anos 70 com a visão da organização baseada em recursos (RBV), com destaque para Galbraith (1977), Miles e Snow (2003) e Peters e Waterman (1982).

O desempenho da organização é dependente tanto do alinhamento interno como do externo e o processo de alcançar o alinhamento é dinâmico e precisa ser continuamente monitorado e ajustado (LABOVITZ; ROSANSKY, 1997; SIGGELKOW, 2001). Nesse contexto, a literatura também propõe ferramentas para monitoramento da implementação e que conduzam a organização a um estágio de controle da estratégia (FUCHS et al., 2000; KAPLAN; NORTON, 1996; LABOVITZ; ROSANSKY, 1997; PRIETO, 2006).

O alinhamento interno também é visto como conjunto de atividades interrelacionadas ou como configurações.

Segundo Siggelkow (2002), o termo configuração usualmente implica em que os elementos centrais são reforçados de maneira em que o sistema como um todo está em um estado de coerência ou consistência, portanto, o alinhamento interno não deveria ser pensado como associação entre variáveis, mas como configurações, descrevendo conjuntos de elementos e seus relacionamentos. Em contraste, um 
sistema organizacional pode bem consistir em elementos centrais que não se reforçam um ao outro.

Identifica-se, ainda, o consenso como uma das dimensões do alinhamento interno (STEPANOVICH; MUELLER, 2002) o qual refere-se à concordância que se estabelece tanto na formulação, quanto na implementação da estratégia, representado pelos trabalhos de Dess (1987), Floyd e Wooldridge (1992a), Homburg, Krohmer e Workman Jr. (1999) e Priem (1990).

\subsubsection{Alinhamento estratégico vertical e horizontal}

As pesquisas envolvendo o construto de alinhamento interno ( $\mathrm{Al}$ ) têm sido conduzidas em termos de alinhamento vertical (AV) e alinhamento horizontal ( $A H)$.

O conceito está atrelado ao da operacionalização da estratégia em diferentes níveis organizacionais. É amplamente aceito pela literatura que a estratégia é elaborada em três níveis distintos da organização, envolvendo a estratégia corporativa, a estratégia de negócios e a estratégia funcional (GINSBERG; VENKATRAMAN, 1985; HITT; IRELAND; HOSKISSON, 2008; THOMPSON JR.; STRICKLAND III, 2003).

Uma estratégia no nível corporativo especifica as ações de empresa ao administrar um grupo de vários negócios que competem em vários mercados de produtos (HITT; IRELAND; HOSKISSON, 2008). Já a estratégia de negócios diz respeito a como competir eficazmente em uma determinada indústria ou negócio.

Nesse sentido, as empresas podem ser guiadas pelas estratégias genéricas para definir e defender a posição estratégica desejada (HITT; IRELAND; HOSKISSON, 2008).

A estratégia funcional é para unidades funcionais específicas dentro de um negócio, por exemplo, uma estratégia de produção, marketing, finanças (THOMPSON JR.; STRICKLAND III, 2003) e foca na maximização dos recursos dentro de cada função (GINSBERG; VENKATRAMAN, 1985).

De acordo com Kathuria, Joshi e Porth (2007) o alinhamento vertical refere-se à configuração das estratégias, objetivos, planos de ação e decisões através dos vários níveis da organização. A orientação estratégica deve fluir do nível corporativo para o nível de negócios, e assim sucessivamente. A implementação da estratégia é essencialmente de cima para baixo, com o objetivo de fazer com que os níveis 
hierárquicos inferiores estabeleçam estratégias, objetivos e planos que viabilizem a concretização de uma estratégia elaborada em um nível superior. Quando essa coerência é alcançada, diz-se que o AV foi realizado.

$\mathrm{O} \mathrm{AH}$ acontece entre as diferentes áreas, funções e operações da organização. Kathuria, Joshi e Porth (2007) definem o AH em termos da integração entre as funções (cross-functional) e dentro das funções (intra-functional). Ainda segundo os autores, a integração entre as funções denota a coerência das decisões estratégicas e atividades entre as áreas de Marketing, Operações e Recursos Humanos, dentre outras, e como elas se complementam e dão suporte umas às outras.

O conceito de alinhamento estratégico vertical e horizontal está presente em dois modelos de alinhamento estratégico analisados por Prieto, Carvalho e Fischmann (2009).

No modelo proposto por Labovitz e Rosansky (1997) a dimensão vertical representa o alinhamento entre estratégia e pessoas e a dimensão horizontal o alinhamento entre clientes e processos. A dimensão horizontal envolve a compreensão das necessidades do cliente e o alinhamento dos processos (interfuncionais) capazes de entregar o que o cliente necessita. A ideia também é identificar quais são os clientes alvo desse processo - o cliente certo.

A mesma relação está presente no Balanced Scorecard (BSC). O modelo propõe que o AV seja alcançado por meio do desdobramento das medidas de desempenho a todas as áreas e níveis hierárquicos da organização (KAPLAN; NORTON, 1996, 2000). Na dimensão horizontal, os indicadores da perspectiva dos clientes devem estar apoiados por processos internos. Os processos devem criar as condições para que a organização ofereça propostas de valor ao cliente, capazes de atrair e reter clientes nos seus segmentos de atuação e, ao mesmo tempo, criar valor aos acionistas (KAPLAN; NORTON, 1992, 1996).

Em ambos os modelos a perspectiva dos clientes consiste na identificação dos segmentos de mercado e clientes que a empresa deseja atender e que são a fonte de receita dos negócios. Pressupõe também que a organização defina mecanismos para conhecer as necessidades deles e tenha propostas específicas de como lhes entregar valor.

$\mathrm{Na}$ perspectiva dos processos a ideia é identificar quais são críticos para a realização dos objetivos dos clientes. No BSC recomenda-se a identificação de uma 
"cadeia de valor completa dos processos internos" que tenha início com o processo de inovação (identificação das necessidades atuais e futuras dos clientes e desenvolvimento de novas soluções para essas necessidades), prossiga com os processos de operações (entrega dos produtos e prestação de serviços aos clientes existentes) e termine com o serviço pós-venda (oferta de serviços que complementem o valor proporcionado aos clientes pelos produtos ou serviços de uma empresa) (KAPLAN; NORTON, 1997).

O AH também está presente no trabalho de Porter (1996), que amplia o seu conceito inicial sobre estratégia com a declaração de que a estratégia se concretiza no conjunto das atividades que reforçam-se umas às outras desde que estejam em linha com o direcionamento estratégico proposto.

\subsection{Formulação e implementação da estratégia}

O alinhamento é considerado ao mesmo tempo um processo e um resultado (MILES; SNOW, 1984). Enquanto resultado, a literatura propõe ferramentas para medir o grau de alinhamento (FUCHS et al., 2000; LABOVITZ; ROSANSKY, 1997; PRIETO; CARVALHO, 2010) ou, como afirmam Kaplan e Norton (1996), o alinhamento deve levar a organização a um estágio de controle da estratégia.

Um processo é comumente definido como um conjunto de tarefas e atividades que contribui para transformar entradas em saídas. No caso do alinhamento enquanto processo, o conceito refere-se ao exercício prático de um conjunto de atividades estruturadas com a finalidade de realizar o alinhamento estratégico. No âmbito do construto de alinhamento interno, o conceito refere-se ao exercício prático de um conjunto de atividades estruturadas com a finalidade promover a implementação da estratégia.

A literatura apresenta uma ampla discussão a respeito da formulação e implementação da estratégia (BOWER, 1982; CHAKRAVARTHY; DOZ, 1992; KAPLAN; NORTON, 1992, 1993, 1996, 2000; MINTZBERG, 1994). Discutem-se, por exemplo, a relação entre o conteúdo e o processo da estratégia, as etapas e os fatores a serem considerados no processo de implementação e os fatores que determinam a sua eficácia.

Cabe, inicialmente, introduzir a discussão a respeito da formulação e implementação da estratégia. 
A ideia de que para promover a implementação é necessário ter uma estratégia claramente definida está presente na literatura acrescida de argumentos sobre os fatores e os processos que favorecem ou não a sua implementação.

Bower (1982) ressalta que enquanto o processo de formulação da estratégia foca em o que a empresa pode fazer de melhor para enfrentar a competitividade do ambiente no qual ela está inserida, o processo de implementação da estratégia muda o foco da pergunta para o que a organização precisa fazer para ter sucesso com uma estratégia já determinada. Estando a estratégia definida, o problema reside na necessidade de escolher uma forma para alcançar os objetivos propostos.

Há ainda outros autores que apresentam argumentos contrários à distinção entre formulação e implementação. Por exemplo, Campbell e Alexander (1997) argumentam que essa separação exclui a média gerência do processo de formulação o que faz com que a organização acabe se privando do seu conhecimento sobre as operações diárias e a gestão de linha de frente do negócio, os quais são fontes importantes para a inovação que se dá justamente no processo criativo de elaboração da estratégia.

Outros argumentos dizem respeito à necessidade de planejar e analisar os ajustes necessários a implementação já na fase de formulação para ter certeza de que a estratégia é viável (HAMBRICK; CANNELLA, 1989). E, ainda, em ambientes turbulentos, a estratégia pode ser modificada devido ao próprio processo de aprendizado e crescimento que acontece quando a estratégia é colocada em ação, não sendo, portanto, conveniente considerá-los processos que não se interpenetram.

Hrebiniak e Joyce (2001, p.603) consideram que formulação e implementação podem ser diferenciadas e discutidas separadamente tanto conceitualmente como na prática, e que fazer a estratégia funcionar, de fato, implica na existência da estratégia. No entanto, advertem que focar em uma das duas variáveis sem considerar a relação simbiótica entre elas no contexto do processo de gestão estratégica pode levar a resultados desastrosos.

O trabalho de Mintzberg e Waters (1985) apresenta uma ampla discussão a respeito do processo de formulação e desenvolvimento da estratégia. Os autores retomam o conceito de estratégia concebido em termos de planos para o futuro, o qual leva a um sistema planejado de objetivos de longo prazo e planos de ação a serem conduzidos pela organização. 
Analisando a estratégia enquanto processo, esses autores identificam que a estratégia existe primeiramente enquanto intenção (estratégias intencionais), ou seja, o que os líderes pretendem para as organizações. Quando formalizada, a estratégia passa a existir como a estratégia planejada ou deliberada. Em outras palavras, em um processo estratégico planejado a estratégia deliberada é a estratégia pretendida pelos líderes. No entanto, uma estratégia não planejada também pode vir a ter lugar na organização, é a estratégia emergente, que se consolida por um padrão de ações manifestadas no ambiente de trabalho.

$\mathrm{Na}$ dinâmica desse processo de transformação da estratégia em ação, o melhor plano estratégico não é considerado linear, mas circular, no sentido de que é continuamente avaliado e revisado a respeito da maneira como está sendo conduzido, por meio das ações de planejamento, mensuração e ajuste (McCONKEY,1988). Mintzberg (1994) considera que um programa estratégico envolve três etapas, que podem ser resumidas em: (1) tornar a estratégia suficientemente clara para que ela possa ser trabalhada em termos operacionais, (2) transformar a estratégia em subestratégias ou planos que possibilitem a concretização de cada estratégia e (3) considerar os efeitos das mudanças nas operações da organização, por exemplo, os efeitos nas finanças.

Bower (1982) apresenta um entendimento semelhante, quando afirma que o processo de implementação não necessariamente precisa começar com a formulação da estratégia, mas que todas as partes do processo estratégico estão ativas a todo o momento. A reformulação da estratégia é considerada etapa final do processo de implementação. A ideia presente é que independentemente de mudanças no ambiente externo, a implementação da estratégia gera mudanças nos recursos, que pode gerar, por exemplo, novas competências ou novas ideias a serem exploradas estrategicamente. No entanto, o processo de formulação da estratégia provê definições suficientes para análise e intervenções na estrutura.

Bower (1982) propõe uma estrutura para o processo de implementação da estratégia. Em síntese, o processo consiste na análise da estratégia, definição da estrutura de implementação e reformulação da estratégia.

Ênfase é dada ao aspecto comportamental presente em todo o processo, destacando-se a relação existente entre as variáveis de escolha da organização formal - sistema de informação e mensuração e sistema de recompensas e punições - e estilo de gestão com o qual estas estruturas formais serão administradas. 
Os aspectos físicos desse processo encontram-se na definição dos aspectos que são críticos para a implementação da estratégia e como provê-los por meio da estrutura. Uma vez que a estrutura esteja definida, o aspecto comportamental está relacionado à capacidade do sistema social de gerar o comportamento necessário para a realização da estratégia. A falta de conhecimento sistemático a respeito do comportamento da estrutura pode impedir que sejam identificados se comportamentos resultantes são decorrentes de problemas na estrutura ou do modo como ela é utilizada.

Bower (1982) ainda destaca que um bom gerente pode fazer até um sistema de trabalho razoavelmente estruturado funcionar bem, enquanto que um mau gerente põe a perder até mesmo uma boa estrutura.

\subsection{Síntese dos conceitos de alinhamento estratégico}

Esta seção sumariza os principais conceitos de alinhamento estratégico explorados até a presente revisão de literatura e que são relevantes para a formação da estrutura desta tese.

Verificou-se que o conceito de alinhamento é investigado em construtos distintos. O alinhamento externo considera a perspectiva da formulação da estratégia e, prioritariamente, o ajuste da estratégia às variáveis ambientais. Em contraste, o foco do alinhamento interno é a implementação da estratégia e o ajuste entre a estratégia e as variáveis internas.

As pesquisas envolvendo o construto de alinhamento interno têm sido conduzidas em termos de alinhamento vertical e alinhamento horizontal.

Os construtos são de fato complementares, mas são tratados de maneira distinta devido à abrangência das variáveis envolvidas.

Nesta tese o foco da pesquisa é o alinhamento interno, o que significa que não é uma prioridade a investigação do ajuste da organização aos fatores externos ou de como esses fatores influenciam a seleção da estratégia. As variáveis selecionadas serão analisadas do ponto de vista da sua implementação ou do impacto que causam na relação alinhamento interno-desempenho. Devido à própria natureza sistêmica da organização, não é possível e nem é objetivo isolar os construtos ou ignorar a sua interdependência. 
Os principais conceitos sobre alinhamento estão sumarizados no Quadro 1, sendo que alguns deles serão expostos em seções posteriores.

Alinhamento: agrupamento, coesão, ajuste, congruência entre diferentes dimensões.

Alinhamento estratégico: tanto um processo como um resultado - uma dinâmica que procura ajustar a organização externamente em relação ao seu ambiente de atuação, por meio da formulação da estratégia e, internamente, buscando um todo coeso entre a estratégia, os recursos e os processos gerenciais.

Alinhamento externo: ajuste da organização ao seu ambiente de atuação, por meio da formulação da estratégia.

Alinhamento interno: alinhamento da organização tanto na dimensão vertical quanto horizontal.

Alinhamento vertical: Refere-se ao conjunto de ações necessárias à implementação da estratégia, desde a estratégia formulada até o seu desdobramento por todos os níveis da organização.

Alinhamento horizontal: A dimensão horizontal envolve a compreensão das necessidades do cliente e o alinhamento dos processos (inter-funcionais) capazes de entregar o que o cliente necessita.

Aspectos internos da organização: refere-se aos elementos a serem alinhados internamente, por exemplo, a estratégia, a estrutura, processos, pessoas, clientes, habilidades, liderança, sistemas de remuneração, sistemas de informação e processos gerenciais. Cada uma das dimensões precisa ser consistente com a estratégia e umas com as outras.

Modelo de alinhamento estratégico: representação sistemática de um conjunto de princípios e ações com a finalidade de promover o alinhamento estratégico.

Processo de alinhamento estratégico: exercício prático de um conjunto de atividades estruturadas com a finalidade de realizar o alinhamento estratégico.

Processo de alinhamento estratégico interno: exercício prático de um conjunto de atividades estruturadas com a finalidade promover a implementação da estratégia.

Processos gerenciais (no contexto do alinhamento estratégico): atividades desenvolvidas por líderes e pessoas responsáveis visando o planejamento e a execução da estratégia.

Quadro 1 - Definição dos termos-chave sobre alinhamento

\subsection{Desempenho organizacional e o conceito de alinhamento}

No cerne deste trabalho está a importância da relação alinhamentodesempenho para o campo de estudos sobre estratégia.

Neste ponto do trabalho, um dos objetivos é tratar do conceito de desempenho empregado nesta tese e da fundamentação teórica que foi considerada para a seleção das dimensões propostas para a sua mensuração. Outro objetivo é 
especificar como esse conceito vem sendo considerado nas pesquisas empíricas sobre alinhamento.

A melhoria do desempenho dos negócios está no centro das discussões sobre estratégia, no entanto, a despeito da sua importância, a sua operacionalização apresenta dificuldades quanto aos termos utilizados para a sua definição e às dimensões aos meios utilizados para a obtenção dos dados (VENKATRAMAN; RAMANUJAM, 1987).

Quanto a esse último aspecto, Venkatraman e Ramanujam (1987) demonstram que a mensuração perceptual do desempenho, acessada por meio dos executivos-chave da organização, está fortemente correlacionada com a medição objetiva tradicional. Eles afirmam, com base em pesquisas empíricas, que essa forma de coleta dos dados pode ser empregada como uma operacionalização aceitável da medição do desempenho econômico dos negócios.

O conceito de desempenho é considerado um fenômeno multifacetado, de difícil compreensão e medição e que pode variar de acordo com o ponto de vista (por exemplo, clientes ou acionistas), o período em que é observado ou o critério utilizado (SNOW; HREBINIAK, 1980).

Venkatraman e Ramanujam (1986) propõem um modelo de mensuração do desempenho representado por três círculos concêntricos. O círculo mais amplo é o da eficácia organizacional, considerado por eles muito amplo para ser aplicado nas pesquisas sobre estratégia. O círculo intermediário é o do desempenho operacional, representado por indicadores não financeiros, tais como qualidade do produto, inovação, satisfação dos clientes, reputação e resultados de marketing, destinados a medir o desempenho de áreas específicas da organização. Por fim, o círculo interno é o do desempenho financeiro, representado por indicadores como lucratividade, valor de mercado, crescimento das vendas, retorno sobre o investimento, dentre outros.

Assim como Venkatraman e Ramanujam (1986), autores como Combs, Crook e Shook (2005) e Ray, Barney e Muhanna (2004) também distinguem entre desempenho operacional e desempenho organizacional, este relacionado aos resultados gerais obtidos pela organização, e aquele relacionado aos resultados dos processos.

Um ponto central que leva esses autores à proposição desse modelo é a multidimensionalidade do construto desempenho e o emprego de diferentes 
abordagens para a sua mensuração (CAMERON, 1986, CHAKRAVARTHY, 1986; MONTEIRO DE BARROS, 2007). Por isso, recomenda-se a definição das dimensões que estão sendo utilizadas para mensurar o desempenho e o teste, a priori, da dimensionalidade entre as medidas (COMBS; CROOK; SHOOK, 2005; VENKATRAMAN; RAMANUJAM,1986).

Do ponto de vista de Chakravarthy (1986), indicadores para a mensuração do DO não devem ser restritos aos tradicionais relacionados à lucratividade e indicadores financeiros do mercado porque compõem um critério único, com foco apenas nos resultados e não no processo dentro da organização. O autor propõe conjuntos de indicadores que contemplem os resultados financeiros, as necessidades dos principais stakeholders e a habilidade da empresa se transformar em resposta às mudanças em seu ambiente de atuação.

Uma proposta que contempla a necessidade de vários stakeholders pode ser encontrada no trabalho de Santos (2008). A autora propõe a mensuração do desempenho por meio de quatro fatores correlacionados: desempenho financeiro (crescimento e lucratividade), consciência sócio-ambiental (desempenho social e ambiental), satisfação dos clientes e satisfação dos funcionários. Respectivamente, os stakeholders contemplados no modelo são os investidores, o governo e a sociedade, os clientes e os funcionários. A autora ressalta que nem todos os stakeholders têm demandas alinhadas, mas todos se interessam pelo modo como a organização gerencia as outras partes.

Quanto à necessidade de transformação das empresas, Zajac, Kraatz e Bresser (2000) propõem uma abordagem segundo a qual para cada segmento de negócios existe um conjunto de fatores que determinam seu sucesso e que deveriam, em teoria, definir o alinhamento estratégico. Qualquer mudança nestes fatores implica na necessidade de promover mudanças na estratégia e a comparação entre a estratégia atual e as mudanças estratégicas necessárias determinam o grau de alinhamento estratégico, o qual subsequentemente irá afetar o DO.

Zaccarelli (2000) também provê um framework para analisar o uso ou não de vantagens competitivas pelas empresas. O framework agrega um conjunto de possibilidades agrupadas em crescer, lucrar, melhorar ou desperdiçar. Essa abordagem aplica-se a análise da tendência de desempenho futuro da empresa. 
Essas duas últimas propostas são consideradas mais proativas, no sentido de prover ao gestor mecanismos para mudar a estratégia e realinhar a organização com base nas tendências do mercado (PRIETO; CARVALHO, 2010).

Considerando-se o que o contexto desta pesquisa é o alinhamento interno, é importante ressaltar que ambos os contextos, do ambiente interno e externo, afetam o DO (MILES; SNOW, 1984; ZAJAC; KRAATZ; BRESSER, 2000). Nesse sentido, para os contingencialistas, o bom desempenho das organizações é resultado do alinhamento adequado entre as variáveis endógenas (ex:: estratégia, estrutura e processos de gestão) e as variáveis exógenas (ex.: incerteza ambiental e tecnologia) ou, conforme afirmam Drazin e Van de Ven (1985, p.515), uma proposição central para os contingencialistas é que a estrutura e os processos de uma organização precisam estar ajustados ao seu contexto (características da cultura organizacional, ambiente, tecnologia, tamanho ou tarefa) se quiser sobreviver ou ser eficaz.

Esta proposição encontra respaldo na literatura de estratégia, no trabalho de Miles e Snow (1984). Os autores consideram apropriado distinguir entre graus de alinhamento, bem como a natureza do alinhamento e desempenho e apresentam um framework baseado em quatro graus de alinhamento: mínimo alinhamento, forte alinhamento, frágil e inicial.

Alinhamento mínimo refere-se ao ajuste essencial entre estratégia, estrutura e processos, sendo uma condição essencial para sobreviver em ambientes competitivos.

Forte alinhamento, tanto internamente quanto externamente, está relacionado com excelência na oferta de produtos e serviços, com o desempenho e também tem relação com uma forte cultura corporativa. Ainda segundo os autores, tais resultados são característicos de empresas que conhecem a sua área de atuação, suas competências e sabem como direcionar seus esforços para atingir suas metas.

Alinhamento inicial está relacionado a invenções e mudanças na estratégia ou na estrutura que tragam vantagem competitiva, cujo sucesso depende da organização conseguir rapidamente desenvolver um forte alinhamento em torno da mudança em ação.

Alinhamento frágil envolve vulnerabilidade a mudanças externas e desestruturação interna. 
Os autores advertem que devido às condições de mudança no ambiente organizacional um perfeito alinhamento é muito mais uma condição a ser alcançada do que realizada. Por outro lado, mínimo alinhamento é requerido para sobrevivência das organizações. Consideram, ainda, que a linha de demarcação entre alinhamento mínimo e não alinhamento não é óbvia, mas que o sintoma do segundo é o declínio no desempenho, senão, o completo fracasso.

Vários estudos têm demonstrado a complexidade de pesquisas envolvendo a relação entre aspectos internos da organização e o desempenho organizacional. Nesse sentido, Ray Barney e Muhanna (2004) afirmam que pesquisas envolvendo vantagens observadas no nível de determinados processos internos não necessariamente têm refletido no nível do desempenho organizacional, uma vez que este capta o desempenho conjunto dos processos.

Bourne et al. (2003) também chamam a atenção para o fato de que a literatura tem apresentado vários relatos de problemas na adoção de sistemas de mensuração de desempenho, considerados uma forma de alinhamento interno das organizações, que acabam por fracassar na fase de implementação ou por não refletirem, como esperado, nos resultados da organização.

Nesse sentido, Bourne et al. (2003) chamam a atenção para aspectos intangíveis que não têm sido observados na sua adoção.

Prieto e Carvalho (2010), como resultado de um estudo de múltiplos casos, concluem que as empresas correm o risco de estarem internamente alinhadas, porém, com a estratégia errada, o que pode comprometer o seu desempenho e sustentabilidade.

Por fim, Kathuria, Joshi e Porth (2007) afirmam que ainda é necessário investigar a relação alinhamento-desempenho porque nem todos os estudos têm sido capazes de evidenciar essa relação direta, mas indiretamente, por meio de variáveis moderadoras ou mediadoras.

\subsubsection{Alinhamento estratégico na perspectiva normativa}

Autores como Drazin e Van de Ven (1985) e Venkatraman (1989a, 1990) são enfáticos em afirmar que para desenvolver pesquisas sobre alinhamento é fundamental esclarecer qual o conceito de alinhamento que está sendo empregado. 
Tal definição irá determinar as implicações teóricas das escolhas realizadas e os procedimentos metodológicos a serem adotados.

A conceituação do alinhamento estratégico segue duas maiores orientações, a descritiva e a normativa (VENKATRAMAN, 1989a).

A orientação descritiva especifica a relação entre um conjunto de variáveis teoricamente relacionadas sem, no entanto, relacioná-las com desempenho. O foco de estudos neste sentido é descobrir padrões existentes entre construtos relevantes e que ajudam a organização a sobreviver. A relação com o desempenho é implícita. Venkatraman (1989a) cita como exemplo a clássica proposição estratégia-estrutura de Chandler (1962) que pode ser analisada sem fazer relação com o desempenho. Para o autor as perspectivas de ajuste como combinação (fit as matching) e ajuste como combinação ou congruência (fit as gestalt) seguem a perspectiva descritiva. No primeiro caso examina-se a relação entre duas variáveis e no segundo entre múltiplas variáveis.

Em contraste, a orientação normativa explicitamente incorpora a relação alinhamento-desempenho organizacional. Venkatraman (1989a) cita a clássica proposição presente nos estudos de Etzioni (1961) de que os tipos de organizações congruentes são mais eficazes do que as incongruentes. O autor ressalta a importância da perspectiva normativa para os estudos no campo da estratégia, que tem como uma das suas proposições centrais a expectativa de que organizações eficazes são aquelas que conseguem reconciliar as forças competitivas mais coerentemente do que as ineficazes.

Para Venkatramann (1989a), quatro perspectivas de alinhamento estratégico refletem a orientação normativa, e são: ajuste como moderação, ajuste como mediação, ajuste como desvio de perfil e ajuste como covariação.

Ajuste como moderação: é empregado quando a hipótese é que o efeito de um determinado construto sobre o desempenho é contingente a uma terceira variável. A ideia central sobre esta perspectiva é de que não há uma estratégia universalmente superior e de que o impacto de uma variável preditora (ex. estratégia) sobre uma variável de critério (ex. desempenho) é dependente do nível de uma terceira variável (por exemplo, estrutura, processos).

O alinhamento entre as variáveis preditora e moderadora determina 0 resultado. A ideia subjacente é a da interação (DRAZIN; VAN DE VEN, 1985). O efeito interativo entre as duas variáveis tem efeito sobre o desempenho. 
As técnicas estatísticas recomendadas para esse tipo de análise são técnicas de análise de subgrupos e análise de regressão moderada (GERDIN; GREVE, 2004; VENKATRAMAN,1989a).

Homburg, Krohmer e Workman (1999) testaram a hipótese de que a relação entre o consenso estratégico e o desempenho organizacional pudesse ser moderada pelo dinamismo do mercado e pela estratégia.

Verifica-se a aplicação do ajuste como moderação em Xu, Cavusgil e White (2006). Os autores utilizaram a técnica de análise de regressão moderada para verificar a hipótese da relação entre a implementação de uma estratégia global de marketing padronizada e o desempenho ser moderada pela estrutura e os processos gerenciais.

Chan, Sabherwal e Thatcher (2006) utilizaram a estratégia como variável moderadora da relação alinhamento-desempenho, na área de SI e Rhee e Mera (2006), a empregaram como moderadora do coalinhamento entre as estratégias de marketing, operações e competitiva e o desempenho organizacional (DO).

Ajuste como mediação: pressupõe a existência de um fator interveniente entre o antecedente e a variável de resultado. Por exemplo, a estratégia poderia agir como um mecanismo de mediação entre a variável independente, contexto, e a variável dependente, desempenho (VENKATRAMAN,1989a).

Mediação completa é obtida quando o principal efeito da variável antecedente (independente) sobre a variável de saída (dependente) não é significante, ao passo que ambos os coeficientes entre a variável independente e a variável dependente e entre a variável interveniente e a variável dependente são significantes (VENKATRAMAN, 1989a). Isto indica que a presença da variável interveniente é necessária para que o efeito da variável antecedente sobre a consequente seja levado a termo. Uma mediação parcial acontece quando tanto o efeito principal quanto o de mediação são significantes, o que significa que a variável dependente é conjuntamente determinada pela presença da variável antecedente e da variável interveniente.

Para testar o alinhamento como mediação utiliza-se análise de caminhos (path analisys). Exemplo dessa aplicação pode ser encontrado no trabalho de $\mathrm{Xu}$, Cavusgil e White, 2006.

Ajuste como Desvio de Perfil: o conceito de alinhamento é visto como a aderência a um perfil externamente especificado. A aderência a este perfil ideal está 
associada com alto desempenho, enquanto que o desvio deste perfil implica em baixo desempenho. Recomenda-se a distância euclidiana para calcular o desvio de perfil e o uso de medidas intervalares.

Baier, Hartmann e Moser (2008) calcularam o alinhamento com base no desvio de perfil em relação a prioridades competitivas de compras ideais para implementar uma estratégia de negócios em particular (diferenciação ou liderança em custos). O perfil ideal foi definido empiricamente, tendo como parâmetro as empresas de cada grupo estratégico com melhor perfil de prioridades competitivas.

Chan, Sabherwal e Thatcher (2006) calcularam o desvio ideal de alinhamento entre a estratégia de negócios e a estratégia de SI.

Joshi, Kathuria e Porth (2003) calcularam o desvio de perfil entre prioridades competitivas de dois grupos de gestores, Gerentes Gerais e Gerentes de Manufatura.

No trabalho de Xu, Cavusgil e White (2006), também se verifica a aplicação desta perspectiva de alinhamento.

Ajuste como covariação: esta perspectiva vê o alinhamento como um padrão de consistência interna entre um conjunto de variáveis latentes. A referência não é um perfil externamente especificado, mas o grau de consistência interna entre as dimensões. Especificar o ajuste em termos de covariação requer explicação sobre a lógica subjacente entre as dimensões especificadas (VENKATRAMAN, 1990 , p. 24). Matematicamente, a regressão ordinária não preenche os requisitos para esta perspectiva, uma vez que o coeficiente de regressão poderia ser estatisticamente significante, mas falhar em demonstrar a lógica entre as dimensões.

A análise estatística recomendada para testar a covariação é a modelagem de equações estruturais.

Nesse sentido, Carmeli e Tishler (2004) conceituaram o alinhamento como interação entre elementos intangíveis e verificaram que há um impacto positivo desta interação no DO.

Gilbert Jr. e Reid (2009) analisaram a hipótese de que o coalinhamento entre o escopo da informação e a proatividade organizacional teria um significante e positivo impacto sobre o DO. Eles se basearam no argumento teórico de que as organizações são mais eficazes quando há um alinhamento entre os mecanismos estruturais e a estratégia. Estabeleceram, então, o escopo da informação como um 
importante elemento do design dos sistemas de informação (mecanismo estrutural) e a proatividade como um elemento da estratégia organizacional.

Da mesma forma, Menor e Roth (2008) formularam a hipótese de que o crescimento da competência em oferecer novos serviços está relacionado com o DO no desenvolvimento de novos serviços. A competência em novos serviços foi conceituada como um construto latente de segunda ordem, multidimensional, composto por um sistema de quatro dimensões inter-relacionadas (1) formalização dos processos de desenvolvimento de novos serviços, (2) acuracidade do marketing, (3) estratégia de desenvolvimento de novos serviços e (4) experiência e uso na tecnologia de informação.

Outros autores também confirmaram a hipótese do efeito positivo do alinhamento sobre o DO, tendo aplicado diferentes conceituações do alinhamento: Chan et al. (1997) - covariação entre orientação estratégica dos negócios e orientação estratégica dos sistemas de informação; Choe (2003) - combinação entre elevado grau de aplicação da estratégia de SI e um elevado uso de aplicação dos facilitadores do alinhamento e Rhee e Mehra (2006) - coalinhamento entre as estratégias de marketing, operações e competitiva.

\subsection{A influência da estratégia na relação alinhamento-desempenho}

A implementação da estratégia de negócios refere-se ao ajuste entre a estratégia de negócios da organização ou estratégia competitiva e seus processos internos (GALBRAITH; KAZANJIAN, 1986). Um adequado ajuste deve contribuir para alcançar desempenho superior. No entanto, diferentes estratégias de negócios podem influenciar o grau e a importância do alinhamento estratégico.

A tipologia proposta por Miles e Snow (2003) é amplamente aceita pela literatura para analisar as estratégias de negócios (HAMBRICK, 1983; 2003; SHORTELL; ZAJAC, 1990).

Segundo essa tipologia quatro orientações estratégicas são identificáveis dentro de uma indústria: Defensores (Defenders), Analisadores (Analyzers), Prospectores (Prospectors) e Reatores (Reactors).

Com base em Miles e Snow (2003) é possível descrever como segue a atuação das empresas de acordo com cada estratégia: 
Defensores concentram-se em nichos de mercado específicos, buscando desenvolver um conjunto estável de produtos e consumidores. Os gestores neste tipo de organização são especialistas dentro da área limite de suas operações e não buscam desenvolver outras oportunidades fora da sua expertise. São organizações que buscam melhorar a eficiência das operações existentes.

O uso de sistemas administrativos deve prover aos Defensores a capacidade de controle e centralização das operações; fazem uso intensivo de planos formais e tendem a utilizar estruturas funcionais, com prerrogativas de decisão centralizadas de acordo com o nível hierárquico e sistema de informação verticalizada.

Prospectores continuamente procuram localizar e explorar novas oportunidades de produtos e mercados. Normalmente são criadores das mudanças e incertezas às quais os seus competidores precisarão responder. Enfatizam a inovação, atuam em um escopo mais amplo de mercado e empregam uma estrutura organizacional orgânica. A ênfase em inovação pode acarretar perdas em eficiência.

O uso de sistemas administrativos pelos Prospectores tem o papel de facilitar, mais do que controlar as operações da organização. O processo de planejamento é usualmente mais amplo do que intensivo, orientado para a solução dos problemas que surgem, é contingente e faz uso do feedback sobre as ações experimentalmente adotadas. Tendem a utilizar uma estrutura descentralizada por produto, com baixo grau de formalização e autonomia para profissionais especializados.

Analisadores ocupam uma posição intermediária entre os dois tipos de estratégia anteriores. Procuram manter um mercado mais estável com produtoschave, enquanto procuram novas oportunidades de mercado e produtos. Nas áreas mais turbulentas em que atuam são seguidores das ideias mais promissoras dos seus competidores. Os sistemas administrativos têm o papel de acomodar a atuação em ambientes estáveis e dinâmicos ao mesmo tempo, sendo uma combinação de como são utilizados nas estratégias anteriores.

É considerado que os Reatores são um tipo de organização que de fato se ressente da definição de uma estratégia clara ou está em transição para definir-se por um dos outros três tipos. Por isso, vários autores excluem este tipo de estratégia dos estudos empíricos anteriores (CHAN; SABHERWAL; THATCHER, 2006; RHEE 1998; SLATER; OLSON, 2000). 
A relação moderadora da estratégia em estudos que investigam a relação alinhamento-desempenho pode ser contemplada em alguns estudos, apresentados a seguir.

Homburg, Krohmer e Workman Jr. (1999) analisam a relação entre o consenso e o DO, moderada pelo tipo de estratégia. Os autores formulam a hipótese de que o consenso tem implicações sobre o DO, dependendo do tipo de estratégia e, mais especificamente, de que o efeito seria positivo no caso da estratégia de diferenciação e neutro no caso da estratégia de liderança em custo, isso porque, segundo os autores, a implementação da estratégia de diferenciação requer um esforço conjunto por parte dos gerentes de diferentes funções a fim de criar um posicionamento único que agregue valor para os clientes.

Note-se que os autores utilizam a tipologia de estratégia proposta por Porter (1986) e assumem, na revisão teórica, que há uma correspondência entre essas estratégias e a tipologia de Miles e Snow (2003), logo, entre a estratégia de diferenciação e estratégia de Prospectores e entre a estratégia de liderança de custo e a estratégia de Defensores.

Os resultados evidenciaram que o consenso aumenta o desempenho quando a empresa adota a estratégia de diferenciação, o mesmo não se evidencia com a estratégia de liderança em custos, confirmando as hipóteses propostas pelos autores.

Chan, Sabherwal e Thatcher (2006) pesquisaram a relação entre antecedentes do alinhamento estratégico de Sistema de Informação e o DO, moderada pela estratégia. Os autores não formularam hipóteses em relação à variável moderadora devido a escassez de estudos anteriores que explorassem a relação entre a estratégia de negócios e o alinhamento (p. 31). No entanto, os autores assumem que a natureza mais estável de Defensores torna mais fácil o alcance do alinhamento se comparado com Prospectores e, ainda, que o alinhamento, deve prover menor vantagem para organizações do tipo Defensoras se comparado com aquelas classificadas como Analisadoras ou Prospectoras.

Os resultados demonstraram que prospectores apresentaram grau de alinhamento menor do que defensores e analisadores, confirmando a proposição dos autores de que a sua natureza torna mais difícil alcançar o alinhamento.

Também foi evidenciado que $\mathrm{O}$ alinhamento afeta positivamente 0 desempenho, com exceção para o caso de empresas defensoras. A proposição dos 
autores era de que o alinhamento traria menor vantagem para organizações defensoras do que para os outros dois tipos, devido natureza mais instável daquela.

Rhee e Mera (2006) estabeleceram a hipótese de que o efeito da integração entre as atividades estratégicas de marketing e operações sobre o desempenho organizacional em organizações de serviço (segmento bancário) é moderado pela estratégia. Os resultados demonstraram que esse efeito é maior para empresas prospectoras, fraco para defensoras e ainda menor para o caso de analisadoras.

Com base nesses estudos, verifica-se que diferentes resultados têm sido obtidos com relação à estratégia como variável moderadora da relação Al-DO.

\subsection{A influência da incerteza ambiental na relação Al-DO}

Lawrence e Lorsch (1967) argumentam que não existe o jeito melhor da empresa se organizar, mas que o desempenho pode sofrer implicações dos fatores contextuais e situacionais. Nesse sentido, uma das variáveis contingenciais mais contempladas nos estudos empíricos, tem sido a incerteza ambiental (GINSBERG; VENKATRAMAN, 1985).

Existem diferentes abordagens na literatura sobre como conceituar e mensurar a incerteza ambiental. Uma das discussões é sobre o ambiente enquanto realidade objetiva ou fenômeno perceptual.

Enquanto realidade objetiva, considera-se que a organização está inserida no ambiente externo, que se apresenta com características próprias, independentemente da realidade organizacional; enquanto fenômeno perceptual, considera-se que a percepção do gestor, particularmente sobre as incertezas, pode moldar as suas escolhas gerenciais (SHARFMAN; DEAN JR., 1991).

O conceito de incerteza ambiental atrelado à percepção dos gestores é discutido por Milliken (1987). A autora define a incerteza em termos da inabilidade individual de perceber a direção das mudanças ambientais, o potencial impacto destas sobre a organização, e a dificuldade de perceber até que ponto uma determinada resposta ao ambiente será bem sucedida ou não.

Outro debate presente na literatura é quanto às dimensões para a mensuração da incerteza. Sharfman e Dean Jr. (1991) fazem um levantamento das dimensões que têm sido utilizadas e as sintetizam em três categorias: complexidade (nível de informação requerido para a compreensão do ambiente), dinamismo (grau 
de instabilidade do ambiente) e disponibilidade de recursos (nível de recursos do ambiente disponível para a firma).

No entanto, inconsistentes resultados foram obtidos em estudos empíricos utilizando-se essas dimensões. Milliken (1987) considera, então, que é importante conhecer o tipo de incerteza que está sendo vivenciada pelo gestor e propõe que o construto seja tratado como multidimensional, sendo composto por três tipos de percepção de incerteza ambiental: incerteza de estado, incerteza de efeito e incerteza de resposta.

A incerteza de estado diz respeito à inabilidade dos administradores em lidar com as instabilidades do ambiente externo. A incerteza de efeito refere-se à inabilidade do administrador em prever o impacto das mudanças ambientais sobre o futuro dos negócios. A incerteza de resposta está relacionada à falta de conhecimento e inabilidade do administrador em selecionar a melhor opção de resposta para as incertezas ambientais e em prever as suas consequências sobre o futuro da organização.

A percepção de um alto grau de incerteza ambiental remete ao risco na tomada de decisão, de forma que erros nesse processo podem comprometer a sobrevivência da organização (WALDMAN et al., 2001).

O conceito de incerteza relaciona-se ao de alinhamento uma vez que fatores do ambiente podem requerer mudança nas decisões estratégicas e o realinhamento (KRAATZ; ZAJAC, 2001; PRIETO; CARVALHO, 2010).

A essência do alinhamento é manter as organizações alinhadas quando a empresa enfrenta as turbulências ambientais (LABOVITZ; ROSANSKY, 1997).

Considera-se que em ambientes dinâmicos é difícil manter um forte alinhamento, por isso, ele é muito mais uma condição a ser alcançada. No entanto, um mínimo alinhamento é requerido para a sobrevivência das organizações (MILES; SNOW, 1984).

A rivalidade do ambiente no qual a organização está inserida exerce forte influência no processo estratégico desde a etapa de formulação, podendo alterar o modelo de plano estratégico a ser adotado, sua flexibilidade, tempo de preparação, nível de detalhamento e o processo de implementação.

Em ambientes de certeza planejar é mais importante do que o processo de planejamento em si por acreditar-se que os planos concebidos serão implementados praticamente sem revisão e sem interferências (MCCONKEY, 1988). Nesse contexto 
tradicional de planejamento, o instrumento que apóia o executivo no processo de formulação da estratégia influencia a sua visão sobre os acontecimentos externos, a velocidade do processo de tomada de decisão e, consequentemente, o alinhamento da estratégia ao ambiente de negócios. Courtney, Kirkland e Viguerie (1997), consideram que a abordagem formal de planejamento leva os executivos a ver as incertezas de maneira binária, como se o ambiente fosse previsível e, portanto, aberto a previsões do futuro ou completamente imprevisível, no qual as incertezas são subestimadas.

Em ambientes de incerteza, existem várias propostas na literatura (CAMPBELL; ALEXANDER, 1997; CHIRSTENSEN, 1997; COURTNEY; KIRKLAND; VIGUERIE, 1997; EISENHARDT; SULL, 2001; MINTZBERG, 1994) procurando distanciar o tomador de decisão do processo tradicional de planejamento estratégico para um processo flexível de elaboração de estratégias. Tem-se o entendimento de que a estratégia não é necessariamente um processo formal (MINTZBERG, 1994), mas também intuitivo (EISENHARDT, 1999), não é única, mas precisa ser constantemente revisada (CHRISTENSEN, 1997; COURTNEY; KIRKLAND; VIGUERIE, 1997) e pode ser simplificada (EISENHARDT; SULL, 2001).

A abordagem formal impede os executivos de desenhar estratégias mais flexíveis. A estratégia enquanto processo assume maior relevância. Mintzberg (1994) atribui ao processo estratégico a característica de inovação e aprendizado, assumindo que a essência deste processo é a concretização da estratégia por meio das ações. Em outras palavras, a estratégia é elaborada para ser concretizada, mas a prática da implementação também pode levar a mudanças estratégicas.

A formulação de um plano continua sendo o ponto inicial do processo estratégico, porém, necessariamente precisa ser acompanhado de outros componentes da gestão estratégica para ser efetivado, tais como: o ajuste da estrutura, das operações, sistema de recompensas, gestão de processos, cooperação interdepartamental e cultura organizacional (McCONKEY,1988). Ainda segundo McConkey (1988), as mudanças veem através da implementação, não através do plano, pensamento este que está em linha com a argumentação de Mintzberg (1994) a respeito do processo formal de planejamento como um estilo calculado e previsível de gestão, mas que, em si mesmo, não pode levar a um estilo de gestão que atraia o comprometimento das pessoas com os objetivos propostos. McConkey (1988), afirma que um plano tecnicamente imperfeito e bem 
implementado frequentemente oferece maior chance de realização do que um plano perfeito que nunca sai do papel em que foi impresso.

$\mathrm{Na}$ abordagem proposta por Zajac, Kraatz e Bresser (2000) a decisão de promover mudanças no alinhamento está diretamente relacionada à habilidade dos gestores em perceber, no ambiente externo, mudança nos fatores que são críticos para o sucesso do negócio, que por sua vez determinam o grau de alinhamento estratégico requerido. Segundo os autores, o DO da empresa é positivamente afetado quando mudanças requeridas são implementadas ou quando o gestor consegue perceber que as mudanças do ambiente não vão afetar significativamente os negócios e por isso não promove mudanças organizacionais. O DO é negativamente afetado quando a empresa implementa mudanças que de fato não eram necessárias ou quando deixa de responder adequadamente às demandas do ambiente por não introduzi-las.

No estudo desenvolvido por Prieto (2006) e Prieto e Carvalho (2010) as autoras relatam casos de empresas em que os gestores não percebem as demandas do ambiente e nem o fato de que estão adotando estratégias que podem estar ultrapassadas, o resultado são empresas não-alinhadas, com desempenho inferior e comprometimento da sustentabilidade.

No trabalho de Homburg, Krohmer e Workman Jr. (1999) confirmou-se a hipótese de que a força da relação entre consenso e DO é negativamente influenciada pelo nível de incerteza ambiental, no caso de empresas que adotam a estratégia de diferenciação. Os autores utilizaram como argumento o fato de que o dinamismo do mercado pode forçar os gestores a tomar decisões mais rapidamente, investindo menos na obtenção do consenso, com impacto sobre a relação consenso-DO.

Carmeli e Tishler (2004) investigaram a relação entre o alinhamento de elementos intangíveis e o DO. Os resultados demonstraram que organizações que percebem 0 ambiente organizacional como altamente incerto apresentam desempenho abaixo do normal em relação àquelas que o percebem como mais estável o que, segundo os autores, pode ter relação com a inabilidade de efetuar mudanças na estratégia.

Chan, Sabherwal e Thatcher (2006) utilizaram a variável incerteza ambiental como antecedente do alinhamento, no estudo que tinha como variável moderadora a 
estratégia. Eles puderam verificar que a Incerteza Ambiental (IA) não afeta os prospectores.

Neste estudo adota-se o conceito de incerteza como fenômeno perceptual, em termos de como o gestor avalia os riscos do ambiente externo e as suas consequências para os resultados organizacionais. Entende-se que a percepção da incerteza ambiental está diretamente relacionada à decisão de efetuar ou não mudanças na estratégia e promover o ajuste das variáveis internas.

\subsection{Fatores envolvidos no alinhamento estratégico}

Esta seção apresenta o "caminho" que foi percorrido, em termos de revisão teórica, até chegar à definição dos construtos componentes do alinhamento estratégico vertical e horizontal. Os construtos são definidos e a relação teórica destes com a dimensão vertical e horizontal também é especificada.

Em uma primeira etapa foram analisados modelos de alinhamento estratégico.

Modelo de alinhamento estratégico é definido como "a representação sistemática de um conjunto de princípios e ações com a finalidade de promover o alinhamento estratégico" (PRIETO; CARVALHO; FISCHMANN, 2009, p. 322). A necessidade de modelos de alinhamento estratégico advém da complexidade do processo de implementação da estratégia que envolve a coordenação de múltiplas variáveis em um período de tempo mais longo quando comparado com a formulação da estratégia. Nesse sentido, Hrebiniak e Joyce (2001) afirmam que para minimizar a complexidade desse processo a utilização de um modelo de implementação estratégica possibilitaria aos administradores um delineamento lógico das principais categorias de atividades de implementação e das relações entre elas.

Nesse sentido, quatro modelos foram selecionados e analisados utilizando-se o método de análise de conteúdo, sendo que os resultados estão relatados em Prieto, Carvalho e Fischmann (2009). O objetivo do estudo foi primeiramente o de identificar modelos na literatura que pudessem servir como referência para o processo de alinhamento estratégico interno e, também, o de investigar quais ações ou etapas fazem parte do processo de alinhamento.

Foram considerados modelos de Al aqueles que tivessem uma proposta para alinhamento dos "aspectos internos da organização", por exemplo, a estratégia, a 
estrutura, processos, pessoas, clientes, habilidades, liderança, sistemas de remuneração, sistemas de informação e os processos gerenciais.

Os autores identificaram quatro modelos:

- Modelo 1 - Labovitz e Rosansky (1997)

- Modelo 2 - Balanced scorecard: Kaplan e Norton (1992, 1993, 1996, 2000)

- Modelo 3 - Hambrick e Cannella (1989)

- Modelo 4 - Organizational Fitness Profiling: Beer e Eisenstat (1996, 2000)

As ações ou etapas necessárias para promover o alinhamento foram organizadas segundo quatro imperativos consolidados pela literatura: ambiente, estrutura/sistema, liderança e estratégia (MILLER, 1987) e estão demonstradas no Quadro 2.

A análise dos modelos traz uma contribuição relevante quanto à necessidade do alinhamento tanto dos elementos formais (como estrutura, processos, indicadores, sistemas de recompensa), quanto dos informais (como pessoas, cultura, sistema de liderança). A eficácia na implementação da estratégia vai depender da forma como a organização é gerenciada, da flexibilidade da estrutura e dos sistemas e do grau de envolvimento das pessoas com as mudanças propostas.

Dessa forma, os modelos buscam mecanismos de desdobramento e comunicação da estratégia e constroem métricas e/ou ferramentas de diagnóstico que permitam monitorar o grau de alinhamento e a evolução da estratégia em curso.

São também estabelecidos mecanismos de retroalimentação para promover ajustes necessários ao longo do processo de transformação das estratégias em ação.

Assuntos relacionados à estratégia e ambiente são tangenciados nos modelos, uma vez que a prioridade destes são as variáveis organizacionais internas.

No entanto, em especial os modelos 1 e 2 dão ênfase ao fato de que a estratégia se concretiza na execução por meio da definição de indicadores de desempenho destinados a monitorar o interesse dos stakeholders. Outro aspecto enfatizado nos modelos selecionados é o quão compreensível a estratégia é para aqueles que vão colocá-la em ação. 


\begin{tabular}{|c|c|}
\hline $\begin{array}{l}\text { Estratégia } \\
\text { Clareza na definição estratégica } \\
\text {. Definição dos fatores críticos de } \\
\text { sucesso } \\
\text {. Estratégia alinhada com as } \\
\text { necessidades dos stakeholders }\end{array}$ & $\begin{array}{l}\text { Ambiente } \\
\text { Ter informações abrangentes } \\
\text { Analisar obstáculos } \\
\text {. Negociar a nova estratégia }\end{array}$ \\
\hline $\begin{array}{l}\text { Estrutura/Sistema } \\
\text {. Desdobrar a estratégia em um } \\
\text { conjunto de medidas de desempenho } \\
\text { balanceadas } \\
\text {. Comunicar a estratégia por meio do } \\
\text { mapa estratégico a todos os níveis da } \\
\text { organização } \\
\text {. Ajustar os processos para atender os } \\
\text { requisitos dos clientes } \\
\text {. Medir o grau de alinhamento e } \\
\text { promover ajustes } \\
\text {. Manter atividades de controle da } \\
\text { estratégia } \\
\text {. Alocação de recursos estratégicos } \\
\text { Sistema de recompensas e } \\
\text { reconhecimento } \\
\text {. Ajuste de políticas e programas das } \\
\text { subunidades } \\
\text {. Definição da estrutura } \\
\text { Organização do Trabalho } \\
\text {. Pessoas }\end{array}$ & $\begin{array}{l}\text { Liderança } \\
\text {. Conhecer antecipadamente os } \\
\text { obstáculos à implementação (tangíveis e } \\
\text { intangíveis) } \\
\text {. Buscar informação e apoio já no estágio } \\
\text { de formulação da estratégia } \\
\text {. Negociar a estratégia interna e } \\
\text { externamente } \\
\text {. Desenvolver as capacidades } \\
\text { organizacionais de coordenação, } \\
\text { comprometimento e competência técnica e } \\
\text { interpessoal voltadas à implementação de } \\
\text { estratégias } \\
\text {. Ajustar os fatores que influenciam a } \\
\text { implementação }\end{array}$ \\
\hline
\end{tabular}

Quadro 2 - Ações para promover o alinhamento estratégico (PRIETO; CARVALHO; FISCHMANN, 2009, p. 328).

Quanto ao imperativo ambiente, os modelos são vagos e retornam à temática do interesse dos stakeholders, mas com a perspectiva do gerenciamento de mudanças na estratégia. Os modelos buscam estabelecer canais de informações que levem à revisão da estratégia formulada e também ao tratamento de possíveis obstáculos a mudanças na estratégia, que se manifestem na fase de implementação.

Por fim, os modelos também se dedicam a explorar o papel da liderança. A própria habilidade de implementar a estratégia é considerada uma fonte de vantagem competitiva. Os modelos atribuem à liderança aspectos como o conhecimento dos obstáculos à implementação (tangíveis e intangíveis) e função 
pró-ativa na negociação da estratégia, interna e externamente. Adicionalmente, deve garantir o desenvolvimento das capacidades organizacionais, atuando na coordenação, e buscando o comprometimento das pessoas para a execução das estratégias. Finalmente, a liderança deve estar atenta às mudanças ocorridas, tanto nas variáveis endógenas, quanto nas variáveis exógenas e promover os ajustes necessários com rapidez.

No âmbito desta tese, esses modelos serão revisitados para compor a visão sobre os fatores envolvidos no alinhamento estratégico.

Em uma segunda etapa foram analisados os estudos empíricos sobre alinhamento estratégico. A base para esta pesquisa foi um levantamento efetuado na base de dados Web of Science, por palavra-chave, utilizando os termos "strategic fit", "strategic alignment" e "strategic consensus". A busca foi refinada pelas áreas de interesse: gestão, negócios e engenharia industrial, e resultou em um total de 141 artigos.

Os artigos foram exportados utilizando-se o software EndNote. Foi feita uma revisão inicial pelo título e resumo buscando identificar os artigos que tratavam do alinhamento estratégico e 78 artigos foram, então, considerados, sendo 5 teóricos e 73 empíricos.

Os artigos empíricos tratam do alinhamento nas áreas de pesquisa, como indicadas na Figura 2. O maior número de estudos refere-se à área de Tecnologia da Informação/Sistema de Informação (TI/SI) ( 27\%), seguido de estudos relacionados ao consenso estratégico ( 15\%), Operações $(\sim 12 \%)$, Cadeia de Suprimentos ( 10\%), Recursos Humanos ( 6,8\%) Medição de Desempenho ( $4,0 \%$ ) e alinhamento em empresas multinacionais ( 4\%).

Os resumos foram então, analisados, buscando-se identificar aqueles que tratavam do $\mathrm{AV}$ e do $\mathrm{AH}$. Foram identificados diferentes conceitos sobre $\mathrm{AV}$ em estudo. O Apêndice $A$ apresenta os principais artigos que tratam do $A V$ e $A H$, agrupados de acordo com a similaridade do conceito de alinhamento que empregam: estudos de alinhamento entre a estratégia de negócios e a área de operações/compras (referências 1 a 3); alinhamento dos recursos humanos à estratégia de negócios (referência 4); alinhamento envolvendo empresas multinacionais (referências 5 e 6); o consenso estratégico (referências 7 a 13); alinhamento entre a estratégia de negócios e a estratégia de sistema de informações ou de tecnologia da informação (referências 14 a 18); alinhamento dinâmico 
(referências 19 e 20); alinhamento configuracional (referências 21 a 23); alinhamento organizacional (referência 24); alinhamento em empresas de tecnologia (referência 25) e AH (referências 26 e 27).

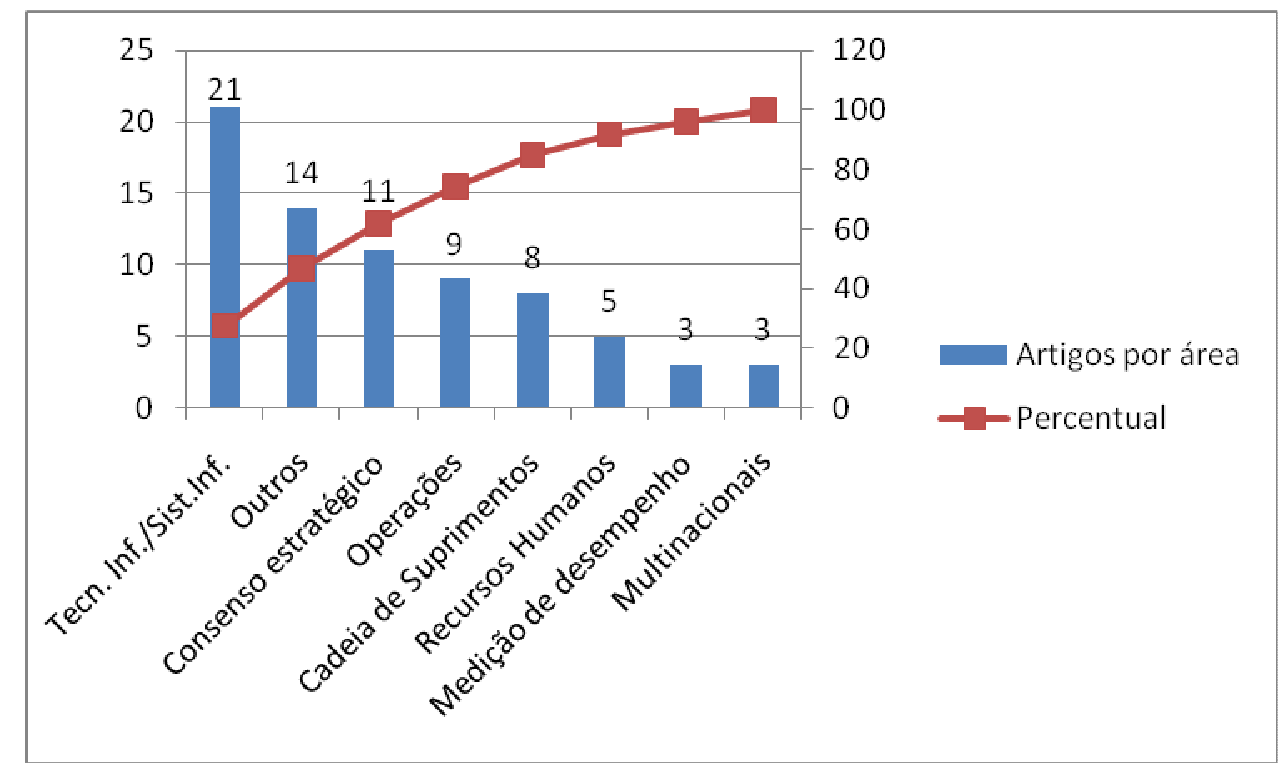

Figura 2 - Distribuição dos artigos coletados por área de pesquisa Fonte: A autora, com base na revisão de literatura

A revisão de literatura efetuada não representa uma pesquisa exaustiva sobre o assunto, podendo ser ampliada, por exemplo, com outras bases de dados, periódicos por área de interesse (ex.: operações, tecnologia da informação) ou periódicos por relevância. Os dados da Figura 2 demonstram, no entanto, a predominância de pesquisas aplicando o conceito nas áreas de TI/SI. Chan et al. (1997) afirmam que o alinhamento é um dos dez temas de maior preocupação dos executivos em Sistemas de Informação e que, no entanto, permanece como um tema nebuloso e difícil de medir. Ainda há poucos estudos voltados a determinar em que extensão e de que maneira os sistemas de informação complementam a estratégia do negócio.

$\mathrm{Na}$ área de operações e compras - ver referências 1, 2 e 3 e Figura 2, os autores investigam o alinhamento entre prioridades competitivas da estratégia de negócios e suas respectivas áreas. Joshi, Kathuria e Porth (2003) e Rhee e Mehra (2006) apontam que ainda há poucos estudos que explicitamente examinam o alinhamento na área de operações e os estudos que existem raramente estabelecem a relação com o DO. No trabalho de Hill e Brown (2007) os autores fazem um levantamento dos artigos que tratam do ajuste interno e externo, na área de manufatura e serviços, entre os anos de 1980 e 2001 e concluem que a área de 
operações não está tão adiantada nos estudos sobre ajuste estratégico como a área de estratégia e que, especialmente, identificam-se raros artigos pesquisando a dimensão do alinhamento interno na área de serviços.

$\mathrm{Na}$ área de Recursos Humanos (Referência 4), identifica-se a necessidade de estudos sobre o envolvimento das pessoas para o alcance dos objetivos estratégicos.

Quanto ao alinhamento em empresas multinacionais (referências 5 e 6), Xu, Cavusgil e White (2006) investigam os fatores internos (estratégia, estrutura e processos) que podem facilitar o sucesso na implementação de uma estratégia de marketing global. Luo e Park (2001) exploram a relação entre ambiente-estratégiadesempenho no contexto de empresas multinacionais em mercados emergentes.

Várias dimensões do consenso (estudos de 7 a 13) vêm sendo pesquisadas na literatura, por exemplo, consenso sobre as metas e os meios para alcançá-las, consenso sobre a percepção do ambiente, entre outras. Uma revisão destes trabalhos pode ser encontrada em Homburg, Krohmer e Workman Jr. (1999).

Os trabalhos 19 e 20 tratam do alinhamento considerando a literatura dos recursos organizacionais e das competências. Esses trabalhos veem de encontro a uma lacuna identificada na literatura quanto à necessidade de predição do alinhamento, de prover instrumentos para medir quando a estratégia de uma organização deveria ou não se ajustar às mudanças ambientais e circunstâncias organizacionais (ZAJAC; KRAATZ; BRESSER, 2000).

Os trabalhos 21 a 23 abordam o alinhamento enquanto interação entre elementos, utilizando a abordagem do alinhamento configuracional.

Apenas dois trabalhos tratam do $\mathrm{AH}$ (26 e 27), corroborando a afirmação de Kathuria, Joshi e Porth (2007, p. 509 e 511) de que os estudos sobre AH são esparsos quando comparados com o de $\mathrm{AV}$ e de que os raros estudos que existem tendem a examinar a relação entre duas áreas funcionais.

Mesmo ampliando-se a pesquisa inicial para outras bases de dados, apenas um artigo conceitual sobre $\mathrm{AV}$ e $\mathrm{AH}$ foi identificado, o já citado de autoria de Kathuria, Joshi e Porth (2007). Uma planilha em Excel, interligada com o EndNote pela numeração sequencial dos artigos, foi construída para registrar as análises efetuadas. Foram coletados e organizados os dados do artigo, da operacionalização da pesquisa (abordagem, método, indústria e amostra), construtos envolvidos e contribuições. 
O Apêndice B traz informações mais detalhadas sobre esses artigos, quanto ao tipo de pesquisa que foi conduzida, a amostra, e as principais contribuições explicitadas.

Também foram pesquisadas, em Janeiro de 2010, as teses e dissertações produzidas no Brasil e no exterior, sobre o assunto. Foi consultada a base de dados ProQuest, utilizando os mesmos termos da pesquisa de artigos. De 2000 a 2008 foram localizadas 14 teses, sendo 2 de alinhamento de pessoas à estratégia e 12 de alinhamento nas áreas de Tecnologia da Informação ou Sistemas de Informação.

No Brasil, foi utilizada a Biblioteca Digital Brasileira de Teses e Dissertações, disponível em http://bdtd.ibict.br, sendo que o termo para a pesquisa foi "alinhamento estratégico". Foram localizados 113 registros. Analisando-os individualmente verificou-se que 35 de fato investigam essa relação, sendo das seguintes áreas: TI/SI (16), Operações (5), Recursos Humanos (3) Sistemas de Desempenho (10) e alinhamento estratégico - abordagem baseada em sistemas (1).

Nesses trabalhos coletados por meio da revisão de literatura buscou-se identificar quais são os fatores envolvidos no alinhamento estratégico, examinados empiricamente. Os principais trabalhos foram organizados no Quadro 3.

Cabe ressaltar que outros fatores também foram identificados e não serão abordados por estarem fora do escopo desta tese. Por exemplo, no trabalho de Carmeli e Tishler (2004) - auditoria interna, capital humano, percepção da reputação organizacional; no trabalho de Chan, Sabherwal e Thatcher (2006) - sucesso anterior na implementação da estratégia e tamanho da organização; no trabalho de Noble e Mokwa (1999) - autonomia pessoal, comprometimento individual, fatores da estratégia - envolvimento das áreas e existência de um líder campeão e importância pessoal e no trabalho de Powell (1992) - locus de controle interno do CEO, formalização da estrutura e estabilidade ambiental.

Os fatores identificados foram confrontados com a delimitação do conceito de AV proposto neste estudo, que tem o foco na implementação da estratégia de negócios.

Conforme exposto anteriormente, a literatura considera que formulação e implementação são atividades claramente relacionadas para o alcance dos objetivos organizacionais. Em uma sequência lógica, a implementação segue a formulação. 


\begin{tabular}{|c|c|c|c|}
\hline $\begin{array}{l}\text { Fatores envolvidos no } \\
\text { alinhamento }\end{array}$ & Fonte & Relação com a tese & Descrição \\
\hline $\begin{array}{l}\text { Domínio compartilhado do } \\
\text { conhecimento }\end{array}$ & $\begin{array}{l}\text { Chan, Sabherwal e } \\
\text { Thatcher (2006) }\end{array}$ & Consenso & $\begin{array}{l}\text { Compartilhamento da visão e da estratégia } \\
\text { pelos gestores. }\end{array}$ \\
\hline $\begin{array}{l}\text { Comprometimento } \\
\text { estratégico }\end{array}$ & Noble, Mokwa (1999) & Consenso & $\begin{array}{l}\text { Compreensão e suporte, por parte do } \\
\text { gerente, para o alcance das metas da } \\
\text { organização. }\end{array}$ \\
\hline $\begin{array}{l}\text { Ajuste da estratégia com } \\
\text { a visão }\end{array}$ & Noble, Mokwa (1999) & Consenso & $\begin{array}{l}\text { Grau de alinhamento da estratégia com a } \\
\text { visão mais ampla da organização. }\end{array}$ \\
\hline $\begin{array}{l}\text { Importância percebida } \\
\text { sobre a estratégia }\end{array}$ & Noble, Mokwa (1999) & Consenso & $\begin{array}{l}\text { Percepção da estratégia como importante } \\
\text { para a organização. }\end{array}$ \\
\hline Consenso estratégico & $\begin{array}{l}\text { Rapert, Velliquette, } \\
\text { Garretson (2002) }\end{array}$ & Consenso & $\begin{array}{l}\text { Conhecimento compartilhado sobre } \\
\text { objetivos organizacionais. }\end{array}$ \\
\hline $\begin{array}{l}\text { Frequência da } \\
\text { comunicação }\end{array}$ & $\begin{array}{l}\text { Rapert, Velliquette, } \\
\text { Garretson (2002) } \\
\end{array}$ & Consenso & $\begin{array}{l}\text { Frequência da comunicação entre gestores } \\
\text { e gerentes }\end{array}$ \\
\hline $\begin{array}{l}\text { Envolvimento pessoal } \\
\text { (Role involvement) }\end{array}$ & Noble, Mokwa (1999) & $\begin{array}{l}\text { Envolvimento da } \\
\text { média gerência na } \\
\text { formulação }\end{array}$ & $\begin{array}{l}\text { Proporção que o gerente interage com os } \\
\text { superiores para determinar a natureza do } \\
\text { seu papel, inclusive na formulação. }\end{array}$ \\
\hline $\begin{array}{l}\text { Fatores da estratégia: } \\
\text { Escopo }\end{array}$ & Noble, Mokwa (1999) & $\begin{array}{l}\text { Envolvimento da } \\
\text { média gerência na } \\
\text { formulação }\end{array}$ & $\begin{array}{l}\text { Proporção que a estratégia abrange um } \\
\text { maior número de gestores e funções dentro } \\
\text { da organização. }\end{array}$ \\
\hline Consenso estratégico & Wooldridge, Floyd (1990) & $\begin{array}{l}\text { Envolvimento da } \\
\text { média gerência na } \\
\text { formulação }\end{array}$ & $\begin{array}{l}\text { Envolvimento da média gerência na } \\
\text { formação da estratégia. }\end{array}$ \\
\hline
\end{tabular}


conclusão

\begin{tabular}{|l|l|l|l||}
\hline $\begin{array}{l}\text { Fatores envolvidos no } \\
\text { alinhamento }\end{array}$ & Fonte & Relação com a tese & Descrição \\
\hline $\begin{array}{l}\text { Processo de } \\
\text { planejamento estratégico }\end{array}$ & $\begin{array}{l}\text { Chan, Sabherwal e } \\
\text { Thatcher (2006) }\end{array}$ & $\begin{array}{l}\text { Processo formal de } \\
\text { planejamento }\end{array}$ & $\begin{array}{l}\text { Existência de um processo de planejamento } \\
\text { estratégico. }\end{array}$ \\
\hline Ajuste com a visão & Noble, Mokwa (1999) & $\begin{array}{l}\text { Processo formal de } \\
\text { planejamento }\end{array}$ & $\begin{array}{l}\text { Percepção de que a estratégia está alinhada a } \\
\text { um propósito mais amplo da organização. }\end{array}$ \\
\hline $\begin{array}{l}\text { Abrangência do } \\
\text { planejamento formal }\end{array}$ & Powell (1992) & $\begin{array}{l}\text { Processo formal de } \\
\text { planejamento }\end{array}$ & $\begin{array}{l}\text { Existência de um processo de planejamento } \\
\text { estratégico bem estabelecido. }\end{array}$ \\
\hline Capacidades gerenciais & $\begin{array}{l}\text { Carmeli e Tishler } \\
(2004)\end{array}$ & $\begin{array}{l}\text { Capacidades } \\
\text { gerenciais }\end{array}$ & $\begin{array}{l}\text { Habilidades e capacidades dos gestores como } \\
\text { potencial para gerar vantagem competitiva. }\end{array}$ \\
\hline $\begin{array}{l}\text { Suporte da alta direção } \\
\text { Comprometimento }\end{array}$ & $\begin{array}{l}\text { Noble, Mokwa (1999) } \\
(2001), \text { Gagnon, } \\
\text { Jansen e Michael } \\
(2008), \text { Noble e Mokwa } \\
(1999)\end{array}$ & $\begin{array}{l}\text { Capacidades } \\
\text { gerenciais }\end{array}$ & $\begin{array}{l}\text { Suporte da alta direção para viabilizar a } \\
\text { implementação. }\end{array}$ \\
\hline $\begin{array}{l}\text { Relações de trabalho e } \\
\text { cultura organizacional }\end{array}$ & $\begin{array}{l}\text { Carmeli e Tishler } \\
(2004)\end{array}$ & $\begin{array}{l}\text { Envolvimento das } \\
\text { pessoas }\end{array}$ & $\begin{array}{l}\text { Relação entre os gestores e os colaboradores; } \\
\text { clima organizacional. }\end{array}$ \\
\hline
\end{tabular}

Quadro 3 - Fatores envolvidos no alinhamento estratégico, elaborado pela autora com base na revisão de literatura 
Fazer a estratégia funcionar implica na existência da estratégia (BOWER,1982; HREBINIAK; JOYCE, 2001, NADLER; TUSHMAN 2001). Em essência, a implementação é dependente do processo de formulação que é usado (HAMBRICK; CANNELLA, 1989).

Quando se analisa a formulação da estratégia no contexto da literatura de AV emergem aspectos da qualidade e abrangência das informações que são analisadas e que vão dar origem à estratégia (HAMBRICK; CANNELLA,1989; NADLER; TUSHMAN, 2001; POWELL, 1992), aspectos sobre a comunicação da estratégia (RAPERT; VELLIQUETTE; GARRETSON, 2002) e dos instrumentos que serão utilizados para a sua formalização e comunicação (KAPLAN; NORTON, 1996, 2000; LABOVITZ; ROSANSKY, 1997) e aspectos relacionados às pessoas envolvidas no processo, por exemplo, o envolvimento da média gerência (WOOLDRIDGE; FLOYD, 1990), o grau de consenso entre os estrategistas (HOMBURG; KROHMER; WORKMAN JR., 1999) e o comprometimento das pessoas (BOSWELL; BOUDREAU, 2001; GAGNON; JANSEN; MICHAEL, 2008).

Dessa forma, evidencia-se que as variáveis envolvidas no AV denotam um processo que vai desde a definição da estratégia até a compreensão e realização desta pelas pessoas. Nesse sentido, os fatores identificados foram agrupados nos seguintes fatores:

- processo formal de planejamento (PFP)

- envolvimento da média gerência na formulação (EMG)

- consenso estratégico (CE)

- capacidades gerencias para a implementação da estratégia (CG) e

- envolvimento das pessoas com a estratégia (EP)

No Quadro 3, já mencionado anteriormente, estabelece-se a relação entre os fatores envolvidos no alinhamento identificados nos estudos empíricos e os fatores que estão sendo considerados nesta tese, de acordo com o agrupamento de fatores sugerido.

Segue-se a definição de cada um deles e a sua relação com o AV.

\subsubsection{Fatores envolvidos no alinhamento estratégico vertical}

\subsubsection{Processo Formal de Planejamento (PFP)}

O PFP compreende a existência de um processo de planejamento estratégico estabelecido. 
Na dinâmica do processo de transformação da estratégia em ação, a formulação de um plano continua sendo o seu ponto inicial ( MINTZBERG, 1994).

A existência de um processo formal de planejamento está associada à formalização da estratégia, para posterior comunicação aos responsáveis pela implementação e acompanhamento da realização.

Nesse sentido é que, por exemplo, o Balanced Scorecard tem alcançado uma grande aceitação entre teóricos e práticos (NEELY, 2005; SPECKBACHER; BISCHOF; PFEIFFER, 2003). Enquanto sistema de alinhamento estratégico, o modelo apóia-se em dois eixos principais, o da comunicação e do controle da estratégia, tendo como elemento central justamente a formalização da estratégia por meio do mapa estratégico (KAPLAN; NORTON, 1996, 2000).

Labovitz e Rosansky (1997) apresentam uma proposta semelhante ao BSC para o alinhamento estratégico, por meio do desdobramento da estratégia em um sistema de métricas. Os autores propõem uma estrutura para a realização do AV, denominada PDR, um ciclo de planejamento, desenvolvimento e revisão. O planejamento inicia-se com a definição ou revisão do propósito essencial, e a partir daí, em uma estrutura em árvore são definidos indicadores críticos de sucesso, metas, atividades e táticas. Cada departamento ou unidade tem a sua própria árvore ligada a um nível hierarquicamente superior, sendo que o que é uma meta para uma unidade torna-se o propósito essencial para uma unidade que ocupa um nível abaixo.

No modelo proposto por Hambrick e Cannella (1989), o alinhamento é visto como um processo gerencial a ser conduzido pelo estrategista. O modelo para realizar o alinhamento caracteriza-se pela definição das etapas a serem conduzidas pelo executivo, desde a formulação até a implementação da estratégia. A primeira etapa os autores consideram uma "preparação de terreno" para a nova estratégia e inclui aspectos da formulação da estratégia, como uma amplitude de entradas e tratamento cuidadoso dos obstáculos de implementação.

A existência de um processo formal aparece como variável nos estudos empíricos desenvolvidos por Chan, Sabherwal e Thatcher (2006), Noble e Mokwa (1999) e Powell (1992) - ver Quadro 3.

Chan, Sabherwal e Thatcher (2006) encontraram relação positiva entre a formalização do planejamento e o conhecimento compartilhado entre os executivos a respeito da estratégia. 
Para Noble e Mokwa (1999), fatores relacionados à estratégia afetam dimensões de comprometimento organizacional, que por sua vez afetam o desempenho individual e o sucesso na implementação de estratégias. Dentre esses fatores, o ajuste da estratégia com a visão, definido como à medida que a estratégia a ser implementada está alinhada a uma direção estratégica mais ampla da organização.

Powell (1992) estabelece hipóteses de que o melhor alinhamento entre a abrangência de um plano formal e variáveis contingenciais, como o tamanho da organização e a estabilidade ambiental estão relacionados a um desempenho superior.

\subsubsection{Envolvimento da média gerência na formulação (EMG)}

O EMG compreende a participação da média gerência na formulação da estratégia e no processo posterior de implementação.

A teoria contemporânea sobre decisão estratégica considera que o papel da média gerência vai além do tradicional fornecimento de informações de entrada e condução do processo de implementação para o de regularmente influenciar a estratégia e prover o impulso para novas iniciativas (BURGELMAN, 1988; FLOYD; WOOLDRIDGE, 1992b; MINTZBERG; WATERS, 1985).

Campbell e Alexander (1997) afirmam que apesar da média gerência não ter necessariamente o perfil requerido de um estrategista, o conhecimento das operações diárias e a gestão de linha de frente do negócio são fontes importantes para a inovação estratégica, sendo que a probabilidade dessas ideias emergirem é maior no processo criativo de formulação da estratégia. Outros argumentos dizem respeito à necessidade de planejar e analisar os ajustes necessários à implementação já na fase de formulação para ter certeza de que a estratégia é viável (HAMBRICK; CANNELLA, 1989).

Wooldridge e Floyd (1990) afirmam que o envolvimento dos gerentes de nível médio na fase de elaboração da estratégia está associado à melhoria do desempenho. Em relação às atividades de implementação da estratégia, a atuação da média gerência é no sentido de alinhar as ações organizacionais com as intenções estratégicas, por meio da intervenção na estrutura, pessoas e sistemas (FLOYD; WOOLDRIDGE, 1992a).

Identifica-se o construto nos trabalhos de Chan, Sabherwal e Thatcher (2006), Noble e Mokwa (1999) e Wooldridge e Floyd (1990) - ver Quadro 3. 
Para Noble e Mokwa (1999), a participação da média gerência na formulação ajuda a determinar o seu papel na implementação e tem relação com o comprometimento individual em relação aos objetivos e metas estabelecidos.

\subsubsection{Consenso estratégico (CE)}

O CE envolve o quanto os gestores compreendem e dão suporte à estratégia da empresa.

O consenso é considerado crítico para a resolução de diferenças, para promover uma direção estratégica única para a empresa, para aumentar o comprometimento estratégico e também impulsionar o sucesso na implementação da estratégia (DESS; PRIEM, 1995).

Existem várias dimensões do consenso sendo abordadas em pesquisas empíricas no campo da estratégia. Uma das dimensões é o grau de consenso entre os executivos sobre as prioridades estratégicas. Nesse sentido, Floyd e Wooldridge (1992a) definem consenso como o acordo entre a alta direção e os gerentes de nível médio e operacional sobre as prioridades da organização.

Homburg, Krohmer e Workman Jr. (1999) analisam o consenso em relação à estratégia de diferenciação e de baixo custo, utilizando a tipologia de Porter (1986).

Também tem sido pesquisado o consenso entre os executivos quanto às prioridades competitivas entre a estratégia de negócios e a estratégia funcional.

Joshi, Kathuria e Porth (2003) testaram a hipótese da relação positiva entre alinhamento e desempenho, com base no consenso entre o Diretor Geral e o Gerente de Operações, sobre as prioridades da área de manufatura.

Boyer e McDermott (1999) investigam o consenso sobre prioridades competitivas entre diferentes plantas de manufatura, considerando o nível gerencial e o operacional.

Rapert, Velliquette e Garretson (2002) exploraram a importância da frequente comunicação vertical entre os altos executivos e os gerentes operacionais para a obtenção do consenso.

A dimensão do consenso que se pretende explorar nesta tese é a do comprometimento estratégico, definido como a compreensão e suporte, por parte do gerente, para o alcance das metas da organização (NOBLE; MOKWA,1999).

Em geral, o comprometimento com a estratégia depende do quanto os gestores percebem que a estratégia está alinhada aos interesses da organização e do quanto eles 
percebem que a estratégia está alinhada aos seus próprios interesses (FLOYD; WOOLDRIDGE, 1992a).

Nos modelos empíricos propostos por Noble e Mokwa (1999) e Parish, Cadwallader e Busch (2008), a estratégia é considerada um dos antecedentes do comprometimento estratégico e o sucesso na implementação uma das suas consequências. O comprometimento dos gestores com a implementação é afetado pela importância percebida sobre a estratégia, que depende da percepção dos gestores quanto ao impacto da estratégia para os negócios (NOBLE; MOKWA,1999).

Chan, Sabherwal e Thatcher (2006) tratam do domínio compartilhado do conhecimento sobre a estratégia entre a alta gerência e os executivos do nível funcional como positivamente relacionado ao alinhamento.

Entende-se que os fatores até aqui apresentados, processo formal de planejamento, envolvimento da média gerência na formulação e consenso sobre a estratégia fazem parte de um mesmo processo, aqui denominado abrangência da formulação da estratégia (AF), que compreende os aspectos da formulação que vão influenciar o processo de implementação.

O Quadro 4 apresenta uma síntese do relacionamento teórico entre a abrangência da formulação da estratégia e os seus componentes e o alinhamento vertical.

\subsubsection{Capacidades gerencias para a implementação da estratégia (CG)}

CG abrange as capacidades que são requeridas dos executivos para promover o alinhamento estratégico.

A habilidade de efetivamente implementar a estratégia pode ser, em si mesma, uma fonte de vantagem competitiva (AMIT; SHOEMAKER, 1993; FLEURY; FLEURY, 2000; GRANT, 1991; MALINA; SELTO, 2001; POWELL, 1992).

Powell (1992) argumenta que o alinhamento requer que o executivo demonstre uma alta capacidade de integração e que a habilidade de alinhamento organizacional poderia ser considerada um recurso estratégico rentável, capaz de melhorar o DO. Nesse mesmo sentido, Barney e Mackey (2005, pág. 9) afirmam que se a habilidade de uma empresa de implementar a estratégia é válida, rara, difícil de imitar, então a capacidade de implementação de estratégias de uma empresa é uma fonte potencial de vantagem competitiva. 


\begin{tabular}{|c|c|}
\hline \multicolumn{2}{|r|}{ ABRANGÊNCIA DA FORMULAÇÃO DA ESTRATÉGIA } \\
\hline $\begin{array}{l}\text { Principais } \\
\text { referências }\end{array}$ & Relação com o alinhamento vertical \\
\hline \multicolumn{2}{|c|}{ Processo formal de planejamento } \\
\hline $\begin{array}{l}\text { Kaplan e Norton } \\
(1996,2000) \text { e } \\
\text { Labovitz e } \\
\text { Rosansky (1997) } \\
\text { Mintzberg (1994) }\end{array}$ & $\begin{array}{l}\text { O processo formal de planejamento está associado à formalização } \\
\text { da estratégia para posterior comunicação aos responsáveis pela } \\
\text { implementação e acompanhamento da realização. } \\
\text { Um programa estratégico envolve tornar a estratégia clara; } \\
\text { transformá-la em subestratégias ou planos e considerar os efeitos } \\
\text { das mudanças nas operações da organização. }\end{array}$ \\
\hline \multicolumn{2}{|c|}{ Envolvimento da média gerência na formulação } \\
\hline $\begin{array}{l}\text { Floyd e } \\
\text { Wooldridge } \\
\text { (1992b) }\end{array}$ & $\begin{array}{l}\text { A participação da média gerência na formulação: } \\
\text { - é no sentido de alinhar as ações organizacionais com as } \\
\text { intenções estratégicas, por meio da intervenção na estrutura, } \\
\text { pessoas e sistemas. }\end{array}$ \\
\hline $\begin{array}{l}\text { Noble e Mokwa } \\
\text { (1999) }\end{array}$ & $\begin{array}{l}\text { - ajuda a determinar o seu papel na implementação e tem relação } \\
\text { com o comprometimento em relação aos objetivos e metas. }\end{array}$ \\
\hline $\begin{array}{l}\text { Hambrick e } \\
\text { Cannella (1989) }\end{array}$ & - antecipa os ajustes necessários à implementação. \\
\hline $\begin{array}{l}\text { Burgelman (1988), } \\
\text { Floyd e } \\
\text { Wooldridge } \\
\text { (1992b) e } \\
\text { Mintzberg e } \\
\text { Waters (1985) } \\
\end{array}$ & - influencia a estratégia e provê o impulso para novas iniciativas. \\
\hline \multicolumn{2}{|c|}{ Consenso estratégico } \\
\hline $\begin{array}{l}\text { Floyd e } \\
\text { Wooldridge } \\
\text { (1992a) }\end{array}$ & $\begin{array}{l}\text { O grau de consenso entre os executivos sobre as prioridades } \\
\text { estratégicas pode influenciar a execução da estratégia. }\end{array}$ \\
\hline $\begin{array}{l}\text { Noble e Mokwa } \\
(1999)\end{array}$ & $\begin{array}{l}\text { O comprometimento com a estratégia depende do quanto os } \\
\text { gestores percebem que a estratégia está alinhada aos interesses } \\
\text { da organização. }\end{array}$ \\
\hline $\begin{array}{l}\text { Noble e Mokwa } \\
\text { (1999) }\end{array}$ & $\begin{array}{l}\text { Comprometimento estratégico envolve a compreensão e suporte } \\
\text { por parte dos gestores às metas e objetivos da organização. } \\
\text { A importância percebida está relacionada à percepção dos } \\
\text { gestores quanto ao impacto da estratégia para os negócios. }\end{array}$ \\
\hline
\end{tabular}

Quadro 4 - Relacionamento teórico entre abrangência da formulação da estratégia e alinhamento vertical 
É esperado que dentre as habilidades de um gestor estejam aquelas relacionadas à implementação da estratégia relativa à unidade de negócio que ele dirige, que para ter sucesso requer coordenação de decisões e ações entre todas as funções (GOVINDARAJAN, 1989; HITT; IRELAND; PALIA, 1982). Essa afirmação encontra respaldo na afirmação de Hrebiniak (2006, p.31) de que a comunicação entre diferentes funções é um desafio característico da implementação devido ao envolvimento de mais pessoas do que na etapa da formulação.

Hambrick e Cannella (1989) atribuem ao estrategista o papel de negociação e convencimento a respeito da estratégia. Os autores ressaltam que o estrategista precisa ter habilidade para identificar os principais obstáculos à implementação da estratégia, e se perguntar se realmente a estratégia pode ser operacionalizada, antes de colocá-la em ação.

Esses autores também atribuem ao estrategista o papel de negociar a estratégia interna e externamente à organização. Trata-se do papel do estrategista de construir e manter o suporte necessário para a implementação da estratégia em meio às resistências que naturalmente surgem devido ao interesse de determinadas partes em manter a velha estratégia ou por falta de compreensão da nova proposta.

Ainda segundo Hambrick e Cannella (1989) o gestor tem o papel de promover os ajustes nos fatores que são relevantes no processo de implementação, tais como alocação de recursos e ajuste dos programas das subunidades, da estrutura e do sistema de recompensas. Essa afirmação é corroborada por Noble e Mokwa (1999) para quem a média gerência é bastante racional ao avaliar o comprometimento dos seus superiores com a estratégia e esperam que o façam liberando os recursos necessários para a sua eficácia.

As capacidades organizacionais de coordenação, comprometimento e competência funcional e interpessoal são apresentadas como a chave para o alinhamento estratégico em um modelo proposto por Beer e Eisenstat (1996; 2000).

Beer e Eisenstat (2000) listam o que eles denominam de "os seis matadores silenciosos da implementação da estratégia", dentre eles uma comunicação vertical pobre que ocorre quando a cultura da organização não favorece o diálogo aberto entre os níveis hierárquicos e diante da não disposição por parte dos gerentes seniores em confrontar publicamente as barreiras que bloqueiam a implementação da estratégia (BEER; EISENSTAT, 2004). Uma comunicação adequada com os níveis gerenciais tem sido apontada por vários autores como a chave para obter o entendimento compartilhado 
sobre as prioridades estratégicas (NOBLE, 1999; RAPERT; VELLIQUETTE; GARRETSON, 2002; REICH; BENBASAT, 2000).

Identificam-se estudos empíricos investigando a relação entre as habilidades do gestor, as estratégicas genéricas e o desempenho (GOVINDARAJAN, 1989); entre o locus de controle interno do CEO e o desempenho organizacional (POWEL, 1999).

O estudo desenvolvido por Carmeli e Tishler (2004) emprega o conceito de alinhamento entre os elementos intangíveis e a sua contribuição para o desempenho organizacional. Eles definem como uma das variáveis a capacidade gerencial. A mensuração do construto utiliza medidas propostas por Hitt e Ireland (1985), dentre elas, a capacidade da alta administração desenvolver e comunicar um senso único de direção a ser compartilhado por todos na organização, a capacidade de atrair e reter um time de altos executivos bem preparados e competentes, a habilidade de unificar conflitos e opiniões e de melhorar a coordenação e a colaboração entre executivos- chave, o que deve gerar entusiasmo e motivação suficientes para conduzir a um melhor desempenho. Os resultados indicaram que altos índices obtidos em capacidades gerenciais são críticos para o desempenho organizacional, dentre outros elementos.

O Quadro 5 sumariza o relacionamento teórico entre capacidades gerenciais para implementação da estratégia e o alinhamento vertical.

\subsubsection{Envolvimento das pessoas com a estratégia (EP)}

O EP abrange as condições necessárias para promover um comportamento orientado para o alcance dos objetivos e metas, tais como, cultura e sistema de recompensas e reconhecimento.

$\mathrm{O}$ AV requer por parte das pessoas dentro da organização um comportamento orientado para o alcance dos objetivos e metas.

Os modelos de alinhamento propostos por Labovitz e Rosansy (1997) e Kaplan e Norton $(1992,1993,1996)$ definem o alinhamento como processo de desdobramento da estratégia em indicadores de desempenho, o qual envolve as pessoas em todos os níveis e funções dentro da organização. Nesses modelos o sistema de métricas deve ser aliado a recompensas e reconhecimento.

Segundo Kaplan e Norton (2006, p. 295), o alinhamento do capital humano é alcançado quando os objetivos individuais, programas de treinamento e remuneração estiverem alinhados com a estratégia de negócios. 
CAPACIDADES GERENCIAIS PARA IMPLEMENTAÇÃO DA ESTRATÉGIA

Principais referências Relação com o alinhamento vertical

Powell (1992) O alinhamento requer que o executivo demonstre uma alta capacidade de integração.

Govindarajan (1989), A implementação requer coordenação de decisões e ações

Hitt, Ireland e Palia entre todas as funções.

(1982)

Hambrick e Cannella Cabe ao estrategista o papel de negociação e convencimento (1989)

Hambrick e Cannella

(1989)

Hambrick e Cannella

(1989), Noble e

Mokwa (1999)

a respeito da estratégia.

É necessário ter habilidade para identificar os obstáculos à implementação da estratégia, e se perguntar se ela pode ser operacionalizada, antes de colocá-la em ação.

É necessário promover os ajustes nos fatores relevantes ao processo de implementação, incluindo a alocação de recursos.

Beer e Eisenstat

$(1996,2000)$

Noble (1999), Rapert, Velliquette Garretson (2002), Reich e Benbasat (2000).
As capacidades organizacionais de coordenação, comprometimento e competência funcional e interpessoal são a chave para o alinhamento estratégico.

Uma comunicação adequada apresenta-se como a chave para obter o entendimento compartilhado sobre as prioridades estratégicas.

Quadro 5 - Relacionamento teórico entre capacidades gerencias para a implementação da estratégia e o alinhamento vertical

A literatura tem introduzido o conceito de line-of-sight uma combinação entre a compreensão dos objetivos organizacionais pelos funcionários e a sua contribuição para o alcance dos mesmos (BOSWELL; BOUDREAU, 2001).

Estudo empírico realizado por esses autores relata a dificuldade dos gestores em ter uma medida precisa sobre o alinhamento, que permita mensurar até que ponto os funcionários de fato entendem qual é a estratégia e como contribuir para a sua execução.

A despeito dessa dificuldade, o estudo sugere que uma percepção positiva do alinhamento por parte dos funcionários influencia a sua atitude, o que acontece quando os funcionários acreditam que entendem o que se espera deles e sentem que podem contribuir.

Os resultados de estudos conduzidos por Boswell (2006) indicam que a maneira de ver essa relação (line-of-sight) pode variar de acordo com o nível hierárquico, a ocupação e o número de posições ocupadas na empresa, mas de qualquer forma, entender "como" 
contribuir tem provavelmente maior importância para os funcionários alcançarem as metas organizacionais.

Gagnon, Jansen e Michael (2008) exploram a relação entre conhecimento sobre a estratégia e comprometimento, sendo que os resultados demonstram que pessoas comprometidas com a estratégia estão predispostas a se engajar em comportamentos que suportam a estratégia e que o desenvolvimento do comprometimento das pessoas com a estratégia provavelmente auxilia nas transformações estratégicas necessárias. O estudo também provê evidências sobre o fato de que a liderança tem um papel central no desenvolvimento das atitudes positivas dos funcionários e da confiança, com efeito positivo sobre o comprometimento estratégico.

Vários autores assumem a relação entre a cultura e o alcance dos objetivos organizacionais. Para Fleury e Fleury (1997) uma forte cultura pressupõe o comprometimento dos empregados com os objetivos organizacionais.

Labovitz e Rosansky (1997) propõem a criação de uma organização capaz de auto alinhar-se. As bases para esta conduta são a liderança, a cultura e um sistema de medidas de desempenho. Os autores acreditam que as medidas moldam 0 comportamento e o comportamento cria a cultura. Para isso, as medidas têm que fazer sentido para as pessoas e precisam ser apresentadas como tendo relação com o propósito essencial dos negócios e precisam estar ligadas a um sistema de recompensas e reconhecimento. Ainda segundo os autores, trata-se de uma forma de levar as pessoas a adaptar o seu comportamento ao alcance das medidas o tempo todo, de forma que o comportamento coletivo das pessoas forma a cultura de autoalinhamento.

A cultura organizacional também tem o papel de desenvolver mecanismos para minimizar os conflitos inerentes ao processo de mudança estratégica, tais como, conflitos entre funções, falta do devido interesse aos clientes, decisões lentas por parte dos implementadores, os quais são manifestações passíveis de ocorrer no processo de implementação e tornam-se barreiras se não forem confrontadas e removidas.

O estudo desenvolvido por Carmeli e Tishler (2004) demonstra que a interação entre os elementos intangíveis é crítica para o alcance dos objetivos organizacionais, com impacto positivo sobre o desempenho, no entanto, a cultura organizacional e a reputação organizacional percebida se destacam entre os outros elementos.

A motivação e um sistema que recompense os resultados alcançados pelos indivíduos e unidades organizacionais são essenciais para a eficácia na implementação da estratégia. 
Pearce e Robinson (1997) afirmam que se a realização da estratégia é uma prioridade dos altos executivos, o sistema de recompensas precisa estar clara e fortemente relacionado com o desempenho organizacional.

Para Kaplan e Norton (2006, p.297), os líderes criam motivação intrínseca ao explorar o desejo dos funcionários em atuar em organizações bem sucedidas, organizações para as quais eles sintam orgulho de trabalhar. Para gerar essa motivação, eles recomendam a comunicação da visão, da missão e da estratégia por meio dos mapas estratégicos do BSC.

É importante ressaltar que autores como Bartlett e Ghoshal (1994), Campbell e Alexander (1997) e Nohria, Joyce e Roberson (2003) questionam a força das declarações de propósitos comumente definidas pelas organizações em termos de visão, missão, intenção estratégica, objetivos dos acionistas e foco no cliente e a sua força em gerar ações efetivas junto aos executivos e funcionários.

O que se propõe é uma definição estratégica que, como definida por Porter (1996) exige trade-offs e define um posicionamento único, característico da organização, a ser seguido e comunicado insistentemente ao longo dos anos.

Ainda segundo Kaplan e Norton (2006), a motivação extrínseca deve reforçar a mensagem estratégica e pode ser explorada por meio da remuneração por incentivos devido ao alcance de metas. Hrebiniak (2006) recomenda que os incentivos estejam vinculados aos objetivos estratégicos ou aos objetivos de curto prazo que derivam da estratégia.

No Quadro 6 estão reunidas as principais afirmações teóricas que relacionam o construto Envolvimento das Pessoas com a Estratégia ao alinhamento vertical.

\subsubsection{Fatores envolvidos no alinhamento estratégico horizontal}

\subsubsection{Orientação para processos e clientes}

Nesta tese se adota como fatores envolvidos no alinhamento estratégico horizontal a orientação para processos (OP) e a orientação para clientes (OC).

A orientação para processos pretende mensurar o quanto os departamentos e funções são permeáveis no sentido de permitir o cumprimento dos objetivos estratégicos, principalmente quanto ao atendimento das necessidades dos clientes. 


\begin{tabular}{|c|c|}
\hline \multicolumn{2}{|c|}{ ENVOLVIMENTO DAS PESSOAS COM A ESTRATÉGIA } \\
\hline Principais referências & Relação teórica com o alinhamento vertical \\
\hline $\begin{array}{l}\text { Kaplan e Norton } \\
\text { (1992, 1993, 1996), } \\
\text { Labovitz e Rosansy } \\
(1997)\end{array}$ & $\begin{array}{l}\text { O alinhamento vertical requer, por parte das pessoas dentro } \\
\text { da organização, um comportamento orientado para o alcance } \\
\text { dos objetivos e metas. } \\
\text { Um sistema de métricas é a chave para a realização desse } \\
\text { alinhamento, aliado a recompensas e reconhecimento. }\end{array}$ \\
\hline $\begin{array}{l}\text { Boswell e Boudreau } \\
\text { (2001), } \\
\text { Gagnon, Jansen e } \\
\text { Michael (2008), } \\
\text { Bartlett e Ghoshal }\end{array}$ & $\begin{array}{l}\text { Os funcionários contribuem quando acreditam que entendem o } \\
\text { que se espera deles e sentem que podem contribuir. }\end{array}$ \\
\hline $\begin{array}{l}(1994) \\
\text { Fleury e Fleury } \\
\text { (1997) }\end{array}$ & $\begin{array}{l}\text { Uma forte cultura pressupõe o comprometimento dos } \\
\text { empregados com os objetivos organizacionais. }\end{array}$ \\
\hline $\begin{array}{l}\text { Labovitz e Rosansky } \\
\text { (1997) }\end{array}$ & $\begin{array}{l}\text { As bases para o auto-alinhamento são a liderança, a cultura e } \\
\text { um sistema de medidas de desempenho. }\end{array}$ \\
\hline $\begin{array}{l}\text { Kaplan e Norton } \\
(2006)\end{array}$ & $\begin{array}{l}\text { Os líderes criam motivação intrínseca ao explorar o desejo dos } \\
\text { funcionários em trabalhar para organizações bem sucedidas, o } \\
\text { que pode ser explorado por meio da comunicação da visão, da } \\
\text { missão e da estratégia. }\end{array}$ \\
\hline
\end{tabular}

Quadro 6: Relacionamento teórico entre Envolvimento das Pessoas com a Estratégia e o Alinhamento Vertical

Por orientação para clientes entende-se o quanto departamentos e funções seguem uma direção única, estabelecida estrategicamente, no sentido de atender e antecipar as necessidades do cliente.

Processos e clientes são perspectivas presentes nos modelos de alinhamento estratégico de Kaplan e Norton (1992, 1996) e Labovitz e Rosansky (1997).

Labovitz e Rosansky (1997) consideram o AH como o alinhamento entre processos e clientes. O elemento cliente requer que a empresa tenha identificado os clientes estratégicos antes de ter feito qualquer trabalho para melhorar a satisfação do cliente e, ainda, que haja uma relação direta entre as necessidades do cliente, a configuração dos processos e a infra-estrutura organizacional.

O elemento processo requer a identificação dos processos-chave que suportam a estratégia, o melhoramento contínuo e, se necessário, redesenho desses processos como definido pela estratégia e clientes. 
Ainda segundo esses autores, três condições são essenciais para alcançar o $\mathrm{AH}$ : (1) identificar quais são as necessidades dos clientes e identificar oportunidades para atendê-las, (2) manter relacionamento com os consumidores antes, durante e após a entrega de um produto e (3) criar internamente a noção de cliente-fornecedor.

Os conceitos aqui abordados remontam ao pensamento sobre processos popularizado nos anos 80 como um elemento central do movimento da gestão da qualidade total (DAVENPORT; SHORT, 1990; HACKMAN; WAGEMAN, 1995), movimento esse inicialmente baseado nos trabalhos seminais dos gurus da qualidade, Ishikawa, Deming e Juran.

Uma das premissas da área da qualidade é que produzir produtos e serviços com qualidade não é apenas uma questão de otimização dos custos, mas está relacionado à sobrevivência da organização (HACKMAN; WAGEMAN, 1995).

Nesse sentido, obter a qualidade almejada em produtos e serviços depende acima de tudo dos processos nos quais eles são planejados e produzidos (HACKMAN; WAGEMAN, 1995). Engenheiros e precursores do movimento advogam que para melhorar a qualidade das operações é necessário olhar o processo como um todo e não para a tarefa ou para a função em si mesma (DAVENPORT; SHORT, 1990).

O conceito de processos expandiu-se para o nível estratégico por meio do Gerenciamento pelas Diretrizes (GPD). O Policy Deployment, como é conhecido, busca internalizar as preferências dos clientes como um fator de competitividade estratégica (COLE, 1998). Busca, também, integrar a qualidade a um amplo sistema de controle de metas, planos e ações, com ênfase em uma cooperação interfuncional (gestão por processos) para o alcance dos objetivos propostos, que devem estar orientados para o mercado, para o cliente e para as suas necessidades.

A gestão por processos continuou sendo difundida como um elemento central nas iniciativas que expandiram o movimento inicial da qualidade, como a introdução das normas da qualidade (série ISO 9000) e os prêmios da qualidade, tais como o Malcom Baldrige National Quality Award (EUA), European Foundation for Quality Management (EFQM) e, no Brasil, o Prêmio Nacional da Qualidade (PNQ) e, mais recentemente, o programa Seis Sigma. Esses movimentos têm como objetivo o alinhamento da organização aos objetivos estratégicos, dentre eles a gestão orientada para o cliente e para os processos.

A importância da visão por processos é corroborada pelo estudo desenvolvido por Nohria, Joyce e Roberson (2003), que examinou mais de 200 práticas administrativas 
consolidadas em 160 empresas, em um período de 10 anos. O estudo aponta como uma das práticas das empresas mais bem sucedidas a "execução", que segundo os autores, significa que essas empresas reconhecem que não podem ter alto desempenho em todos os processos, então elas focam nos processos que são essenciais para atender as necessidades dos seus clientes e é para esses processos que elas vão despender energia e recursos, tornando-os o mais eficiente possível.

Para Ghoshal e Bartlett (1995) o tradicional processo de informação vertical updown é eficiente no sentido de permitir às empresas desenvolver e refinar operações que dão suporte à estratégia, mas não contém meios para desafiar a estratégia. Ainda segundo os autores, a tradicional doutrina estratégia-estrutura-sistemas se pauta pela alocação de recursos, distribuição de responsabilidades e controle, enquanto que a doutrina propósito-processos-pessoas está voltada para um comportamento mais criativo por parte das pessoas e um ambiente que as capacite a tomar iniciativas, cooperar e aprender.

Conforme já foi apontado anteriormente, existe uma ausência de estudos empíricos envolvendo o $\mathrm{AH}$ e que demonstrem a interação entre as áreas funcionais. Nesse sentido, alguns autores sugerem a integração de funções que cobrem um ciclo produtivo desde a compreensão das necessidades do cliente, até a entrega do produto ou serviço. Por exemplo, Boyer e McDermott (1999) e Hill e Brown (2007) sugerem que as funções a serem pesquisadas incluam marketing, operações, clientes e vendas.

Entende-se que a visão por processos supre essa lacuna, porque em geral os processos atravessam as funções, são horizontais, considerados conjuntamente à estrutura vertical tradicional, e nenhuma pessoa tem a responsabilidade pelo processo como um todo (LEE; DALE, 1998). Uma gestão por processos tem o objetivo de alinhar os processos com os objetivos estratégicos e as necessidades dos clientes (LEE; DALE, 1998).

Nos estudos empíricos sobre alinhamento estratégico, a orientação para processos foi assumida no trabalho conduzido por Xu, Cavusgil e White (2006) - ver Apêndice B. Esses autores argumentam que existe a necessidade de incorporar os processos aos estudos de ajuste estratégico porque a orientação para estrutura não capta a complexidade da integração entre as atividades de operações e a coordenação que atravessa as fronteiras da organização.

Olson, Slater e Hult (2005) investigam a relação entre a estrutura e o comportamento de marketing e o desempenho, moderada pela estratégia de negócios. A 
orientação para cliente é empregada para avaliar o comportamento do marketing. Segundo os autores, a orientação para cliente pode levar à obtenção de vantagem competitiva por colocar como alta prioridade a criação e manutenção do valor ao cliente, o que, consequentemente, fará com que novas capacidades sejam adicionadas para entregar produtos e serviços que agreguem valor.

As principais afirmações teóricas que relacionam a Orientação para Processos e a Orientação para Clientes ao alinhamento horizontal estão descritas no Quadro 7.

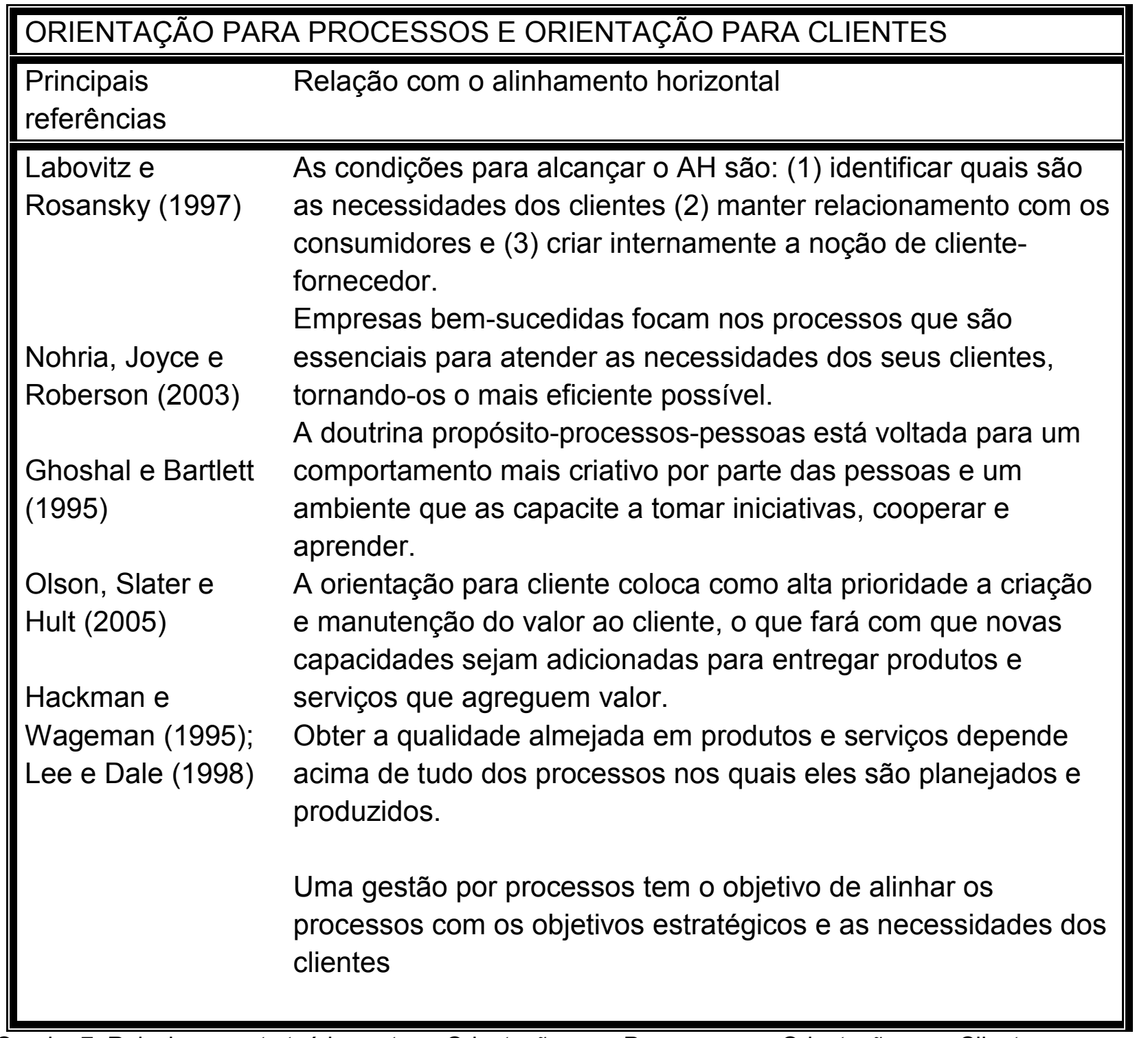

Quadro 7: Relacionamento teórico entre a Orientação para Processos e a Orientação para Clientes e o alinhamento horizontal.

\subsection{Síntese da base teórica}

Uma vez delineada a discussão teórica da pesquisa, esta seção traz a síntese da fundamentação teórica. 
Os principais construtos e variáveis da tese, bem como as principais referências que nortearam a pesquisa podem ser vistas no Quadro 8.

\begin{tabular}{|c|c|}
\hline Variáveis & Principais Fontes \\
\hline $\begin{array}{l}\text { Processo formal de } \\
\text { planejamento }\end{array}$ & $\begin{array}{l}\text { Chan, Sabherwal e Thatcher, } 2006 \\
\text { Kaplan e Norton, 1996, } 2000 \\
\text { Hambrick e Cannella, } 1989 \\
\text { Mintzberg, } 1994 \\
\text { Noble e Mokwa, } 1999 \\
\text { Powell, } 1992\end{array}$ \\
\hline $\begin{array}{l}\text { Envolvimento da média } \\
\text { gerência na formulação da } \\
\text { estratégia }\end{array}$ & $\begin{array}{l}\text { Burgelman,1988 } \\
\text { Campbell e Alexander,1997 } \\
\text { Floyd e Wooldridge,1992b } \\
\text { Hambrick e Cannella,1989 } \\
\text { Mintzberg e Waters, } 1985 \\
\text { Noble e Mokwa, } 1999 \\
\text { Wooldridge e Floyd, } 1990\end{array}$ \\
\hline Consenso Estratégico & $\begin{array}{l}\text { Boyer e Mcdermott, } 1999 \\
\text { Chan, Sabherwal e Thatcher, } 2006 \\
\text { Dess e Priem, } 1995 \\
\text { Floyd e Wooldridge } 1992 \text { a, b } \\
\text { Homburg, Krohmer e Workman Jr., } 1999 \\
\text { Noble e Mokwa, } 1999 \\
\text { Rapert, Velliquette e Garretson, } 2002 \\
\text { Wooldridge e Floyd, } 1990\end{array}$ \\
\hline $\begin{array}{l}\text { Capacidades Gerencias } \\
\text { para a Implementação da } \\
\text { Estratégia }\end{array}$ & $\begin{array}{l}\text { Beer e Eisenstat 1996, } 2000 \\
\text { Benbasat, } 2000 \\
\text { Govindarajan, } 1989 \\
\text { Hambrick e Cannella,1989 } \\
\text { Hitt, Ireland e Palia, } 1982 \\
\text { Noble, } 1999 \\
\text { Noble e Mokwa, } 1999 \\
\text { Powell, } 1992 \\
\text { Rapert, Velliquette e Garretson, } 2002 \\
\end{array}$ \\
\hline $\begin{array}{l}\text { Envolvimento das Pessoas } \\
\text { com a Estratégia }\end{array}$ & $\begin{array}{l}\text { Bartlett e Ghoshal, } 1994 \\
\text { Boswell e Boudreau, } 2001 \\
\text { Fleury e Fleury, } 1997 \\
\text { Gagnon, Jansen e Michael, } 2008 \\
\text { Kaplan e Norton 1992, 1993, 1996, } 2006 \\
\text { Labovitz e Rosansy, 1997 }\end{array}$ \\
\hline
\end{tabular}


conclusão

\begin{tabular}{||l|l||}
\hline Variáveis & Principais Fontes \\
\hline \multirow{3}{*}{ Orientação para clientes } & Kaplan e Norton 1992, 1996 \\
& Labovitz e Rosansky, 1997 \\
& Olson, Slater e Hult, 2005 \\
\hline \multirow{5}{*}{ Orientação para processos } & Davenport e Short, 1990 \\
& Ghoshal e Bartlett, 1995 \\
& Hackman e Wageman, 1995 \\
& Kaplan e Norton 1992, 1996 \\
& Labovitz e Rosansky, 1997 \\
& Lee e Dale, 1998 \\
\hline \multirow{5}{*}{ Desempenho } & Cameron, 1986 \\
& Chakravarthy, 1986 \\
& Combs, Crook e Shook, 2005 \\
& Miles e Snow, 1984 \\
& Snow e Hrebiniak, 1980 \\
& Venkatraman, 1989 a,b \\
& Venkatraman e Ramajunam, 1986, 1987 \\
& Zajac, Kraatz e Bresser, 2000 \\
\hline \multirow{5}{*}{ Incerteza ambiental } & Ginsberg e Venkatraman, 1985 \\
& Kraatz e Zajac, 2001 \\
& Milliken, 1987 \\
& Zajac, Kraatz e Bresser, 2000 \\
\hline Estratégia & Galbraith e Kazanjian, 1986 \\
& Hambrick, 1983, 2003 \\
& Miles e Snow, 2003 \\
& Shortell e Zajac, 1990 \\
\hline \hline
\end{tabular}

Quadro 8 - Síntese da base teórica: principais construtos

Fonte: Elaborado pela autora com base na revisão de literatura

Os estudos que tratam da principal relação estabelecida nesta tese, entre alinhamento interno e desempenho, estão sumarizados no Apêndice C.

No Apêndice $C$ também estão sumarizadas as informações sobre a perspectiva do alinhamento que foi empregada pelos autores para a pesquisa, conforme tratado na seção 2.5.1. Também traz informações sobre as hipóteses formuladas nesses trabalhos e os instrumentos utilizados para mensurar o alinhamento interno e o desempenho organizacional. 


\section{MODELO TEÓRICO, OBJETIVOS E HIPÓTESES DA PESQUISA}

O modelo conceitual da pesquisa tem a finalidade de demonstrar e explicar as relações entre os conceitos que serão operacionalizados na pesquisa empírica (HOYLE; PANTER,1995). Esses autores sugerem uma explanação por meio de uma figura que represente a inter-relação entre os construtos e o uso da terminologia específica da literatura que dá origem à pesquisa, sem necessidade do uso dos conceitos e notações do diagrama de caminhos. Por isso, uma análise mais aprofundada do modelo, do ponto de vista da modelagem de equações estruturais (MEE), será realizada no capítulo posterior.

O modelo de alinhamento interno proposto por esta tese está representado na Figura 3, no qual estão definidas as variáveis componentes do alinhamento vertical e horizontal resultantes da revisão de literatura.

O modelo teórico foi delineado considerando-se o principal objetivo deste trabalho que é o de avaliar o impacto do alinhamento interno sobre o desempenho organizacional.

Sendo o Al o foco da pesquisa, o estudo foi delimitado aos aspectos da implementação da estratégia (Quadro 1). As variáveis organizacionais são examinadas do ponto de vista do seu ajuste internamente à organização, não sendo prioridade examinálas quanto ao ajuste às demandas do ambiente externo.

No entanto, conforme já foi ressaltado na base teórica, o alinhamento externo e interno são complementares e a delimitação proposta se dá em virtude da complexidade e diversidade das variáveis envolvidas, sendo, no entanto, indissociáveis na realidade organizacional.

No modelo de pesquisa adota-se a perspectiva do alinhamento como covariação, definida por Venkatraman (1989a, p.435) como "padrão de covariação ou consistência interna entre um conjunto de variáveis teoricamente relacionadas". Adota-se a perspectiva do alinhamento enquanto covariação entre o alinhamento vertical e o alinhamento horizontal. Entende-se, portanto, que o $\mathrm{AV}, \mathrm{o} \mathrm{AH}$ e o $\mathrm{Al}$ são mais bem explicados pelo coalinhamento entre as variáveis que os compõem.

Na Figura 3, tanto o alinhamento vertical (AV) quanto o alinhamento horizontal (AH) são representados como variáveis latentes $(\mathrm{VL})$ ou construtos de $2^{\mathrm{a}}$ ordem, enquanto o alinhamento interno (Al) apresenta-se como $\mathrm{VL}$ de $3^{\mathrm{a}}$ ordem. 
O AV refere-se ao conjunto de ações necessárias à implementação da estratégia, desde a estratégia formulada até o seu desdobramento por todos os níveis da organização, conforme definido no Quadro 1.

Os fatores envolvidos no AV estão representados pelas seguintes $\mathrm{VL}$ de $1^{\mathrm{a}}$ ordem: abrangência da formulação da estratégia (AF), capacidades gerencias para a implementação da estratégia (CG) e envolvimento das pessoas com a estratégia (EP). $O$ construto abrangência da formulação foi definido como multidimensional, composto pelas variáveis processo formal de planejamento (PFP), envolvimento da média gerência na formulação (EMG) e consenso sobre a estratégia (CE). Essas variáveis não estão representadas na Figura 3 para não complicar a explicação do modelo com variáveis latentes em diferentes níveis, no entanto, o modelo completo pode ser visualizado no Apêndice D.

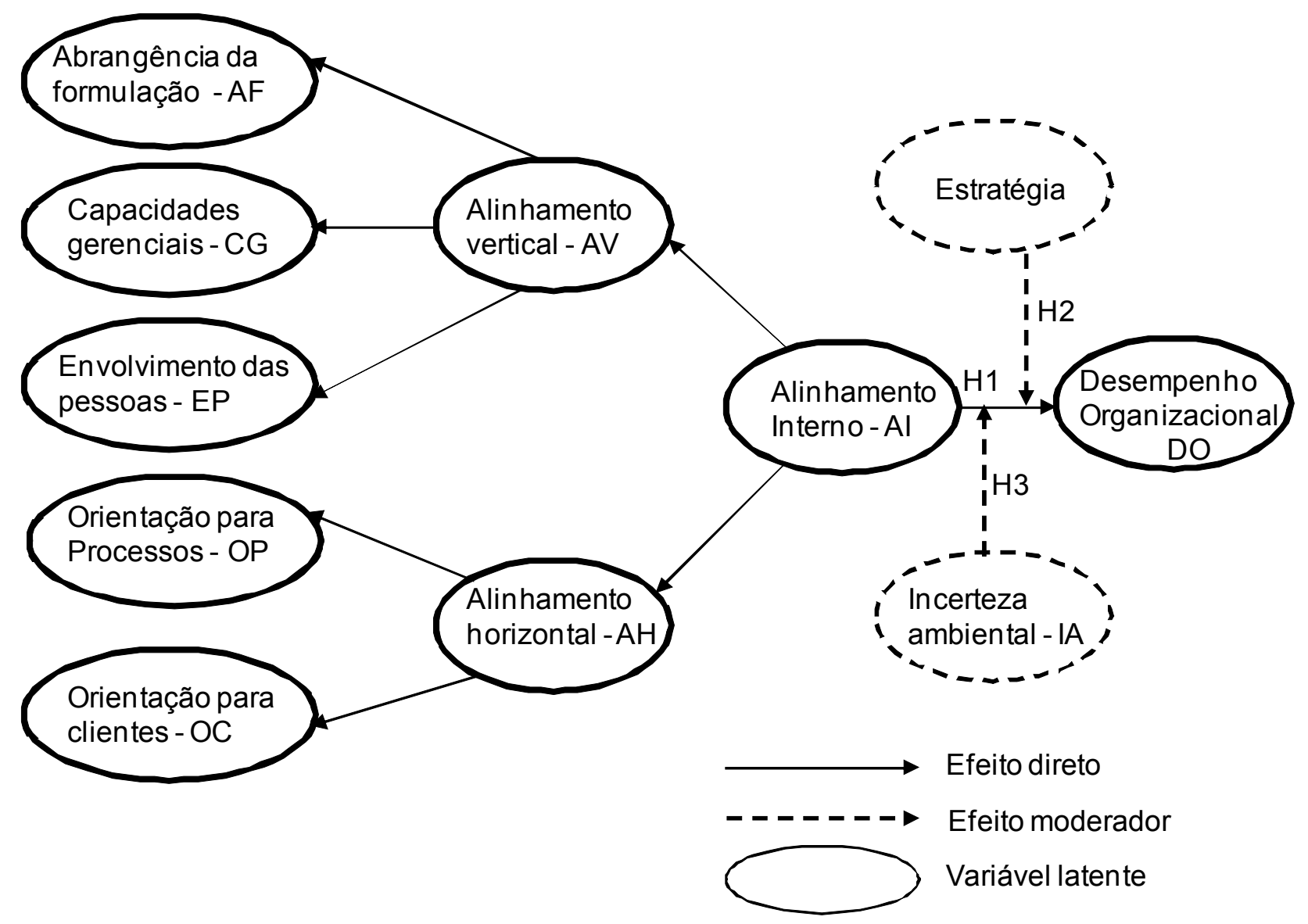

Figura 3 - Modelo teórico da pesquisa

O Alinhamento Horizontal envolve a compreensão das necessidades do cliente e o alinhamento dos processos (interfuncionais) capazes de entregar o que o cliente necessita. As variáveis componentes do $\mathrm{AH}$ são a orientação para processos (OP) e orientação para clientes (OC). 
O Al é representado pelo alinhamento entre as dimensões vertical e horizontal.

O modelo também representa a perspectiva normativa do alinhamento (VENKATRAMAN, 1989a), estabelece-se, portanto, que existe relação entre alinhamento e desempenho organizacional. O DO está representado na Figura 3 como VL de $1^{\text {a }}$ ordem.

O modelo não pode ser entendido sem as relações teóricas que o justificam, dessa forma, na base teórica, ao conceituar o Al também se especifica a sua relação com as dimensões vertical e horizontal, bem como a relação destas com as variáveis latentes que as compõem.

O DO é a variável dependente do estudo e a estratégia e a incerteza ambiental assumem a condição de variável moderadora da relação Al-DO. Essas variáveis e as respectivas hipóteses também estão representadas na Figura 3 e foram assim definidas:

H1: Existe relação significativa e positiva entre o Alinhamento Interno e o Desempenho Organizacional.

H2: O tipo da estratégia influencia a relação alinhamento-desempenho

H3: A força da relação entre alinhamento e desempenho é influenciada pela incerteza ambiental.

A hipótese 1 foi formulada considerando-se que os estudos empíricos anteriores indicam a relação positiva entre alinhamento-desempenho, conforme analisado na seção 2.5 e sumarizado no Apêndice $C$.

Conforme já mencionado na seção 2.6, diferentes resultados têm sido obtidos com relação à estratégia como variável moderadora da relação Al-DO, por isso optou-se por formular a H2 como uma hipótese não-direcional, sem especificar se o efeito da relação é positivo ou negativo (CAVANA; DELAHAYE; SEKARAN, 2001).

O mesmo procedimento foi adotado com relação a H3, conforme analisado na seção 2.7 .

Os objetivos da pesquisa e as hipóteses também estão sumarizados na matriz de amarração, Apêndice E, que representa a estrutura metodológica proposta para a pesquisa. 


\section{PROCEDIMENTOS METODOLÓGICOS}

Neste capítulo são apresentas as técnicas e procedimentos aplicados para o desenvolvimento da pesquisa. Inicia-se pela caracterização da pesquisa e, em seguida, são apresentados os procedimentos utilizados para a análise dos dados. Também são apresentados os critérios que foram utilizados para a validação dos construtos e para a análise dos dados. O capítulo também detalha o processo de construção do instrumento de pesquisa, os procedimentos utilizados para a operacionalização dos construtos e para a definição da amostra.

\subsection{Tipo de Pesquisa}

Considerando-se a estrutura proposta por Creswell (2007), esta tese emprega o método de pesquisa quantitativo, que usa alegações pós-positivistas para o desenvolvimento do conhecimento, as quais se aplicam a este trabalho pela proposição de variáveis específicas, formulação de hipóteses, uso de mensuração e processo de investigação com uso de instrumento predeterminado, com posterior geração e avaliação de dados estatísticos.

Dentre as classificações de pesquisa propostas por Cooper e Schindler (2003) estudo exploratório, descritivo ou causal - este estudo classifica-se como descritivo, que tem como propósito investigar a associação entre diferentes variáveis.

\subsection{Análise dos dados}

\subsubsection{Tratamento preliminar das variáveis}

Em uma primeira etapa, os dados obtidos foram analisados buscando-se caracterizar a amostra quanto ao perfil das empresas e dos respondentes, utilizando-se a análise de frequência das respostas.

Em seguida procedeu-se à análise preliminar dos dados, quanto aos dados omissos (missing values) e dados discrepantes (outliers).

Foram analisadas as frequências absolutas e relativas dos dados omissos para cada variável da pesquisa, buscando-se analisar a sua aleatoriedade ou não. 
O tratamento adotado para os dados omissos foi a substituição de tais variáveis pelo valor médio dos casos válidos dessa variável. Segundo Hair Jr. et al. (2005, p.50), a substituição pela média é um dos métodos mais utilizados e foi utilizado nesta tese para preservar o total da amostra, uma vez que os outros dois métodos, exclude cases listwise e exclude cases pairwise preveem a exclusão de casos.

A existência de dados discrepantes foi verificada na perspectiva univariada, por meio do teste Kolmogorov-Smirnov, que calcula o nível de significância para as diferenças em relação a uma distribuição normal (HAIR JR. et al. 2005, p.78).

Os testes para tratamento preliminar das variáveis e as estatísticas descritivas foram realizados no software SPSS (Statistical Package for Social Sciences), versão 17.0.

\subsubsection{Modelagem de equações estruturais}

Para analisar o modelo da pesquisa especificado no capítulo 3, foi empregada a técnica de Modelagem de Equações Estruturais (MEE), do inglês, Structural Equation Model (SEM).

A Modelagem de Equações Estruturais é uma técnica multivariada que combina aspectos de regressão múltipla (examinando relações de dependência) e análise fatorial (representando conceitos não medidos - fatores - com múltiplas variáveis) para estimar uma série de relações de dependência inter-relacionadas simultaneamente (HAIR JR. et al., 2005, p.468).

Trata-se de uma abordagem estatística abrangente para testar hipóteses envolvendo relações entre construtos observáveis e variáveis latentes (HOYLE, 1995, p.1).

MEE lida não apenas com regressão linear simples ou múltipla, mas com um sistema de equações de regressão, no sentido de que uma mesma variável pode assumir o papel de preditora em uma equação e de critério em outra equação (NACHTIGALL et al., 2003, p.4).

MEE começa com a especificação de um modelo a ser estimado, o qual estabelece a natureza da relação entre as suas variáveis (HOYLE, 1995, p. 2). A representação gráfica dessas relações é realizada por meio do diagrama de caminhos, cujos elementos básicos são as setas e os construtos. 
As variáveis independentes do modelo são chamadas exógenas, pois não são causadas ou preditas por outras variáveis do modelo, e as variáveis dependentes são denominadas endógenas e são preditas por outros construtos endógenos.

MEE exige a definição de dois modelos, o modelo de mensuração e o modelo estrutural, que representam dois conjuntos de equações lineares (HENSELER; RINGLE; SINKOVICS, 2009, p.284).

O modelo de mensuração especifica a relação entre a variável latente e as suas variáveis observáveis ou manifestas e o modelo estrutural especifica a relação entre os construtos não observáveis ou variáveis latentes (HENSELER; RINGLE; SINKOVICS, 2009, p.284).

Dois diferentes tipos de modelo de mensuração podem ser especificados, o modelo reflexivo e o modelo formativo, e esta definição deve estar embasada na teoria.

As principais diferenças entre esses dois tipos de modelo de mensuração podem ser visualizadas no Quadro 9. No modelo reflexivo, a direção de causalidade é do construto latente para os seus indicadores; é esperado que mudanças no construto latente se tornem manifestas nas variáveis observáveis (HENSELER; RINGLE; SINKOVICS, 2009, p.289). Nesse tipo de modelo a inter-relação entre os itens e, em decorrência a consistência interna, são relevantes para a mensuração da confiabilidade (NETMEYER; BEARDEN; SHARMA, 2003, p. 93).

No modelo de mensuração formativo o construto é definido como a combinação dos seus indicadores, a causalidade, portanto, é do indicador para o construto (HENSELER; RINGLE; SINKOVICS, 2009, p.289). Nesse caso, diferenças individuais nos itens explicam diferenças nos construtos. A variável latente é definida como uma pontuação ponderada dos indicadores, sendo que cada um deles representa uma dimensão independente (HENSELER; RINGLE; SINKOVICS, 2009, p. 289). Portanto, a definição de um construto como formativo não implica na necessidade de intercorrelação entre os seus indicadores, a necessidade de consistência interna não é um requisito, e os métodos de confiabilidade baseados na consistência interna não se aplicam (NETMEYER; BEARDEN; SHARMA, 2003, p. 93).

Aplicam-se diferentes métodos de estimação dos modelos de mensuração e estrutural. Sendo que antes da sua escolha é importante distinguir as técnicas de MEE existentes. 


\begin{tabular}{|c|c|c|}
\hline Critério & Modelo formativo & Modelo reflexivo \\
\hline \multirow{4}{*}{ Direção da causalidade } & Dos itens para o construto & Do construto para os itens \\
\hline & $\begin{array}{l}\text { Indicadores são } \\
\text { características do } \\
\text { construto }\end{array}$ & $\begin{array}{l}\text { Indicadores são } \\
\text { manifestações do } \\
\text { construto. }\end{array}$ \\
\hline & $\begin{array}{l}\text { Mudanças nos indicadores } \\
\text { deveriam causar } \\
\text { mudanças no construto }\end{array}$ & $\begin{array}{l}\text { Mudanças nos indicadores } \\
\text { não deveriam causar } \\
\text { mudanças no construto. }\end{array}$ \\
\hline & $\begin{array}{l}\text { Mudanças no construto } \\
\text { não deveriam causar } \\
\text { mudanças nos } \\
\text { indicadores. }\end{array}$ & $\begin{array}{l}\text { Mudanças no construto } \\
\text { deveriam causar } \\
\text { mudanças nos } \\
\text { indicadores. }\end{array}$ \\
\hline \multirow{3}{*}{$\begin{array}{l}\text { Intercambialidade dos } \\
\text { indicadores }\end{array}$} & $\begin{array}{l}\text { Indicadores não precisam } \\
\text { ser intercambiáveis. }\end{array}$ & $\begin{array}{l}\text { Indicadores deveriam ser } \\
\text { intercambiáveis }\end{array}$ \\
\hline & $\begin{array}{l}\text { Indicadores precisam não } \\
\text { ter o mesmo ou similar } \\
\text { conteúdo (não } \\
\text { compartilhar um tema } \\
\text { comum) }\end{array}$ & $\begin{array}{l}\text { Indicadores deveriam ter o } \\
\text { mesmo ou similar } \\
\text { conteúdo (compartilhar um } \\
\text { tema comum). }\end{array}$ \\
\hline & $\begin{array}{l}\text { Eliminando um indicador } \\
\text { pode alterar o domínio } \\
\text { conceitual do construto. }\end{array}$ & $\begin{array}{l}\text { Eliminando um indicador } \\
\text { não altera o domínio } \\
\text { conceitual do construto. }\end{array}$ \\
\hline \multirow[b]{2}{*}{$\begin{array}{l}\text { Covariação entre os } \\
\text { indicadores }\end{array}$} & $\begin{array}{l}\text { Não é necessário que os } \\
\text { indicadores tenham } \\
\text { covariâncias entre si. }\end{array}$ & $\begin{array}{l}\text { É esperado que os } \\
\text { indicadores se } \\
\text { correlacionem. }\end{array}$ \\
\hline & $\begin{array}{l}\text { A mudança em um } \\
\text { indicador não, } \\
\text { necessariamente, tem } \\
\text { relação com a mudança } \\
\text { nos demais indicadores. }\end{array}$ & $\begin{array}{l}\text { A mudança em um } \\
\text { indicador está associada à } \\
\text { mudança em outros } \\
\text { indicadores. }\end{array}$ \\
\hline \multirow[b]{2}{*}{$\begin{array}{l}\text { Rede nomológica dos } \\
\text { indicadores }\end{array}$} & Pode diferir. & Não deveria diferir. \\
\hline & $\begin{array}{l}\text { Não é necessário que os } \\
\text { indicadores tenham os } \\
\text { mesmos antecedentes e } \\
\text { consequências. }\end{array}$ & $\begin{array}{l}\text { Indicadores devem ter os } \\
\text { mesmos antecedentes e } \\
\text { consequências. }\end{array}$ \\
\hline
\end{tabular}

Quadro 9 Características dos modelos reflexivo e formativo

Fonte: Elaborado por Bido (2008) com base em Jarvis, Mackenzie, Podsakoff (2003)

A técnica tradicionalmente mais aplicada é baseada na matriz de covariâncias (MEEBC). A sua origem vem dos criadores do software LISREL, por isso, a própria MEEBC tem sido comumente denominada de LISREL (ZWICKER; SOUZA; BIDO, 2008). 
O método mais utilizado para estimar modelos baseados em covariâncias é o maximum likelihood (ML).

A MEEBC fornece, então, medidas de ajuste do modelo (goodness-of-fit measures) que são obtidas a partir das diferenças existentes entre duas matrizes, a observada e a predita por meio do modelo proposto (por exemplo, o qui-quadrado) (ZWICKER; SOUZA; BIDO, 2008). Ainda segundo os autores, essas medidas permitem avaliar se o modelo tem ou não ajuste aos dados empíricos. Também são fornecidas as cargas fatoriais, que são os coeficientes do modelo de mensuração e os coeficientes referentes ao modelo estrutural (ZWICKER; SOUZA; BIDO, 2008).

Algumas exigências podem restringir a aplicação da MEEBC, como por exemplo, a necessidade de normalidade multivariada dos dados e o tamanho da amostra, que, segundo Hair Jr. et al. (2005, p.284), deveria contemplar uma proporção de 5 a 10 respondentes por parâmetro estimado, sendo que, de fato, os autores recomendam uma amostra de 200 casos.

A outra família de MEE é baseada na estimação via partial least square (PLS).

O método de estimação PLS é baseado em regressão, o seu foco é a explicação da variância e não da covariância (HAIR JR. et al., 2009). Segundo Zwicker, Souza e Bido, 2008, o PLS baseia-se no estudo de um sistema de relações lineares entre variáveis latentes que é resolvido por partes (combinação de construtos teóricos e medidas), uma de cada vez (por isso o partial - parcial), pelo uso de regressões independentes. Ainda segundo os autores, o PLS também gera uma estimativa inicial dos escores da VL, de modo que os fatores tenham variância unitária.

Uma limitação do PLS está na inexistência de uma medida global de ajuste do modelo aos dados empíricos. Dessa forma, embora seja possível determinar em que grau as variáveis dependentes são previstas pelas independentes por meio do coeficiente de determinação $\mathrm{R}^{2}$ calculado, não é possível avaliar se os dados obtidos corroboram ou não as suposições teóricas descritas pelo modelo (ZWICKER; SOUZA; BIDO, 2008). Uma medida de qualidade alternativa é o Goodness-of-Fit (GoF) proposto por Tenenhaus et al. 2005, válido para os casos em que todas as variáveis latentes são reflexivas, que trata-se de um índice de adequação que mede quanto da variância é explicada pelo modelo (ZWICKER SOUZA; BIDO, 2008). Esse e outros índices serão detalhados mais adiante, na seção que trata dos critérios de análise dos dados. 
O PLS tem sido utilizado por um número crescente de pesquisadores em várias disciplinas, como apontam Henseler, Ringle e Sinkovics (2009) e Hulland (1999), sendo que este último trata do uso do PLS na área de administração estratégica.

Henseler, Ringle e Sinkovics (2009) destacam os seguintes benefícios quanto ao uso do PLS:

- não incorre em problemas quando se usa amostras menores;

- pode estimar modelos complexos com muitas variáveis latentes e manifestas;

- processa tanto modelos reflexivos como formativos;

- não há exigência de normalidade na distribuição dos dados.

Hulland (1999) destaca que o nível de rigor e clareza requerido por este método em relação às abordagens metodológicas tradicionais representa um desafio e uma contribuição para alcançar a maturidade no campo de pesquisa sobre estratégia.

\subsubsection{Aplicação e contribuições da MEE neste trabalho}

A MEE, neste trabalho, viabiliza a definição do alinhamento envolvendo a perspectiva holística, ao invés da perspectiva bivariada (VENKATRAMAN; PRESCOTT, 1990), isso devido à possibilidade que a MEE oferece de testar a relação entre múltiplas variáveis latentes.

Adota-se modelo de mensuração reflexivo. O Al é especificado como uma variável latente de $3^{a}$ ordem (Figura 3). A referência para a mensuração do alinhamento é o grau de consistência interna, a inter-relação entre as variáveis latentes que o compõem, o AV e o $\mathrm{AH}$. É esperado que mudanças nos construtos latentes especificados se tornem manifestas nas variáveis observáveis.

O PLS foi adotado como método de estimação do modelo porque admite uma amostra de tamanho menor e devido a não normalidade dos dados coletados, aspectos esses que serão explicados mais adiante.

\subsection{Validação dos construtos e critérios de análise dos dados}

Validação do construto é uma avaliação do grau a que uma medida realmente mede o construto que ela intenciona medir (NETEMEYER; BEARDEN; SHARMA, 2003). Cronbach e Meehl (1955) apontam que demonstrar a validade envolve pelo menos três etapas: (a) especificar a relação teórica entre o construto e a teoria (b) desenvolver 
métodos para medir os construtos teóricos (c) empiricamente testar quão bem os indicadores observáveis mensuram o construto na teoria e testar as hipóteses que relacionam o construto com a teoria (validade nomológica).

Venkatraman e Grant (1986) consideram que, na área de administração estratégica, a validação dos construtos é essencial, sendo que uma das razões é devido à crescente operacionalização quantitativa dos construtos de estratégia, que exige uma avaliação mais sistemática das medidas empregadas para a interpretação adequada dos resultados.

Esses autores assumem que a validação na área de estratégia deve ser realizada por meio (a) da validação de conteúdo, (b) da consistência interna (c) da validade convergente (d) da validade discriminante e (e) da validade nomológica (VENKATRAMAN; GRANT, 1986, p.78).

A validade de conteúdo destina-se a verificar a adequação dos itens do instrumento de medição ao domínio teórico do construto que se intenciona medir (NETEMEYER; BEARDEN; SHARMA, 2003) e deve ser realizada no início do desenvolvimento do instrumento de pesquisa. Recomenda-se que a validação seja realizada por professores especialistas na literatura envolvida, denominados também de juízes.

Outra etapa da validação de conteúdo é também denominada validade de face e deve ser realizada com profissionais que tenham o perfil dos respondentes da pesquisa. Entende-se que a cooperação dos respondentes aumenta à medida que o instrumento parecer fácil de usar, de leitura apropriada, claro, com instruções compreensíveis e formatos de resposta fáceis (NETEMEYER; BEARDEN; SHARMA, 2003, p. 12).

A consistência interna mede a inter-relação entre os itens de uma escala. Itens que compõem uma escala deveriam demonstrar alto grau de consistência interna (NETEMEYER; BEARDEN; SHARMA, 2003, p. 10).

O critério tradicional para medir a consistência interna é o Alfa de Cronbach, desenvolvido por Cronbach e Meehl (1955), que estima a confiabilidade com base nos indicadores conjuntamente. Essa medida tende a subestimar a confiabilidade da consistência interna das variáveis latentes (HENSELER; RINGLE; SINKOVICS, 2009, p. 299). No PLS recomenda-se o uso do indicador de confiabilidade composta (CC) do construto que, assim como no Alfa de Cronbach, também deve ser igual ou superior ao valor de 0,7 (HENSELER; RINGLE; SINKOVICS, 2009, p. 299). 
Validade convergente significa que um conjunto de indicadores representa 0 mesmo construto subjacente e é demonstrado por meio da sua unidimensionalidade (HENSELER; RINGLE; SINKOVICS, p. 299) ou ainda, uma medida possui validade convergente se medidas independentes do mesmo construto convergem, ou estão altamente correlacionadas (NETEMEYER; BEARDEN; SHARMA, 2003, p.77).

Na MEEPLS, aplica-se o critério sugerido por Fornell e Larcker (1981), baseado na variância média extraída (Average Variance Extracted - AVE) do construto (HENSELER; RINGLE; SINKOVICS, 2009, p. 299). Um valor de AVE de pelo menos 0,5 indica validade convergente suficiente, significando que um construto latente é capaz de explicar mais da metade da variância dos seus indicadores.

Para os fatores de primeira ordem, os valores relativos à CC e AVE foram obtidos diretamente do software utilizado para rodar o modelo, o SmartPLS 2.0 (RINGLE; WENDE; WILL, 2005), disponível no site www.smartpls.de. Para os construtos de segunda ordem esses valores foram calculados em planilha eletrônica, seguindo recomendações de Zwicker, Souza e Bido (2008).

Validade discriminante requer que uma medida não se apresente altamente correlacionada com outra da qual ela deveria divergir (NETEMEYER; BEARDEN; SHARMA, 2003). Nesta tese, utilizam-se os critérios sugeridos por Henseler, Ringle e Sinkovics (2009, p. 299). Um dos critérios foi originalmente proposto por Fornell e Larcker (1981). Segundo este critério, uma variável latente deve compartilhar maior variância com seus indicadores do que com qualquer outra variável latente. Para variáveis latentes com indicadores reflexivos, se a raiz quadrada da AVE é maior do que as correlações entre as demais VL quer dizer que há validade discriminante (BIDO, 2008).

O outro critério para medir a validade discriminante é considerado mais liberal (HENSELER; RINGLE; SINKOVICS, 2009, p. 300). Consiste na avaliação das cargas cruzadas - cross-loadings. É esperado que a carga fatorial de cada indicador seja maior em sua variável latente do que em outra VL (HENSELER; RINGLE; SINKOVICS, 2009; BIDO, 2008).

Validade nomológica refere-se ao grau em que as predições realizadas a partir de uma rede teórica são confirmadas (VENKATRAMAN; GRANT, 1986, p.82). Corroborando essa afirmação, Netemeyer, Bearden e Sharma (2003) afirmam que a validade nomológica avalia o grau em que construtos que são teoricamente relacionados também o são empiricamente. Ainda segundo esses autores, a base para a verificação deste tipo 
de validade é a formulação de hipóteses derivadas da teoria e a sua posterior confirmação empírica.

Na MEEPLS a confirmação empírica das hipóteses pode ser verificada pela análise do modelo estrutural, por meio da avaliação do coeficiente de determinação $\mathrm{R}^{2}$ e do índice de ajuste geral do modelo (goodness-of-fit index) (HENSELER; RINGLE; SINKOVICS, 2009; ZWICKER; SOUZA; BIDO, 2008).

$\mathrm{O} \mathrm{R}^{2}$ mede a variância explicada, o grau em que as variáveis dependentes são previstas pelas independentes. Henseler, Ringle e Sinkovics (2009) recomendam a interpretação do $\mathrm{R}^{2}$ segundo o critério estabelecido por Chin (1998), o qual estabelece que valores de $\mathrm{R}^{2}$ de $0.67,0.33$ e 0.19 podem ser interpretados como substancial, moderado e fraco. No entanto, segundo Cohen (1977), a interpretação do $R^{2}$ também deve considerar a maturidade do campo teórico no qual a pesquisa está inserida e, ainda, que o percentual de variância observado seja analisado em comparação com resultados já obtidos. Segundo Cohen (1977), $\mathrm{R}^{2}$ de $0.02,0.15$ e 0.35 podem ser interpretados, respectivamente, como efeito mínimo, médio e forte. Vários autores utilizam essa interpretação, dentre eles, Bido et al. (2010) e Faul, et al. (2007). Esse critério também será utilizado nesta tese, e justificado nas seções que tratam da especificação do tamanho da amostra e de discussão dos resultados.

O Goodness-of Fit (GoF) contempla tanto o modelo de mensuração como o modelo estrutural. É calculado pela média geométrica entre o $\mathrm{R}^{2}$ médio (adequação do modelo estrutural) e a AVE média (adequação do modelo de mensuração) (BIDO, 2008).

Não existem recomendações na literatura a respeito de um valor aceitável para o GoF, no entanto, é possível aceitar 0,5 como valor mínimo, o mesmo estipulado como ponto de corte da validade convergente (AVE) (BIDO, 2008).

O Quadro 10 sintetiza as etapas de validação dos construtos e os critérios aplicados nesta tese. Essas etapas referem-se à avaliação do modelo de mensuração reflexivo adotado neste trabalho. Para modelos formativos, outros critérios devem ser avaliados (ver, por exemplo, Henseler, Ringle e Sinkovics, p. 300-302).

\subsection{Construção do instrumento de coleta de dados}

Esta seção apresenta os procedimentos que foram aplicados para a construção do instrumento de coleta de dados e, em seguida, o conjunto de itens que inicialmente foi proposto e as principais modificações que foram efetuadas. 


\begin{tabular}{|c|c|c|}
\hline Item da validação & Definição & Critério de Avaliação \\
\hline $\begin{array}{l}\text { Validade de } \\
\text { Conteúdo }\end{array}$ & $\begin{array}{l}\text { Verificar a adequação dos } \\
\text { itens do instrumento de } \\
\text { medição ao domínio teórico do } \\
\text { construto. }\end{array}$ & $\begin{array}{l}\text { Validação por professores } \\
\text { especialistas e executivos. }\end{array}$ \\
\hline $\begin{array}{l}\text { Consistência } \\
\text { Interna }\end{array}$ & $\begin{array}{l}\text { Grau de interrelação entre os } \\
\text { itens de uma escala. }\end{array}$ & $\begin{array}{l}\text { Indicador de confiabilidade } \\
\text { composta igual ou superior a } \\
0,7\end{array}$ \\
\hline $\begin{array}{l}\text { Validade } \\
\text { Convergente }\end{array}$ & $\begin{array}{l}\text { Grau em que um conjunto de } \\
\text { indicadores representa o } \\
\text { mesmo construto subjacente e } \\
\text { é demonstrado por meio da } \\
\text { sua unidimensionalidade. }\end{array}$ & $\begin{array}{l}\text { Average Variance Extracted - } \\
\text { AVE } \geq 0,5 .\end{array}$ \\
\hline $\begin{array}{l}\text { Validade } \\
\text { discriminante }\end{array}$ & $\begin{array}{l}\text { Requer que uma medida não } \\
\text { se apresente altamente } \\
\text { correlacionada com outra da } \\
\text { qual ela deveria divergir. }\end{array}$ & $\begin{array}{l}\text { Critério de Fornell-Larcker } \\
\text { (1981): Raiz quadrada da AVE } \\
\text { de uma VL deve ser maior do } \\
\text { que as suas correlações com } \\
\text { as demais VL. } \\
\text { Avaliação das cargas } \\
\text { cruzadas: a carga fatorial de } \\
\text { cada indicador deve ser maior } \\
\text { com sua VL do que com outra } \\
\text { VL. }\end{array}$ \\
\hline $\begin{array}{l}\text { Validade } \\
\text { nomológica }\end{array}$ & $\begin{array}{l}\text { Grau em que as predições } \\
\text { realizadas a partir de uma } \\
\text { rede teórica são confirmadas. }\end{array}$ & $\begin{array}{l}\mathrm{R}^{2}: 0.02,0.15 \text { e } 0.35 \\
\text { (pequeno, médio e grande) } \\
\text { (Cohen, 1977). } \\
\text { GoF (Goodness-of-Fit): } \geq 0,5 \text {. }\end{array}$ \\
\hline
\end{tabular}

Quadro 10 Etapas de validação e critérios adotados

A definição do instrumento de coleta de dados iniciou após a definição do modelo teórico. Inicialmente buscaram-se escalas com indicadores já validadas e que pudessem servir de base para a mensuração dos construtos. A base para esta busca foram os artigos e teses reunidos na revisão de literatura.

No caso dos construtos exógenos que mensuram o alinhamento vertical e horizontal, os trabalhos localizados serviram como referência para a construção de instrumentos de pesquisa originais, que se ajustassem mais adequadamente aos conceitos teóricos propostos para os construtos.

Para a mensuração dos construtos de Incerteza Ambiental e Desempenho Organizacional, utilizou-se instrumentos de pesquisa já validados. Os índices de confiabilidade desses construtos estão demonstrados na seção 4.5 que apresenta os 
instrumentos de pesquisa. Para o levantamento do tipo de estratégia adotado pelas empresas respondentes também foi utilizado um instrumento disponível na literatura. Esses instrumentos já se encontravam traduzidos em teses e dissertações publicadas no Brasil, respectivamente nos trabalhos de Sokoloski (2007), Fernandes Filho (2003) e Blageski Jr. (2008).

Os instrumentos originais e os traduzidos foram submetidos à avaliação por uma tradutora bilíngue, aplicando-se, dessa forma, uma adaptação da "técnica bilíngue" que é uma das técnicas de tradução de instrumentos para aplicação em diferentes culturas, proposta por Cha, Kim e Erlen (2007, p.388).

Não existe uma regra rígida que defina a quantidade de itens em uma escala nesta fase inicial de construção, mas uma quantidade maior é preferível, desde que não comprometa a cooperação dos respondentes (NETEMEYER; BEARDEN; SHARMA, 2003, p.102). Essa recomendação foi levada em consideração, bem como a possibilidade da posterior redução de itens na escala, por recomendação dos especialistas ou quando da realização dos testes estatísticos.

Dessa forma, o construto inicialmente formulado com menor número de itens foi consenso estratégico ( 5 itens) e os demais tinham de 7 a 8 itens.

Os instrumentos originais desta pesquisa foram submetidos à validação de conteúdo por professores especialistas.

Participaram desse processo sete professores doutores, sendo dois da Universidade de São Paulo (USP): um do Departamento de Engenharia de Produção (EPRO) da Escola Politécnica e outro da Faculdade de Economia e Administração (FEA), um professor da Fundação Getúlio Vargas (FGV) e quatro da Universidade Presbiteriana Mackenzie (UPM), ligados a núcleo de estudos que desenvolvem pesquisas voltadas à competitividade e estratégia.

A validação foi conduzida por email com três professores e, pessoalmente, com outros dois.

Os especialistas receberam um documento com os objetivos da pesquisa, o modelo teórico e o instrumento de pesquisa com a definição dos respectivos construtos que deveriam ser mensurados. Eles também foram informados quanto ao tipo e número de itens na escala.

Foi solicitado aos especialistas que avaliassem cada um dos itens do questionário quanto à sua clareza e representatividade para a mensuração do construto. Seguindo um procedimento proposto por Netemeyer, Bearden e Sharma (2003, p.103), solicitou-se que 
a representatividade dos itens fosse avaliada utilizando a seguinte escala: (1) não representativo, (2) representativo e (3) claramente representativo. Os itens classificados na média como representativos seriam mantidos.

Também foi solicitado que quaisquer outras recomendações que pudessem contribuir para o refinamento do instrumento de pesquisa fossem registradas.

$\mathrm{Na}$ prática nem todos os avaliadores utilizaram a escala de representatividade, e preferiram fazer por escrito os seus comentários.

As recomendações dos especialistas foram analisadas e o questionário foi revisado.

Dando prosseguimento ao processo de validação de conteúdo, o instrumento de pesquisa revisado foi submetido à validação por executivos, com o objetivo de verificar o quanto o instrumento parecia válido aos respondentes. Foi solicitado aos executivos que preenchessem o questionário e avaliassem a facilidade de resposta, a compreensão da redação das perguntas, a disponibilidade de informações para as respostas, a apresentação e descrição de como as questões devem ser respondidas e a ordem de apresentação das perguntas.

Quatro executivos participaram desse processo, sendo um Diretor de Controle e Gestão da área de Construção Civil, um Diretor Financeiro (CFO) da área automotiva, uma Gerente Administrativa Financeira da área de Construção Civil e um Gerente de Contas da área bancária.

O Apêndice $F$ apresenta todo o processo de validação de conteúdo, desde a primeira versão até a versão final. As sugestões feitas por especialistas e executivos, as análises e modificações introduzidas nos questionários estão devidamente detalhadas.

A versão final do questionário (ver Apêndice $G$ ) foi dividida em cinco seções.

A primeira seção foi constituída dos fatores envolvidos no alinhamento, contendo tanto os fatores do AV quanto do $\mathrm{AH}$, em um total de sete subseções e 38 assertivas. Apesar do grande número de assertivas na seção, optou-se por não subdividi-la para que o respondente pudesse utilizar a mesma coerência de raciocínio e a mesma escala para as suas respostas. Esse critério foi utilizado para as outras seções, independentemente do número de assertivas.

Na seção 1 foi empregada a escala likert com graus de concordância de 1 a 5 , sendo: (1) discordo totalmente, (2) mais discordo que concordo, (3) não concordo, nem discordo, (4) mais concordo que discordo e (5) concordo totalmente. 
A seção 2 foi constituída do construto de incerteza ambiental, com a utilização da mesma escala anterior.

A seção 3 foi composta das assertivas do construto desempenho organizacional. Foi empregada a escala likert com graus de concordância de 1 a 5, sendo: (1) desempenho muito inferior, (2) desempenho inferior, (3) desempenho similar, (4) desempenho superior e (5) desempenho muito superior.

A quarta seção foi constituída das assertivas sobre estratégia. Foi empregada a escala nominal. A exemplo das pesquisas anteriores, não se atribuiu nome às estratégias, que foram denominadas Tipo 1, Tipo 2 e Tipo 3, correspondendo, respectivamente a Prospectores, Defensores e Analisadores. Aos respondentes foi solicitado assinalar a descrição que melhor definia a orientação estratégica da sua unidade de negócio.

A quinta seção foi constituída do perfil da empresa e do respondente. Foram introduzidos campos para que o respondente pudesse indicar o nome da empresa (não obrigatório), o setor de atuação, os anos da empresa desde a sua fundação, o número de funcionários e o porte da empresa em termos de faturamento. Quanto ao perfil do respondente foram solicitados o nome, o cargo e o e-mail (todos campos de preenchimento não obrigatório).

Ao final foi solicitado aos respondentes que indicassem outros executivos para participar da pesquisa.

O questionário foi disponibilizado para preenchimento on-line no período entre agosto e novembro de 2010, com acesso pelo link http://www.pro.poli.usp.br/alinhamento. Também foram coletadas respostas em papel.

A seção seguinte demonstra o processo de operacionalização dos construtos, incluindo o seu significado teórico, as assertivas inicialmente propostas e a sua origem, de acordo com a revisão de literatura.

\subsection{Definição dos construtos e dos instrumentos de pesquisa}

Para uma medida de um construto latente ter relevância esse precisa estar fundamentado em uma estrutura teórica e a demonstração da sua validade envolve, dentre outras etapas, especificar a relação teórica entre o construto e a teoria (NETEMEYER; BEARDEN; SHARMA, 2003).

Nesta tese a relação teórica com cada construto está especificada na fundamentação teórica e sumarizada nos Quadros 3 a 7, sendo que o Quadro 3 identifica 
estudos empíricos que contemplam os construtos selecionados e os Quadros 5 a 8 estabelecem a relação teórica de cada construto com o $\mathrm{AV}$ ou $\mathrm{AH}$.

A relação teórica preestabelecida serviu de base para a proposição do modelo teórico especificado no capítulo 3 , sendo que a definição dos construtos especificados e o processo de construção dos instrumentos de pesquisa serão detalhados a seguir.

\subsubsection{Definição dos Construtos do Alinhamento Vertical}

A abrangência da formulação da estratégia compreende os aspectos da formulação que vão influenciar o processo de implementação. O construto foi definido como multidimensional, composto pelas variáveis processo formal de planejamento, envolvimento da média gerência na formulação e consenso sobre a estratégia.

\subsubsection{Processo Formal de Planejamento}

O construto PFP pretende mensurar a existência de um processo de planejamento estratégico estabelecido. Identifica-se o construto nas pesquisas de Chan, Sabherwal e Thatcher (2006) e Powell (1992) - ver Quadro 3.

Entende-se que a existência de um processo formal de planejamento está associada à formalização da estratégia, para posterior comunicação aos responsáveis pela implementação e acompanhamento da sua realização.

As assertivas são originais desta pesquisa, mas baseadas em atributos desenvolvidos por Miller (1987) e identificados no trabalho de Powell (1992) e podem ser visualizadas no Quadro 11.

As sugestões para aperfeiçoamento do instrumento vieram dos especialistas e foram, principalmente, no sentido de incluir a palavra "formalizados" para caracterizar os planos, objetivos e metas.

\subsubsection{Envolvimento da média gerência na formulação (EMG)}

O construto EMG pretende mensurar em que medida a média gerência participa da formulação da estratégia e do processo posterior de implementação.

Identifica-se o construto nos trabalhos de Chan, Sabherwal e Thatcher (2006), Noble e Mokwa (1999) e Wooldridge e Floyd (1990) - ver Quadro 3. 


\section{PROCESSO FORMAL DE PLANEJAMENTO (PFP)}

PFP1 As ações da nossa empresa são baseadas mais em planos formais do que na intuição.

PFP2 Nós temos objetivos de longo prazo conhecidos por todos os gerentes. PFP3 Nós temos metas específicas, de curto prazo, conhecidas por todos os gerentes.

PFP4 Nós temos um sistema de planejamento estratégico mais amplo, para o desenvolvimento da organização como um todo.

PFP5 Nós temos um plano estratégico formalizado para os próximos 12 meses. PFP6 Nós temos um executivo ou equipe encarregada da elaboração de um plano estratégico formal.

PFP7 Nós mantemos encontros gerenciais regulares para discutir a estratégia como um todo.

Quadro 11 Assertivas inicialmente propostas para o construto Processo Formal de Planejamento

A participação da média gerência na formulação é no sentido de alinhar as ações organizacionais com as intenções estratégicas, por meio da intervenção na estrutura, pessoas e sistemas. Ajuda a determinar o seu papel na implementação e tem relação com o comprometimento individual em relação aos objetivos e metas estabelecidos.

As assertivas podem ser visualizadas no Quadro 12 e são originais desta pesquisa, mas baseadas em atributos desenvolvidos por Noble e Mokwa (1999).

ENVOLVIMENTO DA MÉDIA GERÊNCIA NA FORMULAÇÃO (EMG)

EMG1 Os superiores e a média gerência trabalham juntos para decidir exatamente o que deve ser feito pela média gerência para implementar a estratégia.

EMG2 Os gerentes tomam conhecimento da estratégia praticamente no momento em que são chamados à implementá-la. $(R)$

EMG3 Durante a implementação da estratégia os gerentes sentem que podem

procurar os seus superiores para sugerir mudanças nas atividades de implementação.

EMG4 Minhas responsabilidades na implementação da estratégia não são tão significativas.(R)

EMG5 Eu desempenho um papel relativamente menor na implementação das estratégias. (R)

EMG6 Eu sou uma das pessoas chave no time de implementação da estratégia.

Quadro 12 Assertivas inicialmente propostas para o construto envolvimento da média gerência $(\mathrm{R})$ escala reversa

A validação de conteúdo levou a alterar a palavra "gerentes" por "média gerência" e também a alterações na redação das assertivas. 
Por recomendação dos executivos, que consideraram que as "frases no negativo confundem", as assertivas em escala reversa foram redigidas positivamente. Esta medida foi adotada para as assertivas em todos os construtos.

A assertiva EMG5 foi excluída por ter o mesmo significado da EMG4 e por ter sido um dos itens considerado de menor relevância pelos especialistas.

\subsubsection{Consenso estratégico (CE)}

O construto CE envolve o quanto a média gerência compreende e dá suporte à estratégia da empresa.

Identifica-se o construto sendo empregado nos trabalhos de Noble e Mokwa (1999) e Rapert, Velliquette, Garretson (2002) - ver Quadro 3.

Entende-se que o grau de consenso entre os executivos sobre as prioridades estratégicas pode influenciar a execução da estratégia. O comprometimento com a estratégia depende do quanto os gestores percebem que a estratégia está alinhada aos interesses da organização.

Os instrumentos de mensuração propostos por Noble e Mokwa (1999) nos construtos "Importância percebida sobre a estratégia" e "Comprometimento estratégico" foram adaptados para esta pesquisa e as assertivas inicialmente propostas estão demonstradas no Quadro 13.

\section{CONSENSO ESTRATÉGICO (CE)}

CE1 A estratégia em ação não tem tanta importância para a realização da missão da empresa. $(\mathrm{R})$

CE2 É esperado que o sucesso da estratégia em ação afete significantemente o futuro da empresa.

CE3 Eu não penso que a estratégia em ação esteja de acordo com os interesses mais relevantes da empresa.(R)

CE4 Eu não posso dizer que possa apoiar esta estratégia. $(R)$

CE5 Eu pessoalmente sinto que os objetivos relacionados à estratégia em ação são apropriados.

Quadro 13 Assertivas inicialmente propostas para o construto consenso estratégico

(R) escala reversa

Por sugestão dos especialistas, na assertiva 2 foi incluído o termo "positivamente" para deixar claro o impacto que se espera da estratégia. 
Outras sugestões, tais como, usar o termo "visão" ao invés de estratégia na CE1, falta de especificação do que seja "sucesso" (CE2) e especificar de que tipo de objetivo se trata na CE5, não foram acatadas, sendo que a justificativa encontra-se no Apêndice $F$.

Conforme já mencionado anteriormente, as assertivas em escala reversa foram excluídas.

\subsubsection{Capacidades Gerencias (CG) para a Implementação da Estratégia}

O construto CG abrange as capacidades que são requeridas dos executivos para promover o alinhamento estratégico.

O instrumento para mensuração do conceito (Quadro 14) é original desta pesquisa, mas baseado em atributos desenvolvidos por Hitt e Ireland (1985) - (HI) e empregado por Carmeli e Tishler (2004) e Noble e Mokwa (1999) - (NM) quanto ao suporte da alta direção para a implementação.

\section{CAPACIDADES GERENCIAIS (CG)}

CG1 A alta administração desenvolve e comunica um senso de direção, um propósito único a ser compartilhado por todos os membros da organização. (HI) CG2 Nossos executivos buscam o consenso entre opiniões conflitantes, a melhoria da coordenação e a efetiva colaboração, buscam gerar o entusiasmo e motivação suficientes para melhorar o desempenho. (HI)

CG3 Nós fazemos uso crescente da tomada de decisão compartilhada entre os executivos sênior e a média gerência. (HI)

CG4 Nossos executivos promovem os ajustes que são necessários para a implementação da estratégia, incluindo a alocação de recursos. *

CG5 Nossos executivos buscam identificar os obstáculos à implementação da estratégia, antes de colocá-la em ação.*

CG6 É notório que a alta direção quer que a estratégia em ação seja um sucesso. (NM)

CG7 Eu não consigo perceber que a alta direção se importe tanto com a estratégia em ação. (R) (NM)

Quadro 14 Assertivas inicialmente propostas para o construto capacidades gerenciais

* assertivas desenvolvidas pela pesquisadora

(R) escala reversa

Como resultado da validação decidiu-se adotar o termo "alta administração" para o nível hierárquico de diretoria e "média gerência" para o nível de decisão intermediário. A palavra "executivos" foi adotada para fazer referência a ambos os níveis hierárquicos. 
A alternativa CG6 foi excluída por ter sido considerada irrelevante, uma vez que a alta direção sempre vai querer que a estratégia seja um sucesso.

\subsubsection{Envolvimento das Pessoas (EP) com a estratégia}

O construto EP abrange as condições necessárias para promover um comportamento orientado para o alcance dos objetivos e metas, tais como, cultura e sistema de recompensas e reconhecimento.

Identifica-se o conceito nos construtos "comprometimento organizacional", no trabalho de Noble e Mokwa (1999), no construto "relações de trabalho e cultura organizacional" proposto por Carmeli e Tishler (2004) e no construto "pessoas" proposto por Labovitz e Rosansky (1997) - ver Quadro 3.

O instrumento para mensuração do conceito encontra-se no Quadro 15 e é original desta pesquisa, mas baseado em atributos desenvolvidos por Carmeli e Tishler (2004) (CT) e Labovitz e Rosansky (1997) - (LR).

\section{ENVOLVIMENTO DAS PESSOAS (EP)}

EP1 Existe um alto envolvimento dos empregados nos processos, decisões e sua implementação. (CT)

EP2 Os empregados são comprometidos e mantém um alto senso de responsabilidade para com a organização. (CT)

EP3 As metas da organização são claras e compreendidas por todos os seus membros. (CT)

EP4 A organização como um todo trabalha arduamente para alcançar suas metas.

(CT)

EP5 Os departamentos ou grupos de trabalho são recompensados por seu desempenho como um time. (LR)

EP6 A organização recompensa o desempenho individual dos seus funcionários.

(LR)

EP7 Os líderes regularmente reconhecem o bom desempenho dos seus funcionários. (LR)

EP8 Os conhecimentos e habilidades que as pessoas precisam são definidos a partir da estratégia da organização. (LR)

Quadro 15 Assertivas inicialmente propostas para o construto envolvimento das pessoas com a estratégia

Expressões de exagero, tais como "arduamente" e em duplicidade, como "claras e compreendidas" foram revisadas para evitar viés na resposta. 


\subsubsection{Definição dos Construtos do Alinhamento Horizontal}

\subsubsection{Orientação para processos (OP)}

O construto OP pretende medir o quanto os departamentos e funções são permeáveis no sentido de permitir o cumprimento dos objetivos estratégicos, principalmente quanto ao atendimento das necessidades dos clientes.

Identifica-se o conceito Orientação para Processos no trabalho de Labovitz e Rosansky (1997).

Utiliza-se o questionário proposto por esses autores e demonstrado no Quadro16.

\section{ORIENTAÇÃO PARA PROCESSOS (OP)}

OP1 Nossos gerentes/supervisores cuidam de como o trabalho é feito, bem como dos seus resultados.

OP2 Nós revisamos nosso processo de trabalho regularmente para saber o quanto ele está funcionando.

OP3 Quando alguma coisa sai errada nós corrigimos as causas apontadas para evitar que aquele problema ocorra novamente.

OP4 Os processos são revisados para assegurar que eles contribuem para alcançar as metas estratégicas.

Quadro 16 Assertivas propostas para o construto orientação para processos

Fonte: adaptado de Labovitz e Rosansky (1997)

O mesmo foi validado na tese de Collins (2002) e apresentou um ajuste adequado em todos os índices considerados, sendo que Goodness of Fit Index (GFI), Non-normed Fit Index (NNFI) e Comparative Fit (CFI), apresentam-se como 0.80 ou acima, e o Alpha de Cronbach é de 0.70 .

Esse mesmo questionário foi utilizado em pesquisas realizadas por Prieto e Carvalho $(2006,2010)$ já tendo sido, nessas ocasiões, traduzido para o português e para o inglês.

Mesmo com a decisão de utilizar um instrumento já validado, esse foi submetido à análise quando da validação de conteúdo e não foram feitas sugestões que ocasionassem a sua alteração. 


\subsubsection{Orientação para Clientes (OC)}

O construto OC pretende medir o quanto departamentos e funções seguem uma direção única, estabelecida estrategicamente, no sentido de atender e antecipar as necessidades do cliente.

Identifica-se o conceito no trabalho de Labovitz e Rosansky (1997) e no trabalho de Olson, Slater e Hult (2005).

As assertivas são originárias do trabalho de Narver, Slater e MacLachlan (2004) e adaptadas por Olson, Slater e Hult (2005) e estão demonstradas no Quadro 17.

\section{ORIENTAÇÃO PARA CLIENTES (OC)}

OC1 Nós continuamente tentamos descobrir necessidades adicionais dos nossos consumidores que eles ainda não perceberam.

OC2 Nós incorporamos soluções em nossos produtos e serviços para necessidades dos consumidores ainda não atendidas.

OC3 Nós discutimos sobre como os consumidores usam nossos produtos ou serviços. OC4 Nós inovamos mesmo sob o risco de tornar nossos próprios produtos obsoletos.

OC5 Trabalhamos intimamente com pessoas chave do mercado que tentam reconhecer as necessidades dos clientes meses ou até mesmo anos antes que a maioria do mercado possa reconhecê-las.

Quadro 17 Assertivas propostas para o construto orientação para clientes

Após a validação de conteúdo, foram introduzidas modificações na redação das assertivas, por exemplo, trocar a palavra "tentar" por "buscar" (OC1), a OC3 foi redigida de forma mais direta, excluindo a palavra "discutimos", assim como a OC5, excluindo o termo "intimamente". A assertiva OC4 foi excluída porque a afirmação não se aplicaria a todas as empresas da amostra, por exemplo, àquelas que são seguidoras ou que praticam a estratégia de baixo custo.

\subsubsection{Definição do Construto de Desempenho Organizacional}

Neste estudo adota-se a perspectiva normativa do alinhamento, que estabelece a relação entre o alinhamento e o DO (VENKATRAMAN, 1989a; VENKATRAMAN, 1989b). A medida do desempenho geral da organização é estabelecida como variável dependente do estudo. 
Optou-se pela mensuração perceptual do desempenho, considerando-se os argumentos expostos no trabalho de Venkatraman e Ramanujam (1987) quanto a sua eficácia em relação à medição objetiva tradicional.

Por isso, sabendo-se que a média gerência seria o público respondente do estudo, houve uma preocupação, na seleção do instrumento de pesquisa, de que os dados necessários fossem de conhecimento desse público, uma vez que, quando se trata de desempenho, algumas informações podem ser restritas a alta gerência.

O instrumento selecionado foi originalmente proposto por Venkatraman (1989b), que propôs a mensuração do desempenho de unidades de negócio em termos de crescimento de mercado e lucratividade. Chan et al. (1997) ampliaram as dimensões inicialmente propostas para quatro: crescimento de mercado, lucratividade, inovação de produtos e serviços e reputação da empresa, mensuradas com um total de 8 itens.

O instrumento foi aplicado nos estudos da área de alinhamento de sistemas de informação desenvolvidos por Chan et al. (1997), Chan, Sabherwal e Thatcher (2006) e Sabherwal e Chan, 2001. Esses últimos realizaram uma análise fatorial com os 8 itens, e eingenvalue $\geq 1$, resultando em dois fatores com variância explicada de 46.4 e 14.3. No entanto, o scree plot sugeria a possibilidade de um fator, por isso o instrumento foi adotado pelos autores. A confiabilidade do instrumento foi mensurada por Sabherwal e Chan (2001), utilizando o Alpha de Cronbach, com resultado de 0,83, acima de 0,7 como é especificado.

Dessa forma, o instrumento selecionado não mensura um critério único, conforme recomenda Chacravarthy (1986), e também foi previamente testado quanto à dimensionalidade dos seus indicadores, como recomendam Combs, Crook e Shook (2005) e Venkatraman e Ramanujam (1986).

Foi utilizada a mesma escala empregada por Sabherwal e Chan (2001), a escala likert de 1 a 5 . Foi solicitado aos respondentes que comparassem o desempenho de suas empresas com a média dos concorrentes do setor, sendo (1) desempenho muito inferior até (5) desempenho muito superior.

O Quadro 18 apresenta as assertivas propostas. 
Desempenho organizacional

D01 Reputação perante os maiores segmentos de clientes.

DO2 Frequência no lançamento de novos produtos ou serviços.

DO3 Retorno sobre o investimento.

DO4 Lucratividade.

DO5 Desenvolvimentos tecnológicos e/ou outras inovações nas operações.

D06 Qualidade de produto.

D07 Ganhos de participação no mercado.

D08 Crescimento do faturamento.

Quadro 18 Assertivas para o construto desempenho organizacional

Fonte: elaborado pela autora com base em Sabherwal e Chan (2001).

\subsubsection{Definição do construto estratégia}

Um dos objetivos propostos para esse estudo é avaliar o impacto da estratégia sobre a relação AI-DO. Nesse sentido, esta tese utiliza a tipologia de Miles e Snow (2003) para classificação do tipo de estratégia.

Propõe-se utilizar o instrumento desenvolvido por McDaniel e Kolari (1987) e empregado em pesquisas envolvendo o conceito de alinhamento por Rhee (1998) e Rhee e Mehra (2006). O instrumento pode ser visualizado no Quadro 19 e consiste de três parágrafos descrevendo as características de cada tipo de estratégia.

\section{Estratégia}

Escolha dentre as descrições a seguir aquela que mais se aproxima da orientação estratégica da sua empresa, quando comparada com outras empresas do mesmo segmento de atuação.

Note que nenhuma das opções listadas é essencialmente boa ou ruim. Mesmo que duas ou mais afirmações pareçam se encaixar com a realidade da empresa, pedimos que seja assinalada apenas 1 (uma) alternativa.

\begin{tabular}{|l|l|}
\hline \multirow{2}{*}{ Tipo 1 1} & $\begin{array}{l}\text { A minha empresa procura identificar e manter um nicho restrito de } \\
\text { produto ou serviço que seja seguro e relativamente estável. A empresa } \\
\text { tende a oferecer um número mais limitado de produtos ou serviços do } \\
\text { que os competidores e busca proteger seu mercado pela oferta de } \\
\text { qualidade mais alta, serviço superior ou preços mais baixos, etc. } \\
\text { Normalmente, a empresa não é a líder nos desenvolvimentos em seu } \\
\text { segmento de atuação, pois tende a ignorar as mudanças que não } \\
\text { tenham uma influência direta nas atuais áreas de operação. Ao invés } \\
\text { disso, se concentra em fazer o melhor trabalho possível em um nicho } \\
\text { restrito de atuação. }\end{array}$ \\
\hline
\end{tabular}

continua 
conclusão

\begin{tabular}{|l}
\hline Estratégia \\
\hline Escolha dentre as descrições a seguir aquela que mais se aproxima da orientação \\
estratégica da sua empresa, quando comparada com outras empresas do mesmo \\
segmento de atuação. \\
Note que nenhuma das opções listadas é essencialmente boa ou ruim. Mesmo que \\
duas ou mais afirmações pareçam se encaixar com a realidade da empresa, pedimos \\
que seja assinalada apenas 1 (uma) alternativa.
\end{tabular}

Quadro 19 Assertivas propostas para o construto estratégia

Fonte: Elaborado por Rhee (1998) com base em McDaniel e Kolari (1987)

A exemplo das pesquisas anteriores, não se atribui nome às estratégias, que são denominadas Tipo 1, Tipo 2 e Tipo 3, correspondendo, respectivamente a Prospectores, Defensores e Analisadores.

Aos respondentes foi solicitado assinalar a descrição que melhor definia a orientação estratégica da sua unidade de negócio.

Vale ressaltar que o instrumento original incluía também a estratégia dos Reatores, não contemplada nesta pesquisa, conforme descrito na seção 2.6, por ser considerado que reatores não têm uma estratégia claramente definida ou estão em transição para definir-se por um dos outros três tipos (SLATER; OLSON, 2000). 


\subsubsection{Definição do construto incerteza ambiental}

Neste estudo adota-se o conceito de incerteza como fenômeno perceptual, em termos de como o gestor avalia os riscos do ambiente externo e as suas consequências para os resultados organizacionais. Entende-se que a percepção da incerteza ambiental está diretamente relacionada à decisão de efetuar ou não mudanças na estratégia e promover o ajuste das variáveis internas.

O instrumento de mensuração que será empregado neste trabalho é originário de Miller e Droge (1986) e foi utilizado nos trabalhos de Carmeli e Tishler (2004) e Waldman et al. (2001). O instrumento consiste de quatro itens (ver Quadro 20). As respostas são em uma escala de cinco pontos com um intervalo variando de "discordo fortemente" (1) até "concordo fortemente" (5). O Alpha de Cronbach para o instrumento é de 0.63, segundo Waldman et al. (2001). Uma vez que a confiabilidade está abaixo do valor indicado de 0,7, no instrumento final (Apêndice $G$ ) foi acrescentada a assertiva IA5.

\section{PERCEPÇÃO DA INCERTEZA AMBIENTAL (IA)}

Como você caracterizaria o ambiente externo no qual a sua empresa atua? Ao avaliar os aspectos do ambiente que são relevantes, por favor considere não apenas os aspectos econômicos, mas também sociais, políticos e tecnológicos.

IA1 Muito dinâmico, mudando rapidamente nas dimensões técnicas, econômicas e culturais.

IA2 Muito arriscado, um passo em falso pode significar a quebra da empresa.

IA3 Caracterizado por rápida expansão, com crescimento dos mercados tradicionais e surgimento de outros novos.

IA4 Muito estressante, exigente, hostil, difícil de sobreviver.

Quadro 20 - Assertivas para o construto de incerteza ambiental

Fonte: Carmeli e Tishler (2004) elaborado com base em Miller e Droge (1986)

Os demais itens do questionário correspondem ao perfil da empresa e do respondente e podem ser visualizados na versão final do questionário (Apêndice $G$ ).

\subsection{Amostra}

O público respondente da pesquisa foi definido como Diretores, média gerência ou executivos que atuam dando suporte à alta gerência. Entende-se que esses profissionais estão habilitados para responder sobre assuntos relacionados à implementação de estratégias de negócios. 
A amostra foi definida por conveniência, portanto, as unidades amostrais (empresas) e os participantes foram escolhidos pela facilidade de acesso e pela disponibilidade em responder a pesquisa.

A despeito do uso de uma amostra não probabilística, buscou-se atender os requisitos necessários para um teste de análise multivariada que utiliza a MEEPLS.

Uma regra geralmente aceita quando a estimação dos parâmetros é via PLS foi proposta por Barclay, Higgins e Thompson (1995), segundo a qual o tamanho da amostra deverá ser (a) igual ou maior a dez vezes o número de indicadores da escala com o maior número de indicadores formativos; ou (b) dez vezes o número de caminhos direcionados para um determinado construto do modelo estrutural, no caso aquele que tiver mais setas de chegada (HENSELER; RINGLE; SINKOVICS, 2009, p.292).

No entanto, Henseler, Ringle e Sinkovics (2009) advertem que essa regra pode levar a inaceitáveis baixos níveis de poder estatístico.

Por isso, nesse trabalho, o tamanho da amostra foi determinado utilizando-se o software G*Power 3.0 (FAUL; et al., 2007), disponível no site http://www.psycho.uniduesseldorf.de/abteilungen/aap/gpower3/. Para o seu cálculo foram considerados o nível de significância estatística ( $\alpha$ ) ou probabilidade de ocorrência do erro tipo I, o nível de poder requerido $(1-\beta)$, o tamanho do efeito e a quantidade de variáveis preditoras (máximo de setas chegando ao modelo estrutural).

Foram especificados um nível de significância de 5\%, um nível de poder requerido de $80 \%$, considerando-se recomendações de Hair Jr. et al. (2005), um tamanho do efeito de 15\%, seguindo indicações de Cohen (1977) e três variáveis preditoras, resultando em uma amostra de 77 respondentes para cada um dos três grupos estratégicos.

Dados esses parâmetros, o $\mathrm{R}^{2}$ previsto para o modelo é de $13 \%$, o que, segundo Cohen (1977, p.80) implica em um médio poder de explicação da variável dependente pelas independentes. 


\section{APRESENTAÇÃO E ANÁLISE DOS RESULTADOS}

Neste capítulo serão apresentados os resultados da pesquisa, considerando-se os procedimentos metodológicos especificados no capítulo anterior. Em uma primeira etapa serão relatados os procedimentos quanto à análise preliminar das variáveis e quanto à análise descritiva dos dados. Nesta etapa serão apresentados e analisados os dados que caracterizam a amostra e, em seguida, a análise de frequência das variáveis, por construtos do modelo. Também foi realizado o teste não paramétrico da mediana de Mood, disponível no software Minitab, versão 16, para verificar a significância estatística dos dados coletados em relação aos tipos estratégicos. Os resultados estão detalhados no Apêndice $\mathrm{H}$ e também serão relatados por construto, para os casos em que tiver sido detectada a significância estatística.

Em uma segunda etapa serão relatados os dados da modelagem de equações estruturais, iniciando-se pela análise do modelo de mensuração e, em seguida, a análise do modelo estrutural. As devidas validações dos construtos serão relatadas.

Para aprofundar as análises, os escores das VL produzidos pela estimação via PLS para os 125 casos, foram analisados em comparação com dados do perfil da amostra. De antemão vale ressaltar que as análises, no que tange aos tipos estratégicos, são limitadas devido ao tamanho da amostra. No entanto, são bastante úteis para esclarecer os resultados obtidos, e identificar as lacunas no estudo proposto.

\subsection{Análise preliminar das variáveis}

A análise de outliers não revelou variáveis com desvio padrão acima de 3. O menor desvio padrão foi 0,815 encontrado na variável DO1 - Reputação perante os maiores segmentos de consumidores e o maior desvio padrão foi 1,365 , encontrado na variável PFP6 - Nós temos um executivo ou equipe encarregada da elaboração de um plano estratégico formal.

As variáveis com maior número de dados omissos são CGI6 e DO4, ambas com 2 dados omissos, representando $1,6 \%$ da amostra e estratégia com 3 dados omissos, representando $2,4 \%$ da amostra.

Evidencia-se que a ocorrência de dados omissos é aleatória, não comprometendo a análise dos dados. 
No teste de aderência à normalidade todas as variáveis apresentaram níveis de significância < 0,05, o que levou à rejeição de $\mathrm{H}_{\mathrm{o}}$, portanto, a distribuição das variáveis não é normal.

\subsection{Caracterização da amostra}

Foram coletadas 129 respostas, das quais 4 foram descartadas, uma por preenchimento incorreto dos dados e as outras 3 por perfil inadequado dos respondentes, resultando em 125 empresas.

A Tabela 1 apresenta o perfil das empresas constantes da amostra por área de atuação e porte.

Tabela 1 - Caracterização da amostra por área de atuação e porte

\begin{tabular}{lccccc}
\hline \hline \multirow{2}{*}{\multicolumn{1}{c}{ Área de Atuação }} & \multicolumn{5}{c}{ Porte } \\
\cline { 2 - 5 } & Pequena & Média & Grande & \multirow{2}{*}{ Total } & \\
\hline Ativ. Financeiras e de Seguros & 1 & 0 & 25 & 26 & 20,8 \\
Alimentos & 0 & 0 & 3 & 3 & 2,4 \\
Automação, tecnologia & 0 & 1 & 1 & 2 & 1,6 \\
Automotiva & 0 & 5 & 6 & 11 & 8,8 \\
Bens de capital & 0 & 1 & 1 & 2 & 1,6 \\
Bens de consumo & 1 & 1 & 1 & 3 & 2,4 \\
Comércio & 1 & 0 & 0 & 1 & 0,8 \\
Construção Civil & 0 & 0 & 5 & 5 & 4,0 \\
Cosméticos & 0 & 1 & 0 & 1 & 0,8 \\
Educação & 0 & 0 & 2 & 2 & 1,6 \\
Eletrônica, eletroeletrônica & 1 & 0 & 5 & 6 & 4,8 \\
Embalagem & 1 & 1 & 2 & 4 & 3,2 \\
Energia & 0 & 0 & 1 & 1 & 0,8 \\
Farmacêutica & 0 & 3 & 2 & 5 & 4,0 \\
Ferramentas de Corte & 0 & 1 & 0 & 1 & 0,8 \\
Papel e Celulose & 0 & 0 & 2 & 2 & 1,6 \\
Plástico, derivados & 0 & 2 & 1 & 3 & 2,4 \\
Química, Petroquímica & 0 & 2 & 4 & 6 & 4,8 \\
Saúde & 0 & 1 & 4 & 5 & 4,0 \\
Serv. Informática, internet & 1 & 2 & 0 & 3 & 2,4 \\
Serviços & 2 & 10 & 9 & 21 & 16,8 \\
Telecomunicação, comunicação & 1 & 1 & 5 & 7 & 5,6 \\
Não Identificou & 0 & 0 & 0 & 5 & 4,0 \\
\hline TOTAL & 9 & 32 & 79 & 125 & \\
\hline \% & 7,2 & 25,6 & 63,2 & 100,0 & 100,0 \\
\hline \hline
\end{tabular}


A classificação se deu com base em critérios estabelecidos pelo BNDES - Banco Nacional de Desenvolvimento Econômico e Social, os quais são aplicados também pelo SEBRAE - Serviço de Brasileiro de Apoio às Micro e Pequenas Empresas, quanto ao número de empregados e receita.

Predominam as empresas de grande porte (63,2\%) seguidas pelas empresas de médio porte $(25,6 \%)$ o que é bastante adequado para a pesquisa em questão, pois existe uma tendência de que empresas maiores façam uso de instrumentos formalizados de gestão, como é o caso do planejamento formal da estratégia.

Predominam as empresas que atuam em atividades financeiras e de seguros $(20,8 \%)$, serviços $(16,8 \%)$ e automotiva $(8,8 \%)$. Quanto ao tipo de estratégia (ver Tabela 2), do total de 125 casos da amostra, 23 empresas $(18,4 \%)$ são do tipo prospectora, 62 $(49,6 \%)$ são do tipo analisadora e 37 (29,6\%) defensoras.

Tabela 2 - Caracterização da amostra por tipo de estratégia e área de atuação

\begin{tabular}{lll}
\multirow{2}{*}{ Área de Atuação } & Estratégia & Notal \\
\cline { 2 - 3 } & Prospectora Analisadora Defensora Identificada &
\end{tabular}

\begin{tabular}{|c|c|c|c|c|c|}
\hline Ativ. Financeiras e de Seguros & 4 & 13 & 8 & & 25 \\
\hline Alimentos & & 2 & 1 & & 3 \\
\hline Automação, tecnologia & & 1 & 1 & & 2 \\
\hline Automotiva & 1 & 7 & 3 & & 11 \\
\hline Bens de capital & & 1 & 1 & & 2 \\
\hline Bens de consumo & 1 & 2 & & & 3 \\
\hline Comércio & & 1 & & & 1 \\
\hline Construção Civil & & 2 & 3 & & 5 \\
\hline Cosméticos & & 1 & & & 1 \\
\hline Educação & 1 & & 1 & & 2 \\
\hline Eletrônica, eletroeletrônica & 1 & 5 & & & 6 \\
\hline Embalagem & 1 & & 4 & & 5 \\
\hline Energia & & & 1 & & 1 \\
\hline Farmacêutica & 1 & 3 & 1 & & 5 \\
\hline Ferramentas de Corte & & 1 & & & 1 \\
\hline Papel e Celulose & & 1 & 1 & & 2 \\
\hline Plástico, derivados & 2 & 1 & & & 3 \\
\hline Química, Petroquímica & 2 & 2 & 2 & & 6 \\
\hline Saúde & 2 & & 2 & 1 & 5 \\
\hline Serv. Informática, internet & & 3 & & & 3 \\
\hline Serviços & 4 & 9 & 6 & 2 & 21 \\
\hline Telecomunicação, comunicação & 1 & 5 & 1 & & 7 \\
\hline Não identificada & 2 & 2 & 1 & & 5 \\
\hline TOTAL & 23 & 62 & 37 & 3 & 125 \\
\hline$\%$ & 18,4 & 49,6 & 29,6 & 2,4 & 100,0 \\
\hline
\end{tabular}


A Tabela 3 apresenta o perfil dos respondentes por cargo e área de atuação. Predominam os Diretores e Gerentes $(47,2 \%)$, seguidos por Supervisores, Coordenadores ou Analistas (31,2\%). A amostra foi considerada adequada, uma vez que o perfil dos respondentes é caracterizado por pessoas que ocupam cargos tradicionalmente caracterizados pelo envolvimento com a implementação da estratégia.

Tabela 3 - Perfil dos respondentes por cargo e área de atuação

\begin{tabular}{|c|c|c|c|c|c|c|}
\hline \multirow[b]{2}{*}{ Área de Atuação } & \multicolumn{5}{|c|}{ Cargo } & \multirow[b]{2}{*}{ Total } \\
\hline & $\begin{array}{l}\text { Presidente/ } \\
\text { Vice- } \\
\text { Presidente }\end{array}$ & $\begin{array}{l}\text { Diretor/ } \\
\text { Gerente }\end{array}$ & $\begin{array}{c}\text { Supervisor/ } \\
\text { Coord. } \\
\text { Analista }\end{array}$ & Consultor & $\mathrm{NI}$ & \\
\hline Ativ. Fin. de Seguros & 2 & 9 & 13 & 1 & 1 & 26 \\
\hline Alimentos & 0 & 0 & 0 & 0 & 3 & 3 \\
\hline Automação, tecnologia & 0 & 0 & 2 & 0 & 0 & 2 \\
\hline Automotiva & 1 & 7 & 2 & 0 & 1 & 11 \\
\hline Bens de capital & 0 & 1 & 1 & 0 & 0 & 2 \\
\hline Bens de consumo & 0 & 2 & 0 & 0 & 1 & 3 \\
\hline Comércio & 0 & 1 & 0 & 0 & 0 & 1 \\
\hline Construção Civil & 0 & 3 & 1 & 0 & 1 & 5 \\
\hline Cosméticos & 0 & 1 & 0 & 0 & 0 & 1 \\
\hline Educação & 0 & & 2 & 0 & 0 & 2 \\
\hline $\begin{array}{l}\text { Eletrônica, } \\
\text { eletroeletrônica }\end{array}$ & 0 & 3 & 3 & 0 & 0 & 6 \\
\hline Embalagem & 0 & 2 & 0 & 0 & 2 & 4 \\
\hline Energia & 0 & & 0 & 0 & 1 & 1 \\
\hline Farmacêutica & 0 & 5 & 0 & 0 & 0 & 5 \\
\hline Ferramentas de Corte & 0 & 1 & 0 & 0 & 0 & 1 \\
\hline Papel e Celulose & 0 & 2 & 0 & 0 & 0 & 2 \\
\hline Plástico, derivados & 0 & 2 & 1 & 0 & 0 & 3 \\
\hline Química, Petroquímica & 0 & 1 & 4 & 0 & 1 & 6 \\
\hline Saúde & 0 & 2 & 2 & 0 & 1 & 5 \\
\hline Informática, internet & 0 & 3 & 0 & 0 & 0 & 3 \\
\hline Serviços & 1 & 11 & 5 & 2 & 2 & 21 \\
\hline Telecom/comunicação & 0 & 3 & 3 & 0 & 1 & 7 \\
\hline Não Identificou (NI) & 0 & 0 & 0 & 0 & 5 & 5 \\
\hline Total & 4 & 59 & 39 & 3 & 15 & 125 \\
\hline$\%$ & $\overline{3,2}$ & 47,2 & 31,2 & 2,4 & 12,0 & 100,0 \\
\hline
\end{tabular}

$\mathrm{NI}$ - não identificou

Os escores das VL para os 125 casos, produzidos pela estimação via PLS, foram analisados com apoio do microsoft office Excel, buscando-se identificar como a relação alinhamento-desempenho se manifesta em relação ao perfil da amostra. 
Verifica-se que do total de empresas, 54 (43,2\%) apresentam escore de alinhamento negativo. Analisando-se individualmente esses casos, 32 deles (59,2\%) também apresentam escore de DO negativo. No outro extremo, do total da amostra, 18 $(14,4 \%)$ apresentam escore de alinhamento maior ou igual a 1. A análise individual desses casos demonstra que $6(33,0 \%)$ deles também são casos de DO maior ou igual a 1.

\subsection{Análise descritiva dos dados}

Os dados serão apresentados e analisados por construto, iniciando-se pelos construtos que compõem o alinhamento vertical, em seguida os construtos do alinhamento horizontal e, finalmente, os construtos desempenho organizacional e incerteza ambiental.

Para facilitar a interpretação dos dados as frequências das assertivas foram agrupadas em três graus de concordância, sendo: discordância (menores ou iguais a dois), neutralidade (igual a três) e concordância (maiores ou iguais a quatro).

\subsubsection{Análise descritiva dos construtos do alinhamento vertical}

\subsubsection{Processo formal de planejamento (PFP)}

A Tabela 4 apresenta os dados do construto PFP. A moda e a mediana indicam que

Tabela 4 Estatísticas descritivas do construto Processo Formal de Planejamento

\begin{tabular}{|c|c|c|c|c|c|c|c|c|c|}
\hline \multirow{2}{*}{ Assertiva } & \multirow{2}{*}{ Moda } & \multirow{2}{*}{ Mediana } & \multirow{2}{*}{$\begin{array}{l}\text { Amostra } \\
\text { efetiva }\end{array}$} & \multicolumn{2}{|c|}{ Discordância } & \multicolumn{2}{|c|}{ Neutralidade } & \multicolumn{2}{|c|}{ Concordância } \\
\hline & & & & Freq. & $\%$ & Freq. & $\%$ & Freq. & $\%$ \\
\hline PFP1 & 4 & 4 & 125 & $\overline{9}$ & 7,2 & 17 & 13,6 & 99 & 79,2 \\
\hline PFP2 & 4 & 4 & 125 & 28 & 22,4 & 14 & 11,2 & 83 & 66,4 \\
\hline PFP3 & 5 & 4 & 124 & 13 & 10,5 & 12 & 9,7 & 99 & 79,8 \\
\hline PFP4 & 4 & 4 & 124 & 23 & 18,5 & 19 & 15,3 & 82 & 66,1 \\
\hline PFP5 & 5 & 4 & 125 & 23 & 18,4 & 17 & 13,6 & 85 & 68,0 \\
\hline PFP6 & 5 & 4 & 125 & 26 & 20,8 & 15 & 12,0 & 84 & 67,2 \\
\hline PFP7 & 4 & 4 & 125 & 27 & 21,6 & 22 & 17,6 & 76 & 60,8 \\
\hline
\end{tabular}

a amostra é composta por empresas que possuem um processo formal de planejamento, o que também é condizente com o porte destas empresas, sendo $63,2 \%$ 
grandes empresas e 25,6\% médias empresas. É esperado que tais empresas possuam instrumentos formais de gestão.

A concordância com as assertivas propostas indica que faz parte desse processo a formalização de objetivos e metas que são conhecidos pela média gerência. Destaque-se a assertiva $1(79,2 \%)$ que avalia se as ações da empresa são baseadas mais em planos formais do que na intuição.

A discordância em relação às assertivas $2(22,4 \%)$ e 7 (21,6\%) são indícios de problemas de comunicação ou da baixa participação da média gerência no processo estratégico.

No teste da mediana de Mood a assertiva PFP5 apresentou diferença significativa para 99\% de confiança ( $p$-valor $=0,002$ ). Esse resultado corrobora a afirmação teórica de que analisadores e defensores (medianas 5 e 4, respectivamente) tendem a fazer uso mais intensivo de um plano estratégico formalizado do que prospectores (mediana 3), que o utilizam de maneira mais ampla e para a orientação na solução de problemas contingentes.

\subsubsection{Envolvimento da média gerência na formulação}

Conforme pode ser visualizado na Tabela 5, a análise das frequências aponta que $74,4 \%$ dos respondentes (assertiva 4) e 75,2\% (assertiva 5) concordam que são relevantes as atividades da média gerência para a implementação da estratégia.

Tabela 5 Estatísticas descritivas do construto Envolvimento da Média Gerência na Formulação

\begin{tabular}{cccccccccc}
\hline \multirow{2}{*}{ Assertiva } & Moda & Mediana & Amostra & \multicolumn{3}{c}{ Discordância } & \multicolumn{3}{c}{ Neutralidade } \\
& & & efetiva & Freq. & $\%$ & Freq. & $\%$ & Freq. & $\%$ \\
EMG1 & 4 & 4 & 125 & 22 & 17,6 & 24 & 19,2 & 79 & 63,2 \\
EMG2 & 4 & 3 & 125 & 29 & 23,2 & 35 & 28,0 & 61 & 48,8 \\
EMG3 & 4 & 4 & 125 & 28 & 22,4 & 19 & 15,2 & 78 & 62,4 \\
EMG4 & 4 & 4 & 125 & 16 & 12,8 & 16 & 12,8 & 93 & 74,4 \\
EMG5 & 4 & 4 & 125 & 12 & 9,6 & 19 & 15,2 & 94 & 75,2 \\
\hline \hline
\end{tabular}

As primeiras três assertivas medem a participação da média gerência na definição das atividades de implementação. Nesse sentido, 48,8\% dos respondentes afirmam tomar conhecimento da estratégia antes da sua implementação. No entanto, 63,2\% trabalham juntos com seus superiores para decidir o que será feito em termos das atividades de implementação e $62,4 \%$ sentem que podem procurar os seus superiores para sugerir mudanças nestas atividades quando a estratégia já está em ação. Esses percentuais 
podem ser indicativos de que a média gerência tem maior participação na definição das atividades de implementação do que na definição da estratégia em si.

\subsubsection{Consenso estratégico (CE)}

As estatísticas descritivas do construto CE são apresentadas na Tabela 6 . $O$ percentual de concordância com relação às assertivas em geral indica que os respondentes consideram que a estratégia em ação em suas empresas é relevante para a realização da missão da empresa e pode afetar positivamente o futuro dos negócios.

Tabela 6 Estatísticas descritivas do construto Consenso Estratégico

\begin{tabular}{|c|c|c|c|c|c|c|c|c|c|}
\hline \multirow{2}{*}{ Assertiva } & \multirow{2}{*}{ Moda } & \multirow{2}{*}{ Mediana } & \multirow{2}{*}{$\begin{array}{c}\text { Amostra } \\
\text { efetiva }\end{array}$} & \multicolumn{2}{|c|}{ Discordância } & \multicolumn{2}{|c|}{ Neutralidade } & \multicolumn{2}{|c|}{ Concordância } \\
\hline & & & & Freq. & $\%$ & Freq. & $\%$ & Freq. & $\%$ \\
\hline CE1 & 5 & 4 & 125 & 9 & 7,2 & 13 & 10,4 & 103 & 82,4 \\
\hline CE2 & 5 & 5 & 125 & 9 & 7,2 & 4 & 3,2 & 112 & 89,6 \\
\hline CE3 & 5 & 4 & 125 & 13 & 10,4 & 6 & 4,8 & 106 & 84,8 \\
\hline CE4 & 4 & 4 & 125 & 15 & 12,0 & 14 & 11,2 & 96 & 76,8 \\
\hline
\end{tabular}

Comparando-se esse resultado com os do construto anterior (EMG) verifica-se que os índices de concordância dos respondentes são maiores com relação às assertivas do construto $C E$, do que com relação às assertivas do construto anterior, EMG, o que indica que a média gerência tem apoiado e dado suporte à estratégia, ainda que não participe, na mesma medida, da sua formulação.

No entanto, quando questionados se pessoalmente estão de acordo com os objetivos relacionados à estratégia em ação (CE4), o grau de concordância é menor do que com relação às outras assertivas que mensuram a opinião dos respondentes sobre a importância da estratégia para os negócios em si. Esse resultado corrobora a afirmação da literatura de que existe relação entre a participação da média gerência na formulação e o seu comprometimento individual com objetivos e metas organizacionais (NOBLE; MOKWA, 1999).

\subsubsection{Capacidades gerenciais para implementação da estratégia}

Os dados da Tabela 7 demonstram que a alta direção evidencia que se importa com a estratégia em ação (CGI6 - 77,2\%). No entanto, os índices de concordância em relação aos demais itens, que abordam capacidades específicas da alta administração no 
que tange à implementação, são menores, entre 50 e 60\%, sendo inclusive menores se comparados aos outros construtos relatados até o momento.

Tais capacidades envolvem a comunicação de um senso de direção único (CGI1$59,2 \%$ ), busca de consenso, melhoria da coordenação e colaboração efetiva entre os executivos (CGI2 - 54,8\%), tomada de decisão compartilhada entre a alta e média gerência (CGI3 - 52,0\%) ajuste dos recursos (CGI4 - 59,2\%), e remoção dos obstáculos à implementação da estratégia (CGI5 - 60,8\%).

Tabela 7 Estatísticas descritivas do construto Capacidades Gerenciais para Implementação

\begin{tabular}{|c|c|c|c|c|c|c|c|c|c|}
\hline \multirow{2}{*}{ Assertiva } & \multirow{2}{*}{ Moda } & \multirow{2}{*}{ Mediana } & \multirow{2}{*}{$\begin{array}{c}\text { Amostra } \\
\text { efetiva }\end{array}$} & \multicolumn{2}{|c|}{ Discordância } & \multicolumn{2}{|c|}{ Neutralidade } & \multicolumn{2}{|c|}{ Concordância } \\
\hline & & & & Freq. & $\%$ & Freq. & $\%$ & Freq. & $\%$ \\
\hline CG1 & 4 & 4 & 125 & 25 & 20,0 & 26 & 20,8 & 74 & 59,2 \\
\hline CG2 & 4 & 4 & 124 & 28 & 22,6 & 28 & 22,6 & 68 & 54,8 \\
\hline CG3 & 4 & 4 & 125 & 32 & 25,6 & 28 & 22,4 & 65 & 52,0 \\
\hline CG4 & 4 & 4 & 125 & 27 & 21,6 & 24 & 19,2 & 74 & 59,2 \\
\hline CG5 & 4 & 4 & 125 & 28 & 22,4 & 21 & 16,8 & 76 & 60,8 \\
\hline CG6 & 4 & 4 & 123 & 17 & 13,8 & 11 & 8,9 & 95 & 77,2 \\
\hline
\end{tabular}

A assertiva CG6 apresentou diferença significativa para 95\% de confiança ( $p$-valor $=0,012)$ em relação à variável moderadora tipo de estratégia.

Os defensores consideram que a alta direção deixa ainda mais evidente (mediana 5) do que prospectores e analisadores (mediana 4) que se importa com a estratégia em ação. De acordo com Miles e Snow (2003), o uso de sistemas administrativos, no caso de Defensores, tem relação com a capacidade de controle e com prerrogativas de decisão de acordo com o nível hierárquico, o que, comparando-se com os resultados, deve fazer com que a alta direção deixe evidente o seu interesse no cumprimento das determinações estratégicas.

\subsubsection{Envolvimento das Pessoas com a Estratégia}

Conforme indica a Tabela 8, a concordância mais elevada dos respondentes com as assertivas $2(63,2 \%)$ e $4(68,5 \%)$ apontam que eles consideram que existe um comprometimento das pessoas com as organizações e suas metas.

No entanto, os índices de discordância e neutralidade com relação à assertiva 1 (47,6\%), envolvimento dos empregados nos processos e sua implementação, são indicativos de que ainda é possível, na opinião dos respondentes, obter maior envolvimento das pessoas. 
Tabela 8 Estatísticas descritivas do construto Envolvimento das pessoas com a estratégia

\begin{tabular}{cccccccccc}
\hline \hline \multirow{2}{*}{ Assertiva } & \multirow{2}{*}{ Moda } & Mediana & Amostra & \multicolumn{3}{c}{ Discordância } & \multicolumn{5}{c}{ Neutralidade } & \multicolumn{3}{c}{ Concordância } \\
\cline { 5 - 10 } & & & efetiva & Freq. & $\%$ & Freq. & $\%$ & Freq. & $\%$ \\
\hline EP1 & 4 & 4 & 124 & 26 & 21,0 & 33 & 26,6 & 65 & 52,4 \\
EP2 & 4 & 4 & 125 & 17 & 13,6 & 29 & 23,2 & 79 & 63,2 \\
EP3 & 4 & 3 & 125 & 33 & 26,4 & 38 & 30,4 & 54 & 43,2 \\
EP4 & 4 & 4 & 124 & 15 & 12,1 & 24 & 19,4 & 85 & 68,5 \\
EP5 & 4 & 3 & 125 & 35 & 28,0 & 28 & 22,4 & 62 & 49,6 \\
EP6 & 4 & 4 & 125 & 38 & 30,4 & 23 & 18,4 & 64 & 51,2 \\
EP7 & 3 & 3 & 125 & 33 & 26,4 & 37 & 29,6 & 55 & 44,0 \\
EP8 & 4 & 3 & 125 & 34 & 27,2 & 33 & 26,4 & 58 & 46,4 \\
\hline \hline
\end{tabular}

Corroboram essa afirmação os índices de discordância e neutralidade com relação à assertiva $3(56,8 \%)$, que indicam que as metas da organização não são adequadamente compreendidas por todos os seus membros. Esses resultados encontram respaldo na literatura, que afirma que a compreensão dos objetivos organizacionais pelos funcionários está diretamente relacionada à sua contribuição para o alcance dos mesmos (BOSWELL; BOUDREAU, 2001).

Os resultados empíricos relatados quanto ao envolvimento das pessoas (assertivas 1 a 3), quando comparados aos resultados das assertivas $5(49,6 \%)$ e $6(51,2 \%)$, corroboram a afirmação teórica de que há relação entre envolvimento pessoal e sistema de recompensas.

\subsubsection{Análise descritiva dos construtos do alinhamento horizontal}

\subsubsection{Orientação para processos}

A análise da Tabela 9 evidencia que os gestores cuidam de como o trabalho é feito e dos seus resultados $(64,8 \%)$ e que quando alguma coisa sai errada a causa do problema é corrigida para evitar nova ocorrência $(73,6 \%)$.

Tabela 9 Estatísticas descritivas do construto Orientação para Processos

\begin{tabular}{cccccccccc}
\hline \multirow{2}{*}{ Assertiva } & \multirow{2}{*}{ Moda } & \multirow{2}{*}{$\begin{array}{c}\text { Amediana } \\
\text { efetiva }\end{array}$} & & \multicolumn{3}{c}{ Discordância } & \multicolumn{4}{c}{ Neutralidade } & \multicolumn{3}{c}{ Concordância } \\
\cline { 5 - 10 } & & & & Freq. & $\%$ & Freq. & $\%$ & Freq. & $\%$ \\
\hline OP1 & 4 & 4 & 125 & 15 & 12,0 & 29 & 23,2 & 81 & 64,8 \\
OP2 & 4 & 4 & 125 & 24 & 19,2 & 37 & 29,6 & 64 & 51,2 \\
OP3 & 4 & 4 & 125 & 16 & 12,8 & 17 & 13,6 & 92 & 73,6 \\
OP4 & 4 & 4 & 125 & 24 & 19,2 & 30 & 24,0 & 71 & 56,8 \\
\hline \hline
\end{tabular}


No entanto, a frequência de respostas quanto à revisão mais proativa dos processos é menor, tanto com relação à assertiva $2(51,2 \%)$ que trata de uma revisão periódica dos processos independentemente da ocorrência de problemas, como com relação à assertiva 4, no que tange à revisão dos processos para assegurar que eles contribuem para alcançar as metas estratégicas $(56,8 \%)$.

\subsubsection{Orientação para clientes}

Em relação às frequências registradas no construto orientação para clientes (Tabela 10), verifica-se que os respondentes concordam que suas empresas buscam descobrir as necessidades adicionais dos consumidores e incorporá-las aos produtos e serviços (67,2\% - assertivas 1 e 2$)$, assim como buscam influenciar o modo como os consumidores usam os produtos e serviços da empresa (OC3, 64\%).

Tabela 10 Estatísticas descritivas do construto Orientação para Clientes

\begin{tabular}{|c|c|c|c|c|c|c|c|c|c|}
\hline \multirow{2}{*}{ Assertiva } & \multirow{2}{*}{ Moda } & \multirow{2}{*}{ Mediana } & \multirow{2}{*}{$\begin{array}{l}\text { Amostra } \\
\text { efetiva }\end{array}$} & \multicolumn{2}{|c|}{ Discordância } & \multicolumn{2}{|c|}{ Neutralidade } & \multicolumn{2}{|c|}{ Concordância } \\
\hline & & & & Freq. & $\%$ & Freq. & $\%$ & Freq. & $\%$ \\
\hline$\overline{\mathrm{OC} 1}$ & 4 & 4 & 125 & 17 & 13,6 & 24 & 19,2 & 84 & 67,2 \\
\hline OC2 & 4 & 4 & 125 & 16 & 12,8 & 25 & 20,0 & 84 & 67,2 \\
\hline OC3 & 4 & 4 & 125 & 15 & 12,0 & 30 & 24,0 & 80 & 64,0 \\
\hline OC4 & 4 & 4 & 125 & 27 & 21,6 & 24 & 19,2 & 74 & 59,2 \\
\hline
\end{tabular}

No entanto, a concordância é menor no que se refere a buscar conhecer as necessidades dos clientes com maior antecedência, meses ou anos, antes da maioria do mercado $(59,2 \%)$. Esse resultado, analisado em conjunto com a menor proatividade verificada na análise do construto anterior, pode estar relacionado ao perfil da amostra, composto por $79,2 \%$ de analisadores e defensores, que estão mais voltados para a manutenção do mercado.

Destaque-se que em todas as assertivas relacionadas à orientação para clientes há diferença significativa, segundo teste da mediana de Mood, em relação à variável moderadora tipo de estratégia. Nas assertivas OC1 ( $p$-valor $=0,028)$, OC3 ( $p$-valor $=$ $0,045)$ e OC4 ( $p$-value $=0,050$ ) existem diferenças significativas para $95 \%$ de confiança e para OC2 ( $p$-valor $=0,001)$ para $99 \%$. O grau de concordância é maior para as empresas classificadas como tipos de estratégia analisadores e defensores (mediana 4) do que as do tipo prospectores (mediana 3). 
Esse resultado não encontra respaldo na teoria (MILES; SNOW, 2003), uma vez que é esperado que prospectores, em comparação com os outros dois tipos estratégicos, possuam maior orientação para clientes, uma vez que a chave para o seu sucesso está no desenvolvimento e colocação de novos produtos no mercado.

\subsubsection{Análise descritiva do construto desempenho organizacional}

Em relação ao construto desempenho organizacional (Tabela 11), os menores índices de concordância referem-se às assertivas que medem a inovação: frequência no lançamento de novos produtos ou serviços (49,6\%) e desenvolvimentos tecnológicos e/ou outras inovações nas operações $(48,8 \%)$. Esses resultados podem ter relação com o tipo de estratégia que prevalece na amostra, como já analisado em construtos anteriores.

Tabela 11 Estatísticas descritivas do construto Desempenho Organizacional

\begin{tabular}{|c|c|c|c|c|c|c|c|c|c|}
\hline \multirow{2}{*}{ Assertiva } & \multirow{2}{*}{ Moda } & \multirow{2}{*}{ Mediana } & \multirow{2}{*}{$\begin{array}{c}\text { Amostra } \\
\text { efetiva }\end{array}$} & \multicolumn{2}{|c|}{ Discordância } & \multicolumn{2}{|c|}{ Neutralidade } & \multicolumn{2}{|c|}{ Concordância } \\
\hline & & & & Freq. & $\%$ & Freq. & $\%$ & Freq. & $\%$ \\
\hline D01 & 4 & 4 & 125 & 15 & 12,0 & 29 & 23,2 & 81 & 64,8 \\
\hline DO2 & 4 & 3 & 125 & 22 & 17,6 & 41 & 32,8 & 62 & 49,6 \\
\hline DO3 & 4 & 4 & 125 & 13 & 10,4 & 35 & 28,0 & 77 & 61,6 \\
\hline DO4 & 4 & 4 & 123 & 11 & 8,9 & 28 & 22,8 & 84 & 68,3 \\
\hline DO5 & 3 & 3 & 125 & 19 & 15,2 & 45 & 36,0 & 61 & 48,8 \\
\hline DO6 & 4 & 4 & 125 & 7 & 5,6 & 35 & 28,0 & 83 & 66,4 \\
\hline DO7 & 4 & 4 & 124 & 17 & 13,7 & 32 & 25,8 & 75 & 60,5 \\
\hline DO8 & 4 & 4 & 124 & 10 & 8,1 & 30 & 24,2 & 84 & 67,7 \\
\hline
\end{tabular}

A alta frequência em relação às outras assertivas que medem o DO indica que a amostra é composta por empresas que possuem alta reputação perante os maiores segmentos de consumidores $(64,8 \%)$ e que nos últimos três anos, comparado com a média dos concorrentes do setor, consideram ter obtido bom desempenho financeiro, $61,6 \%$ e $68,3 \%$, assertivas 3 e 4 , respectivamente, e crescimento de mercado, $60,5 \%$ e $67,7 \%$, assertivas 7 e 8 , respectivamente.

Em praticamente todas as assertivas relacionadas ao desempenho organizacional, exceto a assertiva DO4, há diferença significativa, segundo teste da mediana de Mood, para a variável moderadora tipo de estratégia. Nas assertivas DO1 ( $p$-value $=0,000$ ), DO2 $(p$-value $=0,001)$, DO3 $(p$-value $=0,001)$, DO5 $(p$-value $=0,000)$ e DO6 $(p$-value = 0,002) têm diferenças significaticas para $99 \%$ de confiança, enquanto que as assertivas DO7 $(p$-value $=0,048)$ e DO8 $(p$-value $=0,025)$ para $95 \%$. O grau de concordância é 
maior para as empresas classificadas como tipo de estratégia 2 (analisadoras), quando comparada às demais empresas, o que indica percepção de desempenho superior.

\subsubsection{Análise descritiva do construto incerteza ambiental}

A Tabela 12 demonstra uma concordância mais alta dos respondentes com as assertivas 1 e 3 e menor concordância com as assertivas 2, 4 e 5. Esses dados apontam que o ambiente no qual as empresas está inserida é considerado dinâmico e caracterizado por rápida expansão, porém não ao ponto de ser arriscado, difícil de sobreviver e caracterizado por rápida obsolescência de produtos.

Tabela 12 Estatísticas descritivas do construto Incerteza Ambiental

\begin{tabular}{|c|c|c|c|c|c|c|c|c|c|}
\hline \multirow{2}{*}{ Assertiva } & \multirow{2}{*}{ Moda } & \multirow{2}{*}{ Mediana } & \multirow{2}{*}{$\begin{array}{l}\text { Amostra } \\
\text { efetiva }\end{array}$} & \multicolumn{2}{|c|}{ Discordância } & \multicolumn{2}{|c|}{ Neutralidade } & \multicolumn{2}{|c|}{ Concordância } \\
\hline & & & & Freq. & $\%$ & Freq. & $\%$ & Freq. & $\%$ \\
\hline$\overline{\mathrm{IA} 1}$ & $\overline{4}$ & 4 & 125 & 22 & 17,6 & 29 & 23,2 & 74 & 59,2 \\
\hline IA2 & 2 & 3 & 124 & 60 & 48,4 & 34 & 27,4 & 30 & 24,2 \\
\hline IA3 & 4 & 4 & 124 & 22 & 17,7 & 29 & 23,4 & 73 & 58,9 \\
\hline IA4 & 3 & 3 & 124 & 47 & 37,9 & 35 & 28,2 & 42 & 33,9 \\
\hline IA5 & 3 & 3 & 124 & 54 & 43,5 & 37 & 29,8 & 33 & 26,6 \\
\hline
\end{tabular}

As assertivas IA1 ( $p$-value $=0,008)$ e IA3 ( $p$-value $=0,042)$ apresentam diferença significativa, segundo teste da mediana de Mood, para a variável moderadora tipo de estratégia. Os resultados demonstram que os analisadores (mediana 4) em relação a prospectores e defensores (mediana 3 ) apresentam maior grau de percepção em relação ao dinamismo e a rapidez nas mudanças ambientais.

Analisando-se conjuntamente os construtos DO e IA quanto aos tipos estratégicos, estudos empíricos apontam que existe correlação entre a percepção do ambiente como dinâmico e hostil, a adoção da estratégia do tipo analisadora e o alcance de desempenho organizacional superior (ex.: Luo e Park, 2001).

\subsection{Análise do modelo de mensuração}

Conforme foi explicado na seção 3 , devido à multidimensionalidade do construto abrangência da formulação, o modelo teórico, conforme demonstrado no Apêndice $D$, apresenta os construtos latentes do alinhamento vertical e horizontal em diferentes níveis, o que impedia o cálculo do modelo completo no software SmartPLS. 
Para deixar as variáveis no mesmo nível adotou-se a solução de primeiro rodar o construto abrangência da formulação (AF) para gerar os escores das VL de $1^{\text {a }}$ ordem e usá-las em um modelo revisado, como se fossem indicadores, deixando todas as VL no mesmo nível, conforme apresentado no modelo teórico Figura 3. Dessa forma, a análise do modelo de mensuração inicia-se com a apresentação dos escores da VL AF.

Em seguida analisam-se os construtos componentes do alinhamento vertical (AV), iniciando-se pelas VL de primeira ordem (AF, CG e EP) e depois a VL de $2^{\mathrm{a}}$ ordem $A V$. $\mathrm{Na}$ sequência são analisados os construtos do alinhamento horizontal $(\mathrm{AH})$, os de primeira ordem (OC e OP) e depois a VL de $2^{a}$ ordem $A H$. Por fim, se analisam o alinhamento interno (AI), a VL dependente desempenho organizacional (DO) e as variáveis moderadoras (estratégia e incerteza ambiental).

\subsubsection{Análise do Construto Abrangência da Formulação}

Primeiramente foram analisadas as confiabilidades dos indicadores demonstrados na Figura 4, estando todos acima de 0,7, com exceção de PFP1 (0.593) e PFP3 (0.630). O indicador PFP1 foi extraído e o modelo foi recalculado. Decidiu-se manter o indicador PFP3 porque a variância média extraída (AVE) do construto (Tabela 13) apresenta-se com o valor de 0,650 , acima do especificado, assim como a AVE dos demais construtos.

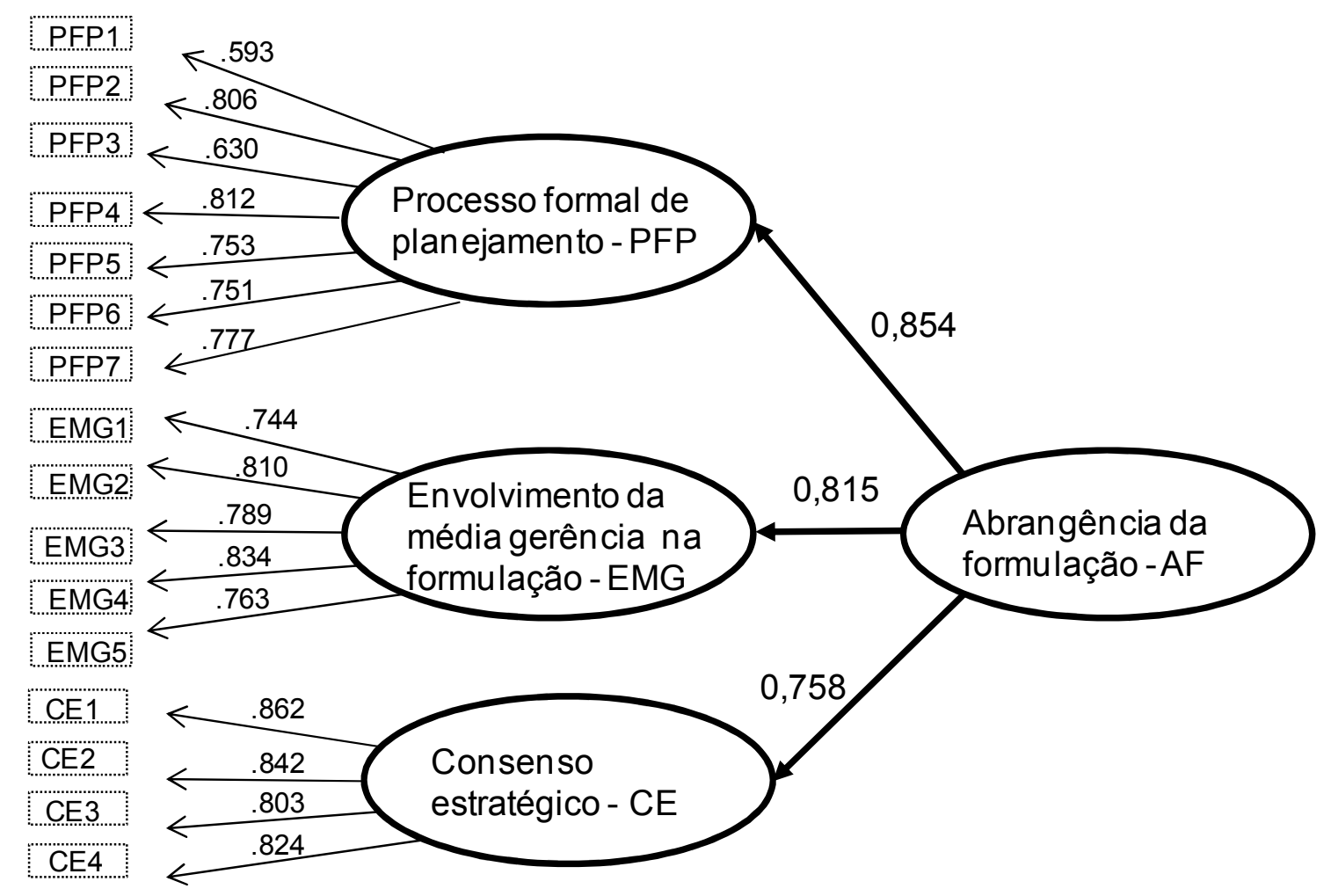

Figura 4 Construto abrangência da formulação com parâmetros estimados pela MEEPLS 
Tabela 13 - Validade convergente e confiabilidade das VL do construto abrangência da formulação

\begin{tabular}{cccc}
\hline $\begin{array}{c}\text { Variáveis } \\
\text { Latentes }\end{array}$ & $\begin{array}{c}\text { Variância Média } \\
\text { Extraída (AVE) }\end{array}$ & $\begin{array}{c}\text { Confiabilidade } \\
\text { composta }\end{array}$ & $\begin{array}{c}\text { Alpha de } \\
\text { Cronbach }\end{array}$ \\
\hline AF & 0,650 & 0,847 & \\
PFP & 0,586 & 0,857 & 0,777 \\
EMG & 0,622 & 0,899 & 0,860 \\
CE & 0,711 & 0,908 & 0,865 \\
\hline \hline
\end{tabular}

Na Tabela 14 é possível observar que as correlações entre as VL são menores do que a raiz quadrada da AVE, por isso há validade discriminante.

Tabela 14 Validade discriminante das VL do construto abrangência da formulação

Correlação entre as variáveis latentes do

construto Abrangência da Formulação

\begin{tabular}{cccc}
\hline & PFP & EMG & CE \\
FPP & $\mathbf{0 , 7 6 6}$ & & \\
EMG & 0,505 & $\mathbf{0 , 7 8 9}$ & \\
CE & 0,463 & 0,460 & $\mathbf{0 , 8 3 3}$ \\
\hline \hline
\end{tabular}

Note-se que a Tabela 14 apresenta a correlação entre as variáveis latentes do modelo estimado pela MEEPLS, que foram geradas pelo SmartPLS. Para avaliação da validade discriminante, os resultados obtidos para a raiz quadrada da AVE, conforme definido na seção 4.3, foram colocados na diagonal da matriz (coeficientes em negrito), sendo que esse procedimento será adotado para os demais construtos.

Os escores das três VL de $1^{\text {a }}$ ordem (CE, EMG e PFP) para os 125 casos foram salvos para usar no próximo modelo. Eles entraram como indicadores do construto Abrangência da Formulação $(A F)$ e passam a ser representados por CE_1, EMG_1 e PFP_1.

\subsubsection{Análise das VL do construto alinhamento vertical}

Os escores da variável AV estão demonstrados na Figura 5. A análise da confiabilidade dos indicadores demonstra que as variáveis EP1, EP2, EP8 e CG3 estão abaixo de 0,7 .

A variável EP1 foi extraída e o modelo foi novamente calculado. Os demais indicadores foram mantidos porque a AVE dos construtos EP e CG encontra-se, respectivamente com 0,575 e 0,607, conforme indicado na Tabela 15, portanto dentro do 
critério: $\geq 0,5$. Os demais construtos também encontram-se com AVE dentro do especificado.

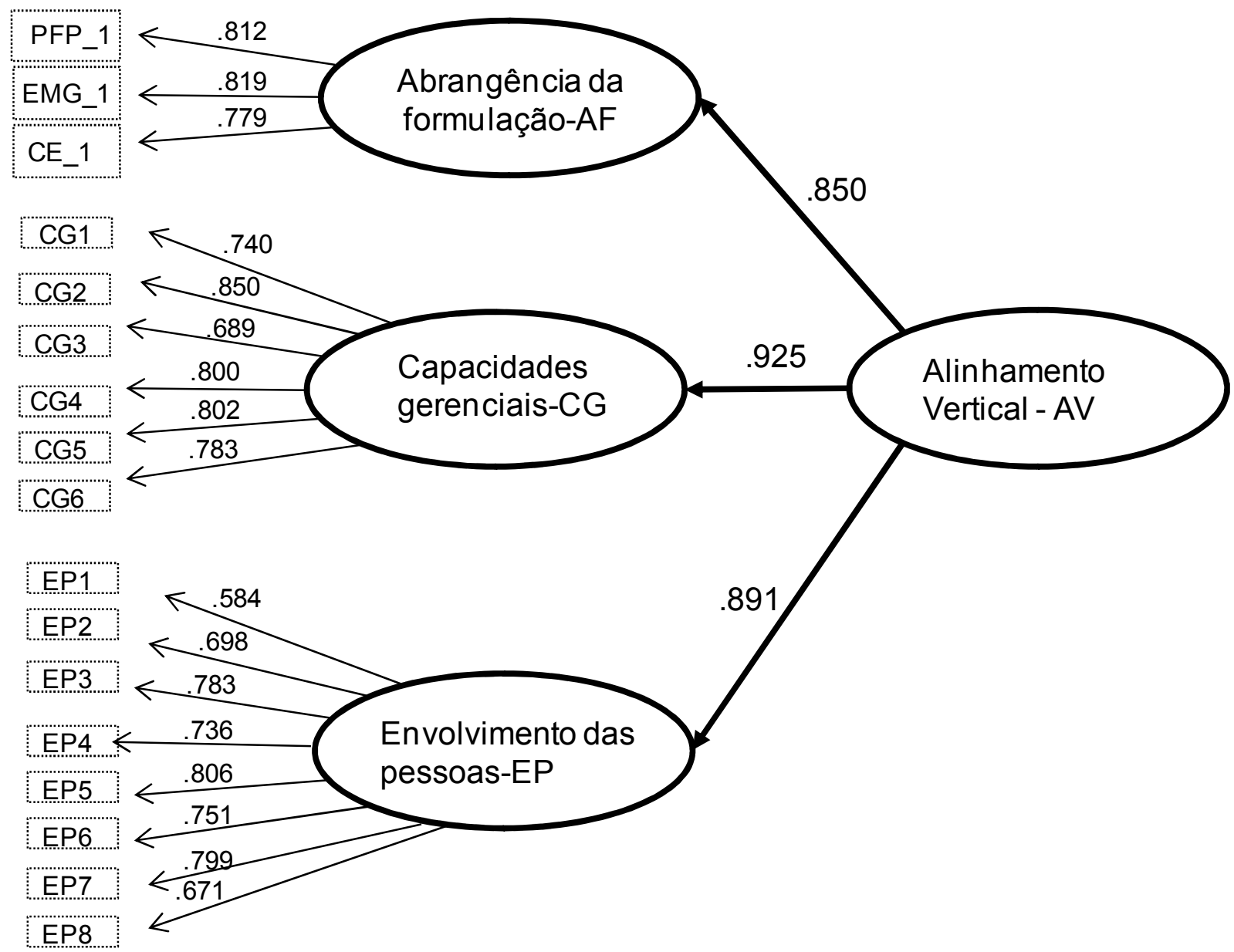

Figura 5 Construtos do alinhamento vertical com parâmetros estimados pela MEEPLS

Tabela 15 Validade convergente e confiabilidade das VL do alinhamento vertical

$\begin{array}{lccc}\text { Variáveis } & \text { Variância Média } & \text { Confiabilidade } & \text { Alpha de } \\ \text { Latentes } & \text { Extraída (AVE) } & \text { composta } & \text { Cronbach }\end{array}$

Variáveis Latentes de Primeira Ordem

\begin{tabular}{llll} 
AF & 0,646 & 0,845 & 0,726 \\
CG & 0,607 & 0,902 & 0,869 \\
EP & 0,575 & 0,904 & 0,875 \\
\hline
\end{tabular}

\begin{tabular}{ccc}
\hline \multicolumn{2}{l}{ Variável Latente de Segunda Ordem } \\
\hline AV & 0,781 & 0,914
\end{tabular}

Os indicadores de confiabilidade, CC e Alpha de Cronbach, das VL de primeira ordem AF, CG e EP estão acima da especificação de 0,7.

A VL de $2^{\mathrm{a}}$ ordem AV também apresenta índices de AVE e confiabilidade acima do especificado, sendo, respectivamente, 0,781 e 0,914. 
O resultado da validade discriminante será demonstrado mais adiante, em conjunto com a análise das demais variáveis latentes.

\subsubsection{Análise das VL do construto alinhamento horizontal}

Conforme demonstrado na Figura 6, as cargas dos construtos de $1^{\mathrm{a}}$ ordem e $2^{\mathrm{a}}$ ordem superam o valor especificado de 0,7 .

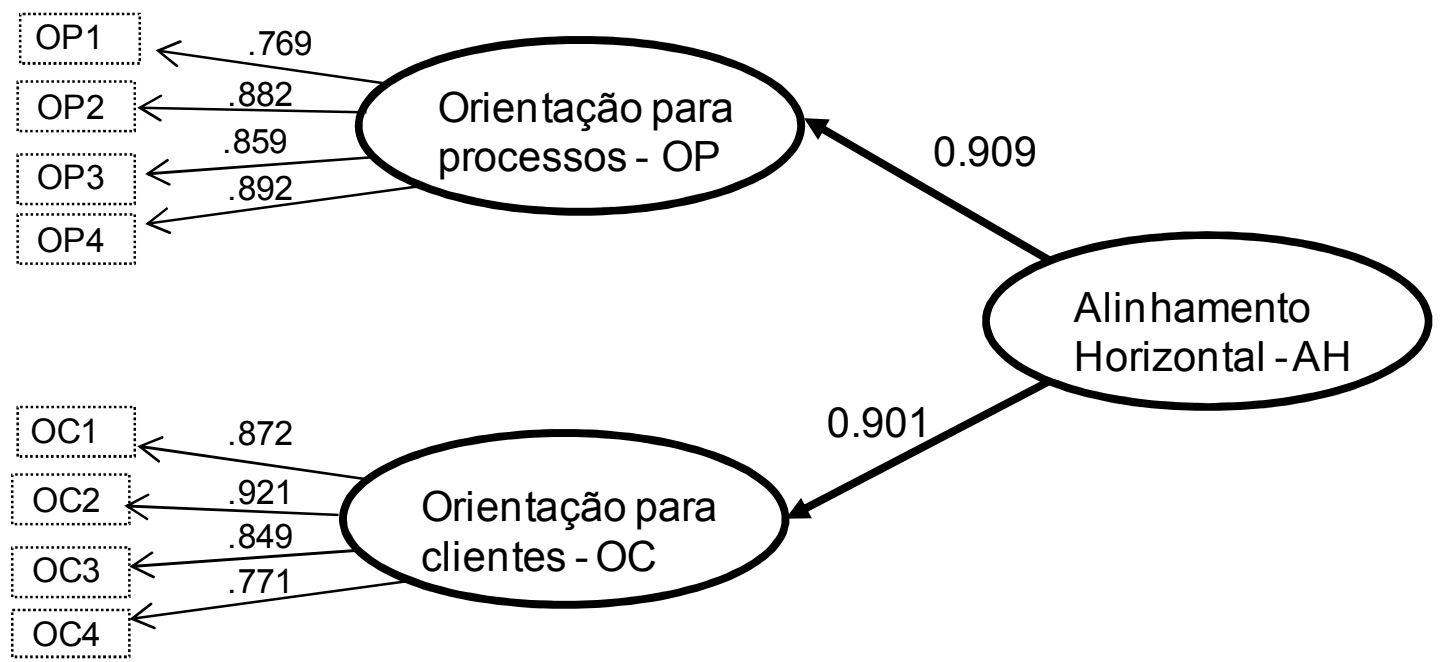

Figura 6 Construtos do alinhamento horizontal com parâmetros estimados pela MEEPLS

Os indicadores de confiabilidade, CC e Alpha de Cronbach das VL de primeira ordem OP e OC estão bem acima da especificação de 0,7 , conforme demonstrado na Tabela 16. A VL de $2^{\mathrm{a}}$ ordem $\mathrm{AH}$ também apresenta índices de consistência interna (AVE) e confiabilidade acima do especificado, sendo, respectivamente, 0,819 e 0,901.

O resultado da validade discriminante será demonstrado mais adiante, em conjunto com a análise das demais variáveis latentes.

\begin{tabular}{|c|c|c|c|}
\hline $\begin{array}{l}\text { Variáveis } \\
\text { Latentes }\end{array}$ & $\begin{array}{l}\text { Variância Média } \\
\text { Extraída (AVE) }\end{array}$ & $\begin{array}{c}\text { Confiabilidade } \\
\text { composta }\end{array}$ & $\begin{array}{l}\text { Alpha de } \\
\text { Cronbach }\end{array}$ \\
\hline \multicolumn{4}{|c|}{ Variáveis Latentes dos construtos de Primeira Ordem } \\
\hline OP & 0,726 & 0,914 & 0,873 \\
\hline $\mathrm{OC}$ & 0,731 & 0,916 & 0,876 \\
\hline \multicolumn{4}{|c|}{ Variável Latente do construto de $2^{\mathrm{a}}$ Ordem } \\
\hline $\mathrm{AH}$ & 0,819 & 0,901 & \\
\hline
\end{tabular}




\subsubsection{Análise da VL Desempenho Organizacional}

Conforme demonstra a Figura 7 , as cargas do construto de $1^{\text {a }}$ ordem DO encontram-se dentro do valor especificado de 0,7 , exceto DO5 e DO6, com cargas de 0,696 e 0,686 . Os indicadores foram mantidos porque a AVE do construto é de 0,559 (Tabela 17) portanto, dentro do padrão especificado de 0,5. A variável DO também apresenta índices de confiabilidade acima do especificado, sendo, CC de 0,910 e Alpha de Cronbach de 0,887 .

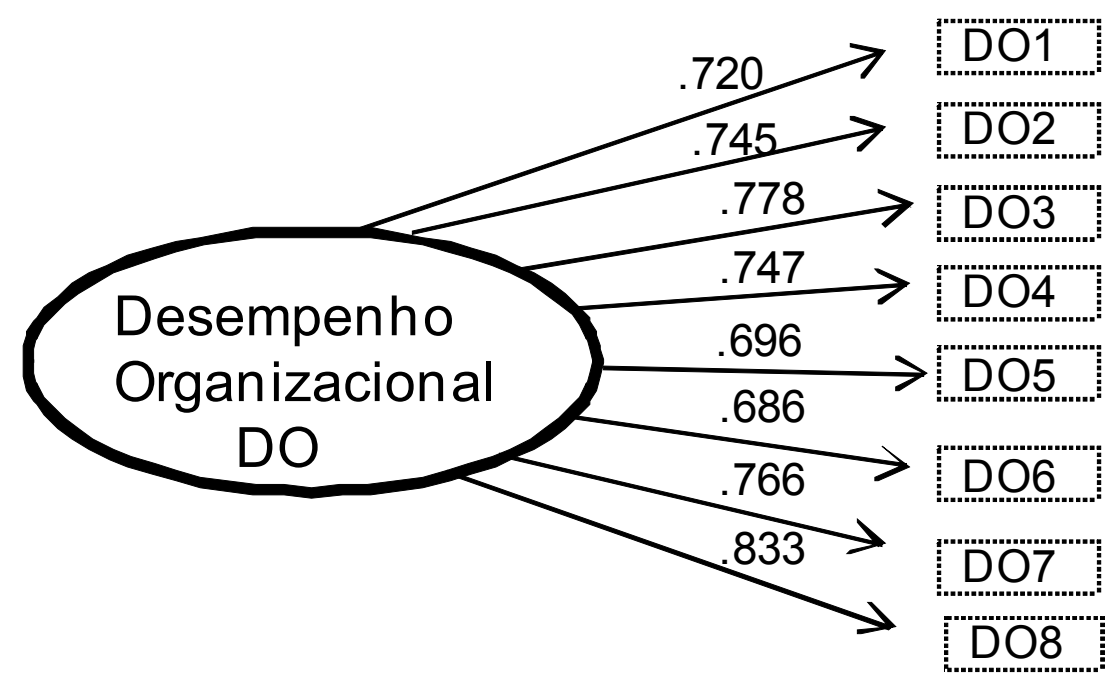

Figura 7 - Construto desempenho organizacional com parâmetros estimados estimados pela MEEPLS

Tabela 17 Validade convergente e confiabilidade da VL DO

\begin{tabular}{cccc}
\hline \hline $\begin{array}{c}\text { Variável } \\
\text { Latente }\end{array}$ & $\begin{array}{c}\text { Variância Média } \\
\text { Extraída (AVE) }\end{array}$ & $\begin{array}{l}\text { Confiabilidade } \\
\text { composta }\end{array}$ & $\begin{array}{l}\text { Alpha de } \\
\text { Cronbach }\end{array}$ \\
\hline DO & 0,559 & 0,910 & 0,887 \\
\hline \hline
\end{tabular}

\subsubsection{Análise da VL Alinhamento Interno}

A Figura 8 demonstra os escores da VL de terceira ordem Al. Os escores encontram-se acima de 0,7. A Tabela 18 também indica que a variável apresenta índices de consistência interna e confiabilidade bem acima do especificado, respectivamente, AVE de 0,830 e confiabilidade de 0,907. 


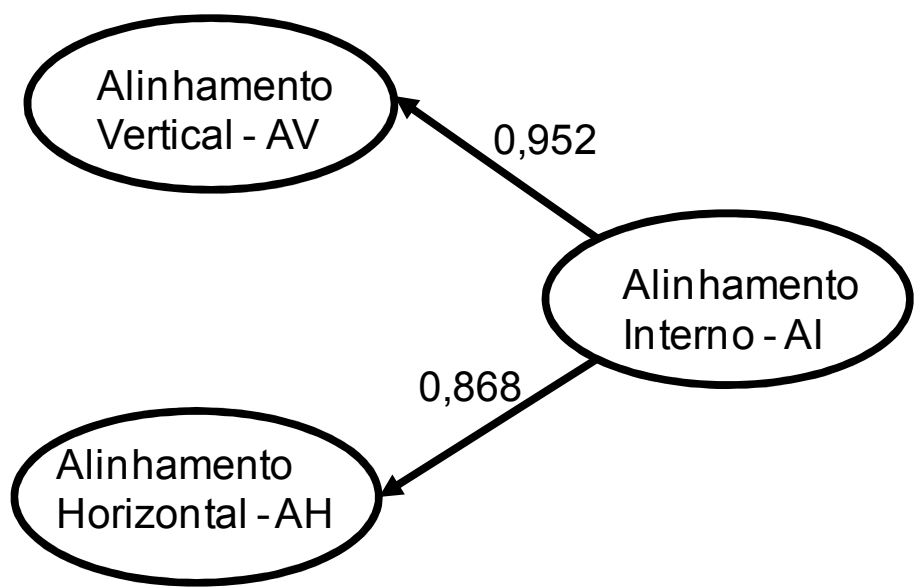

Figura 8 - Construto alinhamento interno com parâmetros estimados pela MEEPLS

Tabela 18 Validade convergente e confiabilidade da VL AI

\begin{tabular}{ccc}
\hline $\begin{array}{l}\text { Variável } \\
\text { Latente }\end{array}$ & $\begin{array}{l}\text { Variância Média } \\
\text { Extraída (AVE) }\end{array}$ & $\begin{array}{l}\text { Confiabilidade } \\
\text { composta }\end{array}$ \\
\hline $\mathrm{Al}$ & 0,830 & 0,907 \\
\hline \hline
\end{tabular}

\subsubsection{Validade Discriminante entre as variáveis latentes}

A Tabela 19 apresenta a correlação entre as VL de primeira ordem. Na diagonal, foi destacada a raiz quadrada da AVE.

Tabela 19 Correlação entre as VL de primeira ordem

\begin{tabular}{rrrrrrr}
\hline \hline & AF & CG & DO & EP & OC & OP \\
\hline AF & $\mathbf{0 , 8 1 0}$ & & & & & \\
CG & 0,811 & $\mathbf{0 , 7 7 9}$ & & & & \\
DO & 0,437 & 0,329 & $\mathbf{0 , 7 4 8}$ & & & \\
EP & 0,575 & 0,656 & 0,261 & $\mathbf{0 , 7 5 6}$ & & \\
OC & 0,438 & 0,497 & 0,305 & 0,438 & $\mathbf{0 , 8 5 5}$ & \\
OP & 0,542 & 0,667 & 0,231 & 0,602 & 0,639 & $\mathbf{0 , 8 5 2}$ \\
\hline \hline
\end{tabular}

Aplicando-se o critério sugerido por Fornell e Larcker (1981), verifica-se que as correlações entre as $V L$ são menores do que a sua $A V E$, exceto no caso da variável $A F$, que apresenta raiz quadrada da AVE de 0,810, inferior à sua correlação com CG $(0,811)$. Portanto, não há validade discriminante entre essas variáveis.

Por se tratar de VL de primeira ordem, a primeira solução possível seria retirar indicadores com cargas baixas de AF para aumentar a variância média extraída do construto. 
Nesse sentido, verificou-se a possibilidade de extrair a variável PFP3, que, quando da mensuração do construto AF apresentou carga fatorial de 0,630 (Figura 4), portanto menor do que o especificado, $\geq 0,7$. Essa medida, no entanto, não alteraria a AVE do construto AF. Além disso, trata-se de um indicador relevante para a mensuração do construto PFP, por ser o único que mensura a existência de metas de curto prazo, enquanto os outros verificam a existência de objetivos de longo prazo.

Outra medida tomada foi avaliar a validade discriminante por meio da análise da matriz de cargas cruzadas (cross-loadings), que pode ser visualizada no Apêndice I. Por esse critério, é esperado que um indicador apresente maior correlação com a sua VL do que com outras (Chin, 1998), o que pode ser evidenciado nos resultados. Os indicadores de AF apresentam correlação média de $80,3 \%$ com a sua VL e de $65,1 \%$ com CG. Por esse critério haveria validade discriminante.

Considerando-se que a validade discriminante não pôde ser constatada pelo critério de Fornell e Larcker (1981), por critérios estatísticos o modelo poderia ser alterado incluindo todos os indicadores para a mensuração de um construto único.

No entanto, uma das críticas que se faz aos pesquisadores quando aplicam a MEE é a de reespecificar os modelos baseando-se apenas nos critérios estatísticos e não nos critérios teóricos. Nachtigall et al. (2003) advertem que essa prática tem sido como um "fetichismo" entre os pesquisadores e que, por isso, acaba-se incorrendo no erro de especificar um modelo que se ajuste aos dados de uma amostra específica, sem dar a chance de que ele seja reproduzido em uma outra população. Com base em argumentos teóricos, decidiu-se manter os construtos AF e CG separados no modelo. Tais argumentos serão expostos no capítulo de discussão dos resultados.

Também foi verificada a validade discriminante entre as VL de $2^{a}$ ordem, AH e AV, conforme pode ser visualizado na Tabela 20. Segundo o critério de Fornell e Larcker (1981) há validade discriminante entre essas variáveis.

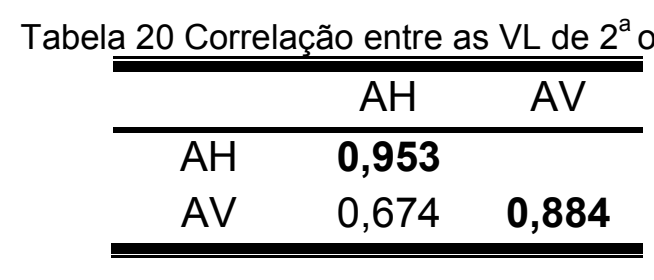




\subsection{Análise do modelo estrutural}

O modelo estrutural foi estimado por meio de bootstrapping, um tipo de reamostragem aleatória com repetições (HAIR JR. et al. 2005). Foram especificados $N=$ 125 e 1000 repetições. Os resultados estão demonstrados na Figura 9.

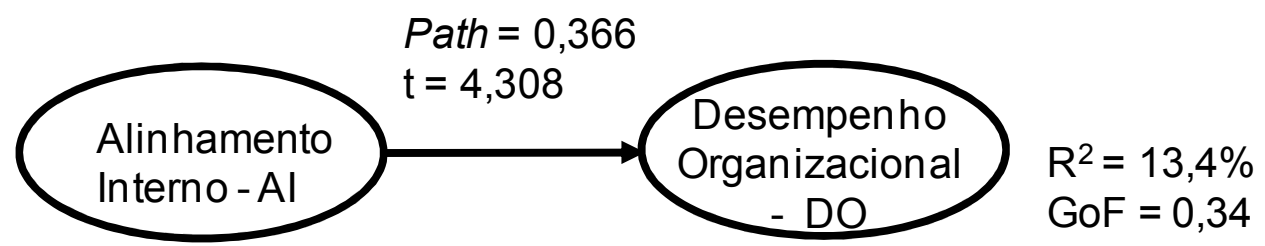

Figura 9 - Resultados do modelo estrutural com parâmetros estimados pela MEEPLS Fonte: Autora, com base nos dados coletados e processados

O valor $\mathrm{t}$ de Student $(4,308)$ é significante ao nível de $5 \%$. A relação Al-DO é altamente significante, com $p$-valor $=0,000018$, portanto, $p<0,0001$.

$O R^{2}$ indica que o Alinhamento Interno explica $13,4 \%$ da variância do Desempenho Organizacional, o que, segundo critério proposto por Cohen (1977) implica em médio poder de explicação.

O Goodness-of-fit (GoF), índice de ajuste geral do modelo, calculado com base no $R^{2}$ foi de 0,34 , portanto, abaixo do valor sugerido: $\geq 0,5$.

\subsection{1 - Efeito moderador da incerteza ambiental}

A análise da confiabilidade dos indicadores propostos para a mensuração da incerteza ambiental (IA) levou à exclusão das variáveis IA2, IA4 e IA5, todas com valores inferiores a 0,7, conforme pode ser visualizado na Figura 10.

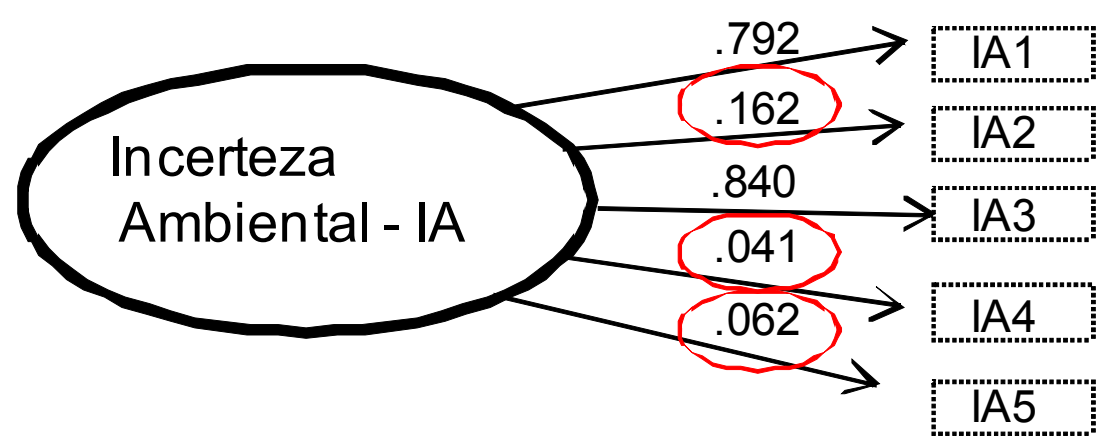

Figura 10 - Construto incerteza ambiental com parâmetros estimados pela MEEPLS 
Excluídas essas variáveis, o construto apresentou indicadores de confiabilidade e de validade convergente acima dos valores especificados, respectivamente de 0,7 e 0,5, conforme demonstrado na Tabela 21. No entanto, o construto passou a ser mensurado por apenas dois indicadores, IA1 e IA3.

Tabela 21 Validade convergente e confiabilidade da VL IA

\begin{tabular}{cccc}
\hline \hline $\begin{array}{c}\text { Variável } \\
\text { Latente }\end{array}$ & $\begin{array}{c}\text { Variância Média } \\
\text { Extraída (AVE) }\end{array}$ & $\begin{array}{c}\text { Confiabilidade } \\
\text { composta }\end{array}$ & $\begin{array}{c}\text { Alpha de } \\
\text { Cronbach }\end{array}$ \\
\hline IA & 0,739 & 0,850 & 0,650 \\
\hline \hline
\end{tabular}

O efeito direto da incerteza ambiental sobre o desempenho organizacional foi mensurado e está indicado na Figura 11. O R ${ }^{2}$ aumentou de 13,4\% (Figura 9) para 16,2\%. No entanto, o valor-t apurado de 1,914, portanto, $t<1,96$ não é significante a $5 \%$.

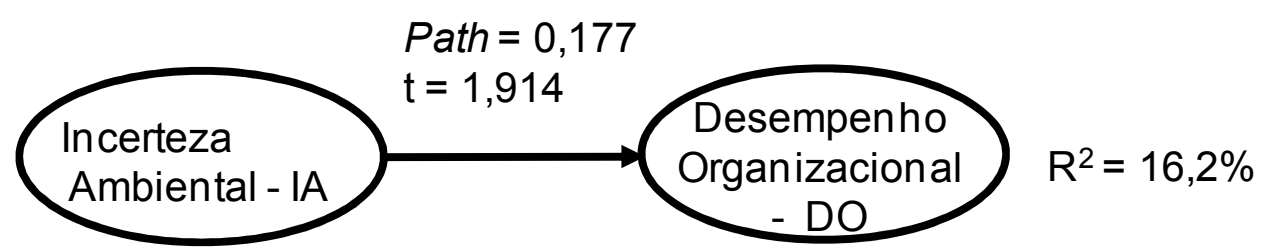

Figura 11 - Efeito da incerteza ambiental sobre o desempenho com parâmetros estimados pela MEEPLS

Ao introduzir a variável IA como moderadora (Figura 12) $\circ \mathrm{R}^{2}$ aumentou para $19,1 \%$, no entanto, os valores-t apurados são todos não significantes a $5 \%$. A relação AlDO apresenta-se com sinal negativo, representando um resultado não previsto para o modelo considerando-se a fundamentação teórica. Dessa forma, optou-se pelo modelo sem a inclusão da variável moderadora.

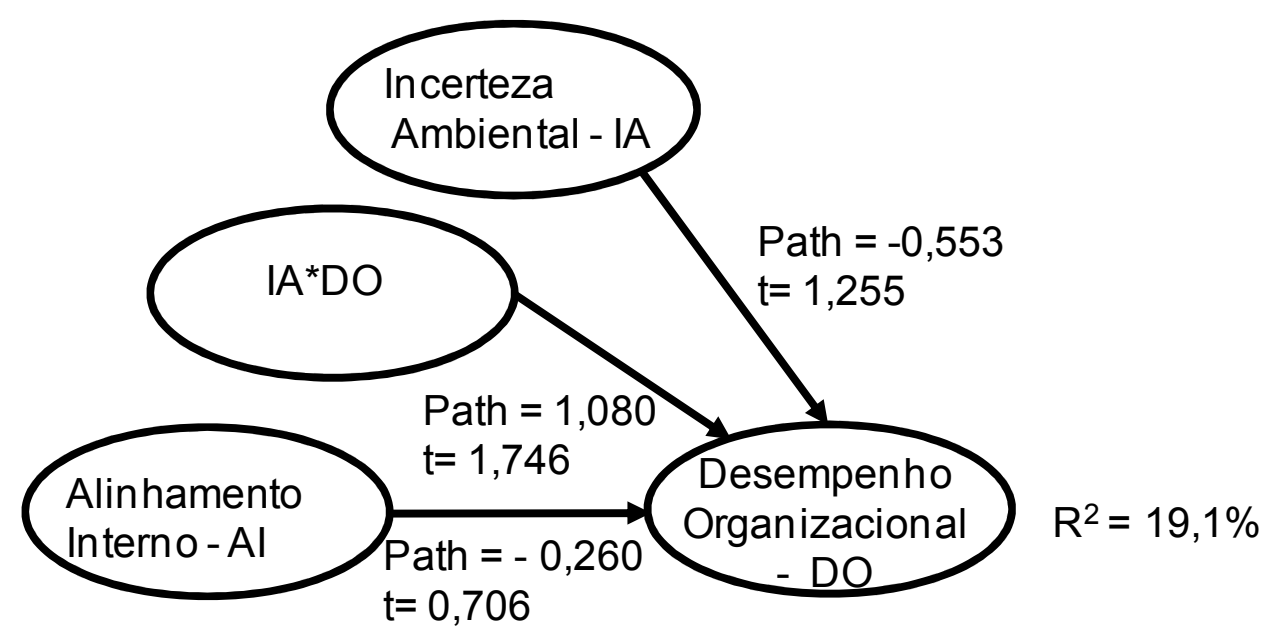

Figura 12 - Efeito moderador da incerteza ambiental sobre o desempenho organizacional 


\subsection{2 - Efeito moderador da estratégia}

Não foi possível testar o efeito moderador da estratégia devido ao número de respondentes ter sido inferior ao necessário para os testes estatísticos. Conforme especificado na seção 4.6, a amostra deveria ser de 77 respondentes para cada um dos três grupos estratégicos, sendo que foi possível coletar o total de 125 questionários.

A síntese dos resultados obtidos na MEE encontra-se na Tabela 22, e serão discutidos no próximo capítulo.

Tabela 22: Síntese dos resultados da avaliação estatística do modelo teórico

\begin{tabular}{|c|c|c|c|}
\hline \multirow{2}{*}{ VARIÁVEIS LATENTES } & $\mathrm{CF}$ & CC & AVE \\
\hline & \multicolumn{3}{|c|}{ Variáveis Independentes } \\
\hline ALINHAMENTO INTERNO & & 0,907 & 0,830 \\
\hline ALINHAMENTO VERTICAL & 0,952 & 0,914 & 0,781 \\
\hline Abrangência da Formulação da Estratégia & 0,850 & 0,845 & 0,646 \\
\hline Capacidades Gerenciais & 0,925 & 0,902 & 0,607 \\
\hline Envolvimento das Pessoas & 0,891 & 0,904 & 0,575 \\
\hline ALINHAMENTO HORIZONTAL & 0,868 & 0,901 & 0,819 \\
\hline Orientação para clientes & 0,901 & 0,916 & 0,731 \\
\hline \multirow[t]{2}{*}{ Orientação para processos } & 0,909 & 0,914 & 0,726 \\
\hline & \multicolumn{3}{|c|}{ Variável Dependente } \\
\hline DESEMPENHO ORGANIZACIONAL & & 0,910 & 0,559 \\
\hline
\end{tabular}

Fonte: a autora, com base em dados da pesquisa

$\mathrm{CF}=$ Carga Fatorial $\mathrm{CC}=$ Confiabilidade composta $\mathrm{AVE}=$ Média da Variância Extraída $\mathrm{R}^{2}=$ índice de variância explicada GoF = Goodness-of-Fit = índice de ajuste geral do modelo

O modelo final com as cargas estimadas via MEEPLS encontra-se no Apêndice J. 


\section{CONSIDERAÇÕES FINAIS}

Este capítulo discute com maior profundidade os resultados relatados e analisados na seção anterior, procurando estabelecer as conexões com a base teórica e com os objetivos propostos. Também apresenta as contribuições e limitações do estudo e sugestões para outros estudos.

A tese propõe um modelo teórico de alinhamento interno na perspectiva holística, também comumente denominada pela literatura como perspectiva sistêmica ou da covariação. Defende também a hipótese de que o alinhamento interno, a partir do modelo proposto, tem impacto positivo sobre o desempenho organizacional.

No modelo teórico de alinhamento interno (AI) proposto o alinhamento vertical (AV) e o alinhamento horizontal $(\mathrm{AH})$ representam as variáveis a serem alinhadas e a ideia presente é que isoladamente não são suficientes para produzir o Al.

Os resultados obtidos, conforme sintetizados na Tabela 22, demonstraram que o modelo apresentou um elevado grau de consistência interna, com índices de confiabilidade composta (CC) variando entre 0,845 e 0,916, portanto com resultados bem superiores ao valor especificado de 0,7 (HENSELER; RINGLE; SINKOVICS, 2009, p. 299). Da mesma forma, o modelo apresentou validade convergente, com média da variância extraída (AVE) entre 0,575 e 0,830, acima de 0,5, de acordo com o critério proposto por Fornell e Larcker (1981).

Devido à especificação de múltiplos construtos no modelo, a validade discriminante também foi avaliada, procurando estabelecer em que medida as VL mensuram construtos independentes.

Foram aplicados dois critérios para a mensuração da validade discriminante, a análise da matriz de cargas cruzadas (cross-loadings) e o critério de Fornell e Lacker (1981). Pelos dois critérios foi constatada a validade discriminante dos construtos de $2^{a}$ ordem ( $\mathrm{AV}$ e $\mathrm{AH})$. No entanto, a validade discriminante entre os construtos de primeira ordem Abrangência da Formulação da Estratégia (AF) e Capacidades Gerenciais para Implementação da Estratégia (CG), foi constatada pela análise da matriz de cargas cruzadas (cross-loadings) , mas não pelo critério de Fornell e Lacker (1981).

O escopo teórico que caracteriza ambos os construtos de fato apresenta fronteiras muito tênues. Apesar do processo de implementação como um todo requerer 0 envolvimento do executivo (HAMBRICK; CANNELLA, 1989), dentre as variáveis especificadas no modelo teórico, AF e CG são as duas que dão maior ênfase às 
responsabilidades diretamente atribuídas a eles. Nesse sentido, o construto AF representa as atividades de formulação do plano estratégico e o construto CG representa as capacidades que são requeridas dos executivos para colocar a estratégia em prática.

Além disso, esses construtos estão na verdade imbricados dentro do processo estratégico, o qual é, de fato, circular, onde as atividades de definição da estratégia e da sua execução podem afetar uma a outra a qualquer momento (BOWER, 1982; HREBINIAK, 2006; KAPLAN; NORTON, 1993, 1996).

A decisão de mantê-los separados no modelo deve-se principalmente à necessidade de mensurar as capacidades gerenciais para colocar a estratégia em prática. Se por um lado a literatura aponta que a habilidade de implementação pode se tornar uma vantagem competitiva, vários autores, tais como, Beer e Eisenstat (1996), Bourne et al. (2003) e Prieto, Carvalho e Fischmann (2009) relatam que mesmo estratégias bem formuladas não têm se concretizado devido a pouca atenção que é dada aos aspectos organizacionais intangíveis, incluindo capacidades de coordenação, comprometimento e competências interpessoais.

Nesta tese também se estabeleceu a hipótese de que existe relação significativa e positiva entre o Alinhamento Interno e o Desempenho Organizacional. Os resultados da MEE levaram à confirmação da hipótese, conforme demonstrado na seção 5.5 - Figura 9 , o que implica na constatação de que a covariação entre o AV e o AH são boas medidas do Al, com impacto positivo sobre o DO.

Esses resultados dão validação empírica ao modelo especificado, tanto do ponto de vista teórico, quanto metodológico. Dessa forma, confirma-se a importância do alinhamento vertical conceituado como conjunto de ações necessárias à implementação da estratégia, envolvendo a existência de um plano formal, capacidades gerenciais para implementação e envolvimento das pessoas com a estratégia, bem como a importância do alinhamento horizontal envolvendo a compreensão das necessidades do cliente e o alinhamento dos processos (inter-funcionais) capazes de entregar o que o cliente necessita.

O Al explica $13,4 \%$ da variância do desempenho organizacional, mensurado pelo $\mathrm{R}^{2}$ do modelo, e o índice de ajuste geral do modelo, calculado com base no $\mathrm{R}^{2}$, foi de 0,34. Segundo Cohen (1977) interpretações sobre a proporção da variância explicada entre duas variáveis estão sujeitas ao avanço da ciência em estudo, bem como devem ser interpretados considerando-se resultados já observados em pesquisas envolvendo o mesmo contexto teórico. 
O resultado obtido é, em geral, equivalente a resultados reportados em pesquisas envolvendo a relação alinhamento-desempenho organizacional, como nos trabalhos desenvolvidos por Chan, Sabherwal e Thatcher (2006) e Joshi, Kathuria e Porth (2003).

Com base em um conjunto de pesquisas mais recentes, Ray, Barney e Muhanna (2004) puderam constatar que nem sempre é possível estabelecer uma relação direta entre o desempenho de determinadas variáveis organizacionais internas e o desempenho geral da organização, porque o que reflete no DO é o desempenho operacional do conjunto dessas atividades.

Ainda com relação às recomendações de Cohen (1977), é importante ressaltar que o campo de estudos sobre estratégia de negócios é contemporâneo (GAVETTI; LEVINTHAL, 2004) e as pesquisas envolvendo aspectos da implementação da estratégia não são predominantes nessa área (ATKINSON, 2006; HREBINIAK; JOYCE, 2001; ZAJAC; KRAATZ; BRESSER, 2000). O próprio conceito de alinhamento está sujeito a múltiplas definições (GALBRAITH; KAZANJIAN, 1986; VENKATRAMAN; PRESCOTT, 1990), o que dificulta comparação dos resultados porque as pesquisas resultam da especificação de diferentes construtos.

Também é importante ressaltar que foi formulada a hipótese de que a relação AlDO é influenciada pelo tipo de estratégia, a qual não foi testada devido a quantidade de respondentes ter sido inferior ao necessário para os testes estatísticos.

O resultado do teste estatístico foi não significativo para a terceira hipótese, de que a relação AI-DO é influenciada pela incerteza ambiental.

Portanto, o modelo final (Apêndice J) não considerou as variáveis moderadoras.

\subsection{Contribuições, limitações e sugestões para outros estudos}

Esta tese traz contribuições quanto à necessidade de estudos envolvendo a implementação da estratégia, uma vez que ênfase tem sido dada à formulação (ATKINSON, 2006; HREBINIAK; JOYCE, 2001; ZAJAC; KRAATZ; BRESSER, 2000); quanto à escassez de modelos de alinhamento estratégico interno que integrem atividades relevantes para a execução bem sucedida da estratégia (HREBINIAK; JOYCE, 2001; PRIETO; CARVALHO; FISCHMANN, 2009) e à necessidade de estudos de alinhamento empregando a perspectiva holística (VENKATRAMAN; PRESCOTT, 1990; KATHURIA; JOSHI; PORTH, 2007). 
Nesse sentido, o modelo de alinhamento estratégico proposto visou contribuir para o preenchimento dessas lacunas, sendo que é de especial importância ressaltar que o modelo foi fundamentado em relacionamentos teóricos, os quais, segundo Whetten (2003), são o escopo para o desenvolvimento da teoria, indo além de uma lista de variáveis.

Por isso, para chegar ao modelo especificado foi realizada e documentada uma revisão de literatura sistematizada, que resultou na seleção de construtos relacionados teoricamente ao conceito de alinhamento interno proposto nesta tese, o qual envolve as dimensões vertical e horizontal.

Ao adotar essa perspectiva foi assumida a existência de um padrão de covariação entre os construtos, e a sua relação positiva com o desempenho organizacional. Os resultados empíricos confirmaram a relação teórica especificada.

Nesse sentido, esse estudo contribuiu com um dos principais objetivos das pesquisas no campo da estratégia, que é o de aumentar a compreensão sobre os determinantes do desempenho organizacional e explicar como os gestores podem obter desempenho superior (MEYER, 1991).

Esta tese também contribui no sentido de avaliar conjuntamente o impacto do alinhamento vertical e do alinhamento horizontal sobre o desempenho, uma vez que são raros os estudos envolvendo ambas as perspectivas, principalmente o alinhamento horizontal (KATHURIA; JOSHI; PORTH, 2007). Dessa forma, o modelo especificado é mais complexo, porém, entende-se, mais representativo do conjunto de variáveis que a literatura reconhece que devem ser ajustadas para a implementação da estratégia.

Outra contribuição é quanto à conceituação do construto Abrangência da Formulação da Estratégia como multidimensional e composto pelas variáveis: processo formal de planejamento, envolvimento da média gerência na formulação e consenso sobre a estratégia. Vários estudos consideram essas variáveis para avaliar o seu impacto sobre o desempenho organizacional, por exemplo, Chan, Sabherwal e Thatcher (2006), Homburg, Krohmer e Workman Jr. (1999) e Wooldridge e Floyd (1990), no entanto, não foram encontrados estudos que as operacionalizem conjuntamente. A literatura, porém, aponta causas de fracassos na implementação que remetem ao não tratamento dessas variáveis desde o processo de formulação da estratégia (BEER; EISENSTAT, 2000; HAMBRICK; CANNELLA, 1989; MALINA; SELTO, 2001).

Também representa uma contribuição a validação dos instrumentos de pesquisa que foram utilizados para mensurar os construtos componentes do alinhamento vertical, 
os quais poderão ser utilizados para o desenvolvimento de pesquisas em novos contextos.

Finalmente, destaca-se que como contribuição deste trabalho, a aplicação de uma metodologia que tem sido "raramente" utilizada nos estudos na área de Gestão de Operações. Um levantamento realizado por Bido (2010), com base nos principais periódicos nacionais da área de Operações, demonstra que apenas $1 \%$ dos estudos utiliza a MEE.

A despeito das contribuições mencionadas, todos os estudos de pesquisa têm as suas limitações.

Uma das limitações é quanto ao emprego da amostragem não probabilística, que faz com que os dados aqui coletados não possam ser generalizados para uma população.

Dada a natureza da pesquisa, o público respondente foi definido como média gerência, sendo que o acesso a este público se deu pela indicação de pessoas que têm relação com o ambiente empresarial. Ainda assim, existe uma proliferação de nomenclatura de cargos dentro das empresas, o que, eventualmente, pode ter representado um viés na seleção dos respondentes.

Outra limitação foi quanto ao número de respondentes, que foi insuficiente para a análise do modelo em relação a diferentes tipos estratégicos.

O instrumento selecionado para mensurar a incerteza ambiental também acabou se revelando uma limitação do estudo. A análise de confiabilidade dos indicadores levou à exclusão de todas as assertivas que propunham que o dinamismo do ambiente pudesse oferecer alto risco de sobrevivência para as empresas, o que levou a uma relação estatisticamente não significante entre alinhamento interno e desempenho organizacional.

Também representa uma limitação do estudo o emprego apenas da técnica quantitativa, que não permite explorar individualmente os casos, por exemplo, para entender porque empresas alinhadas não apresentam desempenho superior.

Portanto, testar a influência desses variáveis moderadoras - tipos estratégicos e incerteza ambiental, que emergiram do quadro teórico, mas não foram validadas no modelo empírico, consiste em sugestão para trabalhos futuros.

Não exatamente uma limitação, mas uma dificuldade são os raros artigos e livros que tratem da MEE com estimação via PLS, o mais comum é a referência ao LISREL.

Como sugestão para estudos futuros entende-se que o modelo de alinhamento proposto pode ser testado em diferentes contextos organizacionais. Uma variável a ser considerada é o tamanho da empresa, que não pôde ser considerada nesse estudo 
devido à amostra ter sido eminentemente composta por grandes empresas. Estudos anteriores demonstram que o tamanho pode influenciar o alinhamento dependendo do segmento de atuação da empresa (CHAN; SABHERWAL; THATCHER, 2006.

Também sugere-se testar a influência de outras variáveis moderadoras sobre a relação AI-DO, por exemplo, de elementos organizacionais intangíveis. Segundo Carmeli e Tishler (2004), a cultura e a reputação organizacional são elementos que influenciam essa relação.

Finalmente, como sugerido por Combs, Crook e Shook (2005) e Ray, Barney e Muhanna (2004) o desempenho operacional também pode ser configurado como uma variável moderadora da relação AI-DO. Sugere-se que o DO seja conceituado como a eficácia na implementação da estratégia. 


\section{REFERÊNCIAS}

AMIT, R.; SCHOEMAKER, P. J. H. Strategic Management Journal, v. 14, n.1, p. 33-46, Jan. 1993.

ANDREWS, K. R. The concept of corporate strategy. Homewood, IL: Dow Jones-Irwin, 1971.

ATKINSON, H. Strategy implementation: a role for the balanced scorecard? Management Decision, v. 44, n.10, p. 1441-1460, 2006.

BAIER, C.; HARTMANN, E.; MOSER, R. Strategic alignment and purchasing efficacy: an exploratory analysis of their impact on financial performance. Journal of Supply Chain Management, v. 44, n.4, p.36-52, 2008.

BARCLAY, D. W.; HIGGINS, C.; THOMPSON, R. The partial least squares approach to causal modeling: personal computer adoption and use as illustration. Technology Studies, v. 2, n.2, p. 285-309, 1995. In: HENSELER; J.; RINGLE, C. M.; SINKOVICS, R. R. The use of partial least squares path modeling in international marketing. Advances in International Marketing, v. 20, p. 277-319, 2009.

BARNEY, J. Firm resources and sustained competitive advantage. Journal of Management, v. 17, n.1, p. 99-120, 1991.

BARNEY, J. B.; MACKEY, T. B. Testing resource-based theory. In: KETCHEN, D. J.; BERGH, D. D. (Eds.) Research metodology in strategy and management. Oxford: Elsevier, 2005.

BARTLETT, C. A.; GHOSHAL, S. Changing the role of top management: beyond strategy to purpose. Harvard Business Review, v.72, n.6, p.79, nov./dec., 1994.

BEER, M.; EISENSTAT, R. A. Developing an organization capable of implementing strategy and learning. Human Relations, v.49, n.5, p. 597-619, 1996.

BEER, M.; EISENSTAT, R. A The silent killers of strategy implementation and learning. Sloan Management Review, v. 41, n. 4, p.29-40, summer, 2000.

BEER, M.; EISENSTAT, R. A. How to have an honest conversation about your business strategy. Harvard Business Review, p. 82-89, Feb., 2004.

BIDO, D. S. Modelagem em equações estruturais com estimação via partial least squares. Material de curso ministrado na Universidade Presbiteriana Mackenzie, São Paulo, de 08 a 20 de maio de 2008. Disponível em: <https://groups.google.com/group/meepls?hl=pt\&pli=1>. Acesso em: 30 Abr. 2010.

BIDO, D. S., GODOY, A. S.; ARAUJO B. F.; LOUBACK, J. C. Articulação entre a aprendizagem individual, grupal e organizacional: um estudo no ambiente industrial. Revista de Administração Mackenzie, v. 11, n. 2, p. 68-95, 2010. 
BLAGESKI JR, E.J. Comportamento estratégico, monitoramento do ambiente e desempenho em pequenas empresas varejistas de veículos. 2008. 113p. Dissertação (Mestrado) - Universidade do Vale do Itajaí, Biguaçu, 2008. Disponível em: <http://bdtd.ibict.br/>. Acesso: 01 Jun. 2010.

BOSWELL, W. Aligning employees with the organization's strategic objectives: out of 'line of sight', out of mind. International Journal of Human Resource Management, v. 17, n. 9, p.1489-1511, 2006.

BOSWELL, W. R.; BOUDREAU, J. W. How leading companies create, measure and achieve strategic results through "line of sight". Management Decision, v. 39, n.10, p. 851859, 2001.

BOURNE, M.; NEELY, A.; MILLS, J.; PLATTS, K. Why some performance measurement initiatives fail: Lessons from the change management literature. International Journal of Business Performance Management. v. 5, n. 2,3, p. $245-269$, 2003.

BOWER, J. L. Solving the problems of business planning. Journal of business strategy. v.2, n.3, p. 32-44, 1982.

BOYER, K. K.; MCDERMOTT, C. Strategic consensus in operations strategy. Journal of Operations Management, v. 17, n. 3, p. 289-305, 1999.

BROADBENT, M.; WEILL, P. Improving business and information strategy alignment: learning from the banking industry. Ibm Systems Journal, v. 32, n. 1, p. 162-179, 1993.

BURGELMAN, R. A. Strategy making as a social learning process: the case of internal corporate venturing. Interfaces. v. 18, n.3, p74-85, 1988.

CAMERON, K. A Study of Organizational effectiveness and its predictors. Management Science, v. 32, n.1, p. 87-112, 1986.

CAMPBELL, A.; ALEXANDER, M. What's wrong with strategy? Harvard Business Review, p. 42-51, 1997.

CARMELI, A; TISHLER, A. The relationships between intangible organizational elements and organizational performance. Strategic Management Journal, v.25, n.13, p.1257-1278, 2004.

CAVANA R.Y.; DELAHAYE, B. L.; SEKARAN, U. Applied business research: qualitative and quantitative methods. Australia: John Wiley \& Sons, $2001 \quad$, 472p.

CHA, E.-S.; KIM, K.H.; ERLEN, J. A. Translation of scales in cross-cultural research: issues and techniques. Journal of Advanced Nursing, v. 58, n. 4, p. 386-395, 2007.

CHAKRAVARTHY, B. Measuring Strategic Performance. Strategic Management Journal, v. 7, n. 5, p 437-458, 1986.

CHAKRAVARTHY, B.; DOZ, Y. Strategy process research: focusing on corporate selfrenewal. Strategic Management Journal, v. 13, special issue, p. 5-14, 1992. 
CHAN, Y. E.; HUFF, S. L.; BARCLAY, D. W.; COPELAND, D. G. Business strategic orientation, information systems strategic orientation, and strategic alignment. Information Systems Research, v. 8, n. 2, p. 125-150, 1997.

CHAN, Y. E.; SABHERWAL, R.; THATCHER, J. B. Antecedents and outcomes of strategic IS alignment: An empirical investigation. IEEE Transactions on Engineering Management, v.53, n.1, p.27-47, 2006.

CHANDLER, ALFRED D. Strategy and structure: chapters in the history of the industrial enterprise. Cambridge, MIT Press, 1962.

CHIN, W. W. The Partial Least Squares approach to structural equation modeling. 1998. In: HENSELER, J.; RINGLE, C. M.; SINKOVICS, R. R. The use of partial least squares path modeling in international marketing. Advances in International Marketing, v. 20, p. 277-319, 2009.

CHOE, J. M. The effect of environmental uncertainty and strategic applications of IS on a firm's performance. Information \& Management, v. 40, n.4, p. 257-268, 2003.

CHRISTENSEN, C. M. Making strategy: learning by doing. Harvard Business Review, v. 75, n.6, p. 141-156, 1997.

COHEN, J. Statistical Power Analysis for the Behavioral Sciences. 2. ed. New York : Academic Press, 1977. 474 p.

COLE, R.E. Learning from the quality movement: what did and didn't happen and why? California Management Review, v.41, n.1, 1998.

COLLIS, D. J.; MONTGOMERY, C. A. Competing on resources: strategy in the 1990s. Harvard Business Review, v. 73, n.4, p. 118-128, Jul.-Ago., 1995.

COMBS, J. G.; CROOK, T. R.; SHOOK, C. L. The dimension of organizational performance and its implications for strategic management research. In: KETCHEN, D. J.; BERGH, D. D. (Org) Research methodology in strategy and management. San Diego: Elsevier, 2005. p. 259-286.

COOPER, D. R.; SCHINDLER, P. S. Métodos de pesquisa em administração. 7.ed. Porto Alegre: Bookman, 2003, 640p.

COURTNEY, H.; KIRKLAND, J.; VIGUERIE, P. Strategy under uncertainty. Harvard Business Review, v. 75, n. 6, p. 67 - 79, Nov.-Dec., 1997

CRESWELL, J. W. Projeto de pesquisa: métodos qualitativo, quantitativo e misto. Porto Alegre: Artmed, 2007.

CRONBACH, L. J.; MEEHL, P. E. Construct validity in psychological tests. Psychological Bulletin, v. 52, n.4, p. 281- 302, 1955.

CROTEAU, A. M.; RAYMOND, L. Performance outcomes of strategic and IT competencies alignment. Journal of Information Technology, v.19, n.3, p. 178-190, 2004. 
DAVENPORT, T. H. SHORT, J. E. The new industrial engeneering: information technology and business process redesign. Sloan management review, v. 31, n. 4, p. 11-27, 1990.

DESS, G. G. Consensus on strategy formulation and organizational performance: competitors in a fragmented industry. Strategic Management Journal, v. 8, n.3, p. 259-277, 1987.

DESS, G. G., PRIEM, R. L. Consensus-performance research: Theoretical and empirical extensions. The Journal of Management Studies, v. 32, n.4, p. 401-417, 1995.

DRAZIN, R.; VAN DE VEN, A. H. Alternative Forms of Fit in Contingency Theory. Administrative Science Quarterly, v. 30, n. 4, p. 514-539, 1985.

EISENHARDT, K. M. Strategy as strategic decision making. Sloan Management Review, v. 40, n.3, p.65-72, 1999.

EISENHARDT, K. M.; SULL, D. M. Strategy as simple rules. Harvard Business Review, v. 79, n.1, p.106-116, 2001.

ENNEN, E.; RICHTER, A. The Whole Is More Than the Sum of Its Parts-- Or Is It? A Review of the Empirical Literature on Complementarities in Organizations. Journal of Management, v. 36, n. 1, p. 207-233, 2010.

ETZIONI A. A Comparative analysis of complex organizations. New York: Free Press, 1961.

FAUL, F.; ERDFELDER, E.; LANG, A.-G.; BUCHNER, A. G*power3: a flexible statistical power analysis program for the social, behavioral, and biomedical sciences. Behavior Research Methods, v. 39, n.2, p. $175-191,2007$.

FERNANDES FILHO, A. Identificação do grau de alinhamento estratégico da tecnologia de informação com os planos de negócios: o caso da UNISINOS. 2003. 137p. Dissertação (Mestrado) - Universidade Federal do Rio Grande do Sul, Porto Alegre, 2003. Disponível em: <http://bdtd.ibict.br/>. Acesso: 01 Jun. 2010.

FLEURY, A. C.; FLEURY, M. T. L. Aprendizagem e inovação organizacional: as experiências de Japão, Coréia e Brasil. 2. ed., São Paulo: Atlas, 1997.

FLEURY, A. C.; FLEURY, M. T. L. Estratégias empresariais e formação de competências. São Paulo: Atlas, 2000.

FLOYD, S. W.; WOOLDRIDGE, B. Managing strategic consensus: the foundation of effective implementation. Academy of Management Executive, v.6, n.4, p. 27-39, 1992a.

FLOYD, S. W.; WOOLDRIDGE, B. Middle management involvement in strategy and its association with strategic type: a research note. Strategic Management Journal. v.13, n.8, p. $153-167,1992 b$.

FORNELL, C.; LARCKER, D. F. Evaluating structural equation models with unobservable variables and measurement error. Journal of Marketing Research, v. 18, p. 39-50, 1981. 
FUCHS, P. H. et al.. Strategic integration: competing in the age of capabilities. California Management Review, v. 42, n.3, p.118 - 147, 2000.

GAGNON, M.; JANSEN, K.; MICHAEL, J. Employee Alignment with Strategic Change: a study of strategy-supportive behavior among blue-collar employees. Journal of Managerial Issues, v.20, n.4, p.425, 2008.

GALBRAITH, J. R. Organization design. Reading, Mass.: Addison-Wesley Pub.Co., 1977.

GALBRAITH, J. R.; KAZANJIAN, R. K. Strategy implementation: structure, systems and process. St Paul: West Pub., 1986.

GERDIN, J.; GREVE, J. Forms of contingency fit in management accounting research - a critical review. Accounting, Organizations and Society, v. 29, n. 3,4, p. 303-326, 2004.

GHOSHAL, S.; BARTLETT, C. A. Changing the role of top management: beyond structure to process. Harvard Business Review. v. 73, n.1, p.86 - 96, 1995.

GILBERT JR., A. H.; REID, R. C. An analysis of the relationships among information scope, organizational proactiveness, and firm performance. Academy of Accounting \& Financial Studies Journal, v.13, n.4, p.1-19, 2009.

GINSBERG, A.; VENKATRAMAN, N. Contingency perspectives of organizational strategy: a critical review of the empirical research. Academy of Management. The Academy of Management Review, v. 10, n. 3, p. 421-434, 1985.

GOVINDARAJAN, V. Implementing competitive strategies at the business unit level: implications of matching managers to strategies. Strategic Management Journal, v. 10, $\mathrm{n}$. 3, p. 251-269, 1989.

GRANT, R. M. The resource-based theory of competitive advantage: implications for strategy formulation. California Management Review. v.33, n.3, p.114-135,1991.

HACKMAN, R. J.; WAGEMAN, R. Total quality management: empirical conceptual and pratical issues. Administrative Science Quarterly, v. 40, n. 2, p. 309-342, 1995.

HAIR JR. J. F.; ANDERSON, R. E.; TATHAM, R.L. ; BLACK, W. C. Análise muitivariada de dados. 5. ed. Porto Alegre: Bookman, 2005.

HAIR JR. J. F.; ANDERSON, R. E.; TATHAM, R.L.; BLACK, W. C. Multivariate data analysis. $5^{\text {th }}$ ed. New Jersey: Prentice Hall, 2009.

HAMBRICK, D. C. Some tests of the effectiveness and functional attributes of miles and snow's strategic types. Academy of Management Journal, v. 26, n. 1, p. 5-26, 1983.

HAMBRICK, D. C. On the staying power of defenders, analyzers, and prospectors. The Academy of Management Executive, v. 17, n. 4, 2003.

HAMBRICK, D. C.; CANNELLA JR. A. A. Strategy implementation as substance and selling. Academy of Management Executive, v.3, n.4, p. 278-285, 1989. 
HENSELER; J.; RINGLE, C. M.; SINKOVICS, R. R. The use of partial least squares path modeling in international marketing. Advances in International Marketing, v. 20, p. 277319, 2009.

HILL, A.; BROWN, S. Strategic profiling - A visual representation of internal strategic fit in service organisations. International Journal of Operations \& Production Management, v. 27, n. 12, p. 1333-1361, 2007.

HITT, M. A.; IRELAND, R. D. Corporate Distinctive Competence, Strategy, Industry and Performance. Strategic Management Journal, v.6, n.3, p.273-293, 1985.

HITT, M. A.; IRELAND; R. D.; HOSKISSON, R. E. Administração estratégica: competitividade e globalização. São Paulo: Thomson Learning, 2. ed., 2008.

HITT, M., A.; IRELAND, R. D.; PALIA, K. A. Industrial firms' grand strategy and functional importance: Moderating effects of technology and uncertainty. Academy of Management Journal, v. 25, n. 2, p. 265- 298, 1982.

HOMBURG, C.; KROHMER, H.; WORKMAN JR., J. P. Strategic consensus and performance: The role of strategy type and market-related dynamism. Strategic Management Journal, v. 20, p. 339-357, 1999.

HOYLE, R. H. 1995. Structural equation modeling: concepts, issues, and applications. Thousand Oaks, CA.: Sage Pub.

HOYLE, R. H.; PANTER, A. T. Writing about structural equation models. In: Structural equation modeling: concepts, issues, and applications. Thousand Oaks, CA: CA.: Sage Pub., 1995, p. $158-176$.

HREBINIAK, L. G. Fazendo a estratégia funcionar: o caminho para uma execução bemsucedida. Porto Alegre: Bookman, 2006.

HREBINIAK, L. G.; JOYCE, W. F. Implementing Strategy: An appraisal and agenda for future research. In: HITT, M.; FREEMAN, R. E.; HARRISON, J. (Eds). Handbook of Strategic Management. Oxford: Blackwell Business, 2001, p. 602-626.

HULLAND, J. Use of partial least squares (PLS) in strategic management research: a review of four recent studies. Strategic Management Journal, v. 20, n. 2, p. $195-204$, 1999.

JARVIS, C. B.; MACKENZIE, S. B.; PODSAKOFF, P. M. A critical review of construct indicators and measurement model misspecification in marketing and consumer research. Journal of Consumer Research, v. 30, n.2, p. 199-218, 2003. In: BIDO, D. S. Modelagem em equações estruturais com estimação via partial least squares. Material de curso ministrado na Universidade Presbiteriana Mackenzie, São Paulo, de 08 a 20 de maio de 2008. Disponível em: <https://groups.google.com/group/mee-pls?hl=pt\&pli=1>. Acesso em: 30 Abr. 2010.

JOSHI, M. P., KATHURIA, R., PORTH, S., J. Alignment of strategic priorities and performance: An integration of operations and strategic management perspectives. Journal of Operations Management, v. 21, n. 3, p. 353-369, 2003. 
KAPLAN, R. S.; NORTON, D. P. The balanced scorecard: measures that drive performance. Harvard Business Review, v. 70, n.1, p. 71-79, Jan./Feb., 1992.

KAPLAN, R. S.; NORTON, D. P. Putting the balanced scorecard to work. Harvard Business Review, v. 71, n. 5, p. 134 - 147, Sep./Oct., 1993.

KAPLAN, R. S.; NORTON, D. P. Using the balanced scorecard as a strategic management system. Harvard Business Review, v. 74, n. 1, p. 75 - 85, Jan./Feb., 1996.

KAPLAN, R. S.; NORTON, D. P. A estratégia em ação: balanced scorecard. Rio de Janeiro:Campus, 1997, 333p.

KAPLAN, R. S.; NORTON, D. P. Having Trouble With Your Strategy? Then map it. Harvard Business Review, v. 78, n. 5, p. 167-176, Sep/Oct, 2000.

KAPLAN, R. S.; NORTON, D. P. Alinhamento: Utilizando o balanced scorecard para criar sinergias corporativas. Rio de Janeiro: Elsevier, 2006.

KATHURIA, R.; JOSHI, M. P.; PORTH, S. J. Organizational alignment and performance: past, present and future. Management Decision, v. 45, n. 3, p. 503-517, 2007.

KRAATZ, M. S.; ZAJAC, E. J. How organizational resources affect strategic change and performance in turbulent environments: Theory and evidence. Organization Science, v. 12, n.5, 632-657, 2001.

LABOVITZ, G.; ROSANSKY, V. The power of alignment: how great companies stay centered and accomplish extraordinary things. EUA: John Wiley e Sons, 1997.

LAWRENCE, P.; J. LORSCH. Organization and Environment. Boston: Harvard Business School Press, 1967.

LEE, R. G.; DALE, B. G. Business process management: a review and evaluation. Business Process Management Journal, v.4, n. 3, p. 214 - 225, 1998.

LUO, Y. D.; PARK, S. H. Strategic alignment and performance of market-seeking MNCs in China. Strategic Management Journal, v. 22, n.2, p. 141-155, 2001.

MALINA, M. A.; SELTO, F. H. Communicating and controlling strategy: an empirical study of the effectiveness of the balanced scorecard. Journal of Management Accounting Research, v.13, p.47-90, 2001.

McCONKEY, D. Planning in a changing environment. Business Horizons. v. 31, n.5, p.6472,Sep.-Oct., 1988.

MCDANIEL, S. W.; KOLARI, J. W. Marketing strategy implications of the miles and snow strategic typology. Journal of Marketing, v. 51, n.4, p. 19-30, 1987.

MENOR, L.; ROTH, A. New Service Development Competence and Performance: An Empirical Investigation in Retail Banking. Production and Operations Management, v. 17, n.3, p. 267-284, 2008. 
MEYER, A. D. Visual data in organizational research. Organization Science, v.2, n.2, p. 218-236, 1991.

MILES, R. E.; SNOW, C. C. Fit, Failure and the Hall of Fame. California Management Review, v. 26, n. 3, p. $10-28,1984$.

MILES, R. H; SNOW, C. C. Organizational strategy, structure and process. Sanford, CA: University Press, 2003.

MILLER, D. The structural and environmental correlates of business strategy. Strategic Management Journal, v. 8, n.1, p. $55-76,1987$.

MILLIKEN, F. J. Three Types of Perceived Uncertainty About the Environment: State, Effect, and Response Uncertainty. Academy of Management. The Academy of Management Review, v. 12, n.1, p. 133-143, 1987.

MINISTÉRIO DA CIÊNCIA E TECNOLOGIA. Biblioteca Digital Brasileira de Teses e Dissertações. Disponível em < http://bdtd.ibict.br/>. Acesso em Jan. 2010.

MINTZBERG, H. Patterns in strategy formation. Management Science, v. 24, n.9, p. 934948, 1978.

MINTZBERG, $\mathrm{H}$. The fall and rise of strategic planning. Harvard Business Review, p.107114, Jan./Feb., 1994.

MINTZBERG, H.; WATERS, J. A. Of strategies, deliberate and emergent. Strategic Management Journal. v. 6, p. 257-272, Jul.-Sep., 1985.

MONTEIRO DE BARROS, L. A. Alinhamento Estratégico. São Paulo: 2007. 159p. Tese (Doutorado) - Faculdade de Economia, Administração e Contabilidade, Universidade de São Paulo. São Paulo, 2007.

NACHTIGALL, C.; KROEHNE, U.; FUNKE, F.; STEYER, R. (Why) Should we use SEM? pros and cons of structural equation modeling. Methods of psychological research on line, v. 8, n.2, p. 1-22, 2003.

NADLER, D.; TUSHMAN, M.L. Designing organizations that have good fit. A framework for understanding new architectures. In: NADLER, D.A., GERSTEIN, M.S.; SHAW, R.B. (Eds.), Organizational Architecture: Designs for Changing Organizations. San Francisco: Jossey-Bass Publishers, 2001.

NAMAN, J.N.; SLEVIN, D. Entrepeneurship and the concept of fit: a model and empirical tests. Strategic Management Journal, v. 14, n.2, p. 137 - 153, 1993.

NARVER, J. C.; SLATER, S. F.; MACLACHLAN, D. L. Responsive and proactive market orientation and new product success. Journal of Product Innovation Management, v. 21, $\mathrm{n}$. 5, p. $334-347,2004$.

NEELY, A. The evolution of performance measurement research: developments in the last decade and a research agenda for the next. International Journal of Operations \& Production Management, v. 25, n. 12, p. 1264-1277, 2005. 
NETEMEYER, R.G.; BEARDEN, W. O.; SHARMA, S. Scaling Procedures: issues and applications. Thousand Oaks: Sage Publications, 2003. 206p.

NOBLE, C. $\mathrm{H}$. The eclectic roots of strategy implementation. Journal of Business Research, v. 45, p. $119-134,1999$.

NOBLE, C., H.; MOKWA M. P. Implementing marketing strategies: Developing and testing a managerial theory. Journal of Marketing, v.63, n.4, p. $57-73,1999$.

NOHRIA, N.; JOYCE, W.; ROBERSON, B. What really works. Harvard Business Review, p. 42-52. July, 2003.

OLSON, E., M.; SLATER, S., F.; HULT, G. T. M. The Performance Implications of Fit Among Business Strategy, Marketing Organization Structure, and Strategic Behavior. Journal of Marketing, v. 69, n.3, p. 49-65, 2005.

PARISH, J. T.; CADWALLADER, S.; BUSCH, P. Want to, need to, ought to: employee commitment to organizational change. Journal of Organizational Change Management, $v$. 21, n.1, p. 32-52, 2008.

PEARCE, J. A., ROBINSON, R. B. Strategic Management - Strategy Formulation and Implementation, 6.ed. Chicago et al: Blackwell Publishing, 1997.

PETERAF, M.; REED, R. Managerial discretion and internal alignment under regulatory constraints and change. Strategic Management Journal, v. 28, n.11, 2007.

PETERS, T.; WATERMAN, R. In Search of Excellence: lessons from America's best-run companies. New York, Time Warner, 1982.

PORTER, MICHAEL E. Estratégia competitiva: técnicas para análise de indústrias e da concorrência. Rio de Janeiro: Campus, 1986.

PORTER, MICHAEL E. What is strategy? Harvard Business Review, v.74, n.6, p.61-78, Nov./Dec. 1996.

POWELL, T. C. Organizational alignment as competitive advantage. Strategic Management Journal. v. 13, n.2, p. 119-134, Feb., 1992.

PRIEM, RICHARD L. Top management team group factors, consensus, and firm performance. Strategic Management Journal. v.11, n.6, p.469-478, Oct.1990.

PRIETO, V. C. Análise de modelos de alinhamento estratégico interno. São Paulo: 2006. 145p. Dissertação (Mestrado) - Departamento de Engenharia de Produção, Escola Politécnica da Universidade de São Paulo. São Paulo, 2006.

PRIETO, V. C., CARVALHO, M. M. Análise comparativa de modelos de alinhamento estratégico: estudo de múltiplos casos In: XXVI Encontro Nacional de Engenharia de Produção, ENEGEP, 2006, Fortaleza. Anais eletrônicos - ENEGEP 2006. CD ROM.

PRIETO, V. C.; CARVALHO, M. M. Strategic alignment and performance: Brazilian companies in the medical diagnostics sector. The Service Industries Journal, 2010 (aprovado para publicação). 
PRIETO, V. C.; CARVALHO, M. M.; FISCHMANN, A. A. Análise comparativa de modelos de alinhamento estratégico. Revista Produção, v.19, n.2, p. 317-331, 2009.

RAPERT, M. I.; VELLIQUETTE, A.; GARRETSON, J. A. The strategic implementation process - Evoking strategic consensus through communication. Journal of Business Research, v.55, n.4, p.301-310, 2002.

RAY, G.; BARNEY, J. B.; MUHANNA, W. A. Capabilities, business processes, and competitive advantage: choosing the dependent variable in empirical tests of the resourcebased view. Strategic Management Journal, v. 25, n. 1, p. 23-37, 2004.

REICH, B. H.; BENBASAT, I. Factors that influence the social dimension of alignment between business and information technology objectives. Mis Quarterly, v. 24, n.1, p. 81 $113,2000$.

RHEE, M. S. The impact of the strategic fit on business performance: Empirical study in the banking industry. (Doctoral Dissertation). The University of Memphis, United States Tennessee. (1998). Retrieved from ProQuest Dissertations \& Theses (UMI No. 9834244), 1998.

RHEE, M.; MEHRA, S. Aligning operations, marketing, and competitive strategies to enhance performance: An empirical test in the retail banking industry. Omega-International Journal of Management Science, v. 34, n.5, p. 505-515, 2006.

RINGLE, C. M.; WENDE, S.; WILL, A. SmartPLS 2.0 M3 (beta). Germany: University of Hamburg, 2005. Disponível em: <http://www.smartpls.de>. Acesso em: 28/09/2010.

RUSJAN, B. The impact of a manufacturing focus on manufacturing and business unit performance: an empirical investigation. Economic and Business Review for Central and South - Eastern Europe, v. 8, n. 1, 2006.

SABHERWAL, R.; CHAN, Y. E. Alignment between business and IS strategies: a study of prospectors, analyzers, and defenders. Information Systems Research, v. 12, n. 1, p. $11-$ 33, 2001.

SANTOS, J. B. Uma proposta de conceituação e representação do desempenho empresarial. 2008. 126p. Dissertação (Mestrado) - Escola de Administração de São Paulo, EAESP, FGV, São Paulo, Brasil, 2008.

SHARFMAN, M.; DEAN JR., J. W. Conceptualizing and measuring the organizational environment: a multidimensional approach. Journal of Management, v. 17, n.4, p.681 700, 1991.

SHORTELL, S. M.; ZAJAC, E. J. Perceptual and Archival Measures of Miles and Snow's Strategic Types: A Comprehensive Assessment of Reliability and Validity. Academy of Management Journal, v. 33, n.4, 1990.

SIGGELKOW, N. Change in the presence of fit: The rise, the fall, and the renaissance of Liz Claiborne. Academy of Management Journal, v.44, n.4, 2001.

SIGGELKOW, N. Evolution toward fit. Administrative Science Quarterly, v. 47, n.1, p. 125159, 2002. 
SLATER, S. F.; OLSON, E. M. Strategy type and performance: The influence of sales force management. Strategic Management Journal, v. 21, n.8, p. $813-829,2000$.

SNOW, C. C.; HREBINIAK, L. G. Strategy, distinctive competence, and organizational performance. Administrative Science Quarterly, v.25, p. 336 - 371, 1980.

SOKOLOSKI, P. K. M. O relacionamento entre incerteza ambiental percebida, estratégia organizacional, grupos estratégicos e desempenho. 2007. 99p. Dissertação (Mestrado) Pontifícia Universidade Católica do Paraná, Curitiba 2007. Disponível em: $<$ http://www.biblioteca.pucpr.br/tede//tde busca/arquivo.php?codArquivo=864>. Acesso: 01 Jun. 2010.

SPECKBACHER, G.; BISCHOF, J.; PFEIFFER, T. A descriptive analysis on the implementation of balanced scorecards in german-speaking countries. Management Accounting Research. v. 14, n. 4, p. 361-887, 2003.

STEPANOVICH P.L.; MUELLER, J. D. Mapping strategic consensus. Journal of Business and Management, v. 8, n.2, p. 147-164, 2002.

TALLON, P. P.; KRAEMER, K. L.; GURBAXANI, V., Executives' perceptions of the business value of information technology: A process-oriented approach. Journal of Management Information Systems, v. 16, n.4, p. 145-173, 2000.

TENENHAUS, M.; VINZI, V. E.; CHATELIN, Y.; LAURO, C. PLS Path Modeling. Computational Statistics \& Data Analysis, v. 48, p. 159-205, 2005.

THOMPSON JR., A. A.; STRICKLAND III, A.J. Planejamento Estratégico: elaboração, implementação e execução. São Paulo: Pioneira Thompson Learning, 2003.

VENKATRAMAN, N. The Concept of Fit in Strategy Research: Toward Verbal and Statistical Correspondence. The Academy of Management Review, v. 14, n. 3, p. 423-444, 1989a.

VENKATRAMAN, N. Strategic orientation of business enterprises: the construct, dimensionality, and measurement. Management Science, v. 35, n. 8, p. 942-962, 1989 b.

VENKATRAMAN, N. Performance implications of strategic coalignment: a methodological perspective. Journal of Management Studies, v. 27, n. 1, p. 19-41, 1990.

VENKATRAMAN, N.; CAMILLUS, J. C. Exploring the concept of 'fit' in strategic management. Academy of Management Review. v. 9, n.3, p. 513-525, 1984.

VENKATRAMAN, N.; GRANT, J. H. Construct measurement in organizational strategy research: a critique and proposal. Academy of Management Review, v. 11, n.1, p. 71-87, 1986.

VENKATRAMAN, N.; PRESCOTT, J. E. Environment-Strategy Coalignment: An Empirical Test of Its Performance Implications. Strategic Management Journal, v. 11, n.1, p. 1-23, 1990. 
VENKATRAMAN, N.; RAMANUJAM, V. Measurement of business performance in strategy research: a comparison of approaches. The Academy of Management Review, v. 11, n.4, p. $801-814,1986$.

VENKATRAMAN, N.; RAMANUJAM, V. Measurement of Business Economic Performance: An Examination of Method Convergence. Journal of Management, v. 13, $n$. 1, 109, 1987.

VOSS, C.; TSIKRIKTSIS, N.; FROHLICH, M. Case research in operations management. International Journal of Operations and Production Management, v. 22, n.2, p. 195-219, 2002.

WALDMAN, D., A.; RAMIREZ, G. G.; HOUSE, R., J.; PURANAM, P. Does leadership matter? CEO leadership attributes and profitability under conditions of perceived environmental uncertainty. Academy of Management Journal, v. 44, n. 1, p. $134-143$, 2001.

WANG, E. T. G.; WEI, H. L. The importance of market orientation, learning orientation, and quality orientation capabilities in TQM: an example from Taiwanese software industry. Total Quality Management \& Business Excellence, v. 16, n.10, 2005.

WERNERFELT, B. A resource-based view of the firm. Strategic Management Journal, v. 5, p. 171-180, 1984.

WEST, C. T., JR.; SCHWENK, C. R. Top management team strategic consensus, demographic homogeneity and firm performance: A report of resounding nonfindings. Strategic Management Journal, v. 17, n.7, p. 571 - 576, 1996.

WHETTEN, D. A. O que constitui uma contribuição teórica? RAE-revista de administração de empresas, v. 43, n. 3, p.69-73, 2003.

WOOLDRIDGE, B.; FLOYD. S. W. The Strategy Process, Middle Management Involvement and Organizational Performance. Strategic Management Journal, v.11, n.3, p. $231-241,1990$.

XU, S. C.; CAVUSGIL, S. T.; WHITE, J. C. The impact of strategic fit among strategy, structure, and processes on multinational corporation performance: A multimethod assessment. Journal of International Marketing, v.14, n.2, p. 1-31, 2006.

ZACCARELLI, S.B. A Continuidade do Sucesso. São Paulo, (Working Paper), 2000.

ZAJAC, E. J.; KRAATZ, M. S.; BRESSER, R. K. F. Modeling the dynamics of strategic fit: A normative approach to strategic change. Strategic Management Journal, v.21, n.4, Apr, p.429-453, 2000.

ZWICKER, R.; SOUZA, C. A.; BIDO, D. S. Uma revisão do modelo do grau de informatização de empresas. In: Encontro da Associação Nacional de Pós-Graduação e Pesquisa em Administração - EnANPAD, 32, 2008, Rio de Janeiro. Anais Eletrônicos. Rio de Janeiro: ANPAD 2008. CD-ROM. 


\section{APÊNDICE A - ESTUDOS EMPÍRICOS SOBRE ALINHAMENTO ESTRATÉGICO VERTICAL E HORIZONTAL}

\begin{tabular}{|c|c|c|c|}
\hline Ref. & Autor & $\begin{array}{l}\text { Tema ou conceito de } \\
\text { alinhamento em estudo }\end{array}$ & Objetivos do estudo \\
\hline \multicolumn{4}{|c|}{ Alinhamento vertical } \\
\hline \multicolumn{4}{|c|}{ Alinhamento entre a estratégia de negócios e a área de operações/compras } \\
\hline 1 & Joshi, Kathuria e Porth (2003) & $\begin{array}{l}\text { Alinhamento entre prioridades } \\
\text { competitivas de manufatura }\end{array}$ & $\begin{array}{l}\text { Testar a hipótese de que o alinhamento sobre a percepção } \\
\text { das prioridades competitivas, entre o Diretor Geral (DG) e o } \\
\text { Gerente de Manufatura (GM) tem relação com a desempenho. }\end{array}$ \\
\hline 2 & Rusjan (2006) & $\begin{array}{l}\text { Alinhamento entre prioridades } \\
\text { competitivas da estratégia de } \\
\text { negócios e da área de } \\
\text { operações. }\end{array}$ & $\begin{array}{l}\text { Analisar o consenso entre as prioridades competitivas } \\
\text { (estratégia de negócios e funcional) e a relação com o DO }\end{array}$ \\
\hline 3 & $\begin{array}{l}\text { Baier, Hartmann e Moser } \\
(2008)\end{array}$ & $\begin{array}{l}\text { Alinhamento entre a } \\
\text { estratégia do negócio e a } \\
\text { estratégia de compras }\end{array}$ & $\begin{array}{l}\text { Investigar a relação alinhamento-desempenho na área de } \\
\text { gestão de compras e fornecedores }\end{array}$ \\
\hline \multicolumn{4}{|c|}{ Alinhamento dos recursos humanos à estratégia de negócios } \\
\hline 5 & Luo, Park (2001) & $\begin{array}{l}\text { Alinhamento em empresas } \\
\text { multinacionais }\end{array}$ & $\begin{array}{l}\text { Explorar a relação entre ambiente-estratégia-desempenho no } \\
\text { contexto de empresas estrangeiras. }\end{array}$ \\
\hline
\end{tabular}

continua 
continuação

\begin{tabular}{|c|c|c|c|}
\hline Ref. & Autor & $\begin{array}{l}\text { Tema ou conceito de } \\
\text { alinhamento em estudo }\end{array}$ & Objetivos do estudo \\
\hline \multicolumn{4}{|c|}{ Alinhamento envolvendo empresas multinacionais } \\
\hline 6 & Xu, Cavusgil e White (2006) & $\begin{array}{l}\text { Alinhamento entre uma } \\
\text { estratégia de marketing } \\
\text { global e as características da } \\
\text { organização local. }\end{array}$ & $\begin{array}{l}\text { Examinar os efeitos e a forma de alinhamento entre uma } \\
\text { estratégia de marketing global e as características da } \\
\text { organização local. }\end{array}$ \\
\hline 7 & Wooldridge, Floyd (1990) & Consenso estratégico & $\begin{array}{l}\text { Investigar a relação entre o envolvimento do nível gerencial } \\
\text { médio com a estratégia e o DO. }\end{array}$ \\
\hline 8 & Floyd, Wooldridge (1992a) & Consenso estratégico & $\begin{array}{l}\text { Examinar uma abordagem de implementação que foca no } \\
\text { nível de compreensão e comprometimento compartilhado por } \\
\text { gestores dentro da organização. }\end{array}$ \\
\hline 10 & Boyer e McDermott (1999) & $\begin{array}{l}\text { Consenso entre prioridades } \\
\text { competitivas e operacionais }\end{array}$ & $\begin{array}{l}\text { Examinar a importância e a presença de argumentos teóricos } \\
\text { sobre consenso estratégico em diferentes plantas de } \\
\text { manufatura. }\end{array}$ \\
\hline 11 & $\begin{array}{l}\text { Homburg, Krohmer, } \\
\text { Workman Jr (1999) }\end{array}$ & $\begin{array}{l}\text { Consenso sobre a estratégia } \\
\text { de negócios }\end{array}$ & $\begin{array}{l}\text { Examinar a relação entre o consenso dos gerentes sobre a } \\
\text { estratégia de negócios e o desempenho e os fatores que } \\
\text { podem moderar esta relação. }\end{array}$ \\
\hline
\end{tabular}


continuação

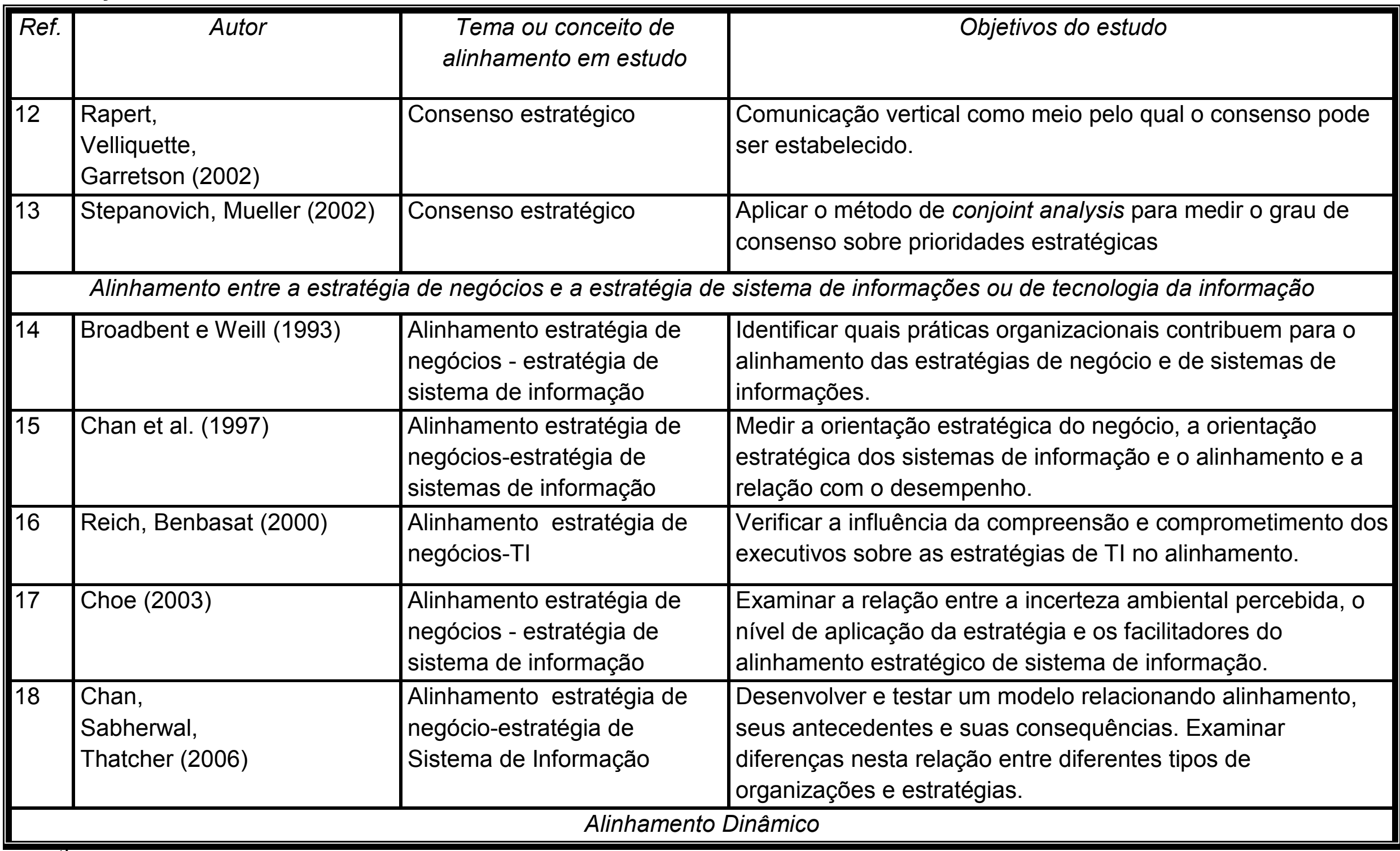


continuação

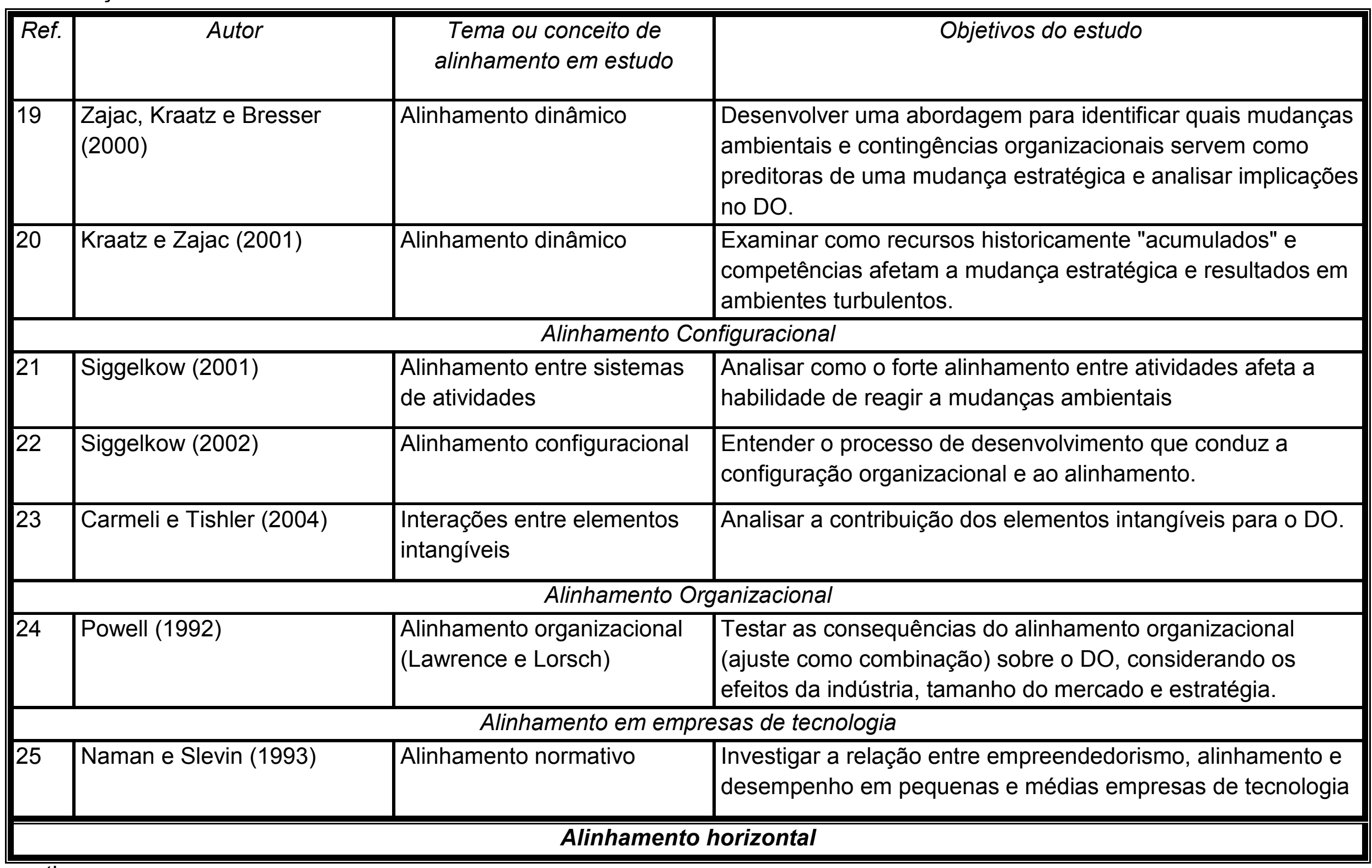

continua 
conclusão

\begin{tabular}{|l|l|l|l||}
\hline \hline Ref. & \multicolumn{1}{|c|}{ Autor } & \multicolumn{1}{|c|}{$\begin{array}{l}\text { Tema ou conceito de } \\
\text { alinhamento em estudo }\end{array}$} & \multicolumn{1}{|c}{ Objetivos do estudo } \\
\hline \hline 26 & $\begin{array}{l}\text { Rhee e } \\
\text { Mehra (2006) }\end{array}$ & $\begin{array}{l}\text { Alinhamento entre operações } \\
\text { e marketing. }\end{array}$ & $\begin{array}{l}\text { Impacto do alinhamento entre operações e marketing e a } \\
\text { estratégia competitiva para o desempenho. }\end{array}$ \\
\hline 27 & Hill e Brown (2007) & $\begin{array}{l}\text { Alinhamento entre mercado, } \\
\text { estratégia de operações, } \\
\text { sistema de entrega do serviço }\end{array}$ & $\begin{array}{l}\text { Apresentar instrumento para visualização do Alinhamento } \\
\text { Interno. }\end{array}$ \\
\hline
\end{tabular}




\section{APÊNDICE B - ESTUDOS EMPÍRICOS SOBRE ALINHAMENTO ESTRATÉGICO}

\begin{tabular}{|c|c|c|c|c|c|c|c|}
\hline Autor & $\begin{array}{c}\text { Abordagem } \\
\text { Pesquisa } \\
\text { (1) }\end{array}$ & $\begin{array}{c}\text { Método } \\
\text { (2) }\end{array}$ & $\begin{array}{c}\text { Técnica } \\
\text { estatística }\end{array}$ & Amostra & $\begin{array}{c}\text { Tema ou } \\
\text { conceito de } \\
\text { alinhamento } \\
\text { em estudo }\end{array}$ & $\begin{array}{c}\text { Objetivos do } \\
\text { estudo }\end{array}$ & Contribuições \\
\hline $\begin{array}{l}\text { Baier, } \\
\text { Hartmann e } \\
\text { Moser } \\
(2008)\end{array}$ & QT & SV/QU & \begin{tabular}{|l} 
Distância \\
Euclidiana \\
Análise de \\
regressão
\end{tabular} & $\begin{array}{l}141 \text { executivos } \\
\text { de Compras de } \\
\text { unidades de } \\
\text { negócios } \\
\text { globais, de } \\
\text { diversas } \\
\text { indústrias }\end{array}$ & $\begin{array}{l}\text {. Alinhamento } \\
\text { entre a } \\
\text { estratégia do } \\
\text { negócio e a } \\
\text { estratégia de } \\
\text { compras } \\
\text { Ajuste como } \\
\text { desvio de } \\
\text { perfil }\end{array}$ & $\begin{array}{l}\text { Investigar a relação } \\
\text { alinhamento- } \\
\text { desempenho na } \\
\text { área de gestão de } \\
\text { compras e } \\
\text { fornecedores }\end{array}$ & $\begin{array}{l}\text { O perfil ideal de } \\
\text { prioridades competitivas } \\
\text { em compras difere entre } \\
\text { unidades de negócios de } \\
\text { acordo com as } \\
\text { estratégias adotadas } \\
\text { (custo e diferenciação). } \\
\text { As funções de compras } \\
\text { que aderem ao perfil } \\
\text { ideal suportam a posição } \\
\text { competitiva da unidade } \\
\text { de negócio. }\end{array}$ \\
\hline
\end{tabular}


continuação

\begin{tabular}{|c|c|c|c|c|c|c|c|}
\hline Autor & $\begin{array}{c}\text { Abordagem } \\
\text { Pesquisa } \\
\text { (1) }\end{array}$ & $\begin{array}{c}\text { Método } \\
\text { (2) }\end{array}$ & $\begin{array}{c}\text { Técnica } \\
\text { estatística }\end{array}$ & Amostra & $\begin{array}{c}\text { Tema ou } \\
\text { conceito de } \\
\text { alinhamento } \\
\text { em estudo }\end{array}$ & $\begin{array}{l}\text { Objetivos do } \\
\text { estudo }\end{array}$ & Contribuições \\
\hline $\begin{array}{l}\text { Boyer e } \\
\text { MCDermott } \\
(1999)\end{array}$ & QL/QT & EC-SV & ANOVA & $\begin{array}{l}10 \text { gestores e } \\
10 \text { funcionários } \\
\text { de nível } \\
\text { operacional em } \\
7 \text { empresas de } \\
\text { manufatura }\end{array}$ & $\begin{array}{l}\text { Consenso } \\
\text { entre } \\
\text { prioridades } \\
\text { competitivas e } \\
\text { alinhamento } \\
\text { destas com as } \\
\text { diretrizes } \\
\text { operacionais }\end{array}$ & \begin{tabular}{|l} 
Examinar a \\
importância e a \\
presença de \\
argumentos \\
teóricos sobre \\
consenso \\
estratégico em \\
diferentes plantas \\
de manufatura
\end{tabular} & $\begin{array}{l}\text { Discordâncias entre } \\
\text { aspectos fundamentais } \\
\text { como prioridades } \\
\text { competitivas e } \\
\text { investimentos em } \\
\text { infraestrutura e estrutura. }\end{array}$ \\
\hline $\begin{array}{l}\text { Broadbent e } \\
\text { Weill (1993) }\end{array}$ & $\mathrm{BO}$ & QU-E & $\begin{array}{l}\text { estatistica } \\
\text { descritiva }\end{array}$ & 4 bancos & $\begin{array}{l}\text { Alinhamento } \\
\text { estratégia de } \\
\text { negócios - } \\
\text { estratégia de } \\
\text { SI }\end{array}$ & $\begin{array}{l}\text { Quais práticas } \\
\text { organizacionais } \\
\text { contribuem para o } \\
\text { alinhamento das } \\
\text { estratégias de } \\
\text { negócio e de } \\
\text { sistemas de } \\
\text { informações }\end{array}$ & $\begin{array}{l}\text { Proposta de um modelo } \\
\text { de alinhamento com as } \\
\text { práticas agrupadas em } 4 \\
\text { grandes grupos: } \\
\text { amplitude do processo } \\
\text { de formação da } \\
\text { estratégia, } \\
\text { responsabilidades e } \\
\text { diretrizes do Sistema de } \\
\text { Informação, estrutura e } \\
\text { responsabilidades } \\
\text { organizacionais e } \\
\text { estratégia de tecnologia. }\end{array}$ \\
\hline
\end{tabular}


continuação

\begin{tabular}{|c|c|c|c|c|c|c|c|}
\hline Autor & $\begin{array}{c}\text { Abordagem } \\
\text { Pesquisa } \\
\text { (1) }\end{array}$ & $\begin{array}{l}\text { Método } \\
\text { (2) }\end{array}$ & $\begin{array}{l}\text { Técnica } \\
\text { estatística }\end{array}$ & Amostra & $\begin{array}{c}\text { Tema ou } \\
\text { conceito de } \\
\text { alinhamento } \\
\text { em estudo }\end{array}$ & $\begin{array}{l}\text { Objetivos do } \\
\text { estudo }\end{array}$ & Contribuições \\
\hline $\begin{array}{l}\text { Carmeli e } \\
\text { Tishler } \\
(2004)\end{array}$ & QT/QL & QU & $\begin{array}{l}\text { Método de } \\
\text { análise } \\
\text { canônica } \\
\text { robusta } \\
\text { (RCA) }\end{array}$ & $\begin{array}{l}\text { Mail survey, } 99 \\
\text { respondentes, } \\
\text { setor público }\end{array}$ & \begin{tabular}{|l|} 
Interações \\
entre \\
elementos \\
intangíveis
\end{tabular} & $\begin{array}{l}\text { analisar a } \\
\text { contribuição dos } \\
\text { elementos } \\
\text { intangíveis para o } \\
\text { desempenho } \\
\text { organizacional }\end{array}$ & \begin{tabular}{|l} 
Os elementos \\
organizacionais \\
intangíveis estão \\
positivamente \\
relacionados com as \\
medidas de DO, em \\
especial cultura e \\
reputação
\end{tabular} \\
\hline $\begin{array}{l}\text { Chan et al. } \\
(1997)\end{array}$ & QT & SV-QU & MEE & $\begin{array}{l}170 \\
\text { respondentes, } \\
\text { empresas } \\
\text { norte- } \\
\text { americanas de } \\
\text { serviço e } \\
\text { manufatura }\end{array}$ & $\begin{array}{l}\text { alinhamento } \\
\text { estratégia de } \\
\text { negócios- } \\
\text { estratégia de } \\
\text { sistemas de } \\
\text { informação }\end{array}$ & $\begin{array}{l}\text { Medir o } \\
\text { alinhamento entre } \\
\text { estratégica do } \\
\text { negócio, } \\
\text { estratégica dos SI } \\
\text { e relação com DO }\end{array}$ & $\begin{array}{l}\text { Empresas com melhor } \\
\text { alinhamento de SI têm } \\
\text { melhor desempenho. }\end{array}$ \\
\hline $\begin{array}{l}\text { Chan, } \\
\text { Sabherwal, } \\
\text { Thatcher } \\
(2006)\end{array}$ & QT & SVIQU & $\begin{array}{l}\text {.PLS para } \\
\text { testar } \\
\text { hipótese } \\
\text {.Dist. } \\
\text { Euclidiana }\end{array}$ & $\begin{array}{l}244 \\
\text { instituições: } \\
\text { industrial e } \\
\text { acadêmica }\end{array}$ & $\begin{array}{l}\text { Alinhamento } \\
\text { estratégia de } \\
\text { negócio- } \\
\text { estratégia de } \\
\text { Sistema de } \\
\text { Informação }\end{array}$ & $\begin{array}{l}\text { Testar modelo } \\
\text { relacionando } \\
\text { alinhamento, seus } \\
\text { antecedentes e } \\
\text { suas } \\
\text { consequências }\end{array}$ & $\begin{array}{l}\text { Confirma a relação entre } \\
\text { alinhamento e DO }\end{array}$ \\
\hline
\end{tabular}


continuação

\begin{tabular}{|c|c|c|c|c|c|c|c|}
\hline Autor & $\begin{array}{c}\text { Abordagem } \\
\text { Pesquisa } \\
\text { (1) }\end{array}$ & $\begin{array}{c}\text { Método } \\
\text { (2) }\end{array}$ & $\begin{array}{c}\text { Técnica } \\
\text { estatística }\end{array}$ & Amostra & $\begin{array}{c}\text { Tema ou } \\
\text { conceito de } \\
\text { alinhamento } \\
\text { em estudo }\end{array}$ & $\begin{array}{c}\text { Objetivos do } \\
\text { estudo }\end{array}$ & Contribuições \\
\hline Choe (2003) & QT & SV, QU & $\begin{array}{l}\text { Distância } \\
\text { euclidiana }\end{array}$ & $\begin{array}{l}70 \text { empresas } \\
\text { médias }\end{array}$ & $\begin{array}{l}\text { Alinhamento } \\
\text { estratégia de } \\
\text { negócio- } \\
\text { estratégia de } \\
\text { SI }\end{array}$ & $\begin{array}{l}\text { Examinar a relação } \\
\text { entre IA percebida, } \\
\text { nível de aplicação } \\
\text { da estratégia e os } \\
\text { facilitadores do } \\
\text { alinhamento } \\
\text { estratégico de SI. }\end{array}$ & $\begin{array}{l}\text { Em ambientes de } \\
\text { incerteza, um alto nivel } \\
\text { de aplicação da } \\
\text { estratégia pode } \\
\text { contribuir para a } \\
\text { melhoria do DO mais do } \\
\text { que em ambiente mais } \\
\text { estável. }\end{array}$ \\
\hline $\begin{array}{l}\text { Floyd, } \\
\text { Wooldridge } \\
(1992 a)\end{array}$ & QL & $E, Q U$ & & $\begin{array}{l}\text { Alta e média } \\
\text { gerência }\end{array}$ & $\begin{array}{l}\text { Consenso } \\
\text { estratégico }\end{array}$ & $\begin{array}{l}\text { Examinar uma } \\
\text { abordagem de } \\
\text { implementação que } \\
\text { foca no nível de } \\
\text { compreensão e } \\
\text { comprometimento } \\
\text { compartilhado por } \\
\text { gestores dentro da } \\
\text { organização }\end{array}$ & $\begin{array}{l}\text { O artigo produziu um } \\
\text { framework identificando } \\
\text { quatro categorias de } \\
\text { consenso estratégico. }\end{array}$ \\
\hline $\begin{array}{l}\text { Gilbert Jr. e } \\
\text { Reid (2009) }\end{array}$ & QT & SV-QU & MEE & $\begin{array}{l}149 \text { empresas } \\
\text { atuantes em } \\
\text { segmento único }\end{array}$ & $\begin{array}{l}\text { Alinhamento } \\
\text { SI e estratégia }\end{array}$ & $\begin{array}{l}\text { Análise da relação } \\
\text { entre escopo da } \\
\text { informação, } \\
\text { proatividade } \\
\text { organizacional e } \\
\text { DO }\end{array}$ & $\begin{array}{l}\text { Confirmação empírica } \\
\text { do impacto do } \\
\text { alinhamento proposto } \\
\text { sobre o DO. }\end{array}$ \\
\hline
\end{tabular}

continua 
continuação

\begin{tabular}{|c|c|c|c|c|c|c|c|}
\hline Autor & $\begin{array}{c}\text { Abordagem } \\
\text { Pesquisa } \\
\text { (1) }\end{array}$ & $\begin{array}{c}\text { Método } \\
\text { (2) }\end{array}$ & $\begin{array}{c}\text { Técnica } \\
\text { estatística }\end{array}$ & Amostra & $\begin{array}{c}\text { Tema ou } \\
\text { conceito de } \\
\text { alinhamento } \\
\text { em estudo }\end{array}$ & $\begin{array}{c}\text { Objetivos do } \\
\text { estudo }\end{array}$ & Contribuições \\
\hline $\begin{array}{l}\text { Hill e Brown } \\
(2007)\end{array}$ & QT/QL & $\begin{array}{l}E C \\
(E, Q U, \\
A D, D S)\end{array}$ & & $\begin{array}{l}8 \text { organizações } \\
\text { da área de } \\
\text { serviços, mín. } \\
11 \\
\text { respondentes } \\
\text { por caso }\end{array}$ & $\begin{array}{l}\text { Alinhamento } \\
\text { entre } \\
\text { mercado, } \\
\text { estratégia de } \\
\text { operações, } \\
\text { sistema de } \\
\text { entrega do } \\
\text { serviço }\end{array}$ & $\begin{array}{l}\text { Apresentar } \\
\text { instrumento para } \\
\text { visualização do } \\
\text { Alinhamento } \\
\text { Interno }\end{array}$ & $\begin{array}{l}\text { Organizações de serviço } \\
\text { podem usar o perfil de } \\
\text { alinhamento } \\
\text { desenvolvido para } \\
\text { entender seu nível de } \\
\text { alinhamento interno e } \\
\text { porque ele existe, a fim } \\
\text { de entender como } \\
\text { melhorá-lo. }\end{array}$ \\
\hline $\begin{array}{l}\text { Homburg, } \\
\text { Krohmer e } \\
\text { Workman Jr. } \\
(1999)\end{array}$ & QT & SV-QU & $\begin{array}{l}\text { análise de } \\
\text { regressão } \\
\text { múltipla }\end{array}$ & $\begin{array}{l}101 \text { gerentes } \\
\text { de Marketing e } \\
\text { Pesquisa e } \\
\text { Desenv. do } \\
\text { segmento } \\
\text { industrial }\end{array}$ & $\begin{array}{l}\text { Consenso } \\
\text { sobre a } \\
\text { estratégia de } \\
\text { negócios }\end{array}$ & $\begin{array}{l}\text { Examinar a relação } \\
\text { entre o consenso } \\
\text { dos gerentes sobre } \\
\text { a estratégia de } \\
\text { negócios e o } \\
\text { desempenho e os } \\
\text { fatores que podem } \\
\text { moderar esta } \\
\text { relação. }\end{array}$ & $\begin{array}{l}\text { Consenso é mais } \\
\text { importante quando a } \\
\text { empresa adota a } \\
\text { estratégia de } \\
\text { diferenciação, o mesmo } \\
\text { não se evidencia com a } \\
\text { estratégia de liderança } \\
\text { em custos. }\end{array}$ \\
\hline
\end{tabular}

continua 
continuação

\begin{tabular}{|c|c|c|c|c|c|c|c|}
\hline Autor & $\begin{array}{c}\text { Abordagem } \\
\text { Pesquisa } \\
\text { (1) }\end{array}$ & $\begin{array}{c}\text { Método } \\
\text { (2) }\end{array}$ & $\begin{array}{c}\text { Técnica } \\
\text { estatística }\end{array}$ & Amostra & $\begin{array}{c}\text { Tema ou } \\
\text { conceito de } \\
\text { alinhamento } \\
\text { em estudo }\end{array}$ & $\begin{array}{c}\text { Objetivos do } \\
\text { estudo }\end{array}$ & Contribuições \\
\hline $\begin{array}{l}\text { Joshi, } \\
\text { Kathuria e } \\
\text { Porth (2003) }\end{array}$ & QT & SV/QU & & $\begin{array}{l}\text { email survey, } \\
198 \text { dir. e } \\
\text { gerentes } \\
\text { (2/empr) de } 17 \\
\text { industrias }\end{array}$ & $\begin{array}{l}\text { alinhamento } \\
\text { entre } \\
\text { prioridades } \\
\text { competitivas } \\
\text { de manufatura }\end{array}$ & \begin{tabular}{|l} 
Testar a hipótese \\
de que o \\
alinhamento sobre \\
a percepção das \\
prioridades \\
competitivas, entre \\
o Diretor Geral \\
(DG) e o Gerente \\
de Manufatura \\
(GM) tem relação \\
com o desempenho
\end{tabular} & $\begin{array}{l}\text { O estudo não revelou } \\
\text { relação direta entre } \\
\text { alinhamento das } \\
\text { prioridades competitivas } \\
\text { de manufatura e } \\
\text { desempenho da } \\
\text { unidade. Fatores como } \\
\text { tempo de ocupação do } \\
\text { cargo pelos GM e tempo } \\
\text { de trabalho conjunto } \\
\text { entre DG e GM } \\
\text { moderam a relação entre } \\
\text { prioridades de } \\
\text { manufatura e } \\
\text { desempenho da } \\
\text { unidade. }\end{array}$ \\
\hline $\begin{array}{l}\text { Knight et al. } \\
(1999)\end{array}$ & QT & & & $\begin{array}{l}\text { Dados de } 76 \\
\text { empresas de } \\
\text { alta tecnologia }\end{array}$ & & $\begin{array}{l}\text { Investigar como as } \\
\text { características } \\
\text { demográficas e os } \\
\text { processos grupais } \\
\text { influenciam o CE } \\
\text { entre os altos } \\
\text { executivos }\end{array}$ & $\begin{array}{l}\text { A diversidade } \\
\text { demográfica está } \\
\text { negativamente } \\
\text { relacionada com o } \\
\text { consenso. }\end{array}$ \\
\hline
\end{tabular}


continuação

\begin{tabular}{|c|c|c|c|c|c|c|c|}
\hline Autor & $\begin{array}{c}\text { Abordagem } \\
\text { Pesquisa } \\
\text { (1) }\end{array}$ & $\begin{array}{c}\text { Método } \\
\text { (2) }\end{array}$ & $\begin{array}{c}\text { Técnica } \\
\text { estatística }\end{array}$ & Amostra & $\begin{array}{c}\text { Tema ou } \\
\text { conceito de } \\
\text { alinhamento } \\
\text { em estudo }\end{array}$ & $\begin{array}{c}\text { Objetivos do } \\
\text { estudo }\end{array}$ & Contribuições \\
\hline $\begin{array}{l}\text { Luo, Park } \\
(2001)\end{array}$ & QT & $\begin{array}{l}\text { SV/QU/ } \\
\text { DS }\end{array}$ & $\begin{array}{l}\text { Análise de } \\
\text { correlação } \\
\text { canônica } \\
\text { Análise de } \\
\text { regressão } \\
\text { múltipla }\end{array}$ & $\begin{array}{l}113 \\
\text { subsidiárias } \\
\text { com operação } \\
\text { na China }\end{array}$ & $\begin{array}{l}\text { Alinhamento } \\
\text { em empresas } \\
\text { multinacionais }\end{array}$ & $\begin{array}{l}\text { Explorar a relação } \\
\text { entre ambiente- } \\
\text { estratégia- } \\
\text { desempenho no } \\
\text { contexto de } \\
\text { empresas } \\
\text { estrangeiras }\end{array}$ & $\begin{array}{l}\text { Subsidiárias parecem } \\
\text { ver analyzer como a } \\
\text { estratégia apropriada } \\
\text { para China; analyzer tem } \\
\text { melhor desempenho. }\end{array}$ \\
\hline $\begin{array}{l}\text { Naman e } \\
\text { Slevin } \\
(1993)\end{array}$ & QT & SV, QU & $\begin{array}{l}\text { Regressão } \\
\text { linear e } \\
\text { correlação }\end{array}$ & $\begin{array}{l}82 \text { empresas } \\
\text { de manufatura } \\
\text { tecnológica }\end{array}$ & $\begin{array}{l}\text { Alinhamento } \\
\text { normativo }\end{array}$ & $\begin{array}{l}\text { Investigar a relação } \\
\text { entre } \\
\text { empreendedorismo } \\
\text {, alinhamento e DO } \\
\text { em pequenas e } \\
\text { médias empresas } \\
\text { de tecnologia }\end{array}$ & $\begin{array}{l}\text { O construto de } \\
\text { alinhamento tem } \\
\text { influência sobre o DO. }\end{array}$ \\
\hline $\begin{array}{l}\text { Noble, } \\
\text { Mokwa } \\
\text { (1999) }\end{array}$ & QT & SV & path analysis & $\begin{array}{l}486 \text { executivos } \\
\text { envolvidos com } \\
\text { estratégia de } \\
\text { mkt de } 2 \\
\text { empresas } \\
\text { (financeira e } \\
\text { embalagem) }\end{array}$ & $\begin{array}{l}\text { Implement. da } \\
\text { estratégia }\end{array}$ & $\begin{array}{l}\text { Fatores que } \\
\text { influenciam a } \\
\text { implementação da } \\
\text { estratégia do ponto } \\
\text { de vista do } \\
\text { executivo }\end{array}$ & $\begin{array}{l}\text { Fatores que influenciam } \\
\text { a implementação são } \\
\text { integrados em um } \\
\text { framework e o modelo é } \\
\text { testado com gerentes de } \\
\text { nível médio. }\end{array}$ \\
\hline
\end{tabular}

continua 
continuação

\begin{tabular}{|c|c|c|c|c|c|c|c|}
\hline Autor & $\begin{array}{c}\text { Abordagem } \\
\text { Pesquisa } \\
\text { (1) }\end{array}$ & $\begin{array}{c}\text { Método } \\
\text { (2) }\end{array}$ & $\begin{array}{c}\text { Técnica } \\
\text { estatística }\end{array}$ & Amostra & $\begin{array}{c}\text { Tema ou } \\
\text { conceito de } \\
\text { alinhamento } \\
\text { em estudo }\end{array}$ & $\begin{array}{c}\text { Objetivos do } \\
\text { estudo }\end{array}$ & Contribuições \\
\hline $\begin{array}{l}\text { Powell } \\
\text { (1992) }\end{array}$ & QT & SVIQU & $\begin{array}{l}\text { Análise de } \\
\text { Regressão } \\
\text { Hierárquica }\end{array}$ & $\begin{array}{l}113 \text { CEOs da } \\
\text { indústria de } \\
\text { manufatura: } \\
\text { móveis e } \\
\text { vestuário }\end{array}$ & $\begin{array}{l}\text {. Alinhamento } \\
\text { organizacional } \\
\text { (Lawrence e } \\
\text { Lorsch) } \\
\text {. Ajuste como } \\
\text { combinação }\end{array}$ & $\begin{array}{l}\text { Testar as } \\
\text { consequências do } \\
\text { alinhamento sobre } \\
\text { o DO, } \\
\text { considerando os } \\
\text { efeitos da indústria, } \\
\text { tamanho do } \\
\text { mercado e } \\
\text { estratégia. }\end{array}$ & $\begin{array}{l}\text { Os resultados confirmam } \\
\text { a relação entre } \\
\text { alinhamento } \\
\text { organizacional e DO e o } \\
\text { alinhamento como fonte } \\
\text { de vantagem } \\
\text { competitiva. }\end{array}$ \\
\hline $\begin{array}{l}\text { Rapert, } \\
\text { Velliquette, } \\
\text { Garretson } \\
(2002)\end{array}$ & $\overline{Q T}$ & SV & $\begin{array}{l}\text { análise de } \\
\text { componen- } \\
\text { tes } \\
\text { principais, } \\
\text { análise } \\
\text { fatorial } \\
\text { confirmatoria }\end{array}$ & $\begin{array}{l}322 \\
\text { respondentes, } \\
\text { CEO e } \\
\text { executivo de } \\
\text { MKT, área de } \\
\text { saúde }\end{array}$ & $\begin{array}{l}\text { Consenso } \\
\text { estratégico }\end{array}$ & $\begin{array}{l}\text { Comunicação } \\
\text { vertical como meio } \\
\text { pelo qual o } \\
\text { consenso pode ser } \\
\text { estabelecido }\end{array}$ & $\begin{array}{l}\text { Percepção de forças e } \\
\text { fraquezas varia de } \\
\text { acordo com o nível } \\
\text { gerencial. Se os } \\
\text { membros da } \\
\text { organização não estão } \\
\text { conscientes da mesma } \\
\text { informação ou se a } \\
\text { mesma precisa passar } \\
\text { por vários níveis } \\
\text { hierárquicos, pode } \\
\text { resultar em um baixo } \\
\text { nível de consenso. }\end{array}$ \\
\hline
\end{tabular}


continuação

\begin{tabular}{|c|c|c|c|c|c|c|c|}
\hline Autor & $\begin{array}{c}\text { Abordagem } \\
\text { Pesquisa } \\
\text { (1) }\end{array}$ & $\begin{array}{c}\text { Método } \\
\text { (2) }\end{array}$ & $\begin{array}{c}\text { Técnica } \\
\text { estatística }\end{array}$ & Amostra & $\begin{array}{c}\text { Tema ou } \\
\text { conceito de } \\
\text { alinhamento } \\
\text { em estudo }\end{array}$ & $\begin{array}{c}\text { Objetivos do } \\
\text { estudo }\end{array}$ & Contribuições \\
\hline $\begin{array}{l}\text { Reich, } \\
\text { Benbasat } \\
(2000)\end{array}$ & QL & $E$ & & $\begin{array}{l}45 \\
\text { respondentes, } \\
57 \text { entrevistas } \\
\text { em } 10 \text { unid de } \\
\text { negócios }\end{array}$ & $\begin{array}{l}\text { Alinhamento } \\
\text { estratégia de } \\
\text { negócios-TI }\end{array}$ & $\begin{array}{l}\text { Verificar a } \\
\text { influência da } \\
\text { compreensão e } \\
\text { comprometimento } \\
\text { dos executivos } \\
\text { sobre as } \\
\text { estratégias de TI } \\
\text { no alinhamento }\end{array}$ & $\begin{array}{l}\text { Os quatro fatores do } \\
\text { modelo (conhecimento } \\
\text { compartilhado sobre } \\
\text { estratégias de TI, } \\
\text { sucesso na } \\
\text { implementação das } \\
\text { estratégias de TI, } \\
\text { comunicação entre os } \\
\text { executivos da área de } \\
\text { negócios e de TI e } \\
\text { conexão entre o plano } \\
\text { de negócios e de TI } \\
\text { influencia o alinhamento } \\
\text { no curto prazo. Apenas o } \\
\text { domínio compartilhado } \\
\text { do conhecimento parece } \\
\text { ter influência no } \\
\text { alinhamento no longo } \\
\text { prazo. }\end{array}$ \\
\hline
\end{tabular}

continua 
continuação

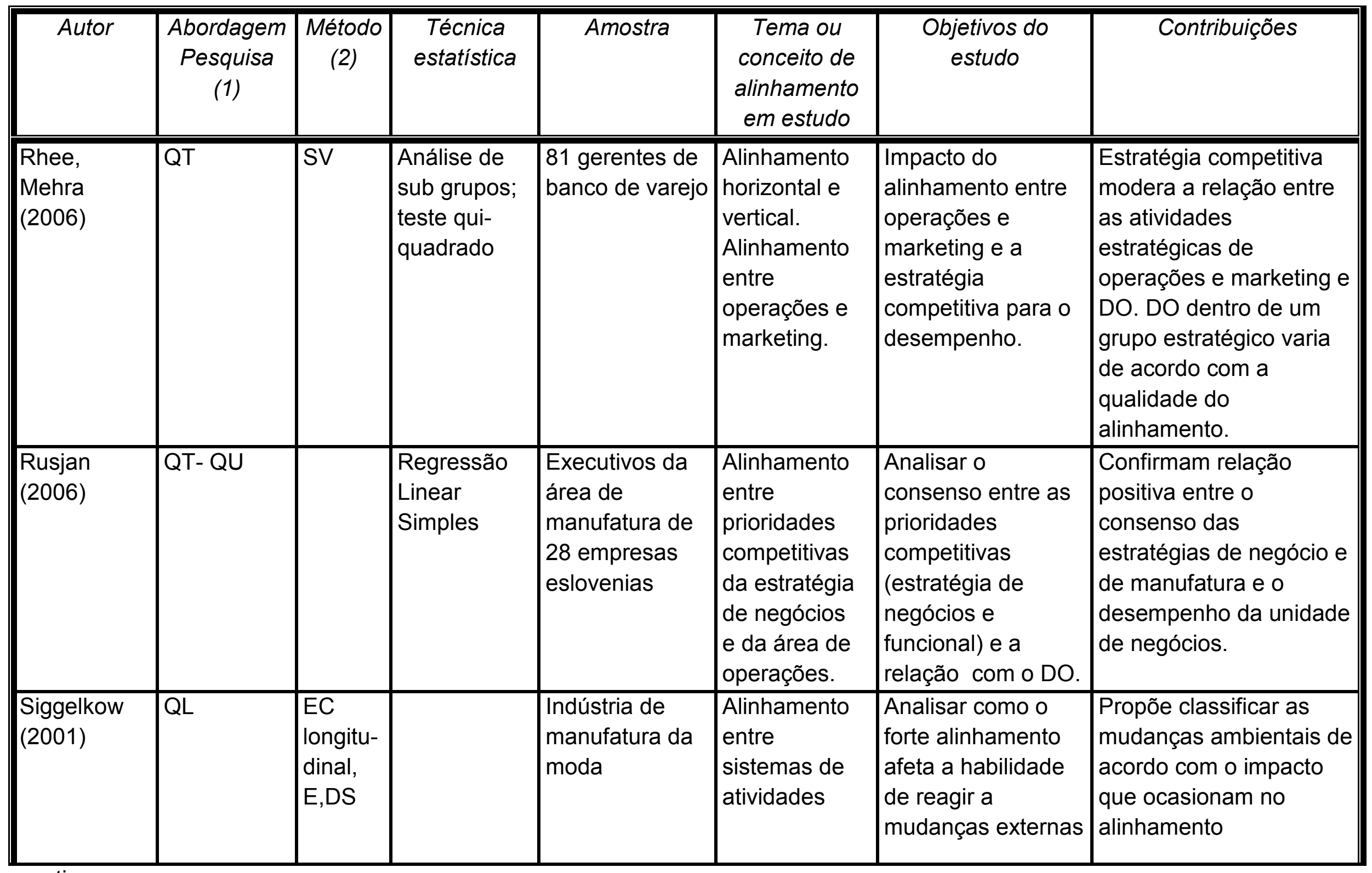


continuação

\begin{tabular}{|c|c|c|c|c|c|c|c|}
\hline Autor & $\begin{array}{c}\text { Abordagem } \\
\text { Pesquisa } \\
\text { (1) }\end{array}$ & $\begin{array}{c}\text { Método } \\
\text { (2) }\end{array}$ & $\begin{array}{c}\text { Técnica } \\
\text { estatística }\end{array}$ & Amostra & $\begin{array}{c}\text { Tema ou } \\
\text { conceito de } \\
\text { alinhamento } \\
\text { em estudo }\end{array}$ & $\begin{array}{l}\text { Objetivos do } \\
\text { estudo }\end{array}$ & Contribuições \\
\hline $\begin{array}{l}\text { Siggelkow } \\
(2002)\end{array}$ & QL & & & $\begin{array}{l}\text { Fundos mútuo } \\
\text { de investimento }\end{array}$ & $\begin{array}{l}\text { Alinhamento } \\
\text { configuracio- } \\
\text { nal }\end{array}$ & $\begin{array}{l}\text { Entender o } \\
\text { processo de } \\
\text { desenvolvimento } \\
\text { que conduz a } \\
\text { configuração } \\
\text { organizacional e ao } \\
\text { alinhamento }\end{array}$ & $\begin{array}{l}\text { Quatro processos são } \\
\text { identificados que } \\
\text { descrevem a criação de } \\
\text { elementos centrais em } \\
\text { torno dos quais ocorre o } \\
\text { alinhamento e elementos } \\
\text { de apoio }\end{array}$ \\
\hline $\begin{array}{l}\text { Stepanovich } \\
\text { e Mueller } \\
(2002)\end{array}$ & $\overline{Q T}$ & $\begin{array}{l}\text { conjoint } \\
\text { analysis }\end{array}$ & & $\begin{array}{l}35 \text { empregados } \\
\text { de uma } \\
\text { pequena } \\
\text { empresa }\end{array}$ & $\begin{array}{l}\text { Consenso } \\
\text { estratégico }\end{array}$ & $\begin{array}{l}\text { aplicar conjoint } \\
\text { analysis como } \\
\text { método para medir } \\
\text { o grau de consenso } \\
\text { sobre prioridades } \\
\text { estratégicas }\end{array}$ & $\begin{array}{l}\text { Desenvolvimento do } \\
\text { método de mensuração } \\
\text { do consenso. }\end{array}$ \\
\hline
\end{tabular}


continuação

\begin{tabular}{|c|c|c|c|c|c|c|c|}
\hline Autor & $\begin{array}{c}\text { Abordagem } \\
\text { Pesquisa } \\
\text { (1) }\end{array}$ & $\begin{array}{c}\text { Método } \\
\text { (2) }\end{array}$ & $\begin{array}{c}\text { Técnica } \\
\text { estatística }\end{array}$ & Amostra & $\begin{array}{l}\text { Tema ou } \\
\text { conceito de } \\
\text { alinhamento } \\
\text { em estudo }\end{array}$ & $\begin{array}{l}\text { Objetivos do } \\
\text { estudo }\end{array}$ & Contribuições \\
\hline $\begin{array}{l}\text { West e } \\
\text { Schwenk } \\
(1996)\end{array}$ & QT & SV-QU & $\begin{array}{l}\text { Análise de } \\
\text { Regressão } \\
\text { hierárquica } \\
\text { moderada }\end{array}$ & $\begin{array}{l}112 \text { CEOs e } \\
\text { Gerentes } \\
\text { Gerais da ind. } \\
\text { de } \\
\text { componentes } \\
\text { eletrônicos }\end{array}$ & $\begin{array}{l}\text { consenso } \\
\text { estratégico }\end{array}$ & \begin{tabular}{|l} 
Investigar a \\
hipótese de que a \\
relação entre o \\
consenso dos altos \\
executivos, \\
homogeneidade \\
demográfica e DO \\
é mais forte em \\
ambientes estáveis
\end{tabular} & $\begin{array}{l}\text { Variável independente } \\
\text { se mostrou inadequada. } \\
\text { Apresenta sugestões } \\
\text { para estudos futuros. }\end{array}$ \\
\hline $\begin{array}{l}\text { Wooldridge, } \\
\text { Floyd (1990) }\end{array}$ & QL,QT & $\mathrm{QU}, \mathrm{E}$, & $\begin{array}{l}\text { Análise de } \\
\text { correlação }\end{array}$ & $\begin{array}{l}157 \text { tomadores } \\
\text { de decisão, } \\
\text { bancos e } \\
\text { manufatura. }\end{array}$ & $\begin{array}{l}\text { consenso } \\
\text { estratégico }\end{array}$ & $\begin{array}{l}\text { Investigar a relação } \\
\text { entre o } \\
\text { envolvimento do } \\
\text { nível gerencial } \\
\text { médio com a } \\
\text { estratégia e o DO }\end{array}$ & $\begin{array}{l}\text { O envolvimento da } \\
\text { média gerência está } \\
\text { relacionado com } \\
\text { melhoria no DO. }\end{array}$ \\
\hline $\begin{array}{l}\text { Xu, } \\
\text { Cavusgil, } \\
\text { White (2006) }\end{array}$ & QT & QU & $\begin{array}{l}\text { análise de } \\
\text { regressão } \\
\text { moderada }\end{array}$ & $\begin{array}{l}206 \text { gerentes } \\
\text { senior de MNC }\end{array}$ & $\begin{array}{l}\text { Alinhamento } \\
\text { entre } \\
\text { estratégia de } \\
\text { marketing } \\
\text { global e } \\
\text { caract. org. } \\
\text { local. }\end{array}$ & $\begin{array}{l}\text { Examinar os efeitos } \\
\text { e a forma de } \\
\text { alinhamento entre } \\
\text { uma estratégia de } \\
\text { marketing global e } \\
\text { as características } \\
\text { da organização } \\
\text { local. }\end{array}$ & $\begin{array}{l}\text { Alinhamento interno, } \\
\text { entre estratégia, } \\
\text { estrutura e processos } \\
\text { está positivamente } \\
\text { associado com o DO. }\end{array}$ \\
\hline
\end{tabular}

continua 
conclusão

\begin{tabular}{|c|c|c|c|c|c|c|c|}
\hline Autor & $\begin{array}{c}\text { Abordagem } \\
\text { Pesquisa } \\
\text { (1) }\end{array}$ & $\begin{array}{c}\text { Método } \\
\text { (2) }\end{array}$ & $\begin{array}{c}\text { Técnica } \\
\text { estatística }\end{array}$ & Amostra & $\begin{array}{c}\text { Tema ou } \\
\text { conceito de } \\
\text { alinhamento } \\
\text { em estudo }\end{array}$ & $\begin{array}{l}\text { Objetivos do } \\
\text { estudo }\end{array}$ & Contribuições \\
\hline $\begin{array}{l}\text { Zajac, } \\
\text { Kraatz } \\
(2001)\end{array}$ & QT & AD/DS & $\begin{array}{l}\text { Estatisticas } \\
\text { descritivas e } \\
\text { correlação }\end{array}$ & \begin{tabular}{|l} 
Dados \\
longitudinais de \\
422 Liberal Arts \\
Colleges entre \\
os anos 70 e 80
\end{tabular} & $\begin{array}{l}\text { Alinhamento } \\
\text { dinâmico }\end{array}$ & $\begin{array}{l}\text { Examinar como } \\
\text { recursos } \\
\text { historicamente } \\
\text { "acumulados" e } \\
\text { competências } \\
\text { afetam a mudança } \\
\text { estratégica e } \\
\text { resultados em } \\
\text { ambientes } \\
\text { turbulentos. }\end{array}$ & \begin{tabular}{|l} 
Organizações que \\
possuem grande \\
estoque de recursos \\
historicamente valiosos \\
foram muito menos \\
propensas a se engajar \\
em mudanças \\
estratégicas adaptativas.
\end{tabular} \\
\hline
\end{tabular}

Legenda: (1) QT Quantitativo, QL Qualitativo (2) EC-Estudo de Caso, SV-Survey, QU-Questionário, E-Entrevista, AD-Análise documental, DS-Dados secundários 


\section{APÊNDICE C - SÍNTESE DA BASE TEÓRICA: ESTUDOS EMPÍRICOS SOBRE A RELAÇÃO ALINHAMENTO} E DESEMPENHO

\begin{tabular}{|c|c|c|c|c|c|}
\hline Referência & $\begin{array}{c}\text { Perspectiva } \\
\text { do } \\
\text { alinhamento }\end{array}$ & $\begin{array}{l}\text { Principal } \\
\text { Técnica } \\
\text { estatística }\end{array}$ & Construtos envolvidos & $\begin{array}{c}\text { Hipóteses } \\
\text { Alinhamento - desempenho }\end{array}$ & $\begin{array}{c}\text { Mensuração } \\
\text { Alinhamento }(A L N) \text { e } \\
\text { desempenho }(D O)\end{array}$ \\
\hline $\begin{array}{l}\text { Carmeli e } \\
\text { Tishler } \\
(2004)\end{array}$ & covariação & $\begin{array}{l}\text { Método de } \\
\text { análise } \\
\text { canônica } \\
\text { robusta - } \\
\text { covariância }\end{array}$ & elementos intangíveis, DO & $\begin{array}{l}\text { Interação entre elementos } \\
\text { intangíveis melhora o } \\
\text { desempenho organizacional. } \\
\text { Confirmada. }\end{array}$ & $\begin{array}{l}A L N \text { : covariação entre os } \\
\text { elementos } \\
D O: \text { taxas de receita } \\
\text { (arrecadação) }\end{array}$ \\
\hline $\begin{array}{l}\text { Chan et al. } \\
(1997)\end{array}$ & $\begin{array}{l}\text { vertical, } \\
\text { covariação }\end{array}$ & MEEPLS & $\begin{array}{l}\text { orientação estratégica dos } \\
\text { negócios, orientação } \\
\text { estratégica dos SI, eficácia } \\
\text { dos SI e DO. }\end{array}$ & $\begin{array}{l}\text { Alinhamento estratégico de } \\
\text { SI está positivamente } \\
\text { relacionado com o } \\
\text { desempenho do negócio. } \\
\text { Confirmada. }\end{array}$ & $\begin{array}{l}A L N \text { : covariação entre os } \\
\text { construtos. } \\
D O: \text { subjetiva; crescimento } \\
\text { do mercado, lucratividade, } \\
\text { inovação e reputação. }\end{array}$ \\
\hline
\end{tabular}


continuação

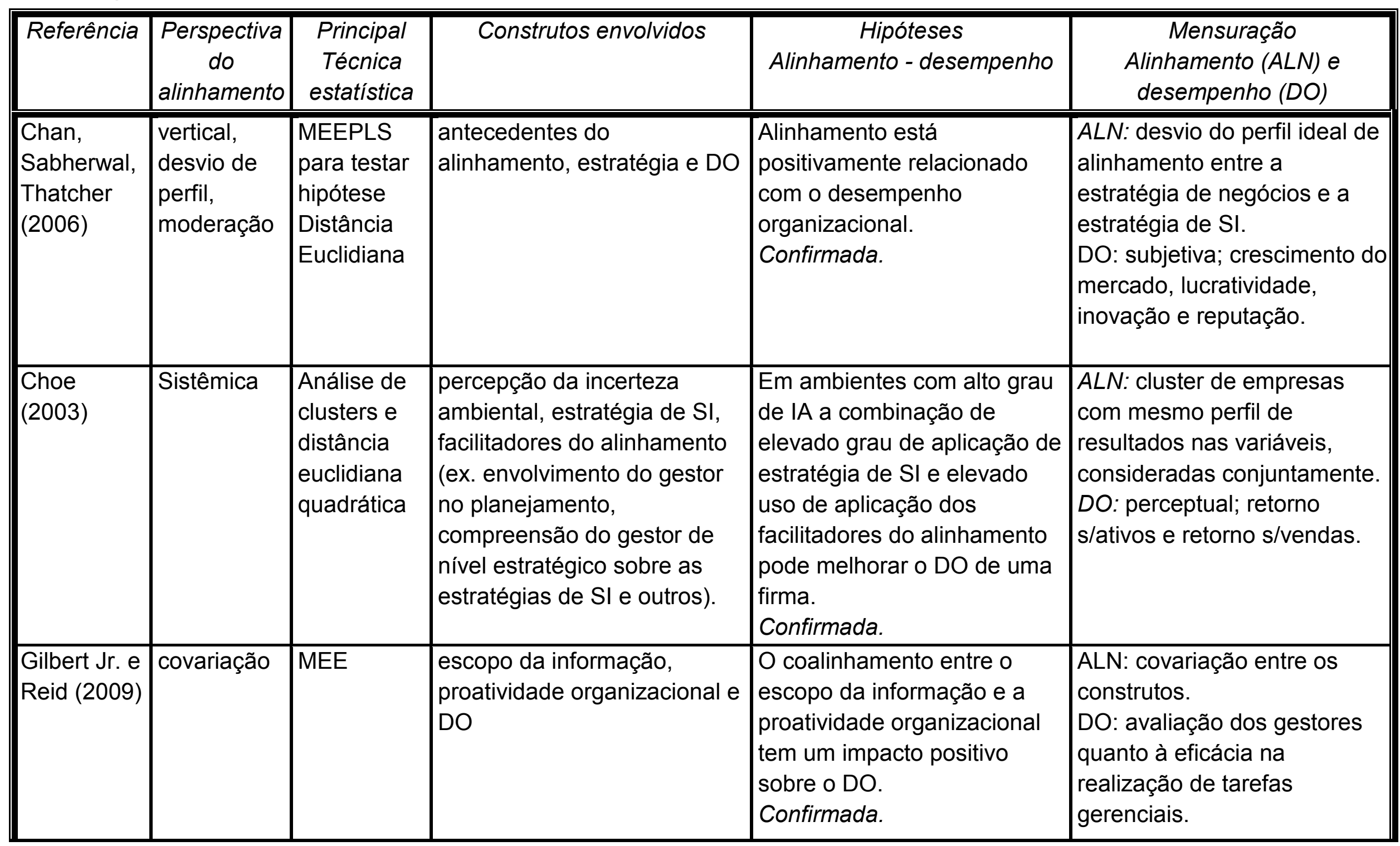


continuação

\begin{tabular}{|c|c|c|c|c|c|}
\hline Referência & $\begin{array}{c}\text { Perspectiva } \\
\text { do } \\
\text { alinhamento }\end{array}$ & $\begin{array}{l}\text { Principal } \\
\text { Técnica } \\
\text { estatística }\end{array}$ & Construtos envolvidos & $\begin{array}{c}\text { Hipóteses } \\
\text { Alinhamento - desempenho }\end{array}$ & $\begin{array}{c}\text { Mensuração } \\
\text { Alinhamento }(A L N) \text { e } \\
\text { desempenho }(D O)\end{array}$ \\
\hline $\begin{array}{l}\text { Homburg, } \\
\text { Krohmer e } \\
\text { Workman } \\
\text { Jr. (1999) }\end{array}$ & $\begin{array}{l}\text { Vertical, } \\
\text { ajuste como } \\
\text { moderação }\end{array}$ & $\begin{array}{l}\text { Análise de } \\
\text { regressão } \\
\text { múltipla }\end{array}$ & $\begin{array}{l}\text { consenso, estratégia, } \\
\text { dinamismo do mercado e DO. }\end{array}$ & $\begin{array}{l}\text { As implicações do consenso } \\
\text { estratégico (CE) sobre o DO } \\
\text { dependem do tipo de } \\
\text { estratégia, sendo positivo } \\
\text { para diferenciação e sem } \\
\text { efeito para liderança em } \\
\text { custos. } \\
\text { A relação CE-DO, no caso da } \\
\text { estratégia de diferenciação, } \\
\text { será negativamente afetada } \\
\text { pelo dinamismo do mercado. } \\
\text { Confirmadas. }\end{array}$ & $\begin{array}{l}A L N \text { : dimensão consenso. } \\
D O: \text { perceptual; eficácia, } \\
\text { eficiência e adaptatividade. }\end{array}$ \\
\hline $\begin{array}{l}\text { Joshi, } \\
\text { Kathuria e } \\
\text { Porth } \\
(2003)\end{array}$ & $\begin{array}{l}\text { bivariada, } \\
\text { vertical, } \\
\text { desvio de } \\
\text { perfil }\end{array}$ & $\begin{array}{l}\text { distância } \\
\text { euclidiana; } \\
\text { análise de } \\
\text { regressão }\end{array}$ & $\begin{array}{l}\text { prioridades de manufatura, } \\
\text { desempenho da unidade }\end{array}$ & $\begin{array}{l}\text { À medida que aumenta o } \\
\text { alinhamento entre as } \\
\text { prioridades competitivas de } \\
\text { manufatura dos gerentes } \\
\text { gerais e dos gerentes de } \\
\text { manufatura o desempenho } \\
\text { da unidade de manufatura } \\
\text { aumenta. } \\
\text { Não confirmada. }\end{array}$ & $\begin{array}{l}A L N \text { : desvio de perfil entre } \\
\text { prioridades competitivas dos } \\
\text { dois grupos de gestores GG e } \\
\text { GM. } \\
D O \text { : perceptual; desempenho } \\
\text { da unidade. }\end{array}$ \\
\hline
\end{tabular}

continua 
continuação

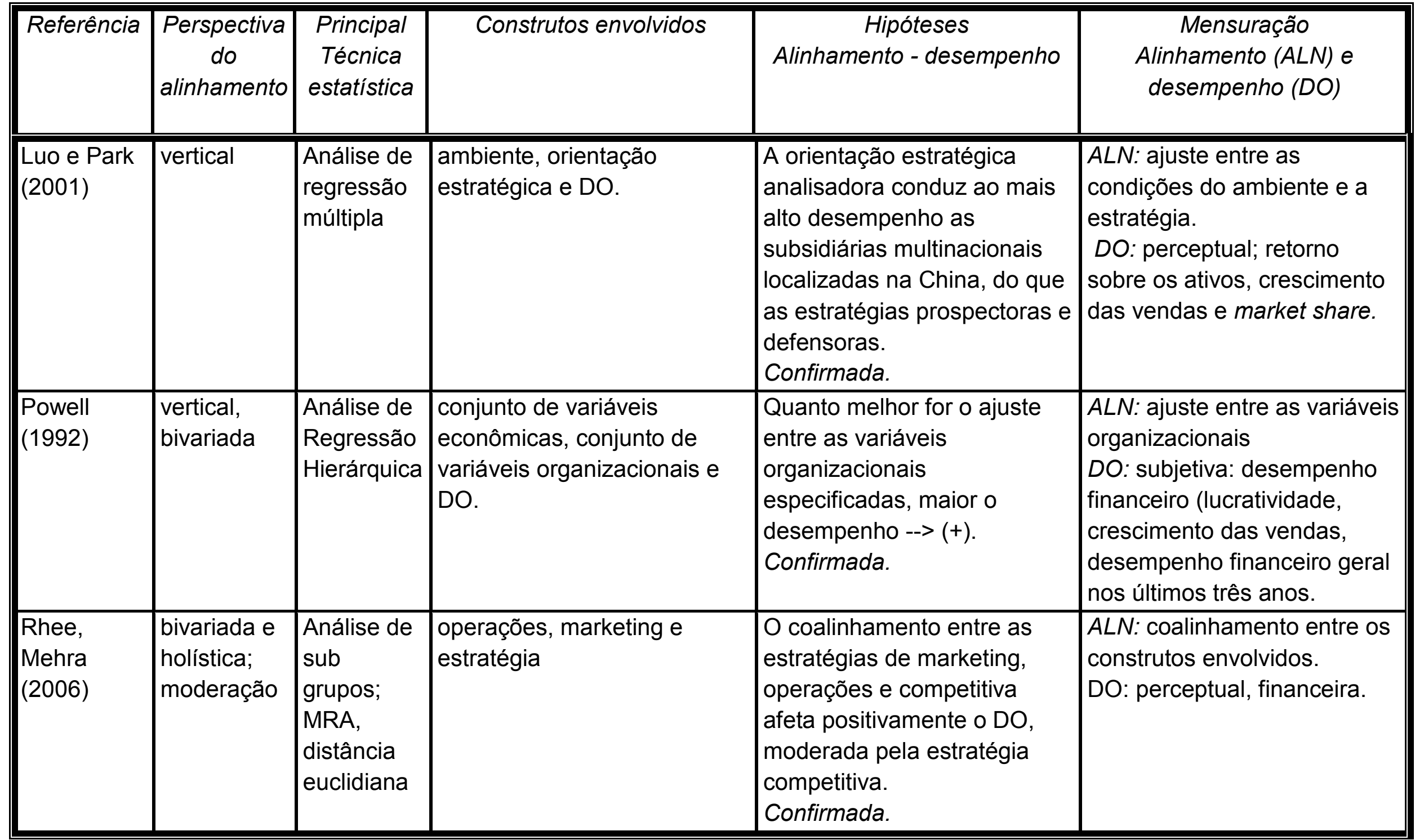

continua 
conclusão

\begin{tabular}{|c|c|c|c|c|c|}
\hline Referência & $\begin{array}{c}\text { Perspectiva } \\
\text { do } \\
\text { alinhamento }\end{array}$ & $\begin{array}{l}\text { Principal } \\
\text { Técnica } \\
\text { estatística }\end{array}$ & Construtos envolvidos & $\begin{array}{c}\text { Hipóteses } \\
\text { Alinhamento - desempenho }\end{array}$ & $\begin{array}{c}\text { Mensuração } \\
\text { Alinhamento }(A L N) \text { e } \\
\text { desempenho }(D O)\end{array}$ \\
\hline $\begin{array}{l}\text { Rusjan } \\
(2006)\end{array}$ & bivariada & $\begin{array}{l}\text { Regressão } \\
\text { Linear } \\
\text { Simples }\end{array}$ & $\begin{array}{l}\text { prioridades competitivas da } \\
\text { estratégia de negócios e da } \\
\text { área de operações. }\end{array}$ & $\begin{array}{l}\text { Existe uma relação entre o } \\
\text { consenso estratégico e o } \\
\text { desempenho da unidade. } \\
\text { Confirmada. }\end{array}$ & $\begin{array}{l}A L N \text { : calculo da diferença } \\
\text { entre a importância dada às } \\
\text { prioridades competitivas } \\
\text { pelos gerentes gerais e de } \\
\text { manufatura. } \\
\text { DO: perceptual, financeira. }\end{array}$ \\
\hline $\begin{array}{l}\text { Wooldridge } \\
\text { e Floyd } \\
(1990)\end{array}$ & $\begin{array}{l}\text { vertical, } \\
\text { bivariada }\end{array}$ & $\begin{array}{l}\text { Análise de } \\
\text { correlação }\end{array}$ & $\begin{array}{l}\text { processo estratégico, } \\
\text { envolvimento da média } \\
\text { gerência, DO }\end{array}$ & $\begin{array}{l}\text { O envolvimento da média } \\
\text { gerência na formação da } \\
\text { estratégia afeta } \\
\text { positivamente o DO --> (+). } \\
\text { Confirmada. }\end{array}$ & $\begin{array}{l}A L N \text { : correlação entre os } \\
\text { construtos. } \\
D O \text { : subjetiva; posição } \\
\text { competitiva geral, retorno } \\
\text { sobre os ativos, eficiência das } \\
\text { operações, desempenho } \\
\text { financeiro e taxa de } \\
\text { crescimento. }\end{array}$ \\
\hline $\begin{array}{l}\text { Xu, } \\
\text { Cavusgil e } \\
\text { White } \\
(2006)\end{array}$ & \begin{tabular}{|l|} 
ajuste como \\
moderação, \\
mediação, \\
desvio de \\
perfil,
\end{tabular} & $\begin{array}{l}\text { análise de } \\
\text { regressão } \\
\text { moderada }\end{array}$ & \begin{tabular}{|l|} 
estratégia de marketing \\
global, estrutura \\
organizacional global, \\
processos de gestão global, \\
DO variáveis \\
de controle: tamanho da \\
firma, experiência \\
internacional, localização e \\
diversidade geográfica
\end{tabular} & $\begin{array}{l}\text { Alinhamento interno, entre } \\
\text { estratégia, estrutura e } \\
\text { processos está positivamente } \\
\text { associado com o } \\
\text { desempenho. } \\
\text { Confirmada. }\end{array}$ & $\begin{array}{l}\text { DO: lucratividade, ROA, fluxo } \\
\text { de caixa }\end{array}$ \\
\hline
\end{tabular}




\section{APÊNDICE D - MODELO TEÓRICO DA PESQUISA (COMPLETO)}

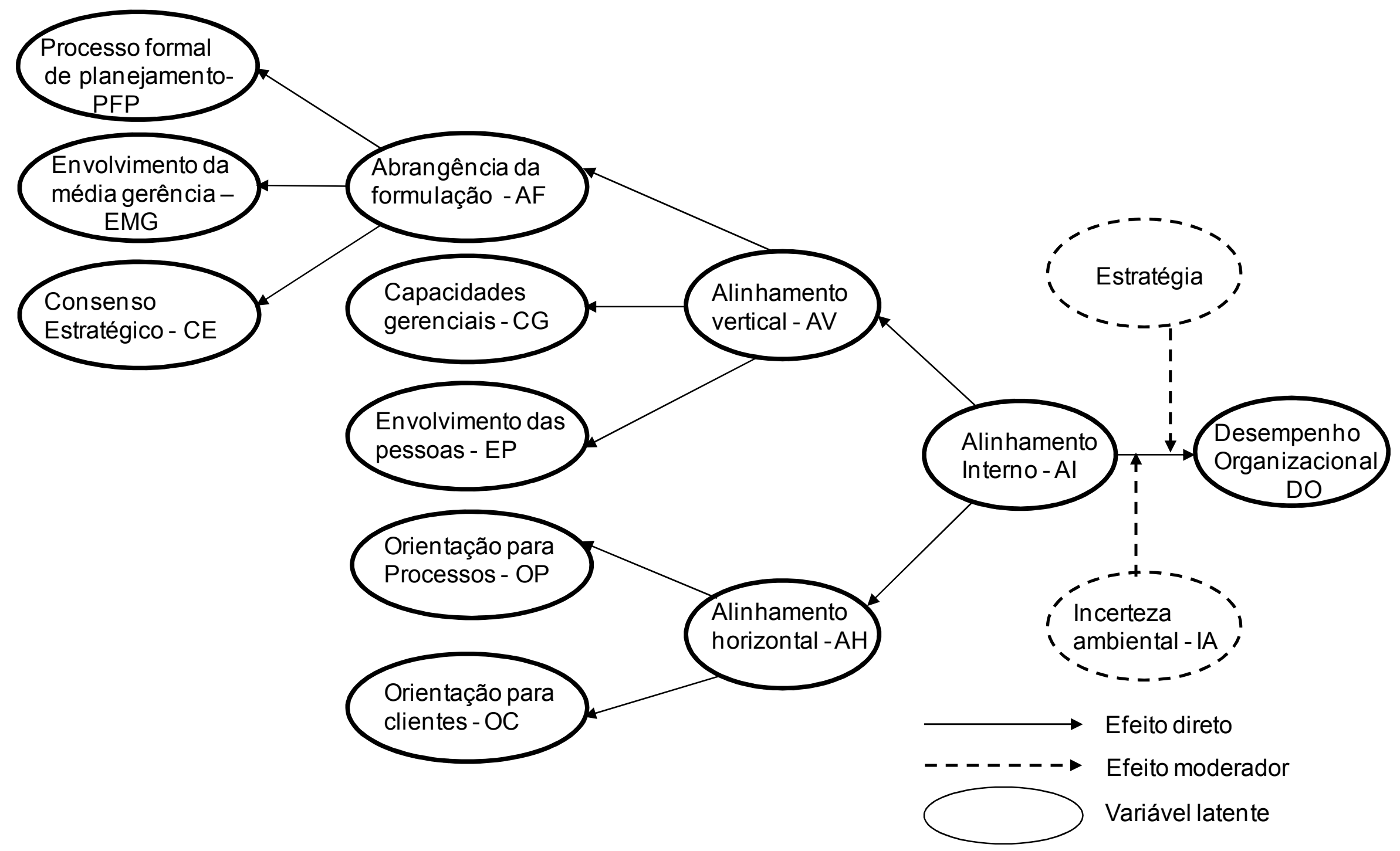




\section{APÊNDICE E - MATRIZ DE AMARRAÇÃO}

\begin{tabular}{|c|c|c|c|}
\hline \multicolumn{4}{|c|}{$\begin{array}{l}\text { OBJETIVO GERAL } \\
\text { Avaliar o impacto do alinhamento interno sobre o desempenho organizacional }\end{array}$} \\
\hline Objetivos & Hipóteses & Dados/amostra & Técnicas de análise \\
\hline $\begin{array}{l}\text { Avaliar o impacto do } \\
\text { alinhamento interno sobre o } \\
\text { desempenho organizacional }\end{array}$ & $\begin{array}{l}\text { H1: Existe relação significativa } \\
\text { e positiva entre o Alinhamento } \\
\text { Interno e o Desempenho } \\
\text { Organizacional. }\end{array}$ & \multirow{2}{*}{$\begin{array}{l}\text { Dados obtidos por meio de } \\
\text { questionário (impresso e } \\
\text { eletrônico). } \\
\text { Unidades amostrais são } \\
\text { unidades de negócios e os } \\
\text { respondentes são } \\
\text { diretores, média gerência } \\
\text { ou executivos que atuam } \\
\text { dando suporte à alta } \\
\text { gerência. }\end{array}$} & \multirow{2}{*}{$\begin{array}{l}\text { Modelagem de equações } \\
\text { estruturais (PLS). } \\
\text { - Análise do Modelo de } \\
\text { Mensuração segundo análise da } \\
\text { confiabilidade } \\
\text { dos indicadores, critérios de } \\
\text { confiabilidade composta, média da } \\
\text { variância extraída (AVE), } \\
\text { e validade discriminante. } \\
\text { - Análise do Modelo Estrutural por } \\
\text { meio do coeficiente de } \\
\text { determinação ( }{ }^{2} \text { ) e do índice de } \\
\text { ajuste geral do modelo } \\
\text { goodness-of-fit (GoF). }\end{array}$} \\
\hline $\begin{array}{l}\text { Avaliar o impacto da estratégia } \\
\text { sobre a relação Al-DO }\end{array}$ & $\begin{array}{l}\text { H2: O tipo da estratégia } \\
\text { influencia a relação } \\
\text { alinhamento-desempenho }\end{array}$ & & \\
\hline
\end{tabular}




\section{APÊNDICE F - RELATÓRIO DA VALIDAÇÃO DE CONTEÚDO}

A seguir apresenta-se o resultado da validação de conteúdo conduzida com professores especialistas e executivos.

A versão 1 apresenta os instrumentos de pesquisa em seu esboço original, após a revisão de literatura.

A versão 2 incorpora as modificações introduzidas após a validação de conteúdo realizada por professores especialistas, a qual foi submetida aos executivos.

A versão 3 incorpora as modificações introduzidas após a validação de face realizada por executivos, sendo que esta foi a versão incorporada ao questionário final (Apêndice G).

Observações:

(1) as assertivas identificadas com "*” foram elaboradas pela pesquisadora com base na revisão de literatura, não estando diretamente relacionadas aos autores referenciados.

(2) as assertivas identificadas com " $R$ " representam escala reversa.

\section{CONSTRUTO PROCESSO FORMAL DE PLANEJAMENTO (PFP)}

\section{VERSÃO 1}

As assertivas são originais desta pesquisa, mas baseadas em atributos desenvolvidos por Miller (1987) e também identificados no trabalho de Powell (1992).

PFP1. As ações da nossa empresa são baseadas mais em planos formais do que na intuição.

PFP2. Nós temos objetivos de longo prazo conhecidos por todos os gerentes.

PFP3. Nós temos metas específicas, de curto prazo, conhecidas por todos os gerentes.

PFP4. Nós temos um sistema de planejamento estratégico mais amplo, para o desenvolvimento da organização como um todo.

PFP5. Nós temos um plano estratégico formalizado para os próximos 12 meses.

PFP6. Nós temos um executivo ou equipe encarregada da elaboração de um plano estratégico formal. 
PFP7. Nós mantemos encontros gerenciais regulares para discutir a estratégia como um todo.

\section{CONSIDERAÇÕES DOS PROFESSORES ESPECIALISTAS}

PFP1. Um professor questionou quanto aos planos informais, se não contam e se são diferentes de intuição. Outro questionamento foi quanto aos planos serem baseados em análises de fatos e percepções e não somente em intuição.

PFP2 Sugeriu-se incluir a palavra "formalizados" para caracterizar os objetivos de longo prazo.

PFP3 Sugeriu-se incluir a palavra "formalizadas" para caracterizar as metas de curto prazo.

PFP4 Sugeriu-se incluir a palavra "formalizado" para caracterizar o sistema de planejamento estratégico.

PFP5 Sugeriu-se substituir a expressão "próximos 12 meses" por "próximo exercício".

PFP7 Surgiu um questionamento quanto ao propósito desses encontros regulares, se seriam para tratar da elaboração, implementação ou monitoramento da estratégia.

Um professor questionou se os respondentes teriam a mesma compreensão do termo "formal" por isso a eventual necessidade de esclarecer se seria um planejamento por escrito ou não.

\section{VERSÃO 2}

PFP1 As ações da nossa empresa são baseadas mais em planos formais do que na intuição.

PFP2 Nós temos objetivos de longo prazo, formalizados, e conhecidos por todos os gerentes.

PFP3 Nós temos metas específicas, de curto prazo, formalizadas, e conhecidas por todos os gerentes.

PFP4 Nós temos um sistema de planejamento estratégico mais amplo, para o desenvolvimento da organização como um todo.

PFP5 Nós temos um plano estratégico formalizado para o próximo exercício. 
PFP6 Nós temos um executivo ou equipe encarregada da elaboração de um plano estratégico formal.

PFP7. Nós mantemos encontros gerenciais regulares para discutir a estratégia como um todo.

\section{CONSIDERAÇÕES DOS EXECUTIVOS}

Não houve proposta de alteração por parte dos executivos.

\section{CONSTRUTO ENVOLVIMENTO DA MÉDIA GERÊNCIA NA FORMULACÃO DA} ESTRATÉGIA (EMG)

\section{VERSÃO 1}

EMG1 Os superiores e a média gerência trabalham juntos para decidir exatamente o que deve ser feito pela média gerência para implementar a estratégia.

EMG2 Os gerentes tomam conhecimento da estratégia praticamente no momento em que são chamados à implementá-la. $(R)$

EMG3 Durante a implementação da estratégia os gerentes sentem que podem procurar os seus superiores para sugerir mudanças nas atividades de implementação.

EMG4 Minhas responsabilidades na implementação da estratégia não são tão significativas.(R)

EMG5 Eu desempenho um papel relativamente menor na implementação das estratégias. $(R)$

EMG6 Eu sou uma das pessoas chave no time de implementação da estratégia.

\section{CONSIDERAÇÕES DOS PROFESSORES ESPECIALISTAS}

EMG1 Sugerida uma nova redação para o item. Também foi apontado que "exatamente" é uma palavra de reforço que pode encabular o respondente, pois o exato não existe na vida real.

EMG2 Proposto substituir a palavra "gerentes" por "média gerência".

EMG3 Proposto substituir a palavra "gerentes" por "média gerência".

EMG4 Sugerida uma nova redação para o item.

EMG5 Foi sugerido incluir o termo "média gerencia". Também foi sugerido especificar: relativo em relação a que ou a quem, para evitar falta de clareza. 
- O item foi excluído por não ter sido um dos itens considerados mais relevantes pelos especialistas e por ter o mesmo significado da assertiva posterior.

EMG6 Sugerida nova redação para o item. Um especialista questionou que pode não haver time ou percepção de time, tratando-se, portanto, de um conceito que pode levar a várias interpretações, além de não ter aparecido antes.

Um especialista alertou para o fato de que a mudança do sujeito na frase poderá causar respostas inválidas se estas forem respondidas pela alta gerência, ou diretoria ou outros que não estejam diretamente envolvidos na implementação da estratégia. Sugeriu, ainda, que, para não correr este risco, talvez fosse prudente perguntar no começo "quem" são os responsáveis pela implementação da estratégia na empresa; e, a partir daí, usar um termo neutro, como "gerência" ou "responsáveis pela implementação".

\section{VERSÃO 2}

EMG1 Média gerência e superiores trabalham juntos para decidir o que será feito para implementação da estratégia, pela média gerencia.

EMG2 A média gerência toma conhecimento da estratégia praticamente no momento em que é chamada a implementá-la. $(R)$

EMG3 Durante a implementação da estratégia a média gerência sente que pode procurar os seus superiores para sugerir mudanças nas atividades de implementação.

EMG4 As responsabilidades da média gerência, na implementação, não são significativas. ( $R$ )

EMG5 A média gerência é peça chave para a implementação da estratégia.

\section{CONSIDERAÇÕES DOS EXECUTIVOS}

Um dos executivos apontou que as "frases no negativo confundem", referindo-se à escala reversa.

\section{VERSÃO 3}

EMG1 Média gerência e superiores trabalham juntos para decidir o que será feito para implementação da estratégia, pela média gerência. 
EMG2 A média gerência toma conhecimento da estratégia com antecedência, antes de ser chamada a implementá-la.

EMG3 Durante a implementação da estratégia a média gerência sente que pode procurar os seus superiores para sugerir mudanças nas atividades de implementação.

EMG4 As responsabilidades da média gerência, na implementação, são significativas.

EMG5 A média gerência é peça chave para a implementação da estratégia.

\section{CONSTRUTO CONSENSO ESTRATÉGICO (CE)}

\section{VERSÃO 1}

Assertivas originais da pesquisa, mas baseadas em assertivas propostas por Noble e Mokwa (1999) nos construtos "Importância percebida sobre a estratégia" e "Comprometimento estratégico"

CE1 A estratégia em ação não tem tanta importância para a realização da missão da empresa. (R)

CE2 É esperado que o sucesso da estratégia em ação afete significantemente o futuro da empresa.

CE3 Eu não penso que a estratégia em ação esteja de acordo com os interesses mais relevantes da empresa.(R)

CE4 Eu não posso dizer que possa apoiar esta estratégia. (R)

CE5 Eu pessoalmente sinto que os objetivos relacionados à estratégia em ação são apropriados.

\section{CONSIDERAÇÕES DOS PROFESSORES ESPECIALISTAS}

CE1 Um dos especialistas questionou se não seria mais adequado usar "visão", que é o caminho que a empresa pretende seguir objetivamente, em determinado período de tempo. Outro questionamento foi quanto ao uso da expressão "tanta" (muito, pouco, mais ou menos) que poderia atrapalhar a resposta.

CE2 Foi mencionada a necessidade de esclarecer se o efeito esperado é positivo. Também se questionou que a palavra sucesso tem múltiplas interpretações que não ajudarão na resposta. 
CE4 Houve um comentário quanto à palavra "apoiar", que seria um pouco vaga e também foi apontado que a frase não estaria clara, fluente.

A frase foi excluída por ter o mesmo sentido da assertiva 5.

CE5 Questionado a quais objetivos se refere - estratégicos ou objetivos de implementação.

\section{VERSÃO 2}

CE1 A estratégia em ação não tem tanta importância para a realização da missão da empresa. (R)

CE2 É esperado que o sucesso da estratégia em ação afete positivamente o futuro da empresa.

CE3 Eu não penso que a estratégia em ação esteja de acordo com os interesses mais relevantes da empresa.(R)

CE4 Eu pessoalmente sinto que os objetivos relacionados à estratégia em ação são apropriados.

\section{CONSIDERAÇÕES DOS EXECUTIVOS}

Um dos executivos fez a mesma consideração feita para o construto Envolvimento da Média Gerência, quanto aos itens expressos negativamente serem confusos.

\section{VERSÃO 3}

CE1 A estratégia em ação é relevante para a realização da missão da empresa.

CE2 É esperado que o sucesso da estratégia em ação afete positivamente o futuro da empresa.

CE3 Eu penso que a estratégia em ação está de acordo com os interesses mais relevantes da empresa.

CE4 Eu pessoalmente sinto que os objetivos relacionados à estratégia em ação são apropriados.

CONSTRUTO CAPACIDADES GERENCIAIS PARA IMPLEMENTACÃO DA ESTRATÉGIA (CG) 


\section{VERSÃO 1}

Instrumento original da pesquisa, mas baseado em atributos desenvolvidos por Hitt e Ireland (1985) - (HI) e empregado por Carmeli e Tishler (2004) e Noble e Mokwa (1999) - (NM) quanto ao suporte da alta direção para a implementação.

CG1 A alta administração desenvolve e comunica um senso de direção, um propósito único a ser compartilhado por todos os membros da organização. $(\mathrm{HI})$ CG2 Nossos executivos buscam o consenso entre opiniões conflitantes, a melhoria da coordenação e a efetiva colaboração, buscam gerar o entusiasmo e motivação suficientes para melhorar o desempenho. $(\mathrm{HI})$

CG3 Nós fazemos uso crescente da tomada de decisão compartilhada entre os executivos sênior e a média gerência. (HI)

CG4 Nossos executivos promovem os ajustes que são necessários para a implementação da estratégia, incluindo a alocação de recursos. *

CG5 Nossos executivos buscam identificar os obstáculos à implementação da estratégia, antes de colocá-la em ação.*

CG6 É notório que a alta direção quer que a estratégia em ação seja um sucesso. (NM)

CG7 Eu não consigo perceber que a alta direção se importe tanto com a estratégia em ação. (R) (NM)

\section{CONSIDERAÇÕES DOS PROFESSORES ESPECIALISTAS}

Foi questionado que capacidades (nome do construto) dizem respeito a resultado (ser capaz de fazer algo) e que, então, o construto poderia avaliar esse resultado, de ser capaz de efetuar o alinhamento.

Mais uma vez questionado sobre a unificação dos termos que nomeiam os cargos.

CG1 Questionado se senso de direção e propósito único não são sinônimos. Um outro entendimento foi que poderiam ser interpretados como duas alternativas, podendo atrapalhar a resposta.

Mencionado sobre a necessidade de unificar os termos "alta administração" e" alta gerência".

CG2 Um dos especialistas opinou que a frase menciona coisas muito diferentes ("opiniões conflitantes", "melhoria da coordenação" e "efetiva colaboração") que certamente confundirão o respondente, além de ficar difícil discriminá-las depois. 
CG3 Foi questionado o uso da palavra "crescente", uma vez que as perguntas anteriores buscavam uma situação existente, muito mais uma foto da situação, e não o movimento.

CG4 Foi sugerido que se for prioridade a "alocação de recursos" deve aparecer como tal e não ao final da linha.

CG5 Idem ao anterior, quanto à unificação dos termos.

CG6 Um dos especialistas sugeriu que o termo "sucesso" precisaria ser melhor especificado. Outro considerou a assertiva irrelevante, pois a alta direção sempre vai querer que a estratégia seja um sucesso.

A assertiva foi excluída porque as outras assertivas são suficientes para a mensuração do construto.

CG7 Não houve comentário. Mesmo assim a assertiva foi reformulada porque a alta direção também pode vir a responder o questionário.

\section{VERSÃO 2}

CG1 A alta administração desenvolve e comunica um senso de direção único a ser compartilhado por todos os membros da organização.

CG2 Nossos executivos chave buscam obter, entre si, o consenso entre opiniões conflitantes, a melhoria da coordenação e a efetiva colaboração.

CG3 Nós fazemos uso da tomada de decisão compartilhada entre a alta administração e a média gerência.

CG4 Nossos executivos promovem os ajustes dos recursos que são necessários para a implementação da estratégia.

CG5 Nossos executivos buscam identificar os obstáculos à implementação da estratégia, antes de colocá-la em ação.

CG7 A alta direção evidencia que se importa com a estratégia em ação.

\section{CONSIDERAÇÕES DOS EXECUTIVOS}

Não houve. 
O instrumento é original desta pesquisa, mas baseado em atributos desenvolvidos por Carmeli e Tishler (2004) - (CT) e Labovitz e Rosansky (1997) - (LR).

EP1 Existe um alto envolvimento dos empregados nos processos, decisões e sua implementação. (CT)

EP2 Os empregados são comprometidos e mantém um alto senso de responsabilidade para com a organização. (CT)

EP3 As metas da organização são claras e compreendidas por todos os seus membros. (CT)

EP4 A organização como um todo trabalha arduamente para alcançar suas metas. (CT)

EP5 Os departamentos ou grupos de trabalho são recompensados por seu desempenho como um time. (LR)

EP6 A organização recompensa o desempenho individual dos seus funcionários. (LR)

EP7 Os líderes regularmente reconhecem o bom desempenho dos seus funcionários. (LR)

EP8 Os conhecimentos e habilidades que as pessoas precisam são definidos a partir da estratégia da organização. (LR)

\section{CONSIDERAÇÕES DOS PROFESSORES ESPECIALISTAS}

EP1 Questionado se a intenção é envolver todos os empregados ou apenas a média gerência.

Mencionado que o uso de três termos ("processos", "decisões" e "implementação") pode dificultar a resposta caso o envolvimento dos empregados não seja o mesmo nas três atividades.

EP2 Questionado se o uso de “empregados" está adequado, uma vez que os responsáveis pela implementação são a média gerencia.

EP3 Mais uma vez foi questionado se a intenção é envolver todos os empregados ou apenas a média gerência.

Considerado desnecessário o reforço "claras" e "compreendidas".

EP4 Foi alertado que o uso de "arduamente", por ser expressão de exagero, pode causar um viés na resposta, pois não existe na vida real.

EP5 Mencionado que pode não haver time ou percepção de time, tratando-se, portanto, de um conceito que pode levar a várias interpretações. 
EP7 Questionado se seria importante especificar de que tipo de reconhecimento se trata. Também foi questionado o sentido da palavra "regularmente" na assertiva.

EP8 Questionado o uso conjunto de "conhecimento" e "habilidade", uma vez que a empresa poderia focar em apenas um dos dois, complicando a resposta.

\section{VERSÃO 2}

EP1 Existe um alto envolvimento dos empregados nos processos e sua implementação.

EP2 Os empregados são comprometidos e mantém um elevado senso de responsabilidade para com a organização.

EP3 As metas da organização são compreendidas por todos os seus membros.

EP4 A organização como um todo se esforça para alcançar suas metas.

EP5 Os departamentos ou grupos de trabalho são recompensados por seu desempenho.

EP6 A organização recompensa o desempenho individual dos seus funcionários.

EP7 Os líderes recompensam o bom desempenho dos seus funcionários.

EP8 Os conhecimentos e habilidades que as pessoas precisam são definidos a partir da estratégia da organização.

\section{CONSIDERAÇÕES DOS EXECUTIVOS}

Não houve.

\section{CONSTRUTO ORIENTACÃ̃O PARA PROCESSOS (OP)}

\section{VERSÃO 1}

Utiliza-se o questionário proposto por Labovitz e Rosansky (1997).

OP1 Nossos gerentes/supervisores cuidam de como o trabalho é feito, bem como dos seus resultados.

OP2 Nós revisamos nosso processo de trabalho regularmente para saber o quanto ele está funcionando.

OP3 Quando alguma coisa sai errada nós corrigimos as causas apontadas para evitar que aquele problema ocorra novamente.

OP4 Os processos são revisados para assegurar que eles contribuem para alcançar as metas estratégicas. 


\section{CONSIDERAÇÕES DOS PROFESSORES ESPECIALISTAS}

OP1 Sugeriu-se não atribuir a algum cargo, se não for necessário.

Um professor questionou o fato de ter duas afirmativas na questão ("trabalho" e "resultado"), podendo acontecer de apenas uma ser realidade na organização e complicar a resposta.

\section{VERSÃO 2}

OP1 Nossos gestores cuidam de como o trabalho é feito, bem como dos seus resultados.

OP2 Nós revisamos nossos processos de trabalho regularmente para saber o quanto eles estão funcionando.

OP3 Quando alguma coisa sai errada, nós corrigimos as causas apontadas para evitar que o problema ocorra novamente.

OP4 Os processos são revisados para assegurar que eles contribuem para alcançar as metas estratégicas.

\section{CONSIDERAÇÕES DOS EXECUTIVOS}

Não houve.

\section{CONSTRUTO ORIENTACÃ̃O PARA CLIENTES}

As assertivas são originárias do trabalho de Narver, Slater e MacLachlan (2004) e adaptadas por Olson, Slater e Hult (2005).

\section{VERSÃO 1}

OC1 Nós continuamente tentamos descobrir necessidades adicionais dos nossos consumidores que eles ainda não perceberam.

OC2 Nós incorporamos soluções em nossos produtos e serviços para necessidades dos consumidores ainda não atendidas.

OC3 Nós discutimos sobre como os consumidores usam nossos produtos ou serviços. 
OC4 Nós inovamos mesmo sob o risco de tornar nossos próprios produtos obsoletos.

OC5 Trabalhamos intimamente com pessoas chave do mercado que tentam reconhecer as necessidades dos clientes meses ou, até mesmo, anos antes que a maioria do mercado possa reconhecê-las.

\section{CONSIDERAÇÕES DOS PROFESSORES ESPECIALISTAS}

OC1 Foi sugerido trocar a palavra "tentar" por "buscar"

OC3 Sugerido nova redação para o item.

OC4 Um dos especialistas questiona para que adotar a inovação se é para "matar" o produto. Outro especialista questiona se a afirmação se aplica a todas as empresas da amostra. Também foi sugerido alterar a construção da frase.

Assertiva foi excluída por não se aplicar a todos os tipos de empresa da amostra.

OC5: Foi sugerida uma nova redação para o item

\section{VERSÃO 2}

OC1 Nós continuamente buscamos descobrir necessidades adicionais dos nossos consumidores que eles ainda não perceberam.

OC2 Nós incorporamos soluções em nossos produtos e serviços para necessidades dos consumidores ainda não atendidas

OC3 Buscamos influenciar o modo como nossos consumidores usam nossos produtos ou serviços.

OC4 Trabalhamos próximos a pessoas chave do mercado, visando reconhecer as necessidades dos clientes com antecedência; meses ou, até mesmo, anos antes que a maioria do mercado possa reconhecê-las.

\section{CONSIDERAÇÕES DOS EXECUTIVOS}

Não houve. 


\section{APÊNDICE G - VERSÃO FINAL DO QUESTIONÁRIO}

\section{Alinhamento APRESENTAÇÃO}

Prezado Sr. (a)

Este estudo avalia aspectos relevantes para o sucesso na implementação de estratégias.

Requer no máximo 15 minutos de seu tempo, e nenhuma informação sigilosa é solicitada, nem tampouco o nome da sua organização será mencionado em análises e conclusões deste estudo.

É muito importante que todas as questões sejam respondidas. Se a empresa fizer parte de um grupo, responda com base na empresa onde você trabalha, e não com base no conglomerado como um todo.

Se for do seu interesse, poderemos lhe enviar os resultados da pesquisa e, para tal, indique a sua opção ao final do questionário.

Se tiver alguma dúvida, entre em contato comigo pelo e-mail vanderli.prieto@poli.usp.br ou pelos telefones (11) 9731 0630 ou (11) 30915363 ramal 423 (USP).

Desde já, agradecemos sua preciosa colaboração.

Profa. Vanderli Correia Prieto(autora)- Currículo http://lattes.cnpq.br/3544819713003525

Profa. Dra. Marly Monteiro de Carvalho(orientadora) Curriculo http://lattes.cnpq.br/1386670520349091

\section{FATORES ENVOLVIDOS NO ALINHAMENTO}

Assinale, numa escala de 1 a 5 , a opção que mais adequadamente reflete o seu grau de concordância com as afirmações, sendo que "1" significa "discordo totalmente"; "2", "mais discordo que concordo"; "3", "nem concordo nem discordo"; "4", "mais concordo que discordo"; "5", "concordo totalmente",

\subsection{PROCESSO FORMAL DE PLANEJAMENTO}

1. As açōes da nossa empresa são baseadas mais em planos formais do que na intuição.
2. Nós temos objetivos de longo prazo, formalizados, e conhecidos por todos os gerentes.
3. Nós temos metas específicas, de curto prazo, formalizadas, e conhecidas por todos os
gerentes.
4. Nós temos um sistema de planejamento estratégico mais amplo, para o desenvolvimento da
organização como um todo.
5. Nós temos um plano estratégico formalizado para o próximo exercicio.
6. Nós temos um executivo ou equipe encarregada da elaboração de um plano estratégico
formal.
7. Nós mantemos encontros gerenciais regulares para discutir a estratégia como um todo.

\subsection{ENVOLVIMENTO DA MÉDIA GERÊNCIA NA FORMULAÇÃO}

1. Média gerência e superiores trabalham juntos para decidir o que será feito para implementação da estratégia, pela média gerência.

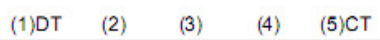

2. A média gerência toma conhecimento da estratégia com antecedência, antes de ser chamada a implementá-la.

3. Durante a implementação da estratégia a média gerência sente que pode procurar os seus superiores para sugerir mudanças nas atividades de implementaçăo.

4. As responsabilidades da média gerência, na implementaçăo, são significativas.

5. A média gerência é peça chave para a implementação da estratégia.

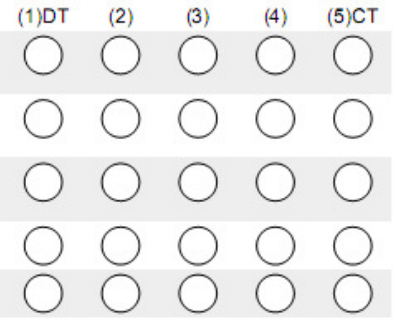

\subsection{CONSENSO ESTRATÉGICO}

1. A estratégia em ação é relevante para a realização da missão da empresa.

2. É esperado que o sucesso da estratégia em ação afete positivamente o futuro da empresa.

3. Eu penso que a estratégia em ação está de acordo com os interesses mais relevantes da empresa.

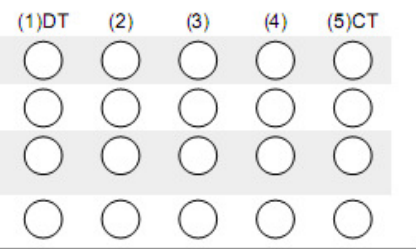




\section{Alinhamento}

\subsection{CAPACIDADES GERENCIAIS PARA A IMPLEMENTAÇÃO DA ESTRATÉGIA}

1. A alta administração de senvolve e comunica um senso de direção único a ser compartilhado
por todos os membros da organização.
2. Nossos executivos chave buscam obter, entre si, o consenso entre opiniōes conflitantes, a
melhoria da coordenação e a efetiva colaboração.
3. Nós fazemos uso da tomada de decisão compartilhada entre a alta administração e a média
gerência.
4. Nossos executivos promovem os ajustes dos recursos que são necessários para a
implementação da estratégia.
5. Nossos executivos buscam identificar os obstáculos à implementação da estratégia, antes de
colocá-la em ação.
6. A alta direção evidencia que se importa com a estratégia em ação.

\subsection{ENVOLVIMENTO DAS PESSOAS COM A ESTRATÉGIA}

1. Existe um alto envolvimento dos empregados nos processos e sua implementação.

2. Os empregados são comprometidos e mantém um elevado senso de responsabilidade para com a organização.

3. As metas da organização são compreendidas por todos os seus membros.

4. A organização como um todo se esforça para alcançar suas metas.

5. Os departamentos ou grupos de trabalho são recompensados por seu desempenho.

6. A organização recompensa o desempenho individual dos seus funcionários.

7. Os lideres recompensam o bom desempenho dos seus funcionários.

8. Os conhecimentos e habilidades que as pessoas precisam são definidos a partir da estratégia da organização.

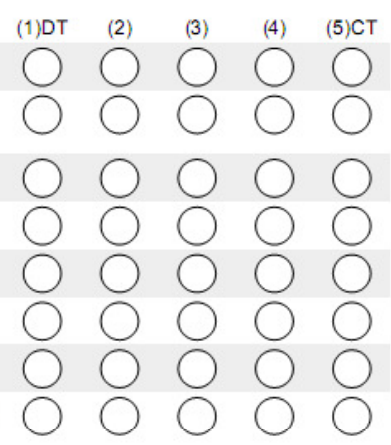

\subsection{ORIENTAÇÃO PARA PROCESSOS}

1. Nossos gestores cuidam de como o trabalho é feito, bem como dos seus resultados.

2. Nós revisamos nossos processos de trabalho regularmente para saber o quanto eles estão funcionando.

3. Quando alguma coisa sai errada, nós corrigimos as causas apontadas para evitar que o problema ocorra novamente.

4. Os processos são revisados para assegurar que eles contribuem para alcançar as metas estratégicas.

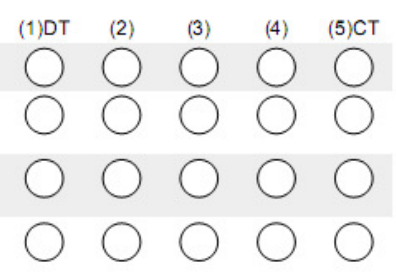

\subsection{ORIENTAÇÃO PARA CLIENTES}

1. Nós continuamente buscamos descobrir necessidades adicionais dos nossos consumidores que eles ainda não perceberam.

2. Nós incorporamos soluções em nossos produtos e serviços para necessidades dos consumidores ainda não atendidas.

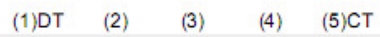

$\bigcirc \bigcirc \bigcirc \bigcirc 0$

$\bigcirc \bigcirc \bigcirc \bigcirc \bigcirc$

3. Buscamos influenciar o modo como nossos consumidores usam nossos produtos ou serviços. 4. Trabalhamos próximos a pessoas chave do mercado, visando reconhecer as necessidades dos clientes com antecedência; meses ou, até mesmo, anos antes que a maioria do mercado possa reconhecê-las. 


\section{Alinhamento}

\section{PERCEPÇÃO DA INCERTEZA AMBIENTAL}

Como você caracterizaria o ambiente externo no qual a sua empresa atua? Ao avaliar os aspectos do ambiente que são relevantes, por favor considere não apenas os aspectos econômicos, mas também sociais, políticos e tecnológicos.

Assinale, numa escala de 1 a 5 , a opção que mais adequadamente reflete o seu grau de concordância com as afirmações, sendo que "1" significa "discordo totalmente"; "2", "mais discordo que concordo"; "3", "nem concordo nem discordo"; "4", "mais concordo que discordo"; "5", "concordo totalmente".

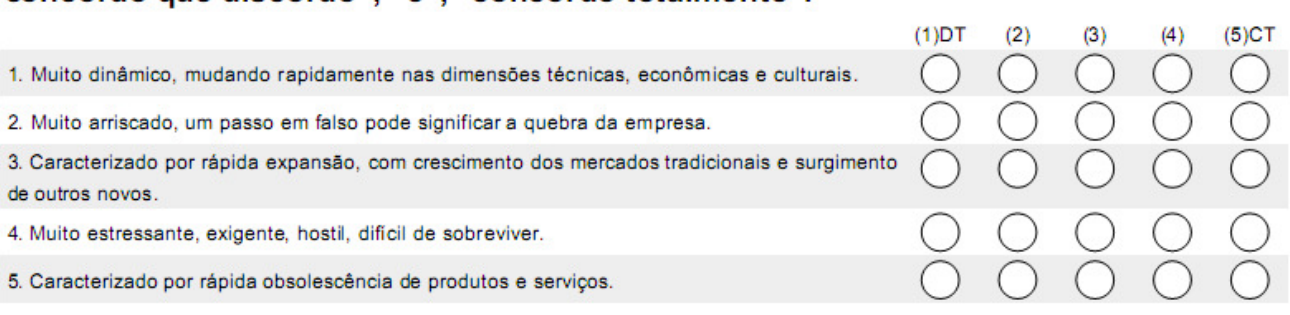

\section{DESEMPENHO ORGANIZACIONAL}

As questões que seguem devem ser respondidas considerando o desempenho geral da empresa, nos últimos três anos, quando comparado à média dos concorrentes do setor.

Em uma escala de 1 a 5, indique a opção que mais adequadamente reflete o seu grau de concordância com a afirmação, sendo que "1" significa "Desempenho Muito Inferior (DMI)"; "2", "Desempenho Inferior "; "3", "Desempenho Similar"; "4", "Desempenho Superior"; "5", "Desempenho Muito Superior (DMS)".

1. Reputação perante os maiores segmentos de consumidores.
2. Frequência no lançamento de novos produtos ou serviços.
3. Retorno sobre o investimento.
4. Lucratividade.
5. Desenvolvimentos tecnológicos e/ou outras inovaçōes nas operaçōes.
6. Qualidade de produto.
7. Ganhos de participação no mercado.

\section{ESTRATÉGIA}

Leia as descrições a seguir. Identifique aquela que mais se aproxima da orientação estratégica da sua empresa, quando comparada com outras empresas do mesmo segmento de atuação.

Note que nenhuma das opções listadas é essencialmente boa ou ruim. Apenas procure identificar a afirmação que melhor se encaixe com a realidade da empresa. Em seguida, assinale a alternativa escolhida. 


\section{Alinhamento}

Tipo 1: A minha empresa procura identificar e manter um nicho restrito de produto ou serviço que seja seguro e relativamente estável. A empresa tende a oferecer um número mais limitado de produtos ou serviços do que os competidores e busca proteger seu mercado pela oferta de qualidade mais alta, serviço superior ou preços mais baixos, etc. Normalmente, a empresa não é a líder nos desenvolvimentos em seu segmento de atuação, pois tende a ignorar as mudanças que não tenham uma influência direta nas atuais áreas de operação. Ao invés disso, se concentra em fazer o melhor trabalho possivel em um nicho restrito de atuação.

Tipo 2: A minha empresa opera oferecendo um amplo leque de produtos e serviços, que passam por redefiniçōes periódicas. A empresa valoriza estar na liderança no desenvolvimento de novos mercados, produtos e serviços, mesmo quando essas iniciativas ainda não se tenham provado altamente lucrativas. A empresa responde rapidamente aos sinais de novas oportunidades, o que frequentemente a leva a tomar novas açōes competitivas. No entanto, a empresa pode não ser forte em todas as áreas em que atua.

Tipo 3: A minha empresa mantém uma linha limitada e estável de produtos e serviços, ao mesmo tempo em que procura desenvolver alguns novos produtos e serviços em áreas cuidadosamente selecionadas e promissoras. A minha empresa raramente está na liderança dos desenvolvimentos e da inovação no segmento em que atua. Porém, observando cuidadosamente as ações dos maiores competidores em áreas compativeis com sua linha limitada e estável de produtos e serviços, a organização pode frequentemente tornar-se um 'segundo entrante', oferecendo um produto ou serviço com um custo mais eficiente.

Selecione, dentre as opções acima, aquela que melhor se encaixa com a realidade da empresa. Mesmo que duas ou mais afirmações pareçam se encaixar com a realidade da empresa, pedimos que seja assinalada apenas 1 (uma) alternativa.
Tipo 1
Tipo 2
Tipo 3

\section{PERFIL DA EMPRESA E DO RESPONDENTE}

Perfil da empresa: Por favor, classifique sua empresa de acordo com as seguintes caracteristicas

\subsection{Nome da empresa}

5.2 Setor de atuação: Assinale o setor no qual se enquadra a principal atividade da empresa:
Alimentos
Construção Civil
Plástico, derivados
Atividades financeiras e de seguros
Cosméticos
Telecomunicação, comunicaçăo
Automação, tecnologia
Eletrônica, eletroeletrônica
Serviços
Automotiva
Embalagem
Comércio
Bens de capital
Farmacêutica
Bens de consumo
Informática, internet

Outro (especifique)

\subsection{Quantos anos tem a empresa desde a sua fundação?}

$[\nabla$

\subsection{Quantos funcionários trabalham em sua empresa?}




\section{Alinhamento}

5.5 Porte da empresa: Qual o faturamento líquido da empresa no exercício anterior? 田

5.6 Seu nome:

\subsection{Cargo na empresa:}

5.8 e-mail (opcional, para receber relatório final):

Para alcançar o sucesso e a continuidade desta pesquisa, gostaria que você indicasse executivos (Gerentes ou Diretores) nas áreas de Operações, Finanças, Vendas, Planejamento, Compras ou Recursos Humanos.

Nome:

Email:

Telefone:

Nome:

Email:

Telefone:

Nome

Email:

Telefone:

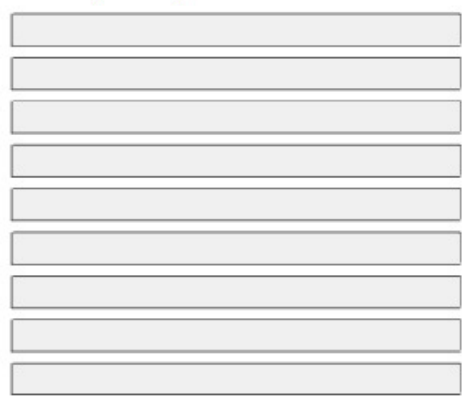


APÊNDICE H - RESULTADOS DO TESTE DA MEDIANA DE MOOD

PROCESSO FORMAL DE PLANEJAMENTO

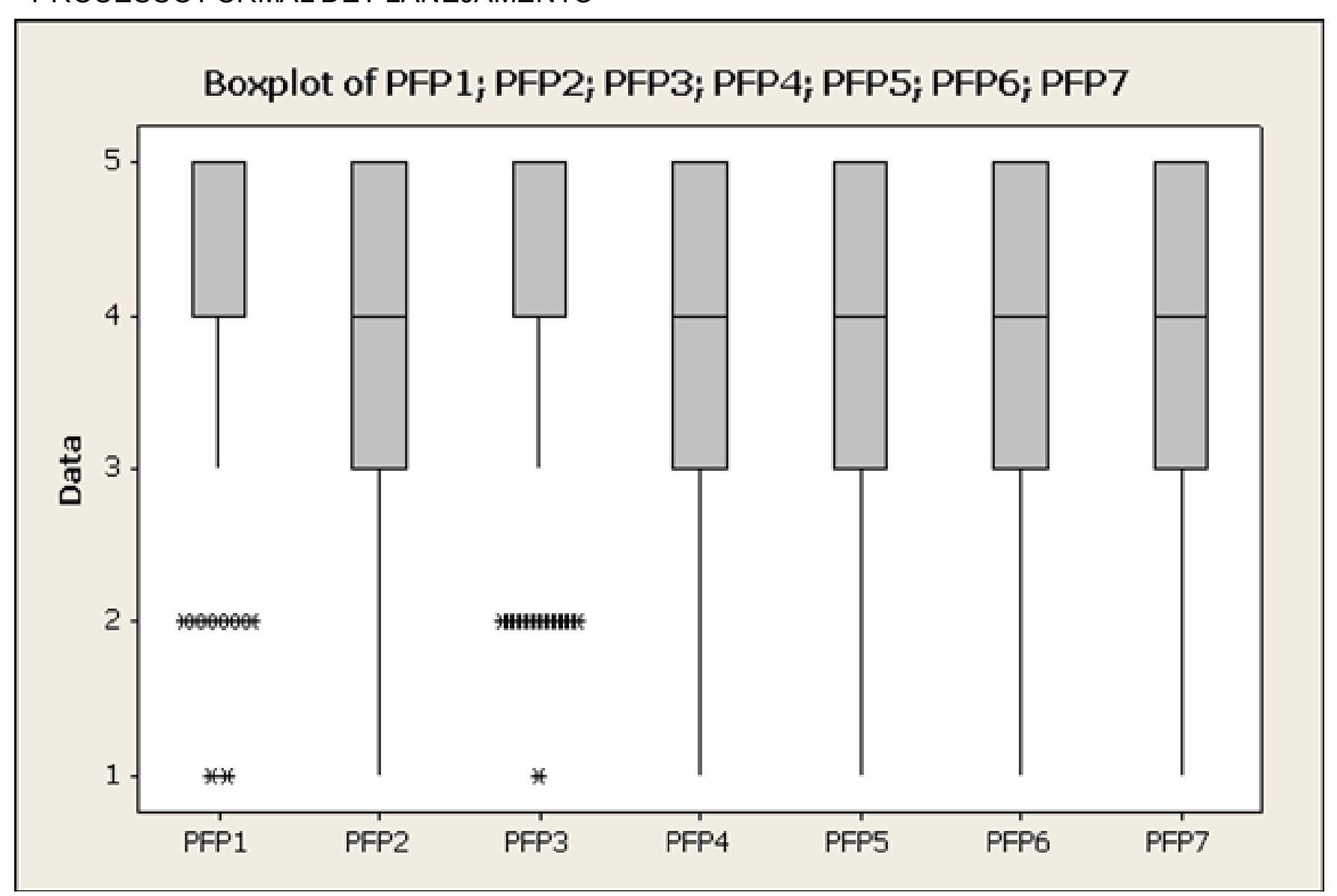

${ }^{*}$ ) Significativo para 99\% de confiança (Mood median test for PFP5,Chi-Square $=12,00 \quad$ DF $=2 \quad P=0,002$ ) O PFP4 e 7 dão significativos para $90 \%$ mas foi considerado apenas de $95 \%$ para cima 
ENVOLVIMENTO DA MÉDIA GERÊNCIA NA FORMULAÇÃO

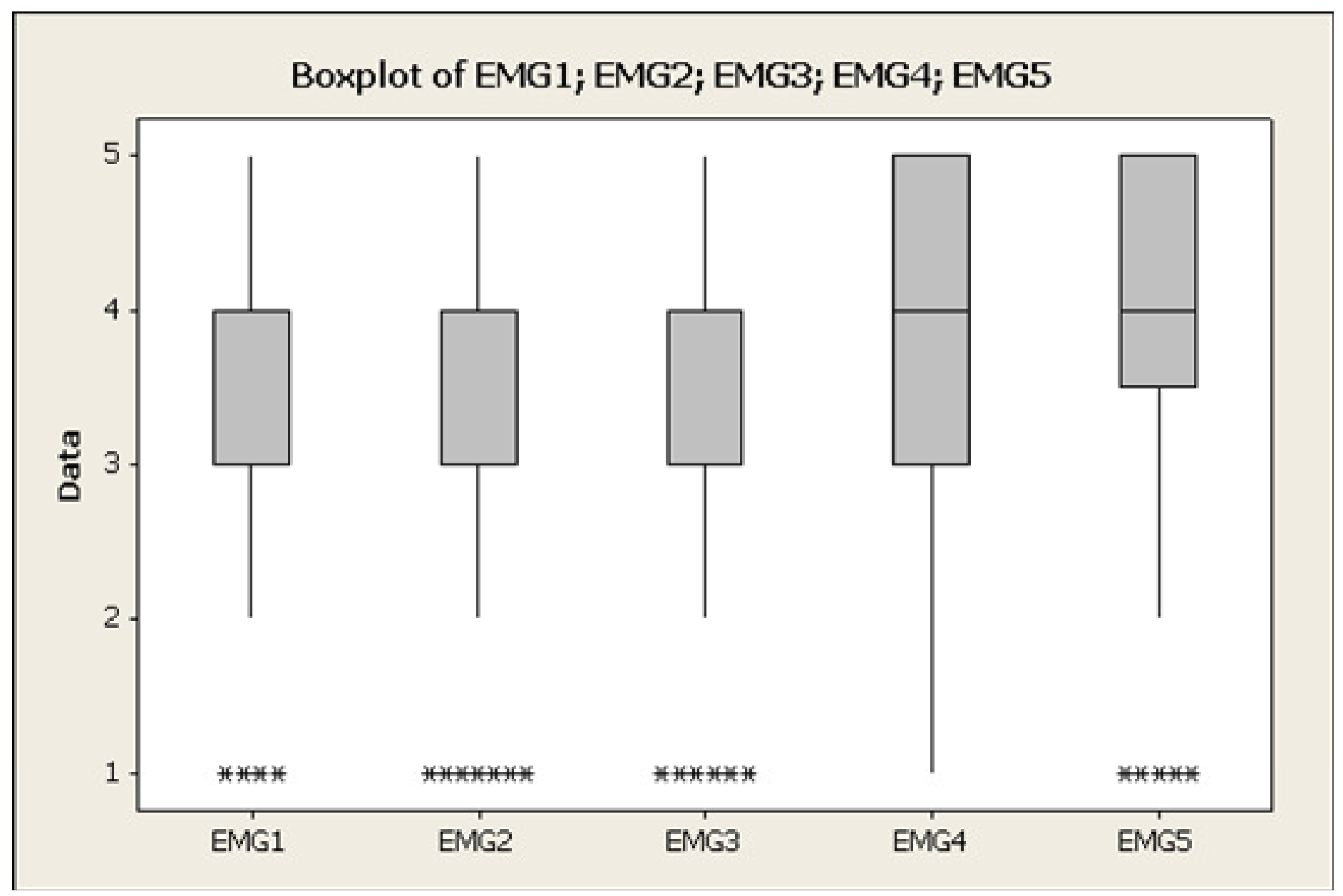

Não há diferenças significativas para $95 \%$ ou mais, apenas a EMG3 é para $90 \%$, mas não foi considerado. 


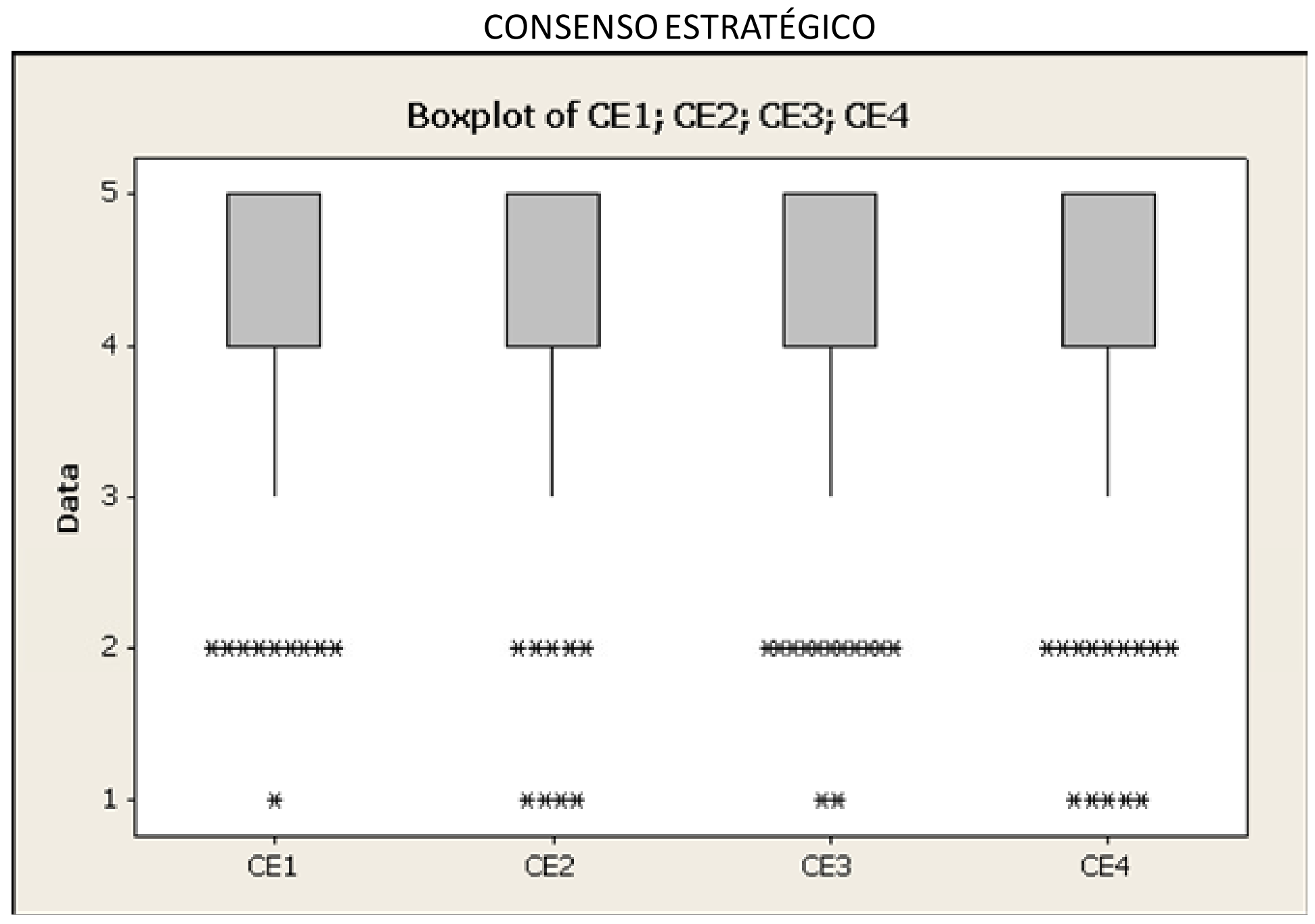

Não há diferen ças sign ificativas para $95 \%$ ou mais 


\section{CAPACIDADES GERENCIAIS PARA A IMPLEMENTAÇÃO DA ESTRATÉGIA}

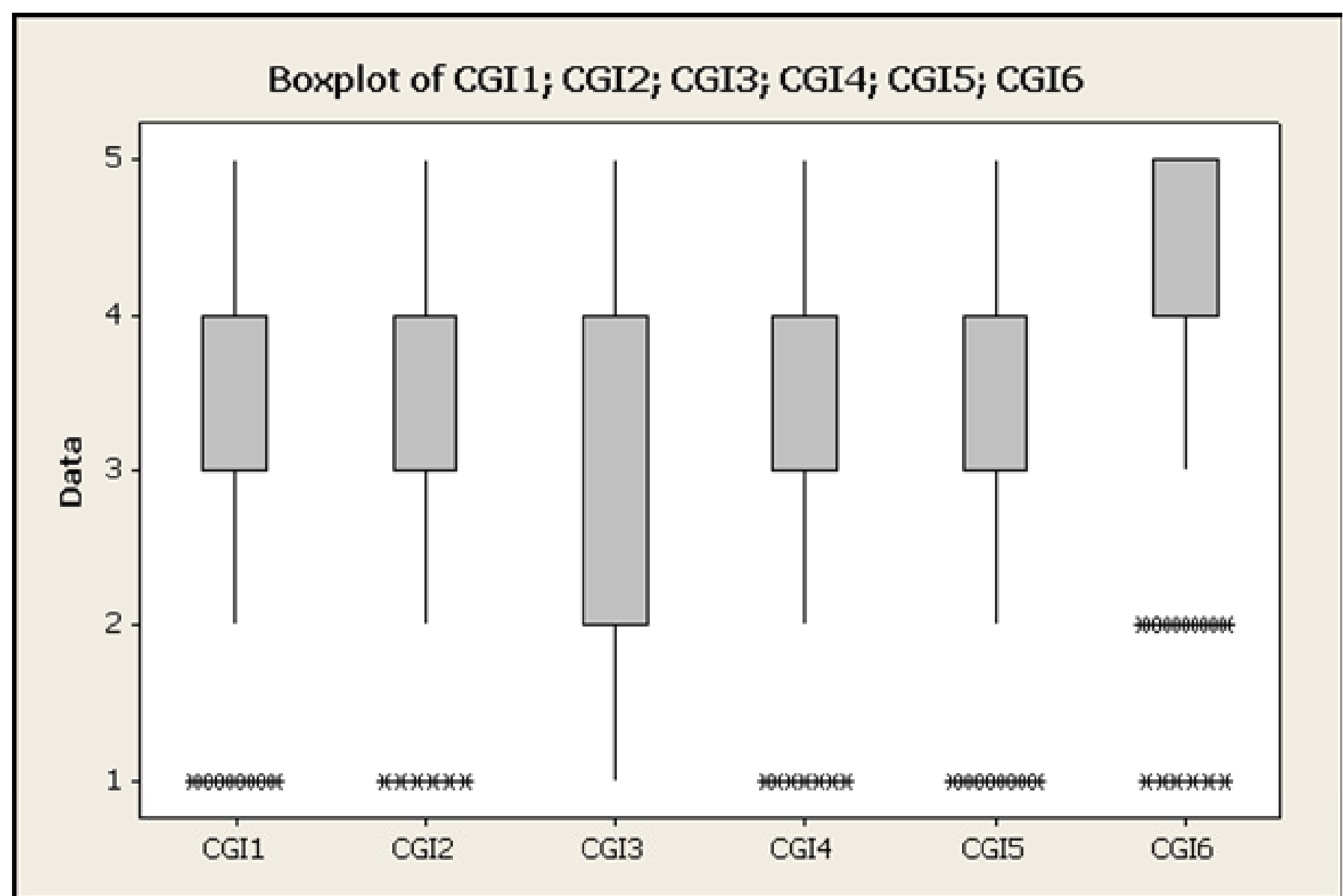

Significativo para 95\% de confiança (Mood median test for CGI6

Chi-Square $=8,91 \quad \mathrm{DF}=2 \quad \mathrm{P}=0,012$ ) 


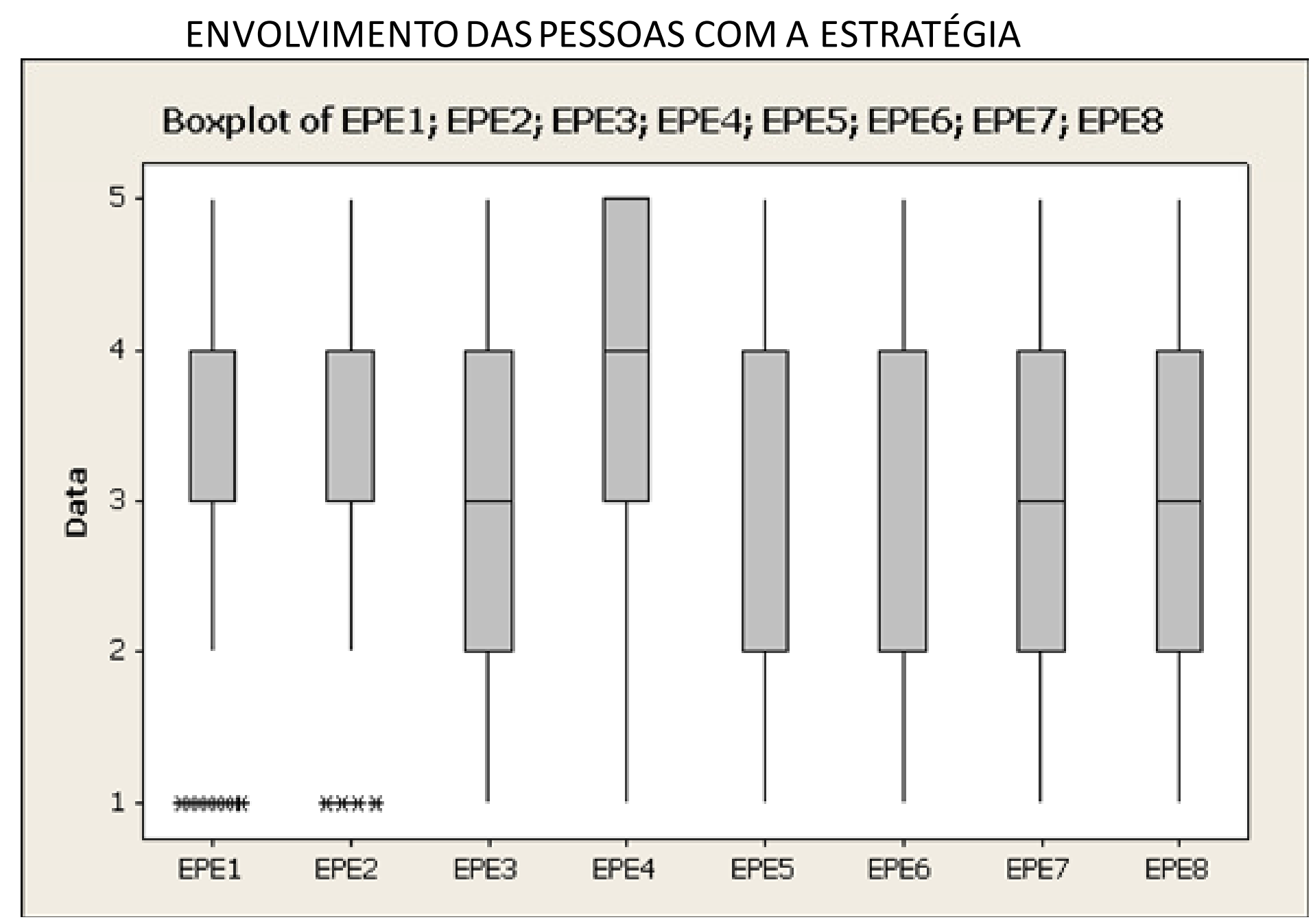

Não há diferenças significativas para nenhum parâmetro 


\section{ORIENTAÇÃO PARA CLIENTES}

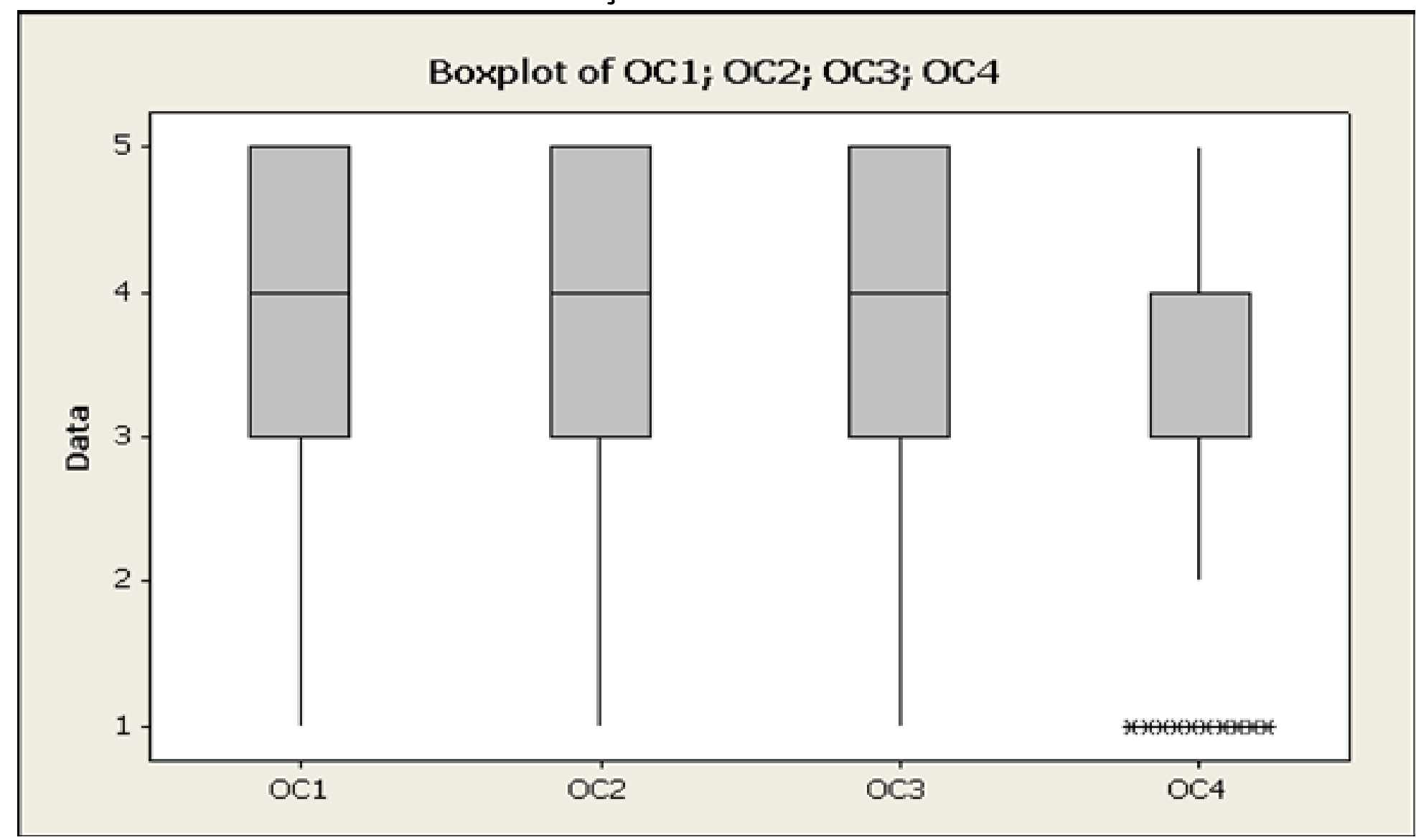

Todas tem diferenças significativas OC1 , 3 e 4 para 95\% e OC2 para 99\%significativas para nenhum parâmetro. 
ORIENTAÇÃO PARA PROCESSOS

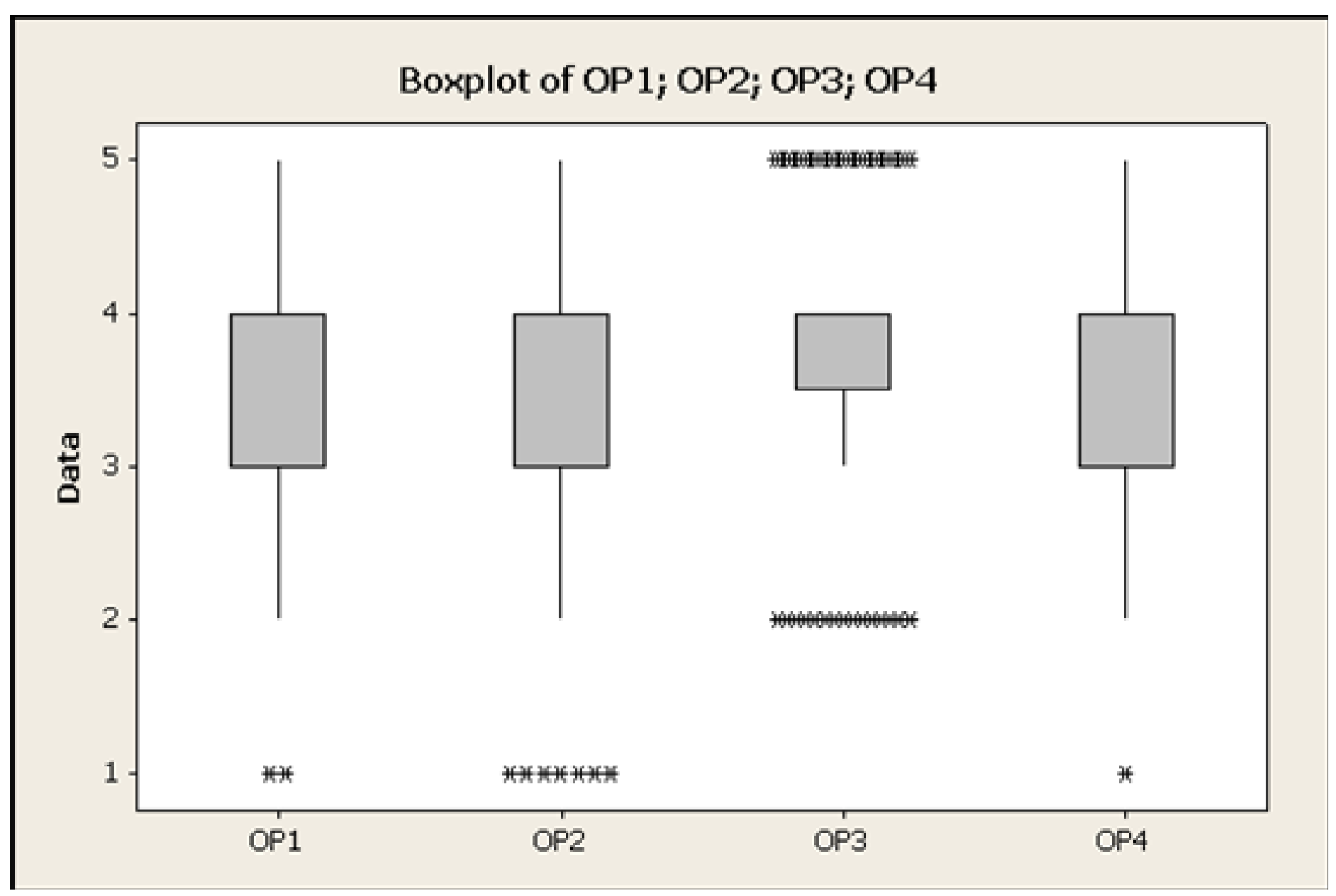

Não há diferenças significativas para nenhum parâmetro. OP3 para $90 \%$ não considerado 
PERCEPÇÃO DA INCERTEZA AMBIENTAL

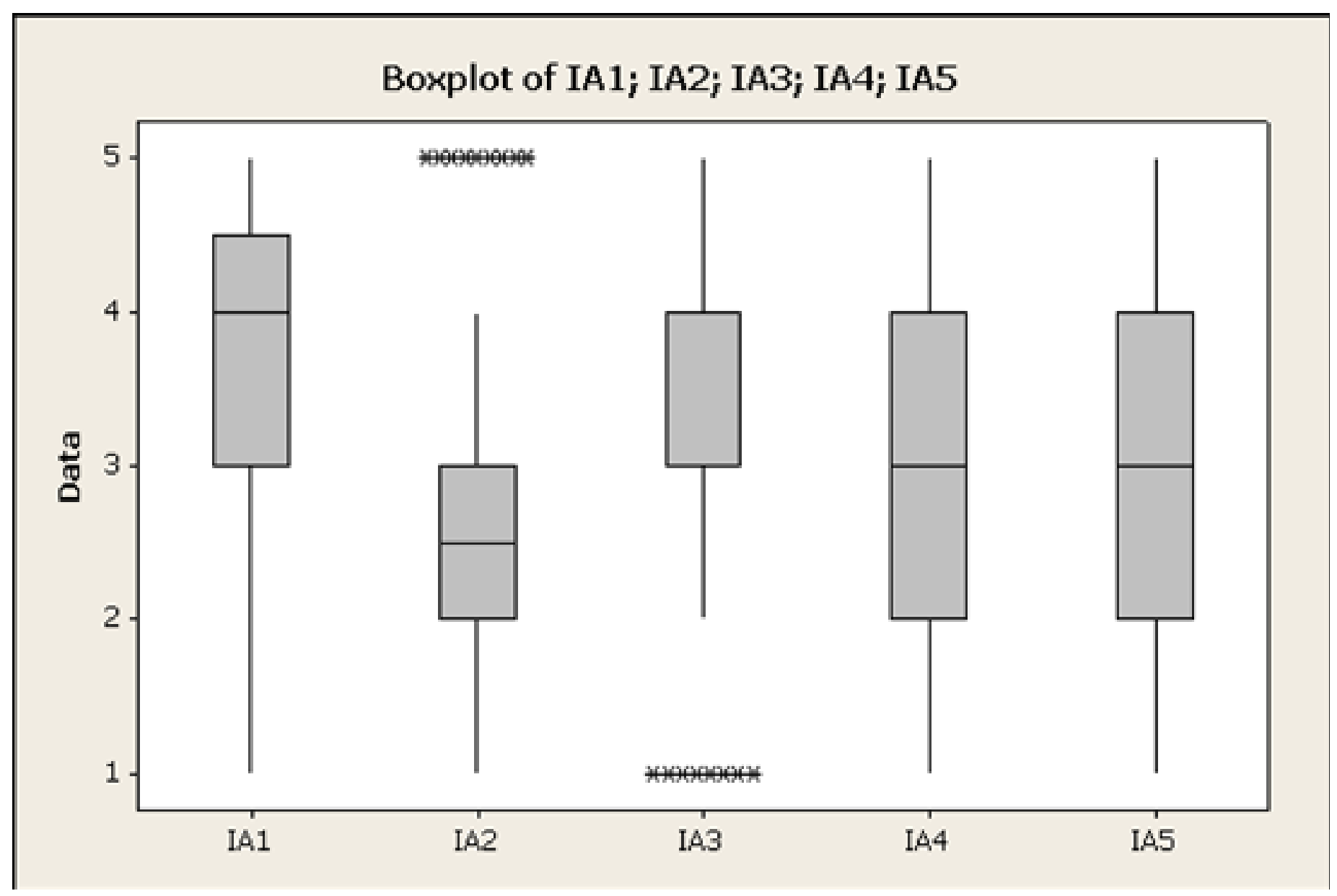

IA1 tem diferenças significativas para 99\% e IA3 para 95\% 
DESEMPENHO ORGANIZACIONAL

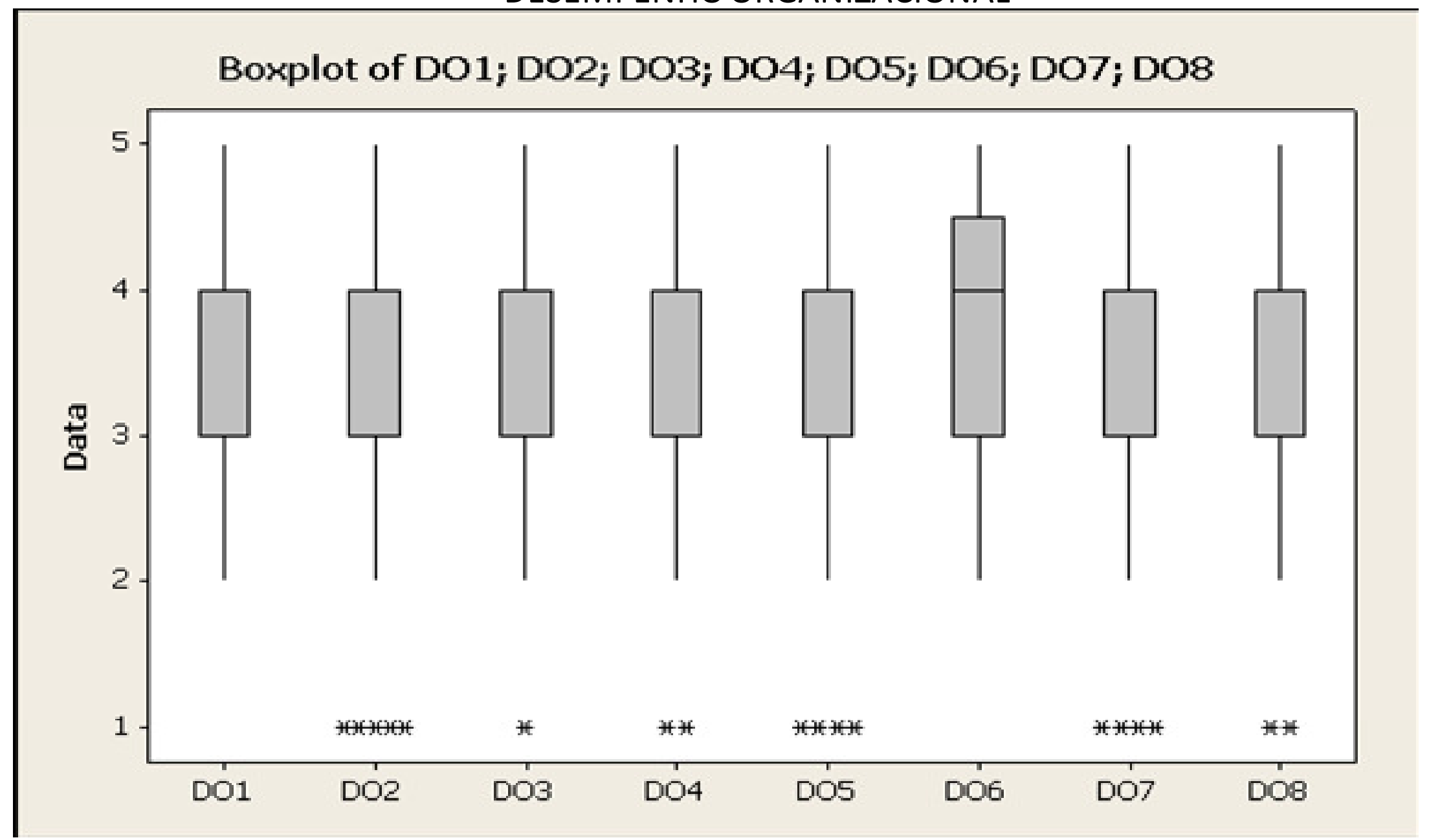

Exceto a DO4, todas tem diferenças significativas,D 01 , 2, 3 , 5 e 6 tem para 99\% e DO7 e 8 para $95 \%$ 


\section{APÊNDICE I - CARGAS CRUZADAS PARA AVALIAÇÃO DA VALIDADE DISCRIMINANTE}

\begin{tabular}{|c|c|c|c|c|c|c|c|c|c|}
\hline & $\overline{A F}$ & $\overline{C G}$ & $\overline{E P}$ & $\mathrm{OC}$ & $\overline{O P}$ & $\overline{\mathrm{DO}}$ & $\overline{A V}$ & $\overline{\mathrm{AH}}$ & $\overline{\mathrm{Al}}$ \\
\hline$P_{\text {PF_1 }}$ & 0,811 & 0,613 & 0,497 & 0,473 & 0,445 & 0,347 & 0,683 & 0,508 & 0,670 \\
\hline EMG_1 & 0,819 & 0,711 & 0,457 & 0,373 & 0,474 & 0,303 & 0,711 & 0,470 & 0,673 \\
\hline CE_1 & 0,781 & 0,629 & 0,430 & 0,202 & 0,384 & 0,407 & 0,650 & 0,326 & 0,569 \\
\hline CGI1 & 0,683 & 0,741 & 0,504 & 0,345 & 0,405 & 0,321 & 0,714 & 0,416 & 0,651 \\
\hline CGI2 & 0,606 & 0,850 & 0,462 & 0,417 & 0,547 & 0,264 & 0,727 & 0,535 & 0,711 \\
\hline CGI3 & 0,559 & 0,689 & 0,409 & 0,303 & 0,480 & 0,211 & 0,619 & 0,435 & 0,597 \\
\hline CGI4 & 0,620 & 0,799 & 0,553 & 0,452 & 0,562 & 0,204 & 0,748 & 0,562 & 0,736 \\
\hline CGI5 & 598 & 0,802 & 0,590 & 0,378 & 0,593 & 0,262 & 0,760 & 0,541 & 0,736 \\
\hline CGI6 & 0,718 & 0,784 & 0,529 & 0,414 & 0,520 & 0,273 & 0,753 & 0,519 & 0,721 \\
\hline EP2 & 0,382 & 0,413 & 0,657 & 0,485 & 0,465 & 0,203 & 0,569 & 0,526 & 0,605 \\
\hline EP3 & 0,448 & 0,522 & 0,795 & 0,303 & 0,443 & 0,244 & 0,693 & 0,415 & 0,640 \\
\hline EP4 & 0,521 & 0,555 & 0,723 & 0,464 & 0,580 & 0,239 & 0,694 & 0,578 & 0,710 \\
\hline EP5 & 0,444 & 0,548 & 0,830 & 0,260 & 0,431 & 0,215 & 0,717 & 0,385 & 0,639 \\
\hline EP6 & 0,3 & 0,404 & 0,776 & & 0 , & 0, & 0,6 & 54 & 0,513 \\
\hline EP7 & 0,365 & 0,454 & 0,822 & 0,307 & 0,411 & 0,212 & 0,653 & 0,400 & 0,604 \\
\hline EP8 & 0,499 & 0,555 & 0,690 & 0,331 & 0,577 & 0,115 & 0,673 & 0,506 & 0,663 \\
\hline OC1 & 0,376 & 0,375 & 0,304 & 0,872 & 0,549 & 0,227 & 0,392 & 0,780 & 0,585 \\
\hline OC2 & 0 & 0,2 & 0,4 & 0,921 & 64 & 0,2 & 0,503 & 0,872 & 0,698 \\
\hline OC3 & 0,335 & 0,408 & 0,369 & 0,849 & 0,517 & 0,267 & 0,425 & 0,750 & 0,594 \\
\hline OC4 & 0,374 & 0,413 & 0,426 & 0,771 & 0,431 & 0,312 & 0,463 & 0,662 & 0,586 \\
\hline OP1 & 0,490 & 0,621 & 0,579 & 0,473 & 0,769 & 0,223 & 0,651 & 0,693 & 0,729 \\
\hline OP2 & 0,404 & 0,535 & 0,491 & 0,562 & 0,882 & 0,081 & 0,553 & 0,800 & 0,704 \\
\hline OP3 & 0,447 & 0,513 & 0,427 & 0,536 & 0,860 & 0,239 & 0,525 & 0,773 & 0,673 \\
\hline OP4 & 0,512 & 0,611 & 0,563 & 0,599 & 0,892 & 0,248 & 0,644 & 0,827 & 0,777 \\
\hline D01 & 0,236 & 0,208 & 0,150 & 0,162 & 0,168 & 0,720 & 0,214 & 0,183 & 0,220 \\
\hline DO2 & 0,359 & 0,331 & 0,294 & 0,294 & 0,204 & 0,745 & 0,361 & 0,275 & 0,357 \\
\hline DO3 & 0,402 & 0,284 & 0,166 & 0,138 & 0,170 & 0,778 & 0,293 & 0,172 & 0,269 \\
\hline DO4 & 0,362 & 0,181 & 0,219 & 0,170 & 0,149 & 0,747 & 0,262 & 0,176 & 0,249 \\
\hline DO5 & 0,277 & 0,198 & 0,126 & 0,362 & 0,159 & 0,696 & 0,208 & 0,285 & 0,254 \\
\hline DO6 & 0,280 & 0,234 & 0,154 & 0,233 & 0,175 & 0,686 & 0,237 & 0,225 & 0,252 \\
\hline DO7 & 0,322 & 0,259 & 0,211 & 0,228 & 0,185 & 0,767 & 0,284 & 0,228 & 0,285 \\
\hline D08 & 0,343 & 0,228 & 0,194 & 0,206 & 0,155 & 0,833 & 0,268 & 0,200 & 0,263 \\
\hline
\end{tabular}




\section{APÊNDICE J - MODELO FINAL COM PARÂMETROS ESTIMADOS VIA MEEPLS}

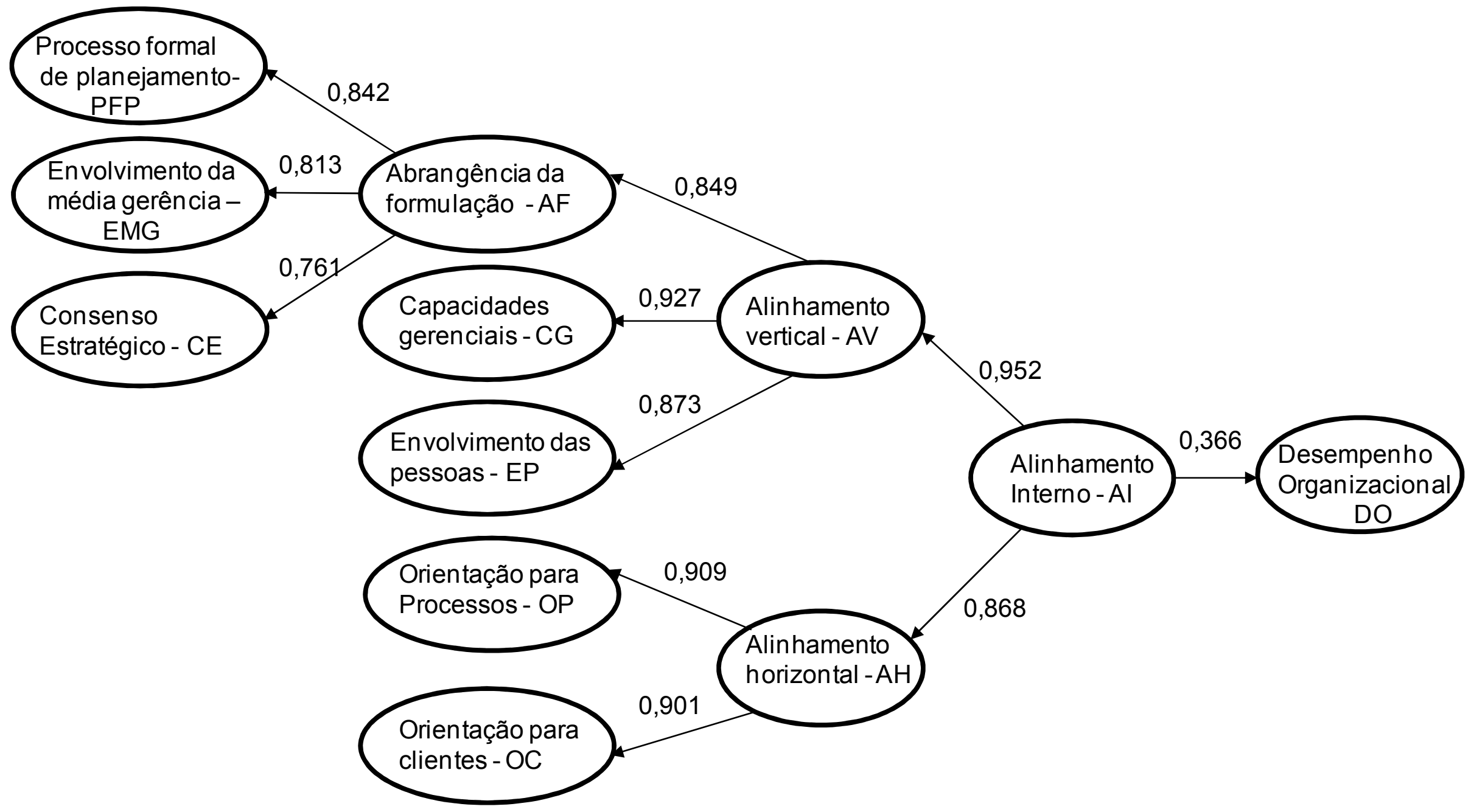

